EPIGENETIC REGULATION OF TUMOR ANGIOGENESIS 
(C) D.M.E.I. Hellebrekers, Maastricht, 2006

ISBN-10: 90-6464-035-1

ISBN-13: 978-90-6464-035-3

Press: Grafisch bedrijf Ponsen en Looijen B.V.

Cover design: Sue van Gageldonk 


\title{
Epigenetic regulation of tumor angiogenesis
}

\author{
PROEFSCHRIFT
}

ter verkrijging van de graad van doctor aan de Universiteit Maastricht, op gezag van de Rector Magnificus, Prof. mr. G.P.M.F. Mols volgens het besluit van het College van Decanen, in het openbaar te verdedigen op donderdag 2 november 2006 om 12.00 uur

$$
\text { door }
$$

Debby Maria Elisabeth Ida Hellebrekers

geboren op 26 augustus 1980 te Sittard 
Promotor

Prof. dr. A.W. Griffioen

\section{Copromotor}

Dr. M. van Engeland

\section{Beoordelingscommissie}

Prof. dr. J.G. Herman (Johns Hopkins University, Baltimore, USA)

Prof. dr. M.J. Post (voorzitter)

Dr. C.P. Reutelingsperger

Prof. dr. H.C. Schouten

Dr. ir. J.W. Voncken

\section{Onco Methylome}

This project was funded by OncoMethylome Sciences. SCIENCES

Financial support by the Dr. Ir. Van de Laar Stichting and Greiner Bio-One for the publication of this thesis is gratefully acknowledged. 
If the DNA sequence of the genome is like the musical score of a symphony, then the epigenome is like the key signatures, phrasing and dynamics that show how the notes of the melody should be played. J. Qiu et al. "Unfinished Symphony" Nature 2006 



\section{Abbreviations}

\begin{tabular}{|c|c|}
\hline AML & Acute myeloid leukaemia \\
\hline Ang & Angiopoietin \\
\hline BCE & Bovine capillary endothelial cell(s) \\
\hline bFGF & Basic fibroblast growth factor \\
\hline $\mathrm{BPI}$ & Bactericidal/permeability-increasing protein \\
\hline CAM & Chorioallantoic membrane \\
\hline cDNA & Complementary DNA \\
\hline CFSE & Carboxyfluorescein diacetate succinimidyl ester \\
\hline CHAP & Cyclic hydroxamic-acid containing peptide \\
\hline ChIP & Chromatin immunoprecipitation \\
\hline Cy & Cyanine \\
\hline DAC & 5-Aza-2'-deoxycytidine \\
\hline DNA & Deoxyribonucleic acid \\
\hline DNMT & DNA methyltransferase \\
\hline EC & Endothelial cell(s) \\
\hline EGF & Epidermal growth factor \\
\hline EndoPDI & Endothelial protein-disulfide isomerase \\
\hline $\mathrm{EZH} 2$ & Enhancer of zeste homologue 2 \\
\hline FACS & Fluorescence activated cell sorting \\
\hline FDA & Food and Drug Administration \\
\hline GFP & Green fluorescent protein \\
\hline HAT & Histone acetyltransferase \\
\hline HDAC & Histone deacetylase \\
\hline HGF & Hepatocyte growth factor \\
\hline $\mathrm{HIF}-1 \alpha$ & Hypoxia inducible factor- $1 \alpha$ \\
\hline HMEC & Human microvascular endothelial cell(s) \\
\hline HMT & Histone methyltransferase \\
\hline HPCE & High performance capillary electrophoresis \\
\hline HUVEC & Human umbilical vein endothelial cell(s) \\
\hline ICAM-1 & Intercellular adhesion molecule-1 \\
\hline IFN & Interferon \\
\hline IGFBP3 & Insulin-like growth factor binding protein 3 \\
\hline IL-1 & Interleukin 1 \\
\hline IL-8 & Interleukin 8 \\
\hline i.p. & Intraperitoneal \\
\hline LFA & Lymphocyte function-related antigen \\
\hline Lys & Lysine \\
\hline Mac-1 & Membrane attack complex-1 \\
\hline MadCAM-1 & Mucosal addressin cell adhesion molecule-1 \\
\hline MBD & Methyl-binding domain protein \\
\hline MDS & Myelodysplastic syndrome \\
\hline MMP & Matrix metalloproteinase \\
\hline
\end{tabular}




\begin{tabular}{ll} 
MSP & Methylation-specfic PCR \\
NFkB & Nuclear factor kappa B \\
NGF & Nerve growth factor \\
NRP & Neuropilin \\
PAI & Plasminogen activator inhibitor \\
PBS & Phosphate buffered saline \\
PcG & Polycomb group \\
PDGF & Platelet-derived growth factor \\
PECAM-1 & Platelet endothelial cell adhesion molecule \\
PEDF & Pigment epithelium-derived factor \\
PF-4 & Platelet factor-4 \\
PFA & Paraformaldehyde \\
PIGF & Placenta growth factor \\
PRC & Polycomb repressive complex \\
RGD & Arginine-glycine-aspartic acid \\
RLGS & Restriction landmark genomic scanning \\
RNA & Ribonucleic acid \\
RNAi & RNA interference \\
ROBO4 & Roundabout-4 \\
SAGE & Serial analysis of gene expression \\
SAHA & Suberoylanilide hydroxamic acid \\
siRNA & Small interfering RNA \\
T-Cad & T-cadherin \\
TEM & Tumor endothelial marker \\
TGF- $\beta$ & Transforming growth factor- $\beta$ \\
TIMP & Tissue inhibitor of matrix metalloproteinase \\
TNF $\alpha$ & Tumor necrosis factor $\alpha$ \\
TrxG & Trithorax group \\
TSA & Trichostatin A \\
TSP1 & Thrombospondin 1 \\
VCAM-1 & Vascular cell adhesion molecule-1 \\
VEGF & Vascular endothelial growth factor \\
VEGFR & \\
& VEGF receptor \\
\hline &
\end{tabular}




\section{Contents}

$\begin{array}{lll}\text { Chapter } 1 \quad \text { General Introduction } & 11\end{array}$

Chapter $2 \quad$ Angiostatic activity of DNA methyltransferase inhibitors 35

Chapter 3 Identification of epigenetically silenced genes in tumor endothelial cells

Chapter $4 \quad$ Epigenetic regulation of tumor endothelial cell anergy; silencing of ICAM-1 by histone modifications $\quad 81$

Chapter 5 Dual targeting of epigenetic therapy in cancer 103

$\begin{array}{lll}\text { Chapter } 6 & \text { General discussion and conclusions } & 133\end{array}$

$\begin{array}{ll}\text { Summary } & 145\end{array}$

$\begin{array}{ll}\text { Samenvatting } & 149\end{array}$

Dankwoord 153

$\begin{array}{lr}\text { Curriculum Vitae } & 157\end{array}$ 



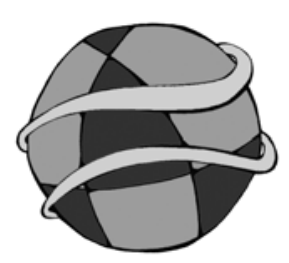

Chapter 1 General Introduction 


\section{Angiogenesis}

Angiogenesis is the sprouting of new capillary vessels out of pre-existing blood vessels. It mainly serves to supply tissues with oxygen and nutrients, and to remove metabolic waste products. Angiogenesis is a key event in physiologic processes such as organ growth and development, wound healing and reproduction. Excessive vessel growth, on the other hand, contributes to the pathogenesis of many diseases, including macular degeneration, psoriasis, endometriosis, arthritis, and cancer. ${ }^{1}$

Angiogenesis is a complex multi-step cascade, which is tightly regulated by a delicate balance between endogenous pro-angiogenic and angiostatic factors. The process of angiogenesis starts with activation of vascular endothelial cells (ECs), which then migrate, proliferate and sprout into the perivascular space, eventually resulting in the formation of new, mature capillary vessels. ${ }^{2}$ During adulthood, most ECs remain quiescent and angiogenesis occurs only in the few tissues that require new vessel formation.

\section{Tumor angiogenesis}

Tumorigenesis is initiated by genetic and epigenetic alterations in oncogenes and tumor suppressor genes, and tumor growth is dependent on angiogenesis. ${ }^{3}$ In addition, development of tumor vasculature also provides a basis for cancer metastasis. Angiogenesis is induced early in tumorigenesis, as a result of accumulating genetic aberrations in genes involved in angiogenesis. This "angiogenic switch" ${ }^{4}$ causes increased expression of pro-angiogenic factors by the tumor cells, and downregulation of angiogenesis inhibitors. ${ }^{5}$ Hypoxic conditions can trigger the angiogenic switch in the tumor, by allowing activation of the transcription factor hypoxia inducible factor-1 $\alpha$ (HIF-1 $\alpha$ ), which induces expression of vascular endothelial growth factor (VEGF) and other angiogenic molecules. ${ }^{6}$ In addition, activating mutations of many oncogenes, including ras, erbB-2/Her2, EGFR and bcl$a b l$, as well as inactivation of tumor suppressor genes like $V H L$ and $p 53$, can also induce upregulation of pro-angiogenic factors and downregulation of angiostatic proteins. ${ }^{7}$ This results in a shift in the balance between angiogenic and angiostatic factors in favor of the angiogenic ones. Stromal components also contribute to tumor development and progression. For example, tumor-associated fibroblasts produce angiogenic factors and release stromal cell-derived factor-1 (SDF-1), resulting in recruitment of bone-marrow derived precursor cells in the tumor vasculature. ${ }^{8}$

Tumor angiogenesis starts with activation of ECs by binding of angiogenic factors to receptors present on the endothelium. As a result, ECs start to produce a series of enzymes that locally degrade the vascular basement membrane and extracellular matrix, including matrix metalloproteinases (MMPs). This allows invasion of ECs into the surrounding matrix, and, subsequently, EC migration and proliferation towards the stimulus. Eventually, ECs adhere to each other and create a lumen, which is accompanied by basement membrane formation and recruitment of pericytes (Fig. $1.1)^{5}$ 


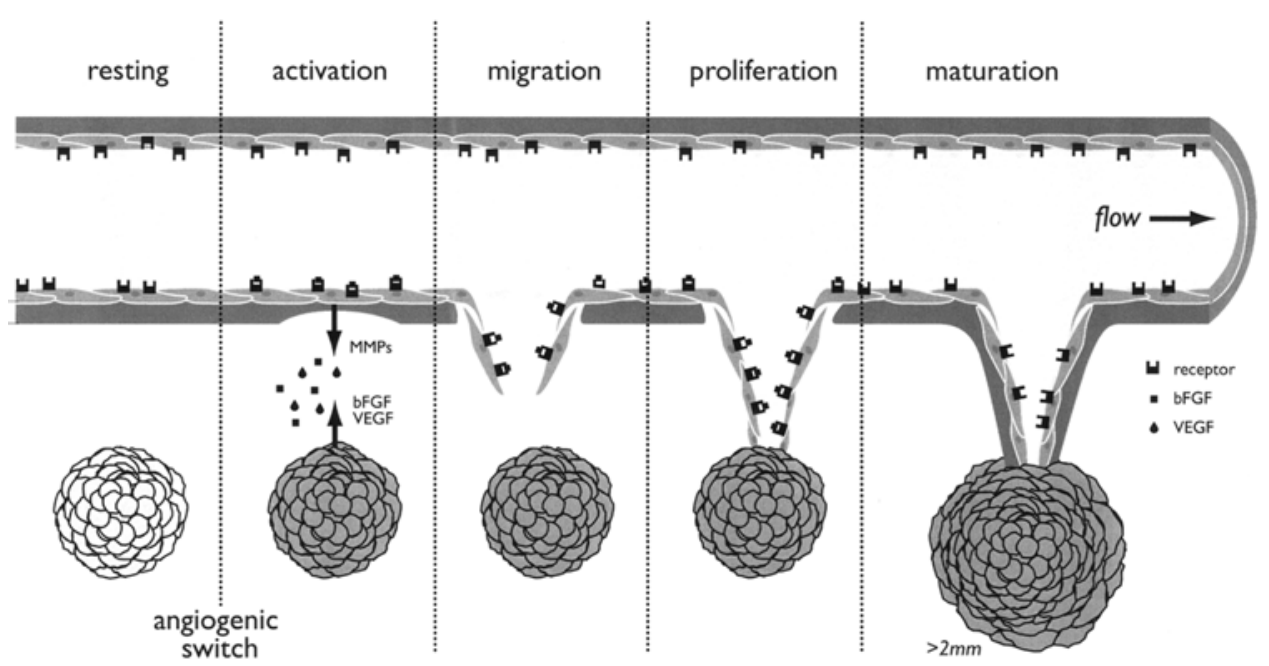

Figure 1.1 The multi-step process of tumor angiogenesis.

The "angiogenic switch" induces increased production of pro-angiogenic factors by the tumor cells, such as bFGF and VEGF. This results in a shift in the balance between angiogenic and angiostatic factors in favor of the angiogenic ones. By binding of angiogenic factors to their receptors on endothelial cells (ECs), these cells become activated and start to produce matrix metalloproteinases (MMPs) that locally degrade the extracellular matrix, allowing invasion of ECs into the surrounding matrix, and, subsequently, EC migration and proliferation towards the tumor. Eventually, ECs adhere to each other and create a lumen, which is accompanied by extracellular matrix formation and recruitment of pericytes. With permission from dr. D.W.J. van der Schaft. ${ }^{158}$

The disturbance of the balance between pro- and anti- angiogenic factors and the resulting continuous growth of new tumor vessels is reflected by the abnormal structure of tumor vessels as compared to normal blood vessels. Tumor vasculature is highly disorganized, permeable, irregularly shaped, tortuous, and lacks the normal organization into arterioles, capillaries and venules. Furthermore, tumor vessels lack the tight EC monolayer, resulting in leakiness and increased interstitial fluid pressure. In addition, pericytes on tumor vessels are irregularly shaped and loosely associated with ECs. Aberrant ECs and pericytes generate defective basement membrane. ${ }^{9}$

Pro- and anti-angiogenic factors

As described above, angiogenesis is determined by the ultimate balance between pro- and anti-angiogenic proteins. VEGF is the most intensively investigated angiogenic factor. ${ }^{10}$ The VEGF family includes VEGF-A (also referred to as VEGF), placenta growth factor (PIGF), VEGF-B, VEGF-C and VEGF-D. There are at least 8 human VEGF-A isoforms that are the result of alternative splicing, of which VEGF165 is the predominant isoform. VEGF induces EC survival, proliferation, migration and angiogenesis, as well as vascular permeability. VEGF-dependence has been demonstrated in ECs of newly formed but not of established tumor vessels. One of the key events resulting in loss of this VEGF dependence seems to be coverage by pericytes. ${ }^{11}$ VEGFR-1 (FIt-1) and VEGFR-2 (KDR, Flk-1) are the two main VEGF receptor tyrosine kinases expressed on ECs. ${ }^{10}$ Instead, VEGFR-3 (FIt-4) is largely 
restricted to lymphatic endothelium. VEGF-A binds both VEGFR-1 and -2. VEGFR-2 is important for the mitogenic, anti-apoptotic, angiogenic and permeability-enhancing effects of VEGF on ECs. PIGF and VEGF-B only bind to VEGFR-1. The function of VEGFR-1 is complex, it might function as a "decoy" receptor, negatively regulating VEGF activity on vascular endothelium by preventing binding of VEGF to VEGFR-2. ${ }^{12}$ However, VEGFR-1 also induces expression of a variety of genes in the endothelium, such as MMP9 and certain growth factors. VEGF-C and VEGF-D are ligands for VEGFR-2 and -3 , and regulate angiogenesis and lymphangiogenesis. Neuropilin-1 (NRP1) and -2 (NRP2), originally discovered as semaphorin receptors for axon guidance, are non-tyrosine kinase receptors for VEGF. In contrast to VEGF, semaphorin $3 \mathrm{~A}$ inhibits growth and survival of axons and ECs. Binding of VEGF to NRP1 and NRP2 potentiates VEGFR-2 signalling in ECs. ${ }^{13}$

Another family of angiogenesis-mediating growth factors produced by tumor cells are fibroblast growth factors (FGFs), which are strong mitogens for many cell types, including ECs. The FGF family is composed of 23 members, of which the two best known are acidic FGF (aFGF, FGF1) and basic FGF (bFGF, FGF2). FGFs can be sequestered in the extracellular matrix or basement membrane, but can also be bound to FGF binding proteins, protecting them from degradation. There are four FGF receptor tyrosine kinases. Binding of FGFs to these receptors is facilitated by heparin sulphate proteoglycans, which bind to FGF receptors. bFGF induces proliferation, migration, chemotaxis and tube formation of ECs. Part of its angiogenic activity can be explained by recruitment of other growth factor signalling pathways. ${ }^{14}$

Besides VEGF and FGF, tumor cells produce various other angiogenic factors, including platelet-derived growth factor (PDGF), interleukin 8 (IL-8), transforming growth-factor- $\beta$ (TGF- $\beta$ ), epidermal growth factor (EGF), hepatocyte growth factor (HGF) and pleiotrophin. Angiopoietins (Ang) are also produced by tumor cells and are critically involved in angiogenesis. They are a family of extracellular ligands that specifically bind to the EC specific receptor tyrosine kinase Tie2. Ang-1 and Ang-2 elicit different responses despite binding to the same receptor. ${ }^{15,16}$ Ang-1 activates the Tie2 signalling pathways, whereas Ang-2 blocks this activation. Ang-1 and Ang-2 can both act as EC survival factors under certain conditions, and Ang-1 also affects EC migration and adhesion. Furthermore, Ang-1 acts as a maturation factor in angiogenesis, recruiting pericytes and smooth muscle cells, whereas Ang-2 acts as a vessels destabilizer.

Endogenous angiogenesis inhibitors defend against the angiogenic switch in pathological conditions and govern physiological angiogenesis in processes such as ovulation and wound healing. ${ }^{17}$ Systemic levels of angiostatic factors in our body likely defend against progression of cancer to a lethal stage, encouraging the therapeutic application of these endogenous inhibitors of angiogenesis. ${ }^{18}$ To date, 28 endogenous angiogenesis inhibitors have been identified in the circulation or in the matrix. ${ }^{19}$ Interferons (IFNs) were the first endogenous angiogenesis inhibitors identified. IFN- $\alpha$ reduces urokinase-type plasminogen activator, plasminogen activator inhibitor-1, and MMP-9 activity. ${ }^{20,21}$ IFN- $\alpha$ and $-\beta$ both decrease bFGF expression. ${ }^{22}$ Platelet factor-4 (PF-4) is secreted by platelets during platelet aggregation and binds with high affinity to heparin. It inhibits binding of endothelial growth factors to the EC surface. ${ }^{23}$ 
Thrombospondin-1, a large multifunctional glycoprotein secreted by most epithelial cells in the extracellular matrix, is a well known, highly specific, and potent endogenous inhibitor of angiogenesis. ${ }^{24}$ It has been shown to induce apoptosis of activated endothelium. ${ }^{25}$ Tissue inhibitor of matrix metalloproteinase-2 (TIMP-2) can inhibit angiogenesis by both MMP-dependent and MMP-independent mechanisms. ${ }^{26}$ Bactericidal/permeability-increasing protein (BPI), originally discovered as a bacterial permeabilizing and lipopolysaccharide-neutralizing protein, was found to inhibit angiogenesis by specific induction of apoptosis in ECs. ${ }^{27}$ Pigment epithelium-derived factor (PEDF), a non-inhibitory member of the serpin superfamily, displays selective angiostatic activity by only targeting new vessel growth, without affecting existing vessels. ${ }^{28}$ Many endogenous angiogenesis inhibitors are fragments of larger proteins. Endostatin is a $20-\mathrm{kDa}$ collagen XVIII-derived angiogenesis inhibitor, ${ }^{29}$ that disturbs the angiogenic balance of the EC genome by downregulating many signaling pathways in human microvascular endothelium associated with pro-angiogenic activity and simultaneously inducing many angiostatic genes. ${ }^{30}$ Angiostatin is a cryptic fragment of plasminogen. It was first determined to have angiostatic properties because it inhibited neovascularization, metastasis and growth of Lewis lung carcinoma. ${ }^{31}$ Tumstatin is a $28-\mathrm{kDa}$ fragment of collagen type IV. ${ }^{32}$ The angiostatic activity of tumstatin is localized within the 54- to 132- amino acid region, which is a binding site for $\alpha v \beta 3$ integrin, and was named Tum- 5 . Via the interaction with $\alpha v \beta 3$ integrin, tumstatin causes EC apoptosis by inhibiting pathways involved in protein synthesis. ${ }^{33}$ Other endogenous inhibitors of angiogenesis that are fragments of larger proteins are canstatin and arresten, both derived from type IV collagen, endorepellin, which is the $\mathrm{COOH}$-terminal end of the basement membrane heparan sulfate proteoglycan perlecan, the fibronectin fragment anastellin, the calreticulin fragment vasostatin, and fibulins, which are basement membrane fragments. ${ }^{19}$

\section{Inhibition of tumor angiogenesis}

The dependence of tumor growth on the development of new blood vessels suggests that inhibition of angiogenesis is a promising strategy to treat cancer. In contrast to tumor cells, tumor ECs are genetically stable, reducing the likelihood of developing drug resistance. Another advantage of targeting ECs over tumor cells is that ECs are in direct connection with the blood and are therefore readily accessible to serum soluble angiostatic agents. Furthermore, side effects of angiogenesis inhibitors tend to be much lower than those of standard chemotherapy, due to the limited amount of angiogenesis in the adult. In addition, by elimination of a single EC, the growth of over 100 tumor cells can be eradicated. ${ }^{34}$

Currently, clinical validation of angiostatic therapy for cancer treatment occurs in the ongoing clinical trials. Several angiogenesis inhibitors have been approved in the United States and other countries. ${ }^{17}$ Endogenous angiogenesis inhibitors might be the safest and least toxic of anti-cancer therapies. ${ }^{35}$ Endostatin (Endostar) has been approved by the state Food and Drug Administration (FDA) in China for the treatment of non-small cell lung cancer. ${ }^{36} \mathrm{~A}$ number of exogenous agents have been developed which have angiostatic potential. TNP-470 is a synthetic analogue of fumagillin with potent angiostatic activity that showed significant anti-tumor effects in clinical trials. ${ }^{37}$ Its clinical use, however, was limited due to neurotoxicity. Caplostatin, a non-toxic 
analogue of TNP-470 conjugated to HPMA (N-(2-hydroxypropyl)methacrylamide), exhibits both angiostatic and antihyperpermeability activity. ${ }^{38}$ Thalidomide was approved in Australia for the treatment of multiple myeloma in December 2003. ${ }^{36}$ Agents targeting the angiogenic growth factor pathways are the furthest developed in the clinic. Avastin (bevacizumab), a humanized anti-VEGF monoclonal antibody, was the first specific angiogenesis inhibitor approved by the FDA in the US. It demonstrated a significant survival advantage in combination with chemotherapy for patients with metastatic colorectal cancer. ${ }^{39}$ Other VEGF-targeting agents in clinical development are receptor tyrosine kinase inhibitors targeting the VEGF receptors. Among these are PTK787/ZK222584 (Vatalanib), which inhibits a number of receptor tyrosine kinases including VEGFR-1 and -2, ${ }^{40}$ BAY 43-9006 (Sorafenib), an inhibitor of Raf kinase and of multiple tyrosine kinases including VEGFR-2, VEGFR-3, PDGFR- $\beta$, FLT-3 and c-kit, ${ }^{41}$ and the multitargeted tyrosine kinase inhibitor SU11248 (Sutent). ${ }^{42}$ The epidermal growth factor receptor tyrosine kinase inhibitor Tarceva (erlotinib) has received FDA approval for the treatment of lung cancer.

Despite the promising (pre)clinical results of angiogenesis inhibition as anti-cancer strategy, it is becoming apparent that resistance can develop over time to many types of angiostatic agents, especially when used as monotherapies. ${ }^{43}$ When the drug used targets an angiogenic growth factor or growth factor receptor, tumor cells may switch to express redundant angiogenic proteins due to new mutations. Such redundancy is a potential cause of acquired resistance when tumors are treated with highly specific targeted angiostatic drugs like avastin, but can also result from treatment with receptor tyrosine kinase inhibitors targeting multiple growth factor receptors. ${ }^{44,45}$ With regard to this phenomenon, angiogenesis inhibitors directly acting on ECs, such as endostatin, might be least likely to develop drug resistance. In addition, genetic alterations that decrease the vascular dependence of tumor cells can influence the therapeutic response of tumors to angiostatic therapy. For example, hypoxia selects for tumor cells with diminished apoptotic potential ${ }^{46}$ Another possible mechanism of acquired resistance to angiostatic therapy is due to vascular remodelling, which causes stabilization of tumor vessels, resulting in lower responsiveness to angiostatic drugs. Furthermore, in contrast to what was originally assumed, tumor ECs in some cases are not genetically stable. ${ }^{47,48}$ The acquired drug resistance to angiostatic therapy might be avoided by the administration of combinations of angiostatic agents, or by using an angiogenesis inhibitor that targets different angiogenic factors. Also, combining angiogenesis inhibitors with conventional cytotoxic agents or radiation therapy might result in additive or synergistic anti-tumor effects. ${ }^{49}$ Furthermore, the anti-endothelial activity of conventional cytotoxic chemotherapeutics seems to be improved by administration of low doses on a frequent schedule, also called "metronomic" chemotherapy. ${ }^{50}$

\section{Vascular targeting}

Besides blocking the process of tumor angiogenesis, destruction of the established tumor vasculature is an alternative anti-tumor strategy. Several studies proved that vascular targeting can be used to eradicate solid tumors in mice. ${ }^{51}$ However, this approach requires the use of targets that are specifically expressed on tumor vessels but not on normal vasculature. This resulted in several attempts to 
General Introduction

search for differentially expressed genes between tumor (-conditioned) and normal ECs in vitro and in vivo by the use of different molecular techniques including microarrays and serial analysis of gene expression (SAGE). In many of these studies, tumor- and quiescent ECs were mimicked in vitro using different culture conditions, and were subjected to transcript profile comparison. ${ }^{52}$ Among the genes preferentially expressed in tumor ECs the ones of particular interest are those that are located on the cell surface, since these are the most accessible to pharmacological agents. Besides examining differences at the transcript level, proteomic analysis can be used to identify differentially expressed proteins on the endothelial surface in normal and tumor tissue. ${ }^{53}$ Another approach has been to identify peptides that can home specifically to tumor endothelium using phase display. ${ }^{54}$ Several studies demonstrated effective tumor vascular targeting and anti-tumor activity in animal models of bioactive molecules coupled to ligands for specific tumor vessel markers. ${ }^{55-59}$ Therapeutic effects of vascular targeting in human cancer is being evaluated in clinical trials. ${ }^{60-64}$ In addition to targeted destruction of tumor vasculature, identification of specific vascular targets can also be used for imaging purposes. ${ }^{65}$

Over the past few years, technological advances enabled the identification of several molecules that are preferentially expressed on the surface of EC of tumor vessels. St Croix et al. performed SAGE on human ECs isolated from normal colonic mucosa and colorectal tumors, resulting in the identification of several novel tumor endothelial markers (TEMs). ${ }^{66}$ The higher expression in tumor vessels was confirmed for 9 of the TEMs, among which were 4 cell-surface TEMs (TEM1, 5, 7, 8). TEM1 (endosialin) is a cell surface glycoprotein that was previously shown to be preferentially expressed on tumor endothelium. ${ }^{67}$ TEM1(-/-) mice are healthy and display normal wound healing, whereas a striking reduction in tumor growth, invasiveness, and metastasis is observed after transplantation of tumors to abdominal sites. $^{68}$ TEM5 belongs to the family of G-protein-coupled receptors, a large receptor family usually involved in cell signalling ${ }^{69}$ In contrast with TEM1, 5 and 8, TEM7 was not detected in mouse tumor vessels. TEM8 is a receptor for anthrax toxin. Binding of anthrax toxin to TEM8 on the endothelium, resulting in EC death, might clarify the antitumor response to this toxin. ${ }^{70}$ To separate tumor-specific angiogenesis makers from markers associated with physiological angiogenesis, van Beijnum et al. used suppression subtractive hybridization to compare gene expression profiles of isolated EC from colon carcinoma tissues, non-malignant angiogenic placental tissues, and non-angiogenic normal tissues. ${ }^{71}$ Those markers that were overexpressed in tumor EC compared to both normal EC and placental EC were considered to be tumor angiogenesis specific. It was demonstrated that targeting of one these markers, i.e. vimentin, resulted in markedly inhibited tumor growth and reduced microvessel density in a mouse tumor model.

Several other potential tumor vascular targets have been identified. Roundabout-4 (ROBO4) is an endothelial-specific roundabout receptor, that shows significant homology with the neuronal roundabout receptors involved in axon guidance, although the arrangement of its extracellular domains diverges significantly from that of all other ROBO family members. The ROBO receptors and their Slit ligands appear to be involved in guidance of vascular EC, besides their role in axon guidance. ROBO4 expression in the adult was restricted exclusively to sites of active angiogenesis, 
notably tumor vessels. ${ }^{72}$ Endothelial protein-disulfide isomerase (EndoPDI) is expressed preferentially in ECs and has a protective effect in ECs exposed to hypoxia. Lack of EndoPDI results in decreased expression of hypoxically induced endothelial survival factors. ${ }^{73}$ DELTA4, a member of the Notch/Delta family of signalling molecules, was found to be upregulated in tumor vasculature and in areas of active angiogenesis. ${ }^{74}$ Notch and its DELTA ligands are highly conserved through evolution and play a fundamental role in the determination of cell fate ${ }^{75}$ In humans, there are four Notch receptors, Notch 1 to 4 , and five ligands, including Jagged-1 and -2 and DELTA1, -3 , and -4 . Upon ligand binding, Notch activation results in cleavage at an intramembrane site, releasing the intracellular Notch domain from the membrane, which translocates to the nucleus to activate transcription. Most of the Notch target genes encode transcription regulators which modulate cell fate by affecting the function of tissue-specific basic helix-loop-helix transcription factors. VEGF can induce expression of Notch1 and its ligand DELTA4 in human arterial ECs via VEGFR-1 and -2. Activation of Notch signaling stabilizes EC network formation on matrigel, whereas blocking Notch signaling can partially inhibit network formation. ${ }^{76}$ Fibronectin extra-domain B (EDB), an alternatively spliced form of fibronectin that contains an additional type III domain, is a marker of the extracellular matrix in tumor vessels. ${ }^{77}$ Therapeutic derivatives of the anti-EDB antibody L19 efficiently localize to tumor blood vessels and display significant anti-tumor activity in animal models, ${ }^{55-58}$ as well as specific tumor targeting in cancer patients. ${ }^{78}$ Tenascin- $\mathrm{C}$ is an extracellular matrix glycoprotein composed of six similar subunits joined at their $\mathrm{NH}_{2}$ terminus by disulphide bonds. Structurally and functionally different human tenascin- $\mathrm{C}$ isoforms are generated by alternative splicing. The $C$ domain of tenascin- $C$ is undetectable in normal adult tissue, but abundantly expressed in high grade astrocytoma, especially around vascular structures and proliferating cells. ${ }^{79}$ Several clinical trails of radiolabelled derivatives of tenascin- $C$ antibodies have been performed in cancer patients. ${ }^{60,62,64} \mathrm{ECs}$ in angiogenic vessels express their own integrin repertoire, which differs from the integrins expressed on quiescent EC. For example, the $\alpha \mathrm{v} \beta 3$ integrin is upregulated in angiogenic tumor ECs, and has a key role in EC survival during angiogenesis. Vitaxin, a humanized anti- $\alpha \vee \beta 3$ antibody, interferes with blood vessel formation by inducing apoptosis in newly generated ECs, and is currently in clinical development as an angiostatic therapeutic for cancer treatment. ${ }^{61}$ The integrin binding sequence RGD (Arg-Gly-Asp) was identified by in vivo selection of phage display peptide libraries to isolate peptides that specifically home to angiogenic tumor blood vessels. $^{80}$

Recently, van Beijnum et al. compared different large-scale gene expression studies on ECs from in vitro and in vivo sources, ${ }^{81}$ demonstrating that EC gene expression profiles parallel the different stages of angiogenesis. Cultured ECs stimulated with growth factors exhibit upregulation of many cell cycle related genes, which can be related to the transition from quiescent to proliferative ECs, an early event in angiogenesis. Genes induced during in vitro tube formation of ECs appear to be mainly involved in cell adhesion processes, whereas genes with a role in extracellular matrix remodeling, a late event in angiogenesis, are upregulated in tumor ECs from in vivo sources. 


\section{Tumor endothelial cell anergy}

In addition to the induction of tumor growth and metastasis, tumor angiogenesis also inhibits formation of a proper anti-tumor immune response. Recruitment of leukocytes from the circulation to the site of inflammation is required to exert an inflammatory response. Vascular ECs play a key role in this process, by expressing adhesion molecules that mediate leukocyte-vessel wall interactions. This multistep cascade is initiated by leukocyte capture and rolling along the vessel wall, which is mediated by selectins. Next, leukocytes become activated by chemotactic cytokines and then enhance expression and activation of integrins such as lymphocyte functionrelated antigen (LFA-1) and membrane attack complex-1 (Mac-1), which are the adhesion molecules on leukocytes required for adhesion to, and diapedesis through, the vessel wall. As a result, the activated leukocytes firmly adhere to the endothelium, and subsequently migrate through the vessel wall into the surrounding tissue. The immunoglobulin superfamily genes intercellular adhesion molecule-1 and -2 (ICAM-1/$2)$, vascular cell adhesion molecule-1 (VCAM-1), platelet endothelial cell adhesion molecule (PECAM-1) and mucosal addressin cell adhesion molecule-1 (MadCAM-1) are EC counterreceptors for the leukocyte integrins, and are crucial in leukocyte adhesion and diapedesis. ${ }^{82}$ Under normal circumstances, inflammatory cytokines such as tumor necrosis factor (TNF), interleukin 1 (IL-1) and IFN facilitate leukocyte adhesion to vascular endothelium and leukocyte extravasation into tissues by increasing expression of endothelial adhesion molecules such as ICAM-1, VCAM-1 and E-selectin. ${ }^{83}$

Tumors have the capacity to prevent the formation of a proper anti-tumor immune response by downregulation of leukocyte adhesion molecules on tumor EC. This decreased EC adhesion molecule expression is mediated via the production of angiogenic growth factors, such as VEGF and FGF, by tumor cells. These angiogenic factors reduce the expression of EC adhesion molecules such as ICAM-1 and -2, CD34, VCAM-1 and E-selectin. ${ }^{84-87}$ The hampered induction of EC adhesion molecules by proinflammatory cytokines is called EC anergy and contributes to the escape of tumors from immune surveillance. ${ }^{88}$ The reduced EC adhesion molecule expression results in decreased leukocyte-EC adhesion in vitro, and suppressed leukocyte-vessel wall interactions in vivo. Intriguingly, large tumors cause a systemic downregulation of leukocyte-vessel wall interactions, which is probably due to production of high amounts of angiogenic growth factors by these tumors and resulting high levels of these factors in the circulation. ${ }^{89}$ The local suppression of leukocyte-vessel wall interactions in a tumor are likely to result in reduced leukocyte extravasation and infiltration into the tumor.

Repression of EC adhesion molecule, and of leukocyte-vessel wall interactions, might explain why several immuno-directed anti-tumor strategies so far have not been as effective as anticipated. It is attractive to propose that immune effector cells are being generated, but can not migrate into the tumor, and therefore are unable to exert an anti-tumor effect. Therefore, co-treatment with compounds able to reverse EC anergy might improve immunotherapy strategies. Recently, Dirkx et al. demonstrated that the angiogenesis inhibitors anginex, endostatin and angiostatin can overcome EC anergy, by upregulation of EC adhesion molecules and subsequent leukocyte-vessel 
wall interactions in tumor vessels. ${ }^{90}$ This was accompanied by an increased inflammatory infiltrate in the tumor. These findings indicate that angiostatic treatment might be used for improvement of various immunotherapeutic approaches.

\section{Epigenetics}

DNA is packaged into chromatin, in which DNA is wrapped around a core of histone proteins to form nucleosomes. A chromosome contains regions of heterochromatin, associated with the silencing of genes, and euchromatin, a more open structure in which genes are often expressed. Chromatin structure is implicated in the epigenetic control of gene expression. Epigenetic changes in gene expression are heritable, but do not result from alterations in the DNA sequence. ${ }^{91}$ The four interacting key players in epigenetics are DNA methylation, histone modifications, Polycomb group proteins and small non-coding RNAs (Fig. 1.2).

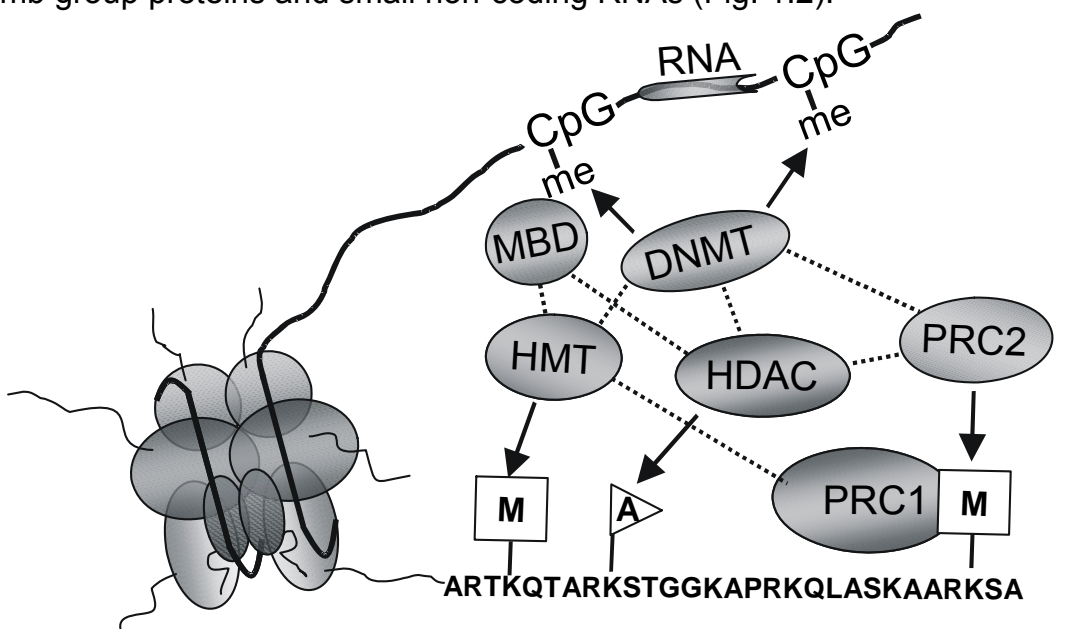

Figure 1.2 Different epigenetic modifications and their interactions.

The four key players in epigenetics are DNA methylation, histone modifications, Polycomb group $(\mathrm{PcG})$ proteins and small non-coding RNAs, which are interconnected in gene silencing. Examples of direct protein-protein interactions between different epigenetic players are indicated by dotted lines. Methyl-binding domain proteins (MBDs) bind methylated CpGs, and interact with histone methyltransferases (HMTs) ${ }^{121}$ and histone deacetylases (HDACs) ${ }^{120}$ to recruit these enzymes to methylated cytosines. Furthermore, DNA methyltransferases (DNMTs) can directly bind to HDACs ${ }^{122-}$ ${ }^{125}$ and HMTs. ${ }^{126,127}$ The Polycomb group protein enhancer of zeste homologue 2 (EZH2) has been shown to bind DNMTs. ${ }^{119}$ Direct interaction between PCG proteins and HDACs proteins has been shown both in humans and Drosophila. ${ }^{159,160}$ Furthermore, selective interactions between vertebrate Polycomb homologs and the SUV39H1 HMT have been demonstrated both in vitro and in vivo. ${ }^{161}$ PRC1 and 2: polycomb repressive complex 1 and 2.

\section{DNA methylation}

Methylation of DNA is the addition of a methylgroup to cytosine located 5 ' to a guanine within a $\mathrm{CpG}$ dinucleotide.$^{92} \mathrm{CpG}$ dinucleotides are not randomly distributed throughout the genome. There is a general underrepresentation of $\mathrm{CpG}$ dinucleotides 
within the human genome, probably due to spontaneous deamination of 5methylcytosine into thymidine. However, there are $\mathrm{CpG}$ rich regions, called $\mathrm{CpG}$ islands, that are often located in gene promoter regions. In normal tissues, these CpG islands are usually unmethylated, with the exception of imprinted genes, Xchromosome genes in women, germline-specific genes and tissue-specific genes. Most methylation in normal tissues occurs outside the $\mathrm{CpG}$ islands, in the non-coding DNA, and serves to repress transcription of repeat elements, inserted viral sequences and transposons. DNA methyltransferases (DNMTs) are the enzymes that catalyze the DNA methylation reaction. DNMT3a and DNMT3b are primarily responsible for de novo DNA methylation at previously unmethylated $\mathrm{CpG}$ sites. DNMT1 is considered to be a maintenance methyltransferase that methylates hemi-methylated DNA, although it also exhibits limited de novo methyltransferase activity. ${ }^{93}$

Promoter DNA methylation is generally associated with silencing of genes. Methylated cytosines can directly repress gene transcription by sterically inhibiting the association of some DNA binding factors with their DNA recognition sequences. ${ }^{94}$ Furthermore, methyl-binding domain proteins (MBDs) can bind methylated $\mathrm{CpGs}$, and exhibit repressive potential themselves, or use transcriptional co-repressor molecules to silence transcription and to modify the surrounding chromatin. Six mammalian MBD family members have been characterized so far (MeCP2, MBD1, MBD2, MBD3, MBD4 and Kaiso). ${ }^{95}$

\section{Histone modifications}

The core histones $\mathrm{H} 2 \mathrm{~A}, \mathrm{H} 2 \mathrm{~B}, \mathrm{H} 3$ and $\mathrm{H} 4$, are the major structural components of chromatin. Each nucleosome comprises two copies of each of the four core histones. The protruding tails of these histones undergo post-translational modifications at multiple sites, including acetylation, methylation, phosphorylation, ubiquitylation, ADPribosylation and glycosylation. ${ }^{96,97}$ The combination of post-translational histone modifications is termed the "histone code" ${ }^{98}$ Histone modifications serve as binding sites for proteins containing domains that specifically recognize a single modification or a combination of modifications, leading to changes in chromatin packaging and gene expression. Some of the histone modifications are generally associated with active genes, such as histone acetylation, whereas others can be associated with both active and repressed genes, like histone methylation. There are now many examples of associations between specific histone modifications, or combinations thereof, and defined functional outcomes. ${ }^{99}$

Histone acetylation is the most extensively studied histone modification, that is maintained by a balance between the activities of histone acetyltransferases (HATs) and histone deacetylases (HDACs). HAT enzymes can be divided into several broad groups based on their conserved sequence domains. Two large families are the GNAT group and the Moz-Ybf2/Sas3-Sas2-Tip60 group (MYST) family, and there are several smaller groups, including the TAF1, CBP/p300, SRC-1, and HAT1 enzymes. ${ }^{100}$ HDAC enzymes have been categorized in three classes based on homology to yeast HDACs. Class I includes HDAC 1, 2, 3, and 8 which are related to yeast RPD3 deacetylase. HDACs 4, 5, 6, 7, 9 and 10 belong to class II HDACs and are related to yeast HDA1 deacetylase. A third class of HDACs has been identified that have an absolute requirement for NAD, the so called Sir2 family of deacetylases, which appear 
not to have histones as their primary substrates. ${ }^{101}$ Histone acetylation is associated with transcriptional activation, whereas histone deacetylation is associated with chromatin condensation and transcriptional repression. ${ }^{102}$ Histone methylation was generally considered as a stable epigenetic modification, until the recent discovery of histone demethylases. ${ }^{103-105}$ The position of histone methylation determines whether it signals transcriptional activation or repression. ${ }^{106,107}$ Methylation of lysines 4, 36 and 79 on histone $\mathrm{H} 3$ are associated with gene activation, while lysine 9 and 27 are associated with gene silencing. Furthermore, histone arginine residues are prone to mono- and di- methylation, and lysine residues can be mono-, di- or tri- methylated. Differences in the distribution of these isoforms have been described, for example trimethylation of histone $\mathrm{H} 3$ lysine $4(\mathrm{H} 3 \mathrm{~K} 4 \mathrm{me} 3)$ is most enriched at the beginning of genes, $\mathrm{H} 3 \mathrm{~K} 4 \mathrm{me} 2$ in the middle, and H3K4me1 at the 3 'end. ${ }^{108,109}$

\section{Polycomb group proteins}

Polycomb group $(\mathrm{PcG})$ proteins are highly conserved chromatin remodeling factors. They are epigenetic silencers of, amongst others, developmental control genes and genes involved in cell cycle regulation. ${ }^{110} \mathrm{PcG}$ proteins are important in cell fate determination, maintenance of embryonic and adult stem cells, X-chromosome inactivation, and regulation of cell proliferation. ${ }^{111} \mathrm{PcG}$ proteins can be divided into at least two distinct complexes that cooperate in gene inactivation. Polycomb repressive complex 1 (PRC1), the maintainance complex which contains BMI1, and polycomb repressive complex 2 (PRC2), the initiation complex containing enhancer of zeste homologue $2(\mathrm{EZH} 2)$ which can methylate target genes at lysine 27 of histone $\mathrm{H} 3$ (H3K27) and lysine 26 of histone H1. PRC1 can be recruited by binding to trimethylated H3K27. After binding to chromatin, the PcG complex can repress transcription by inhibiting ATP-dependent nucleosome remodeling, and by direct interactions with the transcriptional machinery. The repressive function of the PcG proteins can be counteracted by the trithorax group (trxG) proteins. Therefore, the $\mathrm{PcG} / \mathrm{trxG}$ system provides a cellular memory mechanism. ${ }^{12}$

\section{Small non-coding RNAs}

Small non-coding RNAs are processed from double stranded precursors. On the basis of sequence homology, small RNAs target specific regions for transcriptional gene silencing, through establishment of heterochromatin. Small RNA molecules targeted to gene promoter regions can induce transcriptional gene silencing in a DNA methylation-dependent manner in plants (RNA-dependent DNA methylation). ${ }^{113}$ Two independent studies demonstrated that synthetic siRNAs targeted to $\mathrm{CpG}$ islands within the promoter of a specific gene can induce transcriptional gene silencing by means of methylation of DNA in human cells. ${ }^{114,115}$ However, others report that short double-stranded RNA induces transcriptional gene silencing in the absence of DNA methylation in human cancer cells. ${ }^{116}$ These findings suggest that small RNA-directed transcriptional silencing is conserved in mammals, providing a means to inhibit mammalian gene function. 
General Introduction

\section{Interplay of epigenetic modifications}

Clearly, different epigenetic players are interconnected in gene silencing (Fig. 1.2). Possible targeting of DNA methylation and histone modifications to specific DNA sequences by double-stranded RNAs points to interactions between small RNAs, DNA methylation and histone modifications in gene silencing. ${ }^{117}$ In addition, the RNAi machinery is involved in specific nuclear PcG-dependent functions. ${ }^{118}$ Transcriptional silencing of PcG target genes is closely linked to introduction of 'epigenetic marks' such as methylated lysine residues on histone tails. ${ }^{110}$ Furthermore, EZH2 has been shown to interact with DNMTs, which is required for DNA methylation of EZH2-target promoters. ${ }^{119}$

Another important example of interconnection between different epigenetic mechanisms in gene inactivation is the interaction between DNA methylation and histone modifications. MBDs recruit HDACs and histone methyltransferases to methylated cytosines ${ }^{120,121}$ providing a way to target histone modifications to promoter DNA methylation during establishment of epigenetic transcriptional repression. In addition, DNMTs can directly bind to HDACs ${ }^{122-125}$ and histone methyltransferases. ${ }^{126,127}$ Besides direct coupling of DNA methylation and histone modifications, the latter might also be the mechanism behind the non-enzymatic, methylation-independent transcriptional silencing effects of DNMTs. ${ }^{128}$ Thus, by serving as a binding scaffold for HDACs and histone methyltransferases, DNMTs can repress gene transcription independently of their methyltransferase activity.

The issue of timing of DNA methylation and histone modifications that accompany transcriptional inactivation has been raised by many investigators. In some studies, DNA methylation is considered as the initiating event in epigenetic gene silencing. By binding of MBDs, HDACs and histone methyltransferases are recruited, which then induce changes in histone modifications that are characteristic of inactive promoters. ${ }^{129,130}$ According to others, histone modifications are primary events, and DNA methylation serves to maintain genes which are already inactivated in a permanently silenced state. ${ }^{126,131-133}$ In a study on transgene silencing, Mutskov et al. demonstrated that hypoacetylation of histone $\mathrm{H} 3$ and $\mathrm{H} 4$, accompanied by the loss of lysine 4 methylation of histone $\mathrm{H} 3$, precede lysine 9 methylation of histone $\mathrm{H} 3$ and DNA methylation. ${ }^{134}$ They concluded that DNA methylation was a consequence, rather than the primary cause, of transcriptional silencing. In case of this second model, the reported interactions between DNMTs and histone modifying enzymes might enable genes that are already transcriptionally inactivated by certain histone modifications, to become irreversibly silenced by promoter DNA methylation. Probably, the role and exact timing of different histone modifications and DNA methylation during epigenetic gene silencing differs between individual genes, and might also depend on cell type. In addition, the contribution of other epigenetic players, such as small RNAs and/or PcG proteins, is also of major influence.

\section{Epigenetics and cancer}

In addition to genetic defects, the epigenetic landscape of a tumor undergoes major disruption. The best studied epigenetic aberrations in cancer cells are changes in DNA methylation and histone modifications. The genome of a tumor cell undergoes 
global DNA hypomethylation, mainly due to loss of DNA methylation in gene coding regions, introns, and repetitive DNA sequences. ${ }^{135}$ This contributes to carcinogenesis through activation of previously silenced transposable elements and inserted viral sequences, loss of imprinting, chromosomal instability and oncogene activation. Recently, a profile of overall histone modifications in cancer cells has been revealed. Human tumors undergo a global loss of monoacetylation of lysine 16 and trimethylation of lysine 20 of histone $\mathrm{H} 4 .^{136}$

At the same time as the tumor cell genome undergoes massive genomic hypomethylation, promoter CpG islands of tumor suppressor genes become hypermethylated. ${ }^{137}$ Although a number of studies have sought to reconcile this apparent paradox, it has remained unclear whether these epigenetic changes are causally linked. Promoter DNA hypermethylation of tumor suppressor genes is associated with histone $\mathrm{H} 3$ deacetylation, histone $\mathrm{H} 3$ lysine 9 hypermethylation and histone $\mathrm{H} 3$ lysine 4 hypomethylation. ${ }^{138-140}$ Aberrant promoter DNA hypermethylation and associated alterations in post-translational histone modifications result in inappropriate transcriptional repression of tumor suppressor genes. Some studies using inhibitors of DNA methylation and histone deacetylation showed that DNA methylation is dominant in silencing of tumor suppressor genes in cancer cells. ${ }^{138,141}$ Epigenetic tumor suppressor gene inactivation is often the second "hit" required for inactivation of both alleles of a tumor suppressor gene. There is a growing list of epigenetically silenced tumor suppressor genes in various cancer types. Examples are genes involved in cell cycle regulation and apoptosis (p14ARF, p15INK4b, p16INK4a, APC, RASSF1A, HIC1), DNA repair genes ( $h M L H 1$, GSTP1, MGMT, $B R C A 1)$, and genes related to metastasis and invasion (CDH1, TIMP-3, DAPK, p73, maspin, TSP1, VHL). ${ }^{137}$ Thus, DNA hypermethylation is associated with the inactivation of virtually all pathways suggested by Hanahan and Weinberg to be involved with the cancer process. ${ }^{3}$ Aberrant epigenetic silencing marks of tumor suppressor gene promoters in cancer cells can be used to identify novel tumor suppressor genes, i.e. by using several techniques to identify methylated $\mathrm{CpG}$ islands. ${ }^{142}$ An important approach for detection of methylated CpG islands is the chemical modification of DNA by sodium bisulfite, which converts cytosine to uracil unless the base is methylated, allowing discrimination of methylated from unmethylated DNA. Methylation-specific PCR (MSP) is based on detection of the bisulfite induced sequence differences by PCR using specific primer sets for both unmethylated and methylated DNA. ${ }^{143,144}$ Another methylation-based strategy is the digestion of DNA by methylation-sensitive or -insensitive restriction endonuclease, such as restriction landmark genomic scanning (RLGS). ${ }^{145} \mathrm{~A}$ third approach is the treatment of tumor cells with inhibitors of DNA methylation and/or histone deacetylation, to identify epigenetically silenced tumor suppressor genes that are reexpressed by these agents. ${ }^{146}$ In addition to identification of novel tumor suppressor genes, DNA methylation and histone modification patterns can be used for early detection of cancer cells and risk assessment, but also for prediction of disease prognosis or therapeutic response. ${ }^{147,148}$

In contrast with the well-known aberrations in DNA methylation and histone modifications in cancer, comparatively little is known on the potential roles of other epigenetic players in tumorigenesis. PcG proteins are suggested to be involved in 
malignant transformation. Abnormal PcG gene expression has been described in most human cancers, and is associated with cancer development and progression. ${ }^{111,149}$ Recent evidence indicates that small RNAs can function as tumor suppressors and oncogenes, and factors required for the biogenesis of these RNAs have been implicated in tumorigenesis. ${ }^{150}$

\section{Epigenetic therapy}

Cancer cells contain major epigenetic aberrations, in which different epigenetic mediators are involved. The reversibility of epigenetic events, in contrast to genetic aberrations, makes them potentially suitable for therapeutic intervention. For example, siRNAs regulating expression levels of specific genes in mammalian cells by interfering with gene transcription might have potential as a new approach in gene therapy. ${ }^{114}$ Currently, however, (pre)clinical studies of epigenetic therapy against cancer focus almost completely on two types of epigenetic drugs: DNMT- and HDAC inhibitors. By reversal of epigenetic modifications, these compounds can reactivate previously silenced tumor suppressor genes. ${ }^{151}$

5-Azacytidine and 5-aza-2'-deoxycytidine are the most widely used DNMT inhibitors. These cytidine analogues have to be incorporated into the DNA during DNA replication, where they are recognized by DNMTs as natural substrates. As a result, the DNMTs become covalently trapped, leading to demethylation of the DNA after several cell divisions. ${ }^{152} 5$-Azacytidine has gained approval by the FDA for treatment of myelodysplastic syndrome. The cytidine analogue zebularine is a novel DNMT inhibitor with increased stability and comparatively little toxicity. ${ }^{153}$ DNMT inhibitors slow the growth of tumor cells, which is suggested to be due to reactivation of growthregulatory genes silenced by promoter DNA methylation. ${ }^{154}$ A number of HDAC inhibitors have been characterized that cause growth arrest, differentiation or apoptosis of tumor cells in vitro and in vivo. These compounds act very selectively, altering the transcription of only $2-10 \%$ of genes. Several HDAC inhibitors are in various stages of clinical development, including butyrate, valproic acid, depsipeptide (FK-228), benzamide (MS-275), suberoylanilide hydroxamic acid (SAHA), NVPLAQ824 and PDX-101. ${ }^{155}$

Besides the clinical application of DNMT- and HDAC inhibitors as anti-cancer therapeutics, these compounds are also used to study the role of DNA methylation and histone deacetylation in tumor biology, and to identify new epigenetically silenced tumor suppressor genes. Microarray analysis of gene expression profiles in tumor cells treated with DNMT- and/or HDAC inhibitors have been shown powerful in identification of new epigenetically silenced tumor suppressor genes in cancer. Also, comparing the effects of DNMT- and HDAC inhibitors on reactivation of tumor suppressor genes might reveal differences in the contribution of DNA methylation versus histone deacetylation in epigenetic silencing of these genes. 


\section{Aim and outline of the thesis}

During the complex multi-step process of angiogenesis, intricate regulation of gene expression in tumor EC is crucial. Although many studies identified transcripts that are upregulated in tumor EC, only very little is known on the regulation of gene expression in tumor vasculature. Epigenetic regulation of gene expression involves covalent modifications of DNA and of the core histones, resulting in altered chromatin structure. DNA methylation and histone modifications are key players in epigenetics. The aim of the present study was to investigate the role of epigenetic mechanisms in regulation of tumor angiogenesis and EC gene expression.

First, we studied the effects of the DNMT inhibitors 5-aza-2'-deoxycytidine (DAC) and zebularine on EC biology and angiogenesis in vitro and in vivo (Chapter 2). We examined effects of DAC and zebularine on tumor angiogenesis in mouse tumor models. However, since indirect effects of DNMT inhibitors on angiogenesis in vivo, via inhibition of tumor cells, might be expected, direct effects of these inhibitors on angiogenesis and EC angiogenic properties in vitro were also studied. Therefore, tumor EC were mimicked by activating human umbilical vein endothelial cells (HUVEC) with the angiogenic growth factors VEGF and bFGF, and culture supernatants of LS174T and CaCo-2 human colon carcinoma cell lines. Effects of DNMT inhibitors on proliferation and apoptosis of these tumor-conditioned EC were examined, as well as effects on EC migration and sprouting. Furthermore, we studied whether angiogenesis in vivo in the chick chorioallantoic membrane is perturbed by these compounds. In these assays, the HDAC inhibitor trichostatin A (TSA) was included as a positive control, because angiostatic properties of HDAC inhibitors have recently been described. ${ }^{156,157}$ To evaluate whether DNA methylation is involved in regulation of (tumor) angiogenesis, we analyzed global 5-methylcytosine content as well as DNMT1 activity in tumor-conditioned versus quiescent EC, but also studied promoter-specific DNA methylation and histone acetylation of three angiogenesis inhibiting genes (IGFBP3, TSP-1 and JunB) that are downregulated in tumorconditioned EC.

To provide a mechanism for the angiostatic activities of DNMT- and HDAC inhibitors, and to understand the mechanisms behind the epigenetic regulation of tumor angiogenesis, we performed microarray experiments to identify genes downregulated in tumor-conditioned versus quiescent EC, and reexpressed by DAC and TSA (Chapter 3). We examined promoter DNA methylation and histone modifications of the candidate genes in tumor-conditioned and quiescent EC, as well as effects of DAC and TSA on these epigenetic modifications. Another important aim of this chapter was the identification and functional validation of novel genes involved in angiogenesis.

One of the genes identified by the microarray analysis is ICAM-1, the key EC adhesion molecule for leukocytes. As described above, tumors can escape from immunity by repressing leukocyte adhesion molecule expression on tumor EC, thereby reducing leukocyte-vessel wall interactions and attenuating infiltration of leukocytes into the tumor, a phenomenon called EC anergy. In Chapter 4 we 
investigated whether epigenetic mechanisms regulate this angiogenesis-mediated escape from immunity. We therefore studied effects of DAC, zebularine and TSA on ICAM-1 expression in tumor(-conditioned) $\mathrm{EC}$ and on leukocyte-EC adhesion in vitro and in vivo. To explain effects of DNMT- and HDAC inhibitors on EC ICAM-1 expression, DNA methylation and histone modifications of the ICAM-1 promoter were examined.

In Chapter 5 we review the therapeutic potential of epigenetic therapy in cancer. The clinical application and pitfalls of DNMT- and HDAC inhibitors as anti-cancer strategy, as evaluated in ongoing clinical trials, are summarized. By inhibition of both tumor cells, through reactivation of epigenetically silenced tumor suppressor genes, as well as tumor ECs, a dual target for epigenetic therapy in cancer is created. The dual targeting of both tumor cells and tumor vasculature by DNMT- and HDAC inhibitors makes them attractive combinatorial anti-cancer therapeutics. We propose a model suggesting 3 mechanisms by which the anti-tumor effects of DNMT- and HDAC inhibitors can be explained in vivo. 


\section{References}

1. $\quad$ Carmeliet P. Angiogenesis in health and disease. Nat Med. 2003;9:653-660.

2. Carmeliet P. Mechanisms of angiogenesis and arteriogenesis. Nat Med. 2000;6:389-395.

3. Hanahan D, Weinberg RA. The hallmarks of cancer. Cell. 2000;100:57-70.

4. Hanahan D, Folkman J. Patterns and emerging mechanisms of the angiogenic switch during tumorigenesis. Cell. 1996;86:353-364.

5. Bergers G, Benjamin LE. Tumorigenesis and the angiogenic switch. Nat Rev Cancer. 2003;3:401-410

6. Carmeliet P, Dor Y, Herbert JM, et al. Role of HIF-1alpha in hypoxia-mediated apoptosis, cell proliferation and tumour angiogenesis. Nature. 1998;394:485-490.

7. Ferrara N, Kerbel RS. Angiogenesis as a therapeutic target. Nature. 2005;438:967-974.

8. Orimo A, Gupta PB, Sgroi DC, et al. Stromal fibroblasts present in invasive human breast carcinomas promote tumor growth and angiogenesis through elevated SDF-1/CXCL12 secretion. Cell. 2005;121:335-348.

9. Baluk P, Hashizume H, McDonald DM. Cellular abnormalities of blood vessels as targets in cancer. Curr Opin Genet Dev. 2005;15:102-111.

10. Ferrara N, Gerber HP, LeCouter J. The biology of VEGF and its receptors. Nat Med. 2003;9:669-676.

11. Benjamin LE, Golijanin D, Itin A, Pode D, Keshet E. Selective ablation of immature blood vessels in established human tumors follows vascular endothelial growth factor withdrawal. J Clin Invest. 1999;103:159-165.

12. Costa C, Soares R, Schmitt F. Angiogenesis: now and then. Apmis. 2004;112:402-412.

13. Soker S, Takashima S, Miao HQ, Neufeld G, Klagsbrun M. Neuropilin-1 is expressed by endothelial and tumor cells as an isoform-specific receptor for vascular endothelial growth factor. Cell. 1998;92:735-745.

14. Kanda S, Miyata Y, Kanetake H. Fibroblast growth factor-2-mediated capillary morphogenesis of endothelial cells requires signals via Flt-1/vascular endothelial growth factor receptor-1: possible involvement of c-Akt. J Biol Chem. 2004;279:4007-4016.

15. Davis S, Aldrich TH, Jones PF, et al. Isolation of angiopoietin-1, a ligand for the TIE2 receptor, by secretion-trap expression cloning. Cell. 1996;87:1161-1169.

16. Maisonpierre PC, Suri C, Jones PF, et al. Angiopoietin-2, a natural antagonist for Tie2 that disrupts in vivo angiogenesis. Science. 1997;277:55-60.

17. Folkman J. Angiogenesis. Annu Rev Med. 2006;57:1-18.

18. Folkman J, Kalluri R. Cancer without disease. Nature. 2004;427:787.

19. Nyberg $\mathrm{P}$, Xie L, Kalluri R. Endogenous inhibitors of angiogenesis. Cancer Res. 2005;65:3967-3979.

20. Pepper MS, Vassalli JD, Wilks JW, Schweigerer L, Orci L, Montesano R. Modulation of bovine microvascular endothelial cell proteolytic properties by inhibitors of angiogenesis. J Cell Biochem. 1994;55:419-434.

21. Ma Z, Qin H, Benveniste EN. Transcriptional suppression of matrix metalloproteinase-9 gene expression by IFN-gamma and IFN-beta: critical role of STAT-1alpha. J Immunol. 2001;167:5150-5159.

22. Dinney CP, Bielenberg DR, Perrotte $\mathrm{P}$, et al. Inhibition of basic fibroblast growth factor expression, angiogenesis, and growth of human bladder carcinoma in mice by systemic interferon-alpha administration. Cancer Res. 1998;58:808-814.

23. Maione TE, Gray GS, Petro J, et al. Inhibition of angiogenesis by recombinant human platelet factor-4 and related peptides. Science. 1990;247:77-79.

24. Good DJ, Polverini PJ, Rastinejad F, et al. A tumor suppressor-dependent inhibitor of angiogenesis is immunologically and functionally indistinguishable from a fragment of thrombospondin. Proc Natl Acad Sci U S A. 1990;87:6624-6628. 
25. Volpert OV, Zaichuk T, Zhou W, et al. Inducer-stimulated Fas targets activated endothelium for destruction by anti-angiogenic thrombospondin-1 and pigment epithelium-derived factor. Nat Med. 2002;8:349-357.

26. Stetler-Stevenson WG, Seo DW. TIMP-2: an endogenous inhibitor of angiogenesis. Trends Mol Med. 2005;11:97-103.

27. van der Schaft DW, Toebes EA, Haseman JR, Mayo KH, Griffioen AW. Bactericidal/permeability-increasing protein (BPI) inhibits angiogenesis via induction of apoptosis in vascular endothelial cells. Blood. 2000;96:176-181.

28. Dawson DW, Volpert OV, Gillis $\mathrm{P}$, et al. Pigment epithelium-derived factor: a potent inhibitor of angiogenesis. Science. 1999;285:245-248.

29. O'Reilly MS, Boehm T, Shing Y, et al. Endostatin: an endogenous inhibitor of angiogenesis and tumor growth. Cell. 1997;88:277-285.

30. Abdollahi A, Hahnfeldt $\mathrm{P}$, Maercker $\mathrm{C}$, et al. Endostatin's antiangiogenic signaling network. Mol Cell. 2004;13:649-663.

31. O'Reilly MS, Holmgren L, Shing Y, et al. Angiostatin: a novel angiogenesis inhibitor that mediates the suppression of metastases by a Lewis lung carcinoma. Cell. 1994;79:315-328.

32. Maeshima Y, Colorado PC, Torre A, et al. Distinct antitumor properties of a type IV collagen domain derived from basement membrane. J Biol Chem. 2000;275:21340-21348.

33. Maeshima Y, Sudhakar A, Lively JC, et al. Tumstatin, an endothelial cell-specific inhibitor of protein synthesis. Science. 2002;295:140-143.

34. Bouma-ter Steege JC, Mayo KH, Griffioen AW. Angiostatic proteins and peptides. Crit Rev Eukaryot Gene Expr. 2001;11:319-334.

35. Folkman J. Endogenous angiogenesis inhibitors. Apmis. 2004;112:496-507

36. Folkman J. Antiangiogenesis in cancer therapy--endostatin and its mechanisms of action. Exp Cell Res. 2006;312:594-607.

37. Satchi-Fainaro R, Mamluk R, Wang L, et al. Inhibition of vessel permeability by TNP-470 and its polymer conjugate, caplostatin. Cancer Cell. 2005;7:251-261.

38. Satchi-Fainaro R, Puder M, Davies JW, et al. Targeting angiogenesis with a conjugate of HPMA copolymer and TNP-470. Nat Med. 2004;10:255-261.

39. Hurwitz H, Fehrenbacher L, Novotny W, et al. Bevacizumab plus irinotecan, fluorouracil, and leucovorin for metastatic colorectal cancer. N Engl J Med. 2004;350:2335-2342.

40. Wood JM, Bold G, Buchdunger E, et al. PTK787/ZK 222584, a novel and potent inhibitor of vascular endothelial growth factor receptor tyrosine kinases, impairs vascular endothelial growth factor-induced responses and tumor growth after oral administration. Cancer Res. 2000;60:2178-2189.

41. Wilhelm SM, Carter C, Tang L, et al. BAY 43-9006 exhibits broad spectrum oral antitumor activity and targets the RAF/MEK/ERK pathway and receptor tyrosine kinases involved in tumor progression and angiogenesis. Cancer Res. 2004;64:7099-7109.

42. Smith JK, Mamoon NM, Duhe RJ. Emerging roles of targeted small molecule proteintyrosine kinase inhibitors in cancer therapy. Oncol Res. 2004;14:175-225.

43. Kerbel RS, Yu J, Tran J, et al. Possible mechanisms of acquired resistance to antiangiogenic drugs: implications for the use of combination therapy approaches. Cancer Metastasis Rev. 2001;20:79-86.

44. Kerbel RS. Therapeutic implications of intrinsic or induced angiogenic growth factor redundancy in tumors revealed. Cancer Cell. 2005;8:269-271.

45. Kerbel R, Folkman J. Clinical translation of angiogenesis inhibitors. Nat Rev Cancer 2002;2:727-739.

46. Graeber TG, Osmanian C, Jacks T, et al. Hypoxia-mediated selection of cells with diminished apoptotic potential in solid tumours. Nature. 1996;379:88-91.

47. Hida K, Hida Y, Amin DN, et al. Tumor-associated endothelial cells with cytogenetic abnormalities. Cancer Res. 2004;64:8249-8255.

48. Streubel B, Chott A, Huber D, et al. Lymphoma-specific genetic aberrations in microvascular endothelial cells in B-cell lymphomas. N Engl J Med. 2004;351:250-259. 
49. Gasparini G, Longo R, Fanelli M, Teicher BA. Combination of antiangiogenic therapy with other anticancer therapies: results, challenges, and open questions. J Clin Oncol. 2005;23:1295-1311.

50. Kerbel RS, Kamen BA. The anti-angiogenic basis of metronomic chemotherapy. Nat Rev Cancer. 2004;4:423-436.

51. Burrows FJ, Thorpe PE. Eradication of large solid tumors in mice with an immunotoxin directed against tumor vasculature. Proc Natl Acad Sci U S A. 1993;90:8996-9000.

52. Neri D, Bicknell R. Tumour vascular targeting. Nat Rev Cancer. 2005;5:436-446.

53. Oh P, Li Y, Yu J, et al. Subtractive proteomic mapping of the endothelial surface in lung and solid tumours for tissue-specific therapy. Nature. 2004;429:629-635.

54. Pasqualini R, Ruoslahti E. Organ targeting in vivo using phage display peptide libraries. Nature. 1996;380:364-366.

55. Nilsson F, Kosmehl H, Zardi L, Neri D. Targeted delivery of tissue factor to the ED-B domain of fibronectin, a marker of angiogenesis, mediates the infarction of solid tumors in mice. Cancer Res. 2001;61:711-716.

56. Carnemolla B, Borsi L, Balza E, et al. Enhancement of the antitumor properties of interleukin-2 by its targeted delivery to the tumor blood vessel extracellular matrix. Blood. 2002;99:1659-1665.

57. Halin C, Rondini S, Nilsson F, et al. Enhancement of the antitumor activity of interleukin-12 by targeted delivery to neovasculature. Nat Biotechnol. 2002;20:264-269.

58. Borsi L, Balza E, Carnemolla B, et al. Selective targeted delivery of TNFalpha to tumor blood vessels. Blood. 2003;102:4384-4392.

59. Curnis F, Sacchi A, Borgna L, Magni F, Gasparri A, Corti A. Enhancement of tumor necrosis factor alpha antitumor immunotherapeutic properties by targeted delivery to aminopeptidase N (CD13). Nat Biotechnol. 2000;18:1185-1190.

60. Riva $P$, Franceschi $G$, Frattarelli $M$, et al. 131I radioconjugated antibodies for the locoregional radioimmunotherapy of high-grade malignant glioma--phase I and II study. Acta Oncol. 1999;38:351-359.

61. Gutheil JC, Campbell TN, Pierce PR, et al. Targeted antiangiogenic therapy for cancer using Vitaxin: a humanized monoclonal antibody to the integrin alphavbeta3. Clin Cancer Res. 2000;6:3056-3061.

62. Reardon DA, Akabani G, Coleman RE, et al. Salvage radioimmunotherapy with murine iodine-131-labeled antitenascin monoclonal antibody 81C6 for patients with recurrent primary and metastatic malignant brain tumors: phase II study results. J Clin Oncol. 2006;24:115-122.

63. Milowsky MI, Nanus DM, Kostakoglu L, Vallabhajosula S, Goldsmith SJ, Bander NH. Phase I trial of yttrium-90-labeled anti-prostate-specific membrane antigen monoclonal antibody J591 for androgen-independent prostate cancer. J Clin Oncol. 2004;22:2522-2531.

64. Rizzieri DA, Akabani G, Zalutsky MR, et al. Phase 1 trial study of 131/-labeled chimeric $81 \mathrm{C} 6$ monoclonal antibody for the treatment of patients with non-Hodgkin lymphoma. Blood. 2004;104:642-648.

65. McDonald DM, Choyke PL. Imaging of angiogenesis: from microscope to clinic. Nat Med. 2003;9:713-725.

66. St Croix B, Rago C, Velculescu V, et al. Genes expressed in human tumor endothelium. Science. 2000;289:1197-1202.

67. Rettig WJ, Garin-Chesa P, Healey JH, Su SL, Jaffe EA, Old LJ. Identification of endosialin, a cell surface glycoprotein of vascular endothelial cells in human cancer. Proc Natl Acad Sci U S A. 1992;89:10832-10836.

68. Nanda A, Karim B, Peng Z, et al. Tumor endothelial marker 1 (Tem1) functions in the growth and progression of abdominal tumors. Proc Natl Acad Sci U S A. 2006;103:3351-3356.

69. Im DS. Orphan G protein-coupled receptors and beyond. Jpn J Pharmacol. 2002;90:101106. 
70. Duesbery NS, Resau J, Webb CP, et al. Suppression of ras-mediated transformation and inhibition of tumor growth and angiogenesis by anthrax lethal factor, a proteolytic inhibitor of multiple MEK pathways. Proc Natl Acad Sci U S A. 2001;98:4089-4094.

71. van Beijnum J, Dings RP, van der Linden E, et al. Gene expression of tumor angiogenesis dissected; specific targeting of colon cancer angiogenic vasculature. Blood. 2006.

72. Huminiecki L, Gorn M, Suchting S, Poulsom R, Bicknell R. Magic roundabout is a new member of the roundabout receptor family that is endothelial specific and expressed at sites of active angiogenesis. Genomics. 2002;79:547-552.

73. Sullivan DC, Huminiecki L, Moore JW, et al. EndoPDI, a novel protein-disulfide isomeraselike protein that is preferentially expressed in endothelial cells acts as a stress survival factor. J Biol Chem. 2003;278:47079-47088.

74. Mailhos C, Modlich U, Lewis J, Harris A, Bicknell R, Ish-Horowicz D. Delta4, an endothelial specific notch ligand expressed at sites of physiological and tumor angiogenesis. Differentiation. 2001;69:135-144.

75. Artavanis-Tsakonas S, Matsuno K, Fortini ME. Notch signaling. Science. 1995;268:225-232.

76. Liu ZJ, Shirakawa T, Li Y, et al. Regulation of Notch1 and DIl4 by vascular endothelial growth factor in arterial endothelial cells: implications for modulating arteriogenesis and angiogenesis. Mol Cell Biol. 2003;23:14-25.

77. Castellani P, Borsi L, Carnemolla B, et al. Differentiation between high- and low-grade astrocytoma using a human recombinant antibody to the extra domain-B of fibronectin. Am J Pathol. 2002;161:1695-1700.

78. Santimaria M, Moscatelli G, Viale GL, et al. Immunoscintigraphic detection of the ED-B domain of fibronectin, a marker of angiogenesis, in patients with cancer. Clin Cancer Res. 2003;9:571-579.

79. Carnemolla B, Castellani P, Ponassi M, et al. Identification of a glioblastoma-associated tenascin-C isoform by a high affinity recombinant antibody. Am J Pathol. 1999;154:13451352.

80. Pasqualini R, Koivunen E, Ruoslahti E. Alpha v integrins as receptors for tumor targeting by circulating ligands. Nat Biotechnol. 1997;15:542-546.

81. van Beijnum JR, Griffioen AW. In silico analysis of angiogenesis associated gene expression identifies angiogenic stage related profiles. Biochim Biophys Acta. 2005;1755:121-134

82. Springer TA. Traffic signals for lymphocyte recirculation and leukocyte emigration: the multistep paradigm. Cell. 1994;76:301-314.

83. Carlos TM, Harlan JM. Leukocyte-endothelial adhesion molecules. Blood. 1994;84:20682101.

84. Melder RJ, Koenig GC, Witwer BP, Safabakhsh N, Munn LL, Jain RK. During angiogenesis, vascular endothelial growth factor and basic fibroblast growth factor regulate natural killer cell adhesion to tumor endothelium. Nat Med. 1996;2:992-997.

85. Hellwig SM, Damen CA, van Adrichem NP, Blijham GH, Groenewegen G, Griffioen AW. Endothelial CD34 is suppressed in human malignancies: role of angiogenic factors. Cancer Lett. 1997;120:203-211.

86. Griffioen AW, Damen CA, Martinotti S, Blijham GH, Groenewegen G. Endothelial intercellular adhesion molecule-1 expression is suppressed in human malignancies: the role of angiogenic factors. Cancer Res. 1996;56:1111-1117.

87. Griffioen AW, Relou IA, Gallardo Torres HI, et al. The angiogenic factor bFGF impairs leukocyte adhesion and rolling under flow conditions. Angiogenesis. 1998;2:235-243.

88. Griffioen AW, Damen CA, Blijham GH, Groenewegen G. Tumor angiogenesis is accompanied by a decreased inflammatory response of tumor-associated endothelium. Blood. 1996;88:667-673.

89. Dirkx AE, Oude Egbrink MG, Kuijpers MJ, et al. Tumor angiogenesis modulates leukocytevessel wall interactions in vivo by reducing endothelial adhesion molecule expression Cancer Res. 2003;63:2322-2329. 
90. Dirkx AE, oude Egbrink MG, Castermans K, et al. Anti-angiogenesis therapy can overcome endothelial cell anergy and promote leukocyte-endothelium interactions and infiltration in tumors. FASEB J. 2006;20:621-630.

91. Jaenisch R, Bird A. Epigenetic regulation of gene expression: how the genome integrates intrinsic and environmental signals. Nat Genet. 2003;33 Suppl:245-254.

92. Bird A. DNA methylation patterns and epigenetic memory. Genes Dev. 2002;16:6-21.

93. Bestor TH. The DNA methyltransferases of mammals. Hum Mol Genet. 2000;9:2395-2402.

94. Watt F, Molloy PL. Cytosine methylation prevents binding to DNA of a HeLa cell transcription factor required for optimal expression of the adenovirus major late promoter. Genes Dev. 1988;2:1136-1143.

95. Klose RJ, Bird AP. Genomic DNA methylation: the mark and its mediators. Trends Biochem Sci. 2006;31:89-97.

96. Turner BM. Cellular memory and the histone code. Cell. 2002;111:285-291.

97. Strahl BD, Allis CD. The language of covalent histone modifications. Nature. 2000;403:4145.

98. Jenuwein T, Allis CD. Translating the histone code. Science. 2001;293:1074-1080.

99. Nightingale KP, O'Neill LP, Turner BM. Histone modifications: signalling receptors and potential elements of a heritable epigenetic code. Curr Opin Genet Dev. 2006;16:125-136.

100. Chen H, Tini M, Evans RM. HATs on and beyond chromatin. Curr Opin Cell Biol. 2001;13:218-224.

101. Marks P, Rifkind RA, Richon VM, Breslow R, Miller T, Kelly WK. Histone deacetylases and cancer: causes and therapies. Nat Rev Cancer. 2001;1:194-202.

102. Richards EJ, Elgin SC. Epigenetic codes for heterochromatin formation and silencing: rounding up the usual suspects. Cell. 2002;108:489-500.

103. Chen Z, Zang J, Whetstine J, et al. Structural Insights into Histone Demethylation by JMJD2 Family Members. Cell. 2006;125:691-702.

104. Shi Y, Lan F, Matson C, et al. Histone demethylation mediated by the nuclear amine oxidase homolog LSD1. Cell. 2004;119:941-953.

105. Tsukada Y, Fang J, Erdjument-Bromage H, et al. Histone demethylation by a family of JmjC domain-containing proteins. Nature. 2006;439:811-816.

106. Kouzarides T. Histone methylation in transcriptional control. Curr Opin Genet Dev. 2002;12:198-209.

107. Martin $\mathrm{C}$, Zhang $\mathrm{Y}$. The diverse functions of histone lysine methylation. Nat Rev Mol Cell Biol. 2005;6:838-849.

108. Bernstein BE, Kamal M, Lindblad-Toh K, et al. Genomic maps and comparative analysis of histone modifications in human and mouse. Cell. 2005;120:169-181.

109. Schubeler D, MacAlpine DM, Scalzo D, et al. The histone modification pattern of active genes revealed through genome-wide chromatin analysis of a higher eukaryote. Genes Dev. 2004;18:1263-1271.

110. Bantignies F, Cavalli G. Cellular memory and dynamic regulation of polycomb group proteins. Curr Opin Cell Biol. 2006;18:275-283.

111. Valk-Lingbeek ME, Bruggeman SW, van Lohuizen M. Stem cells and cancer; the polycomb connection. Cell. 2004;118:409-418.

112. Ringrose L, Paro R. Epigenetic regulation of cellular memory by the Polycomb and Trithorax group proteins. Annu Rev Genet. 2004;38:413-443.

113. Zilberman D, Cao X, Jacobsen SE. ARGONAUTE4 control of locus-specific siRNA accumulation and DNA and histone methylation. Science. 2003;299:716-719.

114. Kawasaki H, Taira K. Induction of DNA methylation and gene silencing by short interfering RNAs in human cells. Nature. 2004;431:211-217.

115. Morris KV, Chan SW, Jacobsen SE, Looney DJ. Small interfering RNA-induced transcriptional gene silencing in human cells. Science. 2004;305:1289-1292.

116. Ting AH, Schuebel KE, Herman JG, Baylin SB. Short double-stranded RNA induces transcriptional gene silencing in human cancer cells in the absence of DNA methylation. Nat Genet. 2005;37:906-910. 
117. Morris KV. siRNA-mediated transcriptional gene silencing: the potential mechanism and a possible role in the histone code. Cell Mol Life Sci. 2005;62:3057-3066.

118. Grimaud C, Bantignies F, Pal-Bhadra M, Ghana P, Bhadra U, Cavalli G. RNAi components are required for nuclear clustering of Polycomb group response elements. Cell. 2006;124:957-971.

119. Vire E, Brenner C, Deplus R, et al. The Polycomb group protein EZH2 directly controls DNA methylation. Nature. 2006;439:871-874.

120. Jones PL, Veenstra GJ, Wade PA, et al. Methylated DNA and MeCP2 recruit histone deacetylase to repress transcription. Nat Genet. 1998;19:187-191.

121. Sarraf SA, Stancheva I. Methyl-CpG binding protein MBD1 couples histone H3 methylation at lysine 9 by SETDB1 to DNA replication and chromatin assembly. Mol Cell. 2004;15:595605.

122. Robertson KD, Ait-Si-Ali S, Yokochi T, Wade PA, Jones PL, Wolffe AP. DNMT1 forms a complex with Rb, E2F1 and HDAC1 and represses transcription from E2F-responsive promoters. Nat Genet. 2000;25:338-342.

123. Rountree MR, Bachman KE, Baylin SB. DNMT1 binds HDAC2 and a new co-repressor, DMAP1, to form a complex at replication foci. Nat Genet. 2000;25:269-277.

124. Fuks F, Burgers WA, Brehm A, Hughes-Davies L, Kouzarides T. DNA methyltransferase Dnmt1 associates with histone deacetylase activity. Nat Genet. 2000;24:88-91.

125. Fuks F, Burgers WA, Godin N, Kasai M, Kouzarides T. Dnmt3a binds deacetylases and is recruited by a sequence-specific repressor to silence transcription. Embo J. 2001;20:25362544.

126. Lehnertz B, Ueda Y, Derijck AA, et al. Suv39h-mediated histone H3 lysine 9 methylation directs DNA methylation to major satellite repeats at pericentric heterochromatin. Curr Biol. 2003;13:1192-1200

127. Fuks F, Hurd PJ, Deplus R, Kouzarides T. The DNA methyltransferases associate with HP1 and the SUV39H1 histone methyltransferase. Nucleic Acids Res. 2003;31:2305-2312.

128. Burgers WA, Fuks F, Kouzarides T. DNA methyltransferases get connected to chromatin. Trends Genet. 2002;18:275-277.

129. Eden S, Hashimshony T, Keshet I, Cedar H, Thorne AW. DNA methylation models histone acetylation. Nature. 1998;394:842.

130. Schubeler D, Lorincz MC, Cimbora DM, et al. Genomic targeting of methylated DNA influence of methylation on transcription, replication, chromatin structure, and histone acetylation. Mol Cell Biol. 2000;20:9103-9112.

131. Jackson JP, Lindroth AM, Cao X, Jacobsen SE. Control of CpNpG DNA methylation by the KRYPTONITE histone H3 methyltransferase. Nature. 2002;416:556-560.

132. Tamaru H, Selker EU. A histone H3 methyltransferase controls DNA methylation in Neurospora crassa. Nature. 2001;414:277-283.

133. Tamaru $\mathrm{H}$, Zhang $\mathrm{X}$, McMillen $\mathrm{D}$, et al. Trimethylated lysine 9 of histone $\mathrm{H} 3$ is a mark for DNA methylation in Neurospora crassa. Nat Genet. 2003;34:75-79.

134. Mutskov V, Felsenfeld G. Silencing of transgene transcription precedes methylation of promoter DNA and histone H3 lysine 9. Embo J. 2004;23:138-149.

135. Feinberg AP, Vogelstein B. Hypomethylation distinguishes genes of some human cancers from their normal counterparts. Nature. 1983;301:89-92.

136. Fraga MF, Ballestar E, Villar-Garea A, et al. Loss of acetylation at Lys 16 and trimethylation at Lys20 of histone H4 is a common hallmark of human cancer. Nat Genet. 2005;37:391 400.

137. Herman JG, Baylin SB. Gene silencing in cancer in association with promoter hypermethylation. N Engl J Med. 2003;349:2042-2054.

138. Fahrner JA, Eguchi S, Herman JG, Baylin SB. Dependence of histone modifications and gene expression on DNA hypermethylation in cancer. Cancer Res. 2002;62:7213-7218.

139. Nguyen CT, Weisenberger DJ, Velicescu M, et al. Histone H3-lysine 9 methylation is associated with aberrant gene silencing in cancer cells and is rapidly reversed by 5 -aza-2'deoxycytidine. Cancer Res. 2002;62:6456-6461. 
140. Kondo Y, Shen L, Issa JP. Critical role of histone methylation in tumor suppressor gene silencing in colorectal cancer. Mol Cell Biol. 2003;23:206-215.

141. Cameron EE, Bachman KE, Myohanen S, Herman JG, Baylin SB. Synergy of demethylation and histone deacetylase inhibition in the re-expression of genes silenced in cancer. Nat Genet. 1999;21:103-107.

142. Laird PW. The power and the promise of DNA methylation markers. Nat Rev Cancer. 2003;3:253-266.

143. Herman JG, Graff JR, Myohanen S, Nelkin BD, Baylin SB. Methylation-specific PCR: a novel PCR assay for methylation status of CpG islands. Proc Natl Acad Sci U S A. 1996;93:9821-9826.

144. Derks S, Lentjes MH, Hellebrekers DM, de Bruine AP, Herman JG, van Engeland M. Methylation-specific PCR unraveled. Cell Oncol. 2004;26:291-299.

145. Hatada I, Hayashizaki Y, Hirotsune S, Komatsubara H, Mukai T. A genomic scanning method for higher organisms using restriction sites as landmarks. Proc Natl Acad Sci U S A. 1991;88:9523-9527.

146. Suzuki H, Gabrielson E, Chen W, et al. A genomic screen for genes upregulated by demethylation and histone deacetylase inhibition in human colorectal cancer. Nat Genet. 2002;31:141-149.

147. Seligson DB, Horvath S, Shi T, et al. Global histone modification patterns predict risk of prostate cancer recurrence. Nature. 2005;435:1262-1266.

148. Sidransky D. Emerging molecular markers of cancer. Nat Rev Cancer. 2002;2:210-219.

149. Raaphorst FM. Deregulated expression of Polycomb-group oncogenes in human malignant lymphomas and epithelial tumors. Hum Mol Genet. 2005;14 Spec No 1:R93-R100.

150. Esquela-Kerscher A, Slack FJ. Oncomirs - microRNAs with a role in cancer. Nat Rev Cancer. 2006;6:259-269.

151. Egger G, Liang G, Aparicio A, Jones PA. Epigenetics in human disease and prospects for epigenetic therapy. Nature. 2004;429:457-463.

152. Jones PA, Taylor SM. Cellular differentiation, cytidine analogs and DNA methylation. Cell. 1980;20:85-93.

153. Cheng JC, Matsen CB, Gonzales FA, et al. Inhibition of DNA methylation and reactivation of silenced genes by zebularine. J Natl Cancer Inst. 2003;95:399-409.

154. Bender CM, Pao MM, Jones PA. Inhibition of DNA methylation by 5-aza-2'-deoxycytidine suppresses the growth of human tumor cell lines. Cancer Res. 1998;58:95-101.

155. Minucci S, Pelicci PG. Histone deacetylase inhibitors and the promise of epigenetic (and more) treatments for cancer. Nat Rev Cancer. 2006;6:38-51.

156. Kim MS, Kwon HJ, Lee YM, et al. Histone deacetylases induce angiogenesis by negative regulation of tumor suppressor genes. Nat Med. 2001;7:437-443.

157. Deroanne CF, Bonjean K, Servotte S, et al. Histone deacetylases inhibitors as antiangiogenic agents altering vascular endothelial growth factor signaling. Oncogene. 2002;21:427-436.

158. van der Schaft DW, Wagstaff J, Mayo KH, Griffioen AW. The antiangiogenic properties of bactericidal/permeability-increasing protein (BPI). Ann Med. 2002;34:19-27.

159. Tie F, Furuyama T, Prasad-Sinha J, Jane E, Harte PJ. The Drosophila Polycomb Group proteins $E S C$ and $E(Z)$ are present in a complex containing the histone-binding protein p55 and the histone deacetylase RPD3. Development. 2001;128:275-286.

160. van der Vlag J, Otte AP. Transcriptional repression mediated by the human polycomb-group protein EED involves histone deacetylation. Nat Genet. 1999;23:474-478.

161. Sewalt RG, Lachner M, Vargas M, et al. Selective interactions between vertebrate polycomb homologs and the SUV39H1 histone lysine methyltransferase suggest that histone H3-K9 methylation contributes to chromosomal targeting of Polycomb group proteins. Mol Cell Biol. 2002;22:5539-5553. 


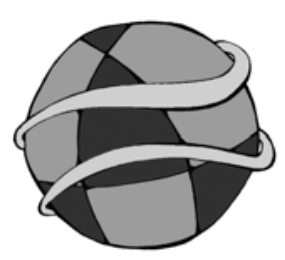

\section{Chapter 2 Angiostatic activity of DNA methyltransferase inhibitors}

Debby M.E.I. Hellebrekers, Kam-Wing Jair, Emmanuelle Viré, Sayaka Eguchi, Nicole T.H. Hoebers, Mario F. Fraga, Manel Esteller, François Fuks,

Stephen B. Baylin, Manon van Engeland and Arjan W. Griffioen

Mol Cancer Ther. 2006 Feb;5(2):467-75. 


\begin{abstract}
Inhibitors of DNA methyltransferases (DNMTs) and histone deacetylases (HDACs) can reactivate epigenetically silenced tumor suppressor genes and thereby decrease tumor cell growth. Little, however, is known on the effects of these compounds in endothelial cell (EC) biology and tumor angiogenesis. Here, we show that the DNMT inhibitors 5-aza-2'-deoxycytidine (DAC) and zebularine markedly decrease vessel formation in different tumor models. We demonstrate that DNMT inhibitors are antiproliferative for tumor-conditioned EC, without affecting EC apoptosis and migration. Furthermore, these compounds inhibit angiogenesis in vitro and in vivo, as shown by inhibition of EC sprouting in a 3-dimensional gel and of microvessel formation in the chorioallantoic membrane, respectively. DAC, as well as the HDAC inhibitor trichostatin A, reactivates the growth inhibiting genes TSP1, JUNB, and IGFBP3, which are suppressed in tumor-conditioned EC. Despite enhanced DNMT activity and increased overall genomic methylation levels in tumor-conditioned EC, silencing of these genes appeared not to be regulated by direct promoter hypermethylation. For IGFBP3, gene expression in EC correlated with histone H3 acetylation patterns. In conclusion, our data show that DNMT inhibitors have angiostatic activity in addition to their inhibitory effects on tumor cells. This dual action of these compounds makes them promising anticancer therapeutics.
\end{abstract}

\title{
Introduction
}

Epigenetic regulation of gene expression by DNA methylation and histone modifications involves the organization of chromatin in gene promoter regions, thereby affecting transcriptional activator complexes. ${ }^{1}$ These phenomena are essential in many biological processes including genomic imprinting, $X$ chromosome inactivation and establishment of tissue specific gene expression. ${ }^{2}$ Epigenetic modifications are also involved in pathology; aberrant epigenetic regulation has been observed in cancer cells and includes alterations in DNA methylation and histone modifications..$^{3-5}$ DNA hypermethylation and histone deacetylation of $\mathrm{CpG}$ islands within the promoter regions of tumor suppressor genes result in undesirable gene silencing and are found in virtually every type of human cancer. ${ }^{6,7}$ In contrast to genetic modifications, epigenetic changes are reversible, creating a target for therapeutic strategies in cancer. It has been shown that DNA methyltransferase (DNMT)- as well as histone deacetylase (HDAC) inhibitors can reactivate epigenetically silenced tumor suppressor genes and decrease tumor cell growth in vitro and in vivo. ${ }^{8,9}$ Because of these characteristics, these drugs are currently being tested in clinical trials. ${ }^{9,10}$

Tumor angiogenesis, a pivotal process in cancer, requires intricate regulation at the molecular level. ${ }^{11,12}$ The rapid identification of novel genes involved in the generation of new vasculature is expected to contribute to the understanding of tumor angiogenesis. ${ }^{13-15}$ Little, however, is known about the role of epigenetics in tumor angiogenesis. Effects of DNMT inhibitors on endothelial cell (EC) biology and tumor angiogenesis have not been described so far. Furthermore, there are no reports on 
epigenetic modifications of gene promoters in tumor EC during tumor angiogenesis. A link between HDAC inhibitors and angiogenesis has recently been suggested. ${ }^{16-18}$ In this study, we investigated the effects of DNMT inhibitors on EC biology and angiogenesis in vitro and in vivo. Furthermore, overall genomic methylation levels and DNMT activity, as well as epigenetic promoter modifications of growth inhibitory genes, are studied in tumor-conditioned and quiescent EC.

\section{Materials and Methods}

\section{Cell Cultures and Reagents}

Human umbilical vein endothelial cells (HUVEC) were cultured in RPMI-1640 supplemented with $20 \%$ heat inactivated human pooled serum, $2 \mathrm{mM} \mathrm{L-glutamin,} 50$ $\mathrm{ng} / \mathrm{ml}$ streptomycin and $50 \mathrm{U} / \mathrm{ml}$ penicillin in $0.2 \%$ gelatin coated tissue culture flasks at $37^{\circ} \mathrm{C}, 5 \% \mathrm{CO}_{2}$. Tumor conditions were mimicked ${ }^{19}$ by a 3-day exposure to $10 \mathrm{ng} / \mathrm{ml}$ basic Fibroblast Growth Factor (bFGF; Peprotech, London, UK), $10 \mathrm{ng} / \mathrm{ml}$ Vascular Endothelial Growth Factor (VEGF; Peprotech) and, where indicated, $20 \%$ (v/v) of a 1:1 mixture of filtered culture supernatants of LS174T and CaCo-2 human colon carcinoma cell lines. Quiescent EC were prepared by culturing HUVEC for 3 days in the presence of $2 \%$ serum.

Mouse b.END5 brain endothelioma cells (ECACC, Salisbury, United Kingdom) were cultured in Dulbecco's MEM containing 10\% fetal calf serum, $2 \mathrm{mM}$ L-glutamin, and $5 \mu \mathrm{mol} / \mathrm{l}$ 2-mercaptoethanol (Sigma, st Louis, MO). Bovine capillary endothelial cells (BCE) were kindly provided by Dr. M. Furie (State University of New York, Stony Brook, USA) and were cultured in gelatin coated flasks in MEM- $\alpha$ supplemented with 10\% FCS, 2 mM L-glutamin and antibiotics. Mouse B16F10 melanoma cells (kindly provided by dr. J. Fidler, Houston, Texas) were cultured using Hank's MEM containing $5 \%$ FCS, $1 \%$ non-essential amino acids, $1 \%$ sodium pyruvate, $1.5 \%$ MEM vitamins, and $2 \%$ sodium bicarbonate. Human LS174T colon tumor cells were grown in DMEM, containing $10 \%$ fetal calf serum and $2 \mathrm{mM}$ L-glutamin. All culture media and standard cell culture materials were obtained from Life Technologies (Breda, the Netherlands).

DNA methyltransferase (DNMT) inhibitor 5-aza-2'-deoxycytidine (DAC) was obtained from Sigma (Zwijndrecht, the Netherlands), zebularine was obtained from the $\mathrm{NCl}$ (Bethesda, US), and the histone deacetylase (HDAC) inhibitor trichostatin A (TSA) from Wako (Neuss, Germany).

\section{Mouse Tumor Models}

The animal experiments were approved by the local ethical review committee. At day 0, 6-wk-old C57BL/6 mice (obtained from Charles River, Maastricht, The Netherlands) were inoculated with $10^{5}$ B16F10 mouse melanoma cells subcutaneously on the right flank. Between day 6 and 9 the tumors became visible in all mice and treatments were initiated. In the LS174T xenograft model, Swiss nu/nu mice (Charles River) were inoculated with $10^{6}$ LS174T human colon carcinoma cells. Between day 10 and 14 the tumors became visible and treatment was initiated. DAC $(n=5)$, at a dose of $10 \mathrm{mg} / \mathrm{kg}$, zebularine $(n=5)$, at a dose of $1000 \mathrm{mg} / \mathrm{kg}^{20}$ and TSA 
$(\mathrm{n}=5)$, at a dose of $1 \mathrm{mg} / \mathrm{kg},{ }^{16}$ were administered daily by intraperitoneal injection in a solution of $0.9 \%$ saline for 7 (B16F10) or 10 (LS174T) days. Tumor volumes were measured daily, and calculated as follows: width ${ }^{2} \times$ length $x 0.52$. The microvessel density was analyzed as described previously. ${ }^{21}$

\section{Proliferation and Apoptosis Measurement}

EC proliferation was measured using a $\left[{ }^{3} \mathrm{H}\right]$ thymidine incorporation assay as described previously. ${ }^{22}$ Tumor-conditioned HUVEC, cultured in a 96-well plate, were exposed for 3 days to a concentration range DAC, zebularine or TSA, replacing drugs and culture medium every 24 hours. During the last 6 hours of the assay, the culture was pulsed with $0.3 \mu \mathrm{Ci}$ [methyl- ${ }^{3} \mathrm{H}$ ] thymidine (Amersham Life Science, Roosendaal, The Netherlands) per well. Activity was measured using liquid scintillation. Four independent experiments were performed and in each experiment, measurements were done in triplicate.

Apoptosis was measured as described previously. ${ }^{22}$ Tumor-conditioned HUVEC were cultured for 72 hours with DAC, zebularine or TSA, replacing drugs and culture medium every 24 hours. Serum deprivation of HUVEC ( 3 days) was used as a positive control for apoptosis.

\section{Migration Measurement}

HUVEC migration was measured using the wound assay. ${ }^{21}$ In brief, confluent monolayers of tumor-conditioned HUVEC cultured for 72 hours with DAC, zebularine or TSA were wounded using the blunt end of a glass pipette. Cultures were washed and medium and drugs were replaced. Wound width was measured in triplicate cultures at four predefined locations at start and at 2, 4, 6, 8 and 24 hours after wounding.

\section{In Vitro Angiogenesis}

Sprouting and tube formation of bovine capillary EC (BCE) was studied using cytodex-3 beads overgrown with EC in a 3-dimensional gel, as described previously. ${ }^{22}$ BCE were mixed with gelatin coated cytodex- 3 microcarrier beads (Sigma, The Netherlands) and cultured for 48 hours in the presence of bFGF, VEGF, CaCo-2 and LS174T supernatants, followed by a 3-day exposure to DAC, zebularine or TSA, replacing drugs and culture medium every 24 hours. Next, the beads were placed in a 3-dimentional gel and medium, containing $10 \mathrm{ng} / \mathrm{ml} \mathrm{bFGF,} 10 \mathrm{ng} / \mathrm{ml} \mathrm{VEGF}$, and 20\% of a 1:1 mixture of culture supernatants of LS174T and CaCo-2 human colon carcinoma cells, with or without DAC, zebularine or TSA at concentrations as indicated, was applied on top of the gel. After 24 hours photographs were taken and digitally analyzed.

\section{Chorioallantoic Membrane (CAM) Assay}

The CAM assay was performed in fertilized white Leghorn eggs as described previously. ${ }^{22}$ In brief, CAMs were treated by daily addition of sterile saline $(0.9 \%$ $\mathrm{NaCl})$, DAC $(5 \mathrm{mM})$, zebularine $(100 \mathrm{mM})$ or TSA $(400 \mu \mathrm{M})$ from day 10 to day 13 . The data from the in vitro assays, were extensive dose ranges were tested, as well as 
literature data, have been used to extrapolate to testing in the CAM assay. For TSA $400 \mu \mathrm{M}$ has been taken from literature. ${ }^{17}$ From this we calculated a 10 times higher dose for DAC (as in the mice). For zebularine a higher dose was used, which was found to be active already at $100 \mathrm{mM}$. On day 14 the CAMs were photographed. Quantification of vascularization was performed by enumeration of intersections with 5 concentric rings that were superimposed on the photographs.

\section{High Performance Capillary Electrophoresis (HPCE)}

Tumor-conditioned HUVEC were treated for 72 hours with or without DAC, replacing drug and culture medium every 24 hours. Quantification of the degree of methylation was carried out as described before. ${ }^{23}$ Quantification of the relative methylation of each DNA sample was determined as the percentage of $\mathrm{mC}$ of total cytosines: $\mathrm{mC}$ peak area x $100 /$ (C peak area $+\mathrm{mC}$ peak area). Three analytical measurements were made per sample and experiments were performed in duplicate.

\section{Methyltransferase Assay and DNMT1 Western Blot}

Tumor-conditioned HUVEC were treated for 72 hours with or without DAC, replacing drug and culture medium every 24 hours. DNA methyltransferase assays were carried out as described before. ${ }^{24}$ DNMT1 Western Blot was performed using rabbit polyclonal DNMT1 antibody (Santa Cruz Biotechnology Inc., Santa Cruz, California, USA).

\section{Quantitative Real-Time RT-PCR}

Tumor-conditioned HUVEC were treated for 72 hours with DAC or TSA, replacing drugs and culture medium every 24 hours. Total RNA isolation, cDNA synthesis and quantitative real-time RT-PCR were performed essentially as described previously ${ }^{25}$ using SYBR Green PCR master mix (Applied Biosystems, Nieuwekerk a/d IJssel, The Netherlands). Primer sequences are available on request.

\section{Bisulfite Sequencing}

Genomic DNA of quiescent HUVEC, tumor-conditioned HUVEC or tumorconditioned HUVEC treated with DAC for 72 hours (replacing DAC and medium every 24 hours) was isolated using the Wizard Genomic DNA Purification Kit (Promega, Leiden, The Netherlands). Bisulfite modification of genomic DNA was carried out essentially as described previously. ${ }^{26} \mathrm{PCR}$ products were cloned using the TA cloning kit (Invitrogen, Breda, The Netherlands) and single colonies were picked and sequenced. Primer sequences are available on request.

\section{ChIP Assay}

ChIP assays on quiescent HUVEC, tumor-conditioned HUVEC or tumorconditioned HUVEC treated for 72 hours with DAC or TSA (replacing DAC, TSA and medium every 24 hours) were performed essentially as described previously ${ }^{27}$ using anti-acetyl histone H3 (06-599) antibody (Upstate Biotechnology, Lake Placid, New York). Primer sequences are available on request. 


\section{Statistical Analyses}

All values are given as mean values \pm SEM. Statistical analysis for the tumor volumes was done by means of the two-way ANOVA test. The Student's t-test was used for statistical analyses of microvessel density levels in the mouse tumors and CAMs and for the migration assay. Statistical analyses of the proliferation, apoptosis and in vitro angiogenesis assays, DNMT activity assay, HPCE, as well as the quantitative real-time RT-PCR were done using the Wilcoxon-Mann-Whitney rank sum test which was performed in SPSS 10.0.5. software. All values are two-sided and $p$ values $<0.05$ were considered statistically significant.

\section{Results}

\section{$D A C$ and zebularine inhibit tumor growth in vivo}

To investigate the effects of DNA methyltransferase (DNMT) inhibitors on tumor angiogenesis in vivo, B16F10 melanoma bearing mice were treated with the DNMT inhibitors 5-aza-2'-deoxycytidine (DAC) or zebularine. Treatment of established tumors (approximately $\left.100 \mathrm{~mm}^{3}\right)$ with DAC $(10 \mathrm{mg} / \mathrm{kg}$, i.p., daily) resulted in a significant abrogation of tumor growth $(p<0.0001)$, causing almost full stasis over the treatment period (Fig. 2.1A). The inhibitory activity of DNMT suppression on B16F10 tumor growth was confirmed by treatment with the DAC-analogue zebularine (1000 $\mathrm{mg} / \mathrm{kg}$, i.p., daily), ${ }^{20}$ a compound recently found to have a similar functional activity but with a lower toxicity profile (Figure 2.1A). Treatment of B16F10 tumors with the histone deacetylase (HDAC) inhibitor TSA $(1 \mathrm{mg} / \mathrm{kg} \text {, i.p., daily })^{16}$ also significantly inhibited tumor growth $(p<0.0001)$ by approximately $60 \%$. The inhibitory effects of DAC and zebularine on growth of B16F10 tumors was associated with suppressed angiogenesis, as suggested by significantly lower microvessel densities in tumors of treated mice ( $47 \%$ and $65 \%$ inhibition, respectively) as compared to untreated control tumors (Fig. 2.1B-C, $p<0.0001$ ). TSA treatment also significantly reduced microvessel density $(52 \%$ inhibition, $p<0.0001)$, as compared to untreated tumors (Fig. 2.1B-C), which confirms earlier data. ${ }^{16}$ Suppressive effects on angiogenesis and tumor growth by zebularine or TSA $(p<0.006$ and $p<0.0001$, respectively) were also observed in the human xenograft model of LS174T colon carcinoma in athymic mice (Fig. 2.1D). Although DAC in this model also inhibited tumor growth, the treatment was associated with toxicity, and the experiment was therefore halted. 
A

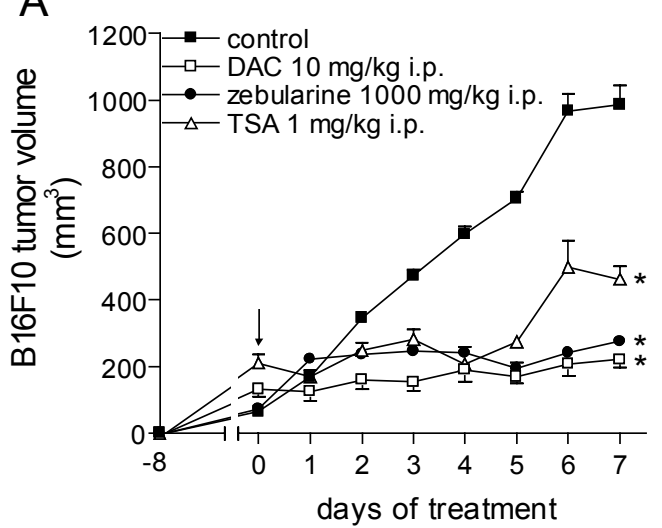

B

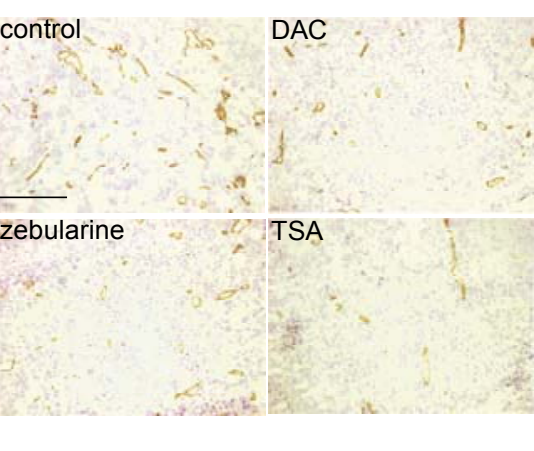

C

D
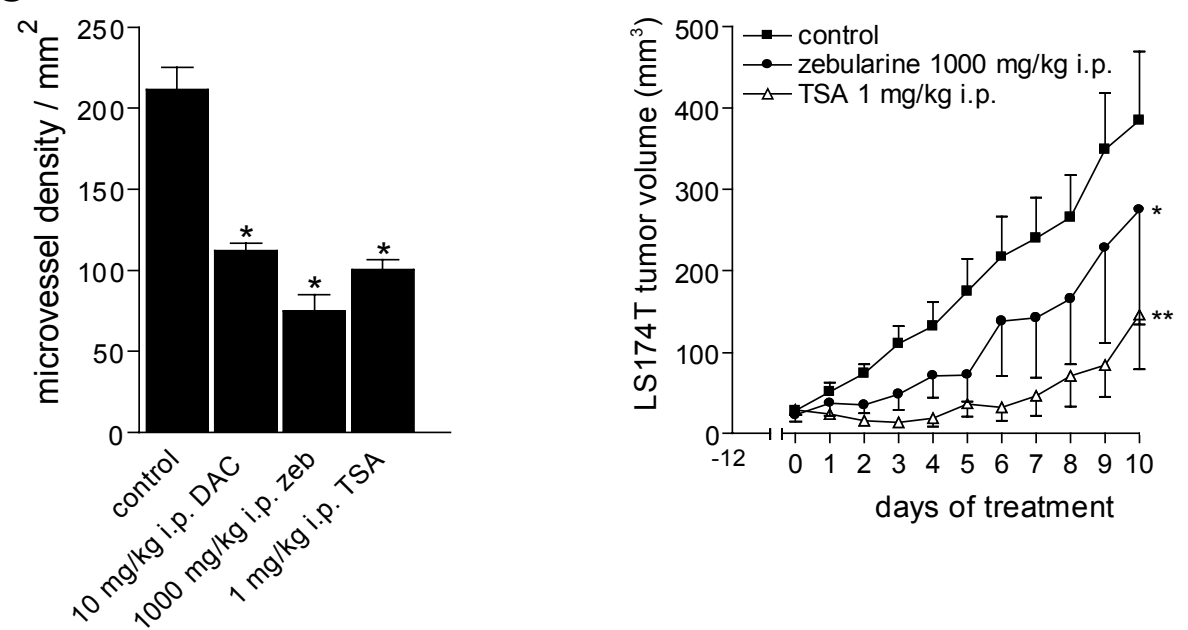

Figure 2.1 DAC, zebularine and TSA inhibit tumor angiogenesis in mice.

(A) Tumor growth inhibition of B16F10 mouse melanoma tumors in C57BL/6 mice by DAC, zebularine (zeb) and TSA treatment. Data are expressed as mean tumor volume $\left(\mathrm{mm}^{3} \pm \mathrm{SEM}\right),{ }^{*} \mathrm{p}<0.0001$. The arrow indicates start of treatment. (B) Cryosections of tumors from control mice and treated mice stained with CD31 antibody for microvessel density assessment (scale bar $=100 \mu \mathrm{m}$ ). (C) Quantification of microvessel density as mean number of vessels per $\mathrm{mm}^{2}$ ( $\left.\pm \mathrm{SEM},{ }^{*} \mathrm{p}<0.0001\right)$. (D) Tumor growth curves of human LS174T colon carcinoma in athymic mice either or not treated daily with zebularine $\left({ }^{*} p<0.006\right)$ or TSA $\left({ }^{* *} p<0.0001\right)$.

\section{$D A C$ and zebularine inhibit EC growth}

Although an indirect effect of DNMT inhibitors on tumor angiogenesis in vivo can be expected due to inhibition of tumor cells, we explored whether these compounds have direct effects on EC growth. To that end, DAC and zebularine were tested for their ability to inhibit proliferation of activated cultured HUVEC using the $\left[{ }^{3} \mathrm{H}\right]$-thymidine incorporation assay. Tumor conditions were mimicked by culturing cells in tumor 
A

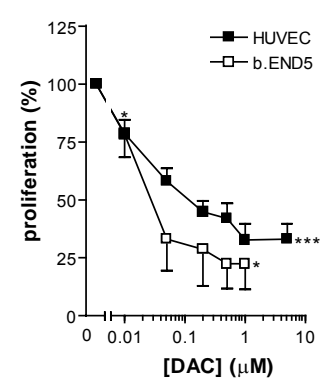

C
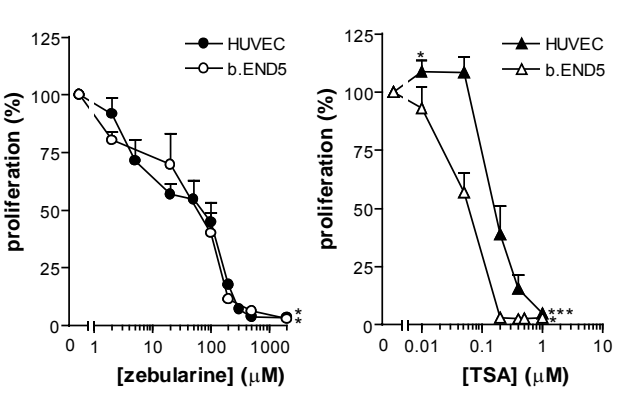

B
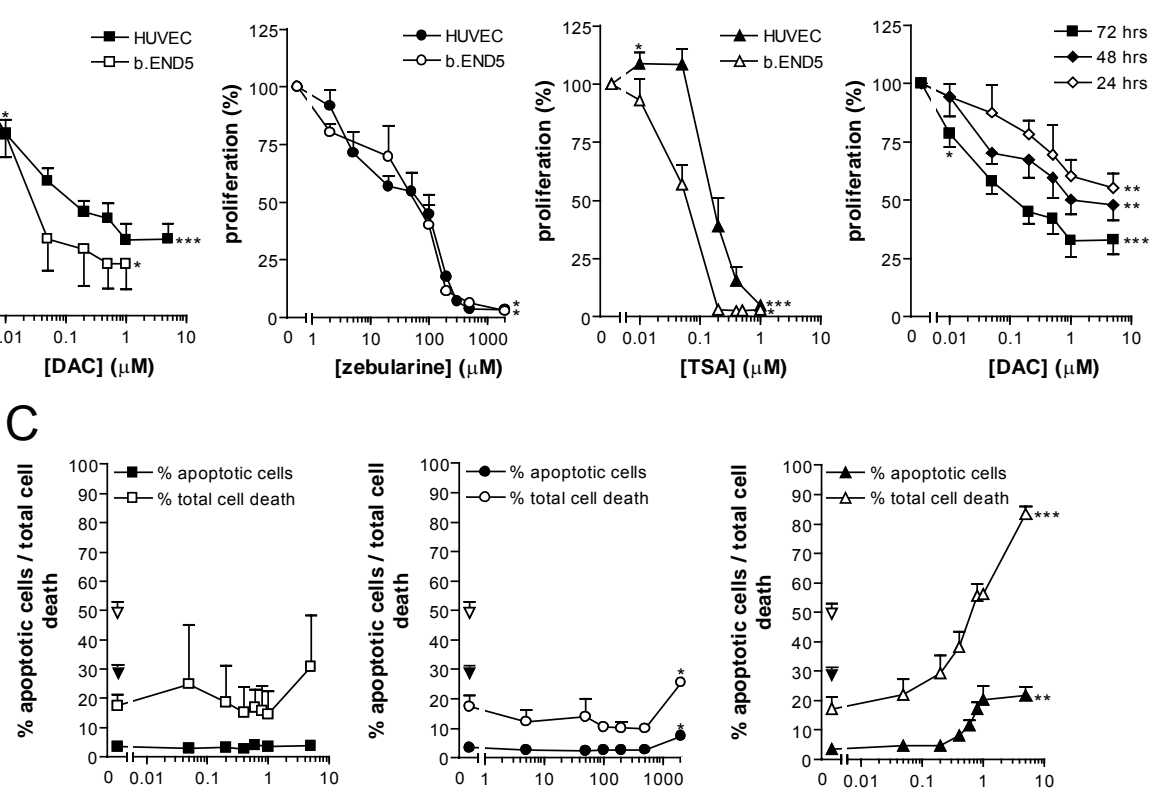

[DAC] $(\mu \mathrm{M})$
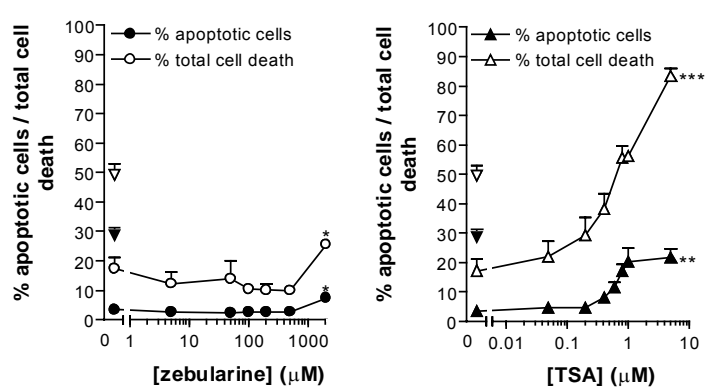

Figure 2.2 DAC, zebularine and TSA inhibit EC growth characteristics.

(A) Dose-response curves of DAC, zebularine and TSA on growth factor-induced and spontaneous proliferation of HUVEC and b.END5 endothelioma cells respectively, after 72 hours of treatment. (B) Kinetic analysis of the response of tumor-conditioned HUVEC after 24, 48 and 72 hours of treatment with DAC. Data are expressed as mean relative proliferation compared to untreated cultures values $( \pm$ SEM) of 4 independent triplicate experiments $\left({ }^{*} p<0.037,{ }^{* *} p<0.005,{ }^{* * *} p<0.001\right)$. (C) Dose-response curves of DAC, zebularine and TSA on apoptosis (solid symbols) and total cell death (open symbols) of growth factor-stimulated HUVEC. HUVEC cultured in the presence of $1 \%$ serum was used as a positive control for apoptosis ( $\boldsymbol{\nabla}$ apoptosis, $\nabla$ total cell death). Data are represented as mean values $\left( \pm\right.$ SEM) of 3 (DAC, zebularine) or 6 (TSA) independent triplicate experiments $\left({ }^{*} p<0.05,{ }^{* *} p<0.006\right.$, $\left.{ }^{* * *} \mathrm{p}<0.001\right)$.

conditioned medium in the presence of bFGF and VEGF. DAC exhibited a concentration dependent inhibition of HUVEC proliferation, with a half-maximal response $\left(E D_{50}\right)$ at about $100 \mathrm{nM}$ (Fig. 2.2A). Similarly, zebularine also inhibited proliferation of activated HUVEC in a concentration dependent way, while the effective concentrations of zebularine, which are standard concentrations,$^{28}$ were about 100fold higher than for DAC. Since inhibitory effects of histone deacetylase (HDAC) inhibitors on EC growth have been described previously, ${ }^{16,17}$ the HDAC inhibitor trichostatin A (TSA) was included as a positive control. As expected, TSA decreased $\mathrm{EC}$ growth, reaching an $\mathrm{ED}_{50}$ at about $200 \mathrm{nM}$ (Fig. 2.2A). Kinetic studies on the response of EC to DAC revealed that a 72-hour exposure resulted in stronger responses as compared with treatment for 48 and 24 hours (Fig. 2.2B). This corresponds with the mechanism of action of this nucleoside analogue, which has to be incorporated into the DNA during replication before it can trap DNMTs during 
progression of the replication machinery. ${ }^{29}$ In contrast, TSA inhibited similarly at all time points (data not shown).

Antiproliferative effects of DAC, zebularine and TSA were similar using HUVEC stimulated with bFGF or VEGF alone, as well as in the human microvascular endothelial cell line (HMEC) (data not shown). In addition, DNMT- and HDAC inhibitors had similar growth-inhibitory activity in b.END5 mouse EC (Fig. 2.2A). To assess the effect of DAC, zebularine and TSA on proliferation of other non-neoplastic cell types, we analysed the effects on proliferation of PHA-stimulated peripheral blood leukocytes. DAC had no significant effect on leukocyte proliferation, whereas zebularine had a moderate inhibitory effect of $30 \%$ at $1 \mathrm{mM}(p<0.05)$, which is minimal as compared to the effect on ECs (data not shown). In contrast, TSA significantly inhibited leukocyte proliferation with an $\mathrm{ED}_{50}$ at about $200 \mathrm{nM}(\mathrm{p}<0.05)$, which is comparable to effects on ECs. Similar findings were observed for normal cultured fibroblasts (data not shown), suggesting that effects of DNMT- and HDAC inhibitors are not specific for EC, as expected, although ECs are more responsive to DAC and zebularine as compared to blood leukocytes and normal fibroblasts.

In order to determine whether inhibition of EC growth was caused by inducing cell death, we quantified the percentage of dying cells in general, as well as the percentage of cells undergoing apoptosis. ${ }^{21}$ At growth inhibitory concentrations, DAC did not significantly affect EC apoptosis or total cell death, as measured by the percentage of cells with subdiploid DNA content using flow cytometry (Fig. 2.2C). Similar results were observed for zebularine, although a small percentage of EC ( $7.5 \%$ as compared to $3.4 \%$ of untreated cells) underwent apoptosis at the highest concentration tested $(p<0.05)$. In contrast to the cytostatic effect of the DNMT inhibitors, TSA caused a strong concentration dependent cytotoxic effect, inducing apoptosis and total cell death (Fig. 2.2C), which might explain the stronger antiproliferative effect.

\section{Effects of DNMT inhibitors on EC migration and angiogenesis in vitro and in vivo}

To assess the effects of DAC and zebularine on EC migration, the wound assay was used. ${ }^{21}$ Migration of EC was not significantly influenced by treatment with DAC at concentrations up to $1000 \mathrm{nM}$ (Fig. 2.3A). Similar results were found for zebularine at concentrations up to $500 \mu \mathrm{M}$. In contrast, TSA effectively inhibited migration of wounded confluent monolayers in a dose dependent manner, which is in agreement with observations by Kim et al. ${ }^{16}$ Significant effects $(p<0.05)$ were already observed 4 hours after wounding at $300 \mathrm{nM}$ concentration (Fig. 2.3A).

In a 3-dimensional EC tube formation assay, ${ }^{22}$ DAC and zebularine dose dependently inhibited growth factor-induced sprout formation of bovine capillary EC (BCE) (Fig. 2.3B). TSA also showed a concentration dependent inhibitory effect in this in vitro angiogenesis assay.

To study whether in vivo angiogenesis is perturbed by DAC and zebularine, we used the chick chorio allantoic membrane (CAM)-assay, a model for developmental angiogenesis. In CAMs treated daily with DAC $(5 \mathrm{mM})$ from day 10 through day 13 , a profound inhibition $(40 \%)$ of microvessel formation was observed, whereas larger 


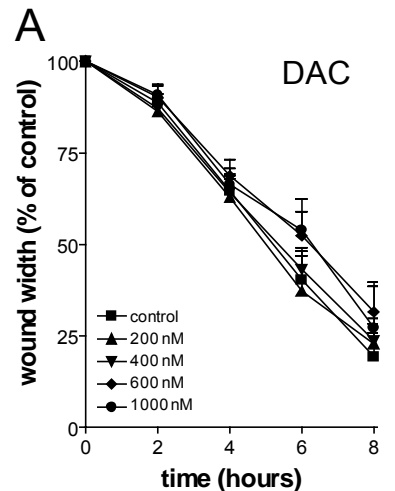

B
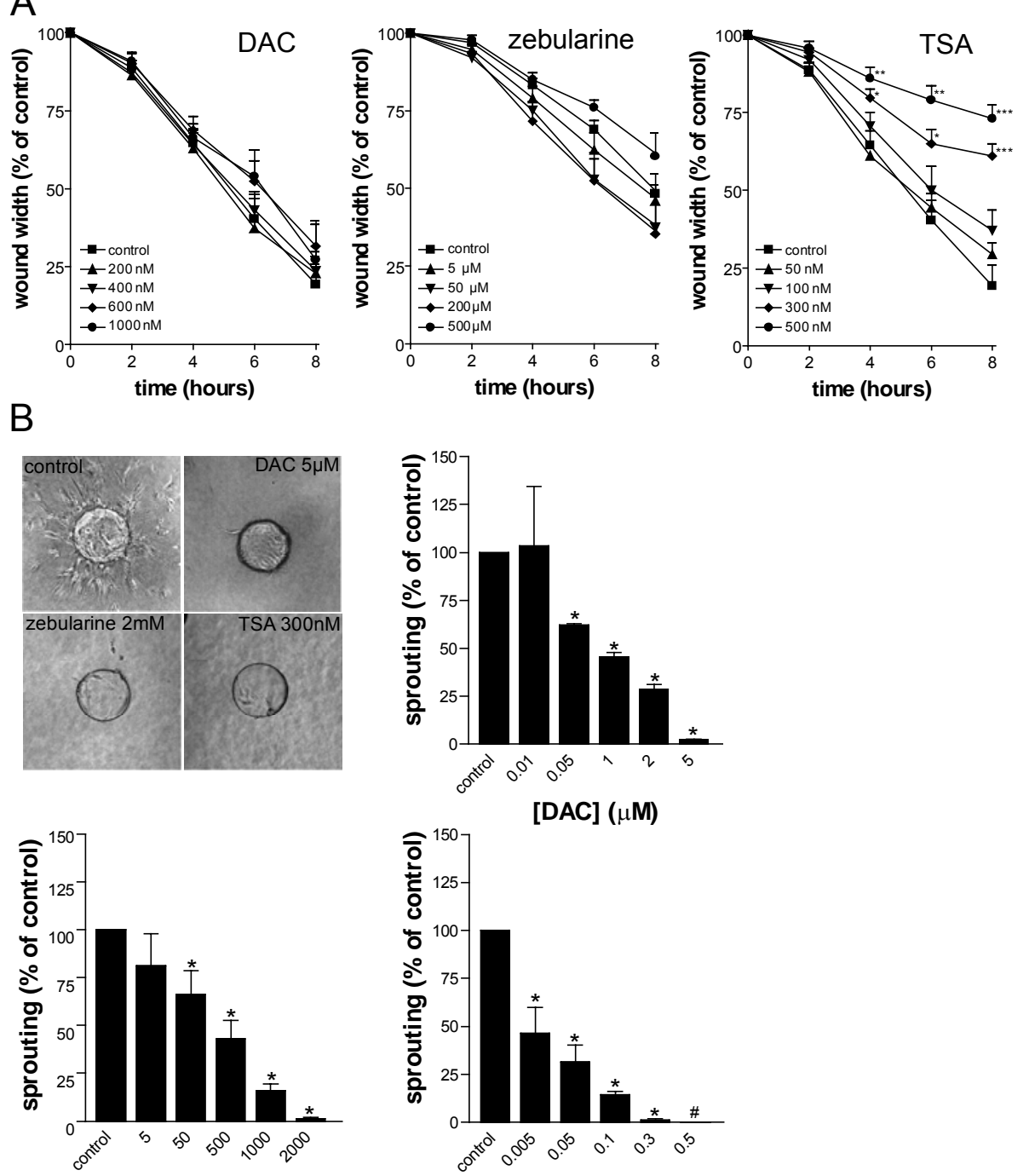

[zebularine] $(\mu \mathrm{M})$

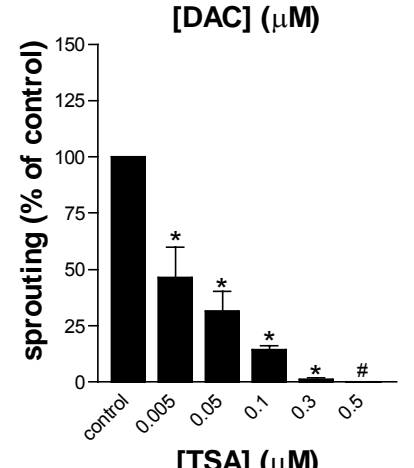

Figure 2.3 Effects of DAC, zebularine and TSA on EC migration, angiogenesis in vitro and the chick chorioallantoic membrane (CAM).

(A) Relative wound width of dose ranges of DAC, zebularine and TSA treated cultures as compared to untreated cultures are shown. Data are represented as mean values ( \pm SEM) of 5 independent experiments $\left({ }^{*} p<0.05,{ }^{* *} p<0.01,{ }^{* * *} p<0.001\right)$. (B) Sprouting of BCE cultured on gelatin-coated Cytodex-3 beads into a collagen matrix. Sprout formation was induced by bFGF, VEGF and tumor cell line conditioned medium (control). Results are quantified as mean values $( \pm S E M)$ of relative sprouting compared to untreated BCE from 3 independent experiments $\left({ }^{*} p<0.037, \# p<0.046\right)$. 
C
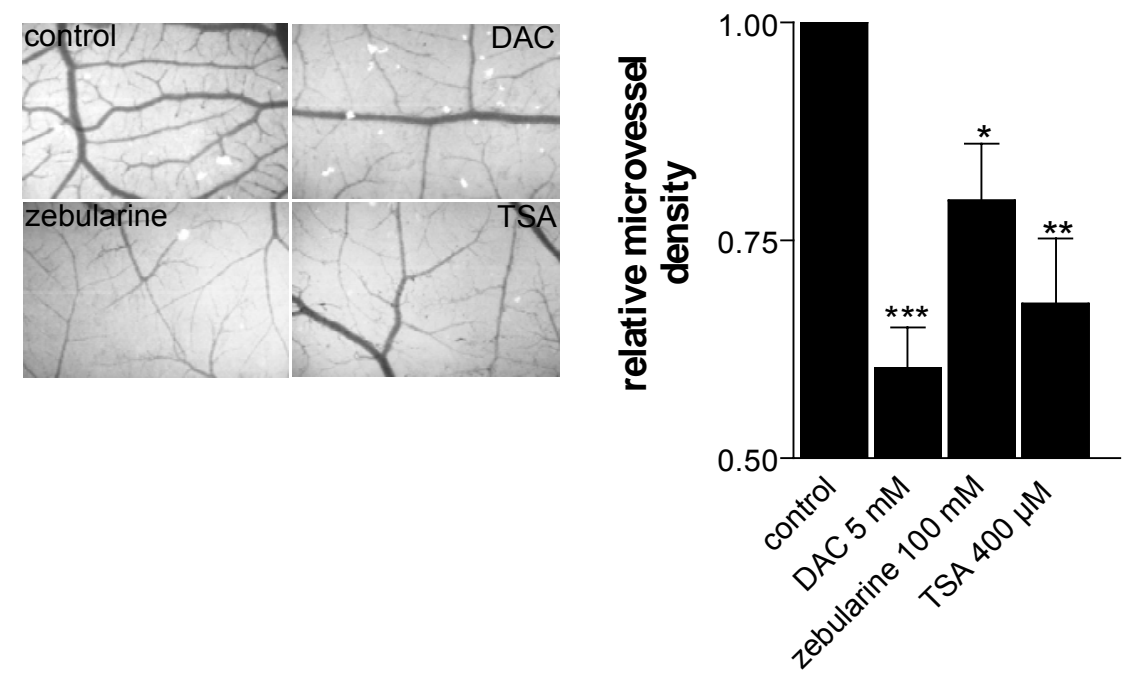

Figure 2.3(C) CAMs treated daily with saline (control), DAC, zebularine or TSA from day 10 to day 13 . Results are quantified as relative microvessel density values ( \pm SEM) of CAMs treated with DAC $(n=7)$, zebularine $(n=4)$ or TSA $(n=5),{ }^{*} p<0.023,{ }^{* *} p<0.001,{ }^{* * *} p<0.0001$.

preexisting vessels were apparently unaffected (Fig. 2.3C). These results were confirmed in zebularine-treated CAMs, in which maximal inhibition of microvessel formation was observed at $100 \mathrm{mM}$ concentration $(p<0.023)$. TSA also had angiostatic activity in the CAMs (32\% inhibition of microvessel formation at $400 \mu \mathrm{M}, \mathrm{p}<0.001$, Fig. 2.3C), as expected. ${ }^{17}$

Increased 5-methylcytosine content and DNA methyltransferase activity in tumorconditioned EC

Although altered DNA methylation levels have been studied in a variety of tumor cells, there are no reports on DNA methylation levels in tumor EC. Total genomic 5methylcytosine content in EC was quantified by high-performance capillary electrophoresis $^{23}$ in quiescent (HUVEC-) and tumor-conditioned EC (HUVEC+). A significant hypermethylation was observed in activated tumor-conditioned HUVEC as compared to quiescent HUVEC $(p<0.004$, Fig. 2.4A). Furthermore, treatment of activated HUVEC with the DNA methyltransferase (DNMT) inhibitor 5-aza-2'deoxycytidine (DAC) at low-dose (200 nM) decreased genomic DNA methylation.

To examine whether the overall genomic hypermethylation in tumor-conditioned EC is caused by increased DNMT activity in these cells, we measured protein expression and activity of DNMT in activated and quiescent EC. HCT116 cells were used as a positive control. ${ }^{30}$ Overall, DNMT activity (Fig. 2.4B) and protein levels (data not shown) were lower in EC as compared to the HCT116 tumor cell line. In activated $E C$, DNMT activity was significantly increased as compared to quiescent EC (2.6 fold increase, $p<0.05$ ), while DAC treatment almost completely eradicated DNMT activity in activated EC (Fig. 2.4B). 
A

\begin{tabular}{llc}
\hline & \multicolumn{2}{c}{$\%$ of total genomic } \\
& \multicolumn{2}{c}{ 5-Methylcytosine content } \\
\cline { 2 - 3 } & \multicolumn{1}{c}{ Mean } & SEM \\
\hline HUVEC- & $\mathbf{3 . 6 5}$ & 0.02 \\
HUVEC+ & $\mathbf{3 . 9 2}$ & 0.03 \\
HUVEC+ / DAC & $\mathbf{1 . 0 4}^{\#}$ & 0.08 \\
\hline${ }^{*} \mathrm{p}<0.004$ versus HUVEC- ${ }^{\#}{ }^{\mathrm{p}<0.004}$ versus HUVEC+
\end{tabular}

B

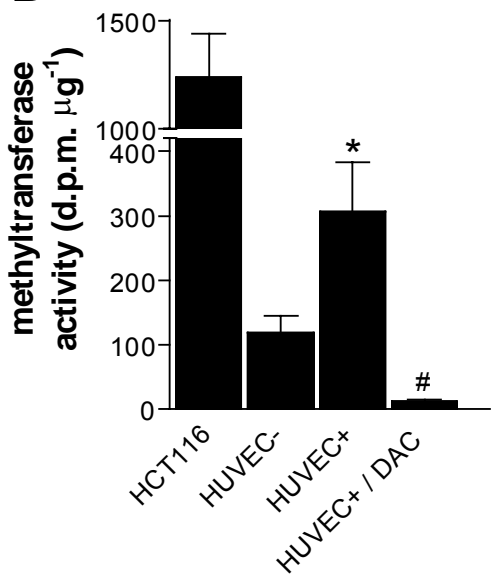

Figure 2.4 Global 5-methylcytosine content and DNMT1 activity in EC.

(A) Measurement of 5-methylcytosine content as a percentage of the total cytosine pool in quiescent HUVEC (HUVEC-), tumor-conditioned HUVEC (HUVEC+) and tumor-conditioned HUVEC treated with $200 \mathrm{nM}$ DAC (HUVEC+ / DAC). Three analytical measurements were made per sample and experiments were performed in duplicate. (B) DNMT1 activity in HUVEC-, HUVEC+, HUVEC+ treated with $200 \mathrm{nM}$ DAC and HCT116. Results are represented as mean values $( \pm$ SEM) of 3 independent experiments ( ${ }^{*} p<0.05$ versus HUVEC-, $\# p<0.05$ versus HUVEC+).

Reexpression of IGFBP3, TSP1 and JUNB in activated EC by DNMT- and HDAC inhibitors through methylation-independent effects

Although the inhibitory effects of DAC and zebularine on tumor angiogenesis in vivo can be indirect, via their effects on tumor cells, the inhibition of EC proliferation and angiogenesis in vitro by these compounds show that DNMT inhibitors directly affect EC growth and angiogenesis. We investigated whether these direct inhibitory effects could be explained by the re-expression of angiogenesis inhibiting genes in activated EC by DNMT inhibitors. Screening the promoters of several well-known endogenous angiogenesis inhibitors (amongst others interferon $\alpha /-\beta$, platelet factor-4, thrombospondin 1 , transforming growth factor- $\beta$, interferon gamma-inducible protein10 , tumor necrosis factor- $\alpha$, plasminogen activator inhibitor, bactericidal permeabilityincreasing protein, pigment epithelium-derived factor) for the presence of $5^{\prime} \mathrm{CpG}$ islands ( $\mathrm{GC}$ content $>60 \%$, ratio of $\mathrm{CpG}$ to $\mathrm{GpC}>0.6$ and minimum length $200 \mathrm{bp})^{31}$ revealed that only thrombospondin 1 (TSP1) ${ }^{32}$ contains a CpG island around the transcription start site. Furthermore, the expression levels of the angiogenesis inhibiting tumor suppressor genes p16INK4a, p73, maspin and TIMP3, which are known to be prone to epigenetic silencing in tumor cells, were studied in endothelial cells. None of these genes met both criteria of significant downregulation in activated versus quiescent HUVEC as well as upregulation by DAC and TSA treatment (data 

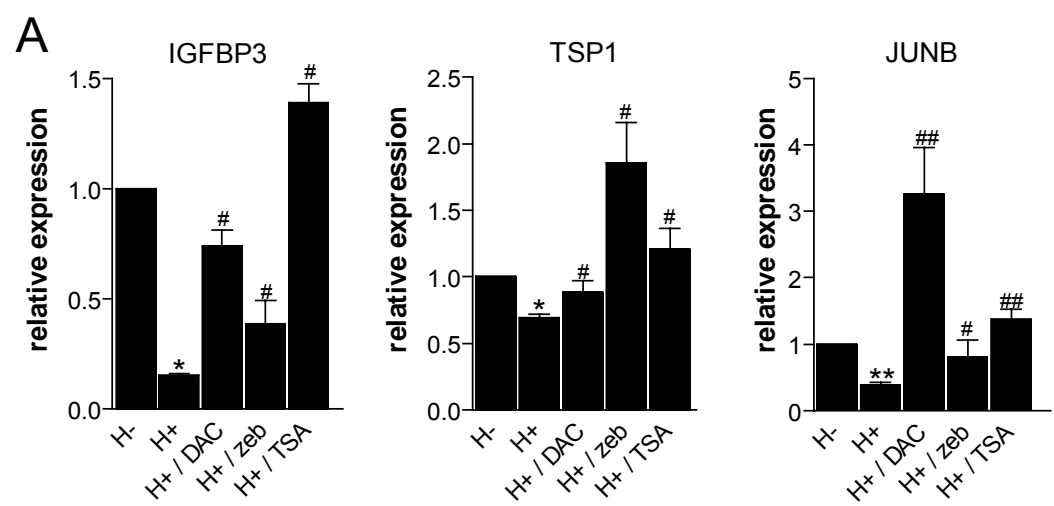

\section{B}

IGFBP3
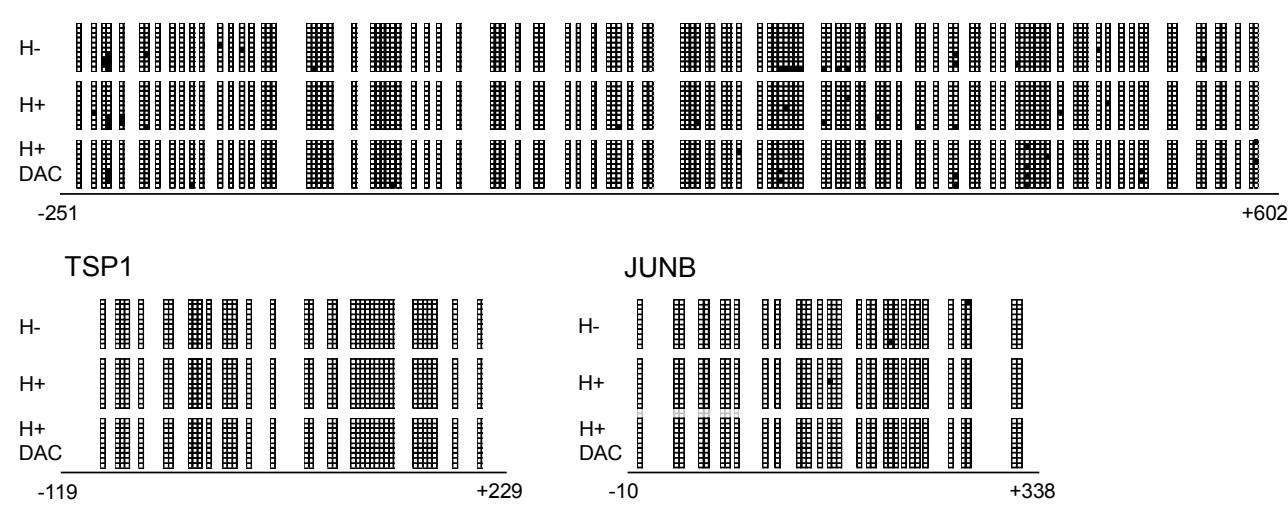

C

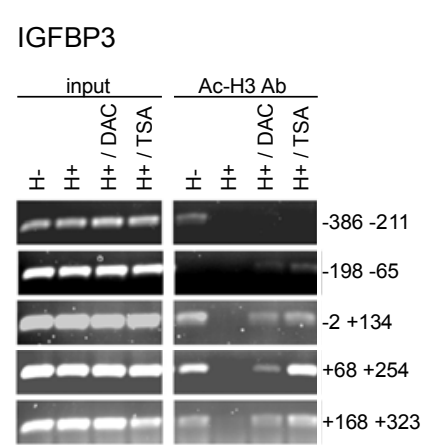

TSP1
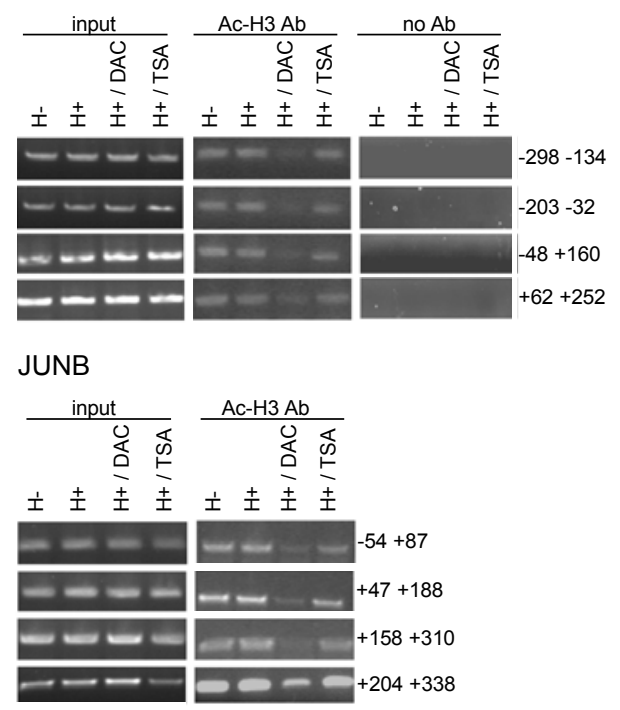
Figure 2.5 mRNA expression, promoter methylation and histone deacetylation of TSP1, JUNB and IGFBP3 in EC.

(A) Relative mRNA expression of IGFBP3, TSP1 and JUNB measured by quantitative real-time RT-PCR in quiescent HUVEC $(\mathrm{H}-)$, activated HUVEC $(\mathrm{H}+)$, and activated HUVEC treated with DAC $(200 \mathrm{nM})$, zebularine $(100 \mu \mathrm{M})$ or TSA $(300 \mathrm{nM})$. Results are plotted as mean values $( \pm$ SEM) of relative mRNA expression compared to $\mathrm{H}$ - from 3 independent experiments $\left({ }^{*} \mathrm{p}<0.04 \mathrm{vs}\right.$. $\mathrm{H}-,{ }^{* *} \mathrm{p}<0.02 \mathrm{vs}$. $\mathrm{H}-, \# \mathrm{p}<0.05$ vs. $\mathrm{H}+, \#$ p $<0.03$ vs. $\mathrm{H}+$ ). (B) Genomic bisulfite sequencing of $5^{\prime} \mathrm{CpG}$ islands of IGFBP3, TSP1 and JUNB. In each clone, the methylation status of each CpG dinucleotide is represented as a box. If a box is shaded, the position is methylated, if white, it is not. Numbers indicate the position relative to transcriptional start site. (C) Chromatin immunoprecipitation (ChIP) of the 5' $\mathrm{CpG}$ islands of IGFBP3, TSP1 and JUNB with anti-acetylated histone $\mathrm{H} 3$ antibody. The numbers on the right indicate the location of the DNA fragments amplified by PCR done on the DNA recovered from ChIP experiments and correspond with the numbers below the schematic promoter $\mathrm{CpG}$ islands in (B). For each primer set, PCR was performed on non-immunoprecipitated (input) DNA, immunoprecipitated DNA (Ac-H3 $A b)$ and a no-antibody (no Ab) control DNA. For IGFBP3 and JunB, no bands were observed in the beads, as is shown for TSP1.

not shown). Next to TSP1, we studied EC expression of some growth inhibiting genes prone to epigenetic silencing in tumor cells, such as insulin-like growth factor binding protein 3 (IGFBP3), a growth inhibitor which also decreases EC proliferation ${ }^{33,34}$ and JUNB, a negative growth regulator and potential tumor suppressor. ${ }^{35}$ Quantitative real-time RT-PCR revealed downregulated transcript levels of these genes in activated- as compared to quiescent EC and reactivation by DAC, zebularine or TSA treatment (Fig. 2.5A).

Reexpression of IGFBP3, TSP1 and JUNB by DAC, zebularine and TSA in activated EC suggests that these genes might be silenced by epigenetic modifications in these cells. To study whether silencing of these growth inhibiting genes in activated $\mathrm{EC}$ is caused by DNA methylation, promoter $\mathrm{CpG}$ island methylation was evaluated using genomic bisulfite sequencing. Interestingly, $\mathrm{CpG}$ islands in the promoters of IGFBP3, TSP1 and JUNB contained only a few methylated CpG sites (Fig. 2.5B). Furthermore, meaningful differences in promoter methylation patterns of these genes between silenced- and activated EC were not present, indicating that silencing of these genes in activated EC and reexpression by DNMT- and HDAC inhibitors occurs independently of direct promoter methylation. Therefore, chromatin immunoprecipitation (ChIP) of IGFBP3, TSP1 and JunB was performed to study whether gene silencing is associated with aberrant patterns of histone deacetylation. For each gene, the area with greatest CpG density in the promoter was analyzed, overlapping the region examined by genomic bisulfite sequencing. Interestingly, acetylated histone $\mathrm{H} 3$ was observed in the transcriptionally active IGFBP3 promoter of quiescent HUVEC, but was undetectable in activated HUVEC in the area from -2 to +323 (Fig. $2.5 \mathrm{C}$ ). In cells treated with DAC or TSA, histone $\mathrm{H} 3$ acetylation reappeared in this promoter region. Thus, silencing of IGFBP3 in activated HUVEC and reexpression by DAC and TSA occurred in conjunction with changes in histone $\mathrm{H} 3$ acetylation patterns. In contrast, for TSP1 and JunB, promoter histone $\mathrm{H} 3$ acetylation patterns do not correlate with silencing in activated $\mathrm{EC}$ and reexpression by DAC and TSA treatment (Fig. 2.5C), suggesting an indirect effect of DAC and TSA on TSP1 and JunB expression. 
Angiostatic activity of DNA methyltransferase inhibitors

\section{Discussion}

We investigated whether DNMT inhibitors directly affect EC biology and tumor angiogenesis, apart from potential indirect angiostatic activities in vivo via inhibition of tumor cells. ${ }^{8,9}$ This report is the first to demonstrate that DNMT inhibitors act directly on activated EC and inhibit angiogenesis in vitro and in vivo, similar as previously described for HDAC inhibitors. ${ }^{16-18}$

DAC and its analogue zebularine showed potent inhibition of tumor growth and angiostatic activity in two different mouse tumor models. Inhibition of tumor angiogenesis in B16F10- and LS174T tumor bearing mice after treatment with DNMT inhibitors can be due to effects of these compounds on tumor cells, ${ }^{9,10}$ which are known to influence tumor angiogenesis by release of pro- and anti- angiogenic factors. However, we show that the DNMT inhibitor DAC directly decreases proliferation of activated HUVEC and mouse b.END5 brain endothelioma cells, an observation which was confirmed using zebularine, a recently described DAC analogue with great potential in clinical use. ${ }^{28}$ Effective concentrations of zebularine were about 100 -fold higher than DAC, which is in agreement with results in tumor cells and can be explained by differences in transport or metabolic activation, as well as by the fact that zebularine is also incorporated into RNA. ${ }^{20}$ The significant inhibition of in vitro tube formation in the absence of tumor cells proves that these agents also directly inhibit EC sprouting. The potent inhibition of activated EC next to tumor cells makes DNMT inhibition a powerful anti-cancer therapy, as reflected by the markedly decreased tumor volumes in mice treated with DAC and zebularine.

In tumor cells, global demethylation of the genome occurs, despite regional promoter hypermethylation of tumor suppressor genes. ${ }^{5}$ This global hypomethylation in tumor cells has been proposed to cause chromosomal instability, harmful expression of endogenous viral sequences and activation of oncogenes. ${ }^{36}$ We found an increase in methylation upon activation of EC, which could explain why these cells are much less prone to genetic modifications. Despite the significant increase in total genomic 5-methylcytosine content in activated versus quiescent $\mathrm{EC}$, silencing of the angiogenesis inhibiting genes TSP1, JUNB and IGFBP3 in activated EC and reexpression by DAC, zebularine and TSA occurs independently of direct promoter methylation of these genes. The angiogenesis inhibitor TSP1 blocks EC migration and induces EC apoptosis. ${ }^{32}$ JUNB negatively regulates cell growth by activating p16INK4A and decreasing cyclin D1 expression. ${ }^{35}$ IGFBP3, a key regulator of cell growth and apoptosis, potently inhibits VEGF-mediated HUVEC proliferation ${ }^{33}$ and angiogenesis. ${ }^{34}$ Remarkably, previous studies have demonstrated that silencing of the same genes in tumor cells is associated with promoter methylation (TSP $1,{ }^{37,38} \mathrm{JUNB}^{39}$ and IGFBP3). ${ }^{40,41}$ Thus, silencing of these angiogenesis inhibiting genes in tumor cells and activated EC occurs through different mechanisms. Several methylationindependent effects of DNMT inhibitors have been described by others. ${ }^{42-44}$ Since EC death is not induced by DAC treatment, cytotoxicity can be excluded as a major cause of gene induction. A possibility is that DAC targets upstream regulators that are suppressed by promoter hypermethylation, or that the minimal promoter comprises other regions than those analyzed by bisulfite sequencing. Furthermore, several 
studies have demonstrated that DNA methylation serves to "lock in" rather than initiate gene silencing. ${ }^{45-47}$ Thus, despite the observed global hypermethylation, specific promoter hypermethylation might not have occurred within the time-frame of our experiments. This is supported by the absence of IGFBP3 promoter hypermethylation in combination with histone $\mathrm{H} 3$ deacetylation after 3 days of $\mathrm{EC}$ activation. Also, DNMTs have additional transcriptional repressor functions apart from their methylation ability. ${ }^{43,44}$ By trapping DNMTs, DAC might inhibit these methylation-independent silencing functions of DNMTs and thus affect gene expression. Finally, gene silencing in activated EC and reactivation by DAC and TSA might be predominantly an HDACdependent mechanism, either HDACs directly or DNMT-mediated HDAC recruitment. Further studies are required to unravel whether (methylation-independent) epigenetic mechanisms are involved in silencing of IGFBP3, TSP1 and JUNB in activated EC and reexpression by DAC and TSA.

In conclusion, our data show for the first time that direct inhibitory effects of DNMT inhibitors regulate EC growth and angiogenesis. Although overall genomic methylation levels and DNMT activity are increased in tumor-conditioned EC, reexpression of growth-inhibiting genes in activated EC by DNMT- and HDAC inhibitors seems to occur through methylation-independent effects. Current studies are focused on the exact role of DNMTs in regulation of EC growth and angiogenesis, as well as in regulating expression of growth inhibiting genes in tumor EC. The dual effects of DNMT- and HDAC inhibitors on both tumor cell growth and tumor EC make them attractive anticancer therapeutics.

\section{Acknowledgements}

We thank dr. V. Thijssen, dr. K. Cleutjens, dr. D. van der Schaft (Maastricht University) and dr. R. Dings (University of Minnesota) for helpful discussions and assistance with the mouse experiments. 


\section{References}

1. Jenuwein T, Allis CD. Translating the histone code. Science. 2001;293:1074-1080.

2. Jaenisch R, Bird A. Epigenetic regulation of gene expression: how the genome integrates intrinsic and environmental signals. Nat Genet. 2003;33 Suppl:245-254.

3. Baylin SB, Esteller M, Rountree MR, Bachman KE, Schuebel K, Herman JG. Aberrant patterns of DNA methylation, chromatin formation and gene expression in cancer. Hum Mol Genet. 2001;10:687-692.

4. Jones PA, Laird PW. Cancer epigenetics comes of age. Nat Genet. 1999;21:163-167.

5. Feinberg AP, Vogelstein B. Hypomethylation distinguishes genes of some human cancers from their normal counterparts. Nature. 1983;301:89-92.

6. Herman JG, Baylin SB. Gene silencing in cancer in association with promoter hypermethylation. N Engl J Med. 2003;349:2042-2054.

7. Esteller M, Corn PG, Baylin SB, Herman JG. A gene hypermethylation profile of human cancer. Cancer Res. 2001;61:3225-3229.

8. Suzuki H, Gabrielson E, Chen W, et al. A genomic screen for genes upregulated by demethylation and histone deacetylase inhibition in human colorectal cancer. Nat Genet. 2002;31:141-149.

9. Baylin SB. Reversal of gene silencing as a therapeutic target for cancer--roles for DNA methylation and its interdigitation with chromatin. Novartis Found Symp. 2004;259:226-233.

10. Villar-Garea A, Esteller M. Histone deacetylase inhibitors: Understanding a new wave of anticancer agents. Int J Cancer. 2004;112:171-178.

11. Folkman J. Fundamental concepts of the angiogenic process. Curr Mol Med. 2003;3:643651.

12. Griffioen AW, Molema G. Angiogenesis: potentials for pharmacologic intervention in the treatment of cancer, cardiovascular diseases, and chronic inflammation. Pharmacol Rev. 2000;52:237-268.

13. St Croix B, Rago C, Velculescu V, et al. Genes expressed in human tumor endothelium Science. 2000;289:1197-1202.

14. Bicknell R, Harris AL. Novel angiogenic signaling pathways and vascular targets. Annu Rev Pharmacol Toxicol. 2004;44:219-238.

15. van Beijnum JR, Griffioen AW. In silico analysis of angiogenesis associated gene expression identifies angiogenic stage related profiles. Biochim Biophys Acta. 2005; 1755:121-134.

16. Kim MS, Kwon HJ, Lee YM, et al. Histone deacetylases induce angiogenesis by negative regulation of tumor suppressor genes. Nat Med. 2001;7:437-443

17. Deroanne CF, Bonjean K, Servotte S, et al. Histone deacetylases inhibitors as antiangiogenic agents altering vascular endothelial growth factor signaling. Oncogene 2002;21:427-436

18. Qian DZ, Wang X, Kachhap SK, et al. The histone deacetylase inhibitor NVP-LAQ824 inhibits angiogenesis and has a greater antitumor effect in combination with the vascular endothelial growth factor receptor tyrosine kinase inhibitor PTK787/ZK222584. Cancer Res. 2004;64:6626-6634.

19. Griffioen AW, Damen CA, Martinotti S, Blijham GH, Groenewegen G. Endothelial intercellular adhesion molecule-1 expression is suppressed in human malignancies: the role of angiogenic factors. Cancer Res. 1996:56:1111-1117.

20. Cheng JC, Matsen CB, Gonzales FA, et al. Inhibition of DNA methylation and reactivation of silenced genes by zebularine. J Natl Cancer Inst. 2003;95:399-409.

21. van der Schaft DW, Dings RP, de Lussanet QG, et al. The designer anti-angiogenic peptide anginex targets tumor endothelial cells and inhibits tumor growth in animal models. FASEB J. 2002;16:1991-1993. 
22. van der Schaft DW, Toebes EA, Haseman JR, Mayo KH, Griffioen AW. Bactericidal/permeability-increasing protein (BPI) inhibits angiogenesis via induction of apoptosis in vascular endothelial cells. Blood. 2000;96:176-181.

23. Fraga MF, Uriol E, Borja Diego L, et al. High-performance capillary electrophoretic method for the quantification of 5-methyl 2'-deoxycytidine in genomic DNA: application to plant, animal and human cancer tissues. Electrophoresis. 2002;23:1677-1681.

24. Vertino PM, Yen RW, Gao J, Baylin SB. De novo methylation of CpG island sequences in human fibroblasts overexpressing DNA (cytosine-5-)-methyltransferase. Mol Cell Biol. 1996;16:4555-4565.

25. Thijssen VL, Brandwijk RJ, Dings RP, Griffioen AW. Angiogenesis gene expression profiling in xenograft models to study cellular interactions. Exp Cell Res. 2004;299:286-293.

26. Herman JG, Graff JR, Myohanen S, Nelkin BD, Baylin SB. Methylation-specific PCR: a novel PCR assay for methylation status of CpG islands. Proc Natl Acad Sci U S A. 1996;93:9821-9826.

27. Metivier R, Penot G, Hubner MR, et al. Estrogen receptor-alpha directs ordered, cyclical, and combinatorial recruitment of cofactors on a natural target promoter. Cell. 2003;115:751763.

28. Cheng JC, Yoo CB, Weisenberger DJ, et al. Preferential response of cancer cells to zebularine. Cancer Cell. 2004;6:151-158.

29. Vesely J. Mode of action and effects of 5 -azacytidine and of its derivatives in eukaryotic cells. Pharmacol Ther. 1985;28:227-235.

30. Rhee I, Jair KW, Yen RW, et al. CpG methylation is maintained in human cancer cells lacking DNMT1. Nature. 2000;404:1003-1007.

31. Gardiner-Garden M, Frommer M. CpG islands in vertebrate genomes. J Mol Biol. 1987;196:261-282.

32. Bocci G, Francia G, Man S, Lawler J, Kerbel RS. Thrombospondin 1, a mediator of the antiangiogenic effects of low-dose metronomic chemotherapy. Proc Natl Acad Sci U S A. 2003;100:12917-12922.

33. Franklin SL, Ferry RJ, Jr., Cohen P. Rapid insulin-like growth factor (IGF)-independent effects of IGF binding protein-3 on endothelial cell survival. J Clin Endocrinol Metab. 2003;88:900-907.

34. Iwatsuki K, Tanaka K, Kaneko T, et al. Runx1 promotes angiogenesis by downregulation of insulin-like growth factor-binding protein-3. Oncogene. 2004.

35. Passegue E, Wagner EF. JunB suppresses cell proliferation by transcriptional activation of p16(INK4a) expression. Embo J. 2000;19:2969-2979.

36. Chen RZ, Pettersson U, Beard C, Jackson-Grusby L, Jaenisch R. DNA hypomethylation leads to elevated mutation rates. Nature. 1998;395:89-93.

37. Yang QW, Liu S, Tian Y, et al. Methylation-associated silencing of the thrombospondin-1 gene in human neuroblastoma. Cancer Res. 2003;63:6299-6310.

38. Li Q, Ahuja N, Burger PC, Issa JP. Methylation and silencing of the Thrombospondin-1 promoter in human cancer. Oncogene. 1999;18:3284-3289.

39. Yang MY, Liu TC, Chang JG, Lin PM, Lin SF. JunB gene expression is inactivated by methylation in chronic myeloid leukemia. Blood. 2003;101:3205-3211.

40. Chang YS, Wang L, Liu D, et al. Correlation between insulin-like growth factor-binding protein-3 promoter methylation and prognosis of patients with stage I non-small cell lung cancer. Clin Cancer Res. 2002;8:3669-3675.

41. Fraga MF, Herranz M, Espada J, et al. A mouse skin multistage carcinogenesis model reflects the aberrant DNA methylation patterns of human tumors. Cancer Res. 2004;64:5527-5534.

42. Schmelz K, Sattler N, Wagner M, Lubbert M, Dorken B, Tamm I. Induction of gene expression by 5-Aza-2'-deoxycytidine in acute myeloid leukemia (AML) and myelodysplastic syndrome (MDS) but not epithelial cells by DNA-methylation-dependent and -independent mechanisms. Leukemia. 2005;19:103-111. 
43. Fuks F, Burgers WA, Brehm A, Hughes-Davies L, Kouzarides T. DNA methyltransferase Dnmt1 associates with histone deacetylase activity. Nat Genet. 2000;24:88-91.

44. Fuks F, Burgers WA, Godin N, Kasai M, Kouzarides T. Dnmt3a binds deacetylases and is recruited by a sequence-specific repressor to silence transcription. Embo J. 2001;20:25362544.

45. Bachman KE, Park BH, Rhee I, et al. Histone modifications and silencing prior to DNA methylation of a tumor suppressor gene. Cancer Cell. 2003;3:89-95.

46. Tamaru H, Selker EU. A histone H3 methyltransferase controls DNA methylation in Neurospora crassa. Nature. 2001;414:277-283.

47. Ting AH, Schuebel KE, Herman JG, Baylin SB. Short double-stranded RNA induces transcriptional gene silencing in human cancer cells in the absence of DNA methylation. Nat Genet. 2005;37:906-910. 



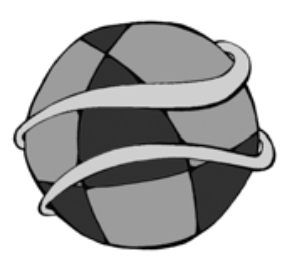

\section{Chapter 3 Identification of epigenetically silenced genes in tumor endothelial cells}

Debby M.E.I. Hellebrekers, Veerle Melotte, Emmanuelle Viré, François Fuks, James G. Herman, Wim Van Criekinge, Arjan W. Griffioen and Manon van Engeland

Submitted 


\begin{abstract}
Tumor angiogenesis requires intricate regulation of gene expression in endothelial cells $(E C)$. We recently showed that DNA methyltransferase (DNMT)- and histone deacetylase (HDAC) inhibitors directly repress EC growth and tumor angiogenesis, suggesting that DNMTs and HDACs are involved in regulation of EC gene expression during tumor angiogenesis. To understand the mechanisms behind the epigenetic regulation of tumor angiogenesis we performed microarray analysis to identify genes downregulated in tumor-conditioned versus quiescent EC, and re-expressed by 5-aza2'-deoxycytidine and trichostatin A. Among the 81 genes identified, $77 \%$ harboured a promoter CpG island. Validation of mRNA levels of a subset of genes confirmed significant downregulation in tumor-conditioned EC and reactivation by treatment with a combination of 5-aza-2'-deoxycytidine and trichostatin A, as well as by both compounds separately. Silencing of these genes in tumor-conditioned EC correlated with promoter histone $\mathrm{H} 3$ deacetylation and loss of $\mathrm{H} 3$ lysine 4 methylation, however did not involve DNA methylation of promoter $\mathrm{CpG}$ islands. Functional validation by RNA interference revealed that clusterin, fibrillin 1 and quiescin Q6 are negative regulators of EC growth and angiogenesis. In summary, our data identify novel angiogenesis suppressing genes which become silenced in tumor EC in association with promoter histone modifications and reactivated by DNMT- and HDAC inhibitors, providing a mechanism for epigenetic regulation of tumor angiogenesis.
\end{abstract}

\title{
Introduction
}

Tumor angiogenesis is essential for tumor progression and the development of metastases. ${ }^{1}$ The angiogenic cascade starts with activation of endothelial cells (EC) by angiogenic factors, resulting in extracellular matrix degradation, EC migration, proliferation and tube formation, and, eventually, maturation of the blood vessel. ${ }^{2}$ During this multi-step process, angiogenic stimulation changes EC gene expression profiles. Analysis of differentially expressed genes in tumor EC versus normal, quiescent endothelium can lead to a better understanding of EC biology during tumor angiogenesis and to the identification of tumor EC specific markers for vascular targeting approaches. ${ }^{3-5}$

Epigenetic processes play a major role in regulation of gene expression by affecting chromatin structure. DNA methylation and histone modifications are important mediators of epigenetic gene silencing and are essential in diverse biological processes. ${ }^{6-10}$ In cancer cells, aberrant promoter CpG island hypermethylation and histone modifications result in inappropriate transcriptional silencing of tumor suppressor genes. ${ }^{11}$ DNA methyltransferase (DNMT)- and histone deacetylase (HDAC) inhibitors can synergistically reactivate epigenetically silenced tumor suppressor genes and cause growth arrest and apoptosis of tumor cells. ${ }^{12,13}$ Microarray based strategies combining gene expression status and pharmacological reversal of epigenetic repression have been shown powerful for identification of new epigenetically silenced tumor suppressor genes in human cancers. ${ }^{14-20}$ 
Recently, we and others showed that DNMT- and HDAC inhibitors directly inhibit EC growth and tumor angiogenesis. ${ }^{21-23}$ These findings suggest that epigenetic modifications mediated by DNMTs and HDACs are involved in regulation of EC gene expression during tumor angiogenesis. However, very little is known on the role of epigenetics in tumor EC gene expression, and on the genes regulated by DNMT- and HDAC inhibitors in tumor EC. Here, we used gene expression microarrays to identify genes silenced in tumor-conditioned ECs and re-expressed by pharmacological inhibition of DNMTs and HDACs, to provide a mechanism for the epigenetic regulation of tumor angiogenesis and for the angiostatic effects of DNMT- and HDAC inhibitors.

\section{Materials and Methods}

\section{Cell Cultures and Reagents}

Human umbilical vein endothelial cells (HUVEC) were isolated from normal human umbilical cords by perfusion with $0.125 \%$ trypsin/EDTA. HUVEC and human microvascular endothelial cells (HMEC) were cultured as previously described. ${ }^{24}$ Quiescent EC were prepared by culturing HUVEC for 3 days in culture medium supplemented with low amounts $(2 \%)$ of serum. ${ }^{5}$ Tumor conditions were mimicked by a 6-day exposure to $10 \mathrm{ng} / \mathrm{ml}$ basic Fibroblast Growth Factor (bFGF; Peprotech, London, UK), $10 \mathrm{ng} / \mathrm{ml}$ Vascular Endothelial Growth Factor (VEGF; Peprotech) and $20 \%(\mathrm{v} / \mathrm{v})$ of a $1: 1$ mixture of filtered culture supernatants of LS174T and CaCo-2 human colon carcinoma cell lines. ${ }^{5,21}$ During the last 3 days, tumor-conditioned HUVEC were treated with low doses of the DNA methyltransferase (DNMT) inhibitor 5-aza-2'-deoxycytidine (DAC; $200 \mathrm{nM})^{14}$ (Sigma, Zwijndrecht, the Netherlands) or the histone deacetylase (HDAC) inhibitor trichostatin A (TSA; $300 \mathrm{nM})^{14}$ (Wako, Neuss, Germany), replacing drugs and culture medium every 24 hours, as described previously. ${ }^{14,21}$ Tumor-conditioned EC treated during the last 3 days with a combination of DAC and TSA were first treated with DAC (200 nM) for $48 \mathrm{~h}$, with drug and medium replaced $24 \mathrm{~h}$ after the beginning of the treatment, followed by medium replacement and addition of TSA $(300 \mathrm{nM})$ for a further $24 \mathrm{~h}$, as described previously. ${ }^{14}$

\section{Microarrays}

A commercial pool (a mixture of 32 donors) of HUVEC (Tebu-bio, Heerhugowaard, The Netherlands) was used for DNA microarray experiments. Total RNA was isolated using the RNeasy RNA isolation kit (Qiagen) according to the supplier's protocol. Possible genomic DNA contaminations were removed by on column DNase treatment with the RNase-free DNase set (Qiagen). The purified RNA was quantified using a Nanodrop spectrophotometer, and RNA quality was evaluated using the Agilent 2100 Bioanalyzer. cDNA synthesis was performed using the Agilent Fluorescent Direct Labelkit with direct incorporation of either cyanine 5 (Cy5) or Cy3 dCTP nucleotides (Perkin Elmer) according to the manufacturer's instructions. Labeled CDNA was purified using QIAquick PCR purification columns (Qiagen), followed by concentration by vacuum centrifugation. The Agilent human 1A cDNA microarray (Agilent Technologies, Amstelveen, The Netherlands) contained 15000 
cDNA probes. Labeled cDNA was resuspended in hybridisation buffer and hybridised to Agilent human $1 \mathrm{~A}$ cDNA microarray for $17 \mathrm{~h}$ at $65^{\circ} \mathrm{C}$, according to the Agilent protocols. All hybridisations were replicated with cy dyes switched.

Two fluorescent microarray comparisons were performed: (1) A comparison of tumor-conditioned HUVEC and quiescent HUVEC and (2) a comparison of tumorconditioned HUVEC treated with or without a combination of DAC and TSA.

\section{Microarray data processing and statistical analysis}

The image file was processed using Agilent's Feature Extraction software (version A.6.1.1, Agilent Technologies). This Feature Extraction program was used to identify pixels corresponding to fluorescent signal (as opposed to background) and to remove pixels with intensities that met the default criteria for outliers. The different normalisation routines applied (Local Background, Minimum signal (feature or background) \& Average of all background areas) resulted in comparable results. For each identified area of signal and each of the two dyes, the basic measure of RNA abundance was taken to be the mean intensity over pixels in the identified signal area. The log ratio of the red to green intensities for each signal area was used for statistical analyses, with all subsequent analyses done using the $\mathrm{R}$ statistical software package (version 1.2). We selected fold change 1.5 as a threshold, since the 4 hybridisations increase the likelihood of statistical reliability.

\section{Quantitative Real-Time RT-PCR}

To validate microarray results, total RNA isolation, CDNA synthesis and quantitative real-time RT-PCR of four independent HUVEC cultures were performed essentially as described previously ${ }^{25}$ using SYBR Green PCR master mix (Applied Biosystems, Nieuwekerk a/d IJssel, The Netherlands). Primer sequences are listed in Supporting Table 3.1.

\section{Bisulfite Sequencing}

Genomic DNA from tumor-conditioned and quiescent HUVEC (prepared from a commercial pool $(n=32)$ of HUVEC (Tebu-bio)) was isolated using the Puregene DNA Isolation Kit (Gentra Systems, Biozym, Landgraaf, The Netherlands). Bisulfite modification of genomic DNA and bisulfite sequencing was carried out essentially as described previously. ${ }^{21,26}$ Primer sequences are listed in Supporting Table 3.2.

\section{Chromatin immunoprecipitation (ChIP) Assay}

Chromatin immunoprecipitation (ChIP) assays were performed essentially as described ${ }^{27}$ using anti-acetyl-histone $\mathrm{H} 3$ (Lys 9 and Lys 14), or anti-trimethyl-histone H3 (Lys 4) antibody (both from Upstate Biotechnology, Lake Placid, New York). See Supporting Methods and Supporting Table 3.3 for more information and primer sequences.

\section{Small interfering RNA (siRNA)}

For transient knockdown of clusterin, fibrillin 1 and quiescin Q6, a 72bp siRNA sequence was inserted into the pRNAT-U6.1/hygro/green fluorescent protein (GFP) 
expression vector (Genscript, Piscataway, NJ). For each gene, a hairpin siRNA was designed using the siRNA construct builder (Genscript) and purchased by Eurogentec (sequences are listed in Supporting Table 3.4). Due to the limited lifespan of primary HUVEC, an endothelial cell line (HMEC) was used for siRNA transfections. One $\mu \mathrm{g}$ plasmid DNA was transfected into $1 \times 10^{6}$ HMEC cells with the Nucleofector sytem (Amaxa, Cologne, Germany), using the T20 protocol according to the manufacturer's instructions. Empty pRNAT-U6.1/hygro/GFP vector was used as a negative control. After $72 \mathrm{hrs}$, viable and GFP-positive cells were purified by FACS sorting, obtaining 98\% GFP-positive cells, of which gene knockdown was examined by quantitative realtime RT-PCR, and subsequently used for angiogenesis assays.

\section{Proliferation and migration measurement}

EC proliferation was measured using a $\left[^{3} H\right]$ thymidine incorporation assay as described previously. ${ }^{21,28} \mathrm{HMEC}$ were seeded at 5000 cells per well in a 96-well plate and cultured for 3 days. During the last 6 hours of the assay, the culture was pulsed with $0.3 \mu \mathrm{Ci}$ [methyl- ${ }^{3} \mathrm{H}$ ]-thymidine (Amersham Life Science, Roosendaal, The Netherlands) per well. Activity was measured using liquid scintillation. Three independent experiments were performed and in each experiment, measurements were done in triplicate. Migration of EC was measured using the wound assay ${ }^{28}$ In brief, confluent monolayers of HMEC were wounded using the blunt end of a glass pipette. Cultures were washed and medium was replaced. Wound width was measured in triplicate cultures at four predefined locations at start and at 2, 4, 6 and 8 hours after wounding.

\section{In vitro angiogenesis}

After harvesting, HMEC were grown in petri-dishes for 24 hours to form spheroids. Next, the spheroids were placed in a three-dimensional collagen gel containing in 8 volumes of vitrogen-100 (Collagen, Fremont, CA), 1 volume $10 \times$ concentrated $\alpha$ MEM (Life Technologies), 1 volume $11.76 \mathrm{mg} / \mathrm{ml}$ sodium bicarbonate, and $20 \mathrm{ng} / \mathrm{ml}$ bFGF. This mixture $(100 \mu \mathrm{l})$ was suspended to each well of a 96 -well culture plate, after which gelation was allowed to take place at $37^{\circ} \mathrm{C}$. After gelation medium was applied on top of the gel containing $20 \mathrm{ng} / \mathrm{ml} \mathrm{bFGF}$ and $30 \mathrm{ng} / \mathrm{ml} \mathrm{VEGF}$. After 24 hours, the relative increase in diameters of the spheroids was measured in two directions.

\section{Statistical Analyses}

All values are given as mean values \pm SEM. Statistical analyses of the quantitative real-time RT-PCR, as well as the proliferation, migration and sprouting assays were done using the Wilcoxon-Mann-Whitney rank sum test which was performed in SPSS 10.0.5. software. All values are two-sided and $p$-values $<0.05$ were considered statistically significant. 


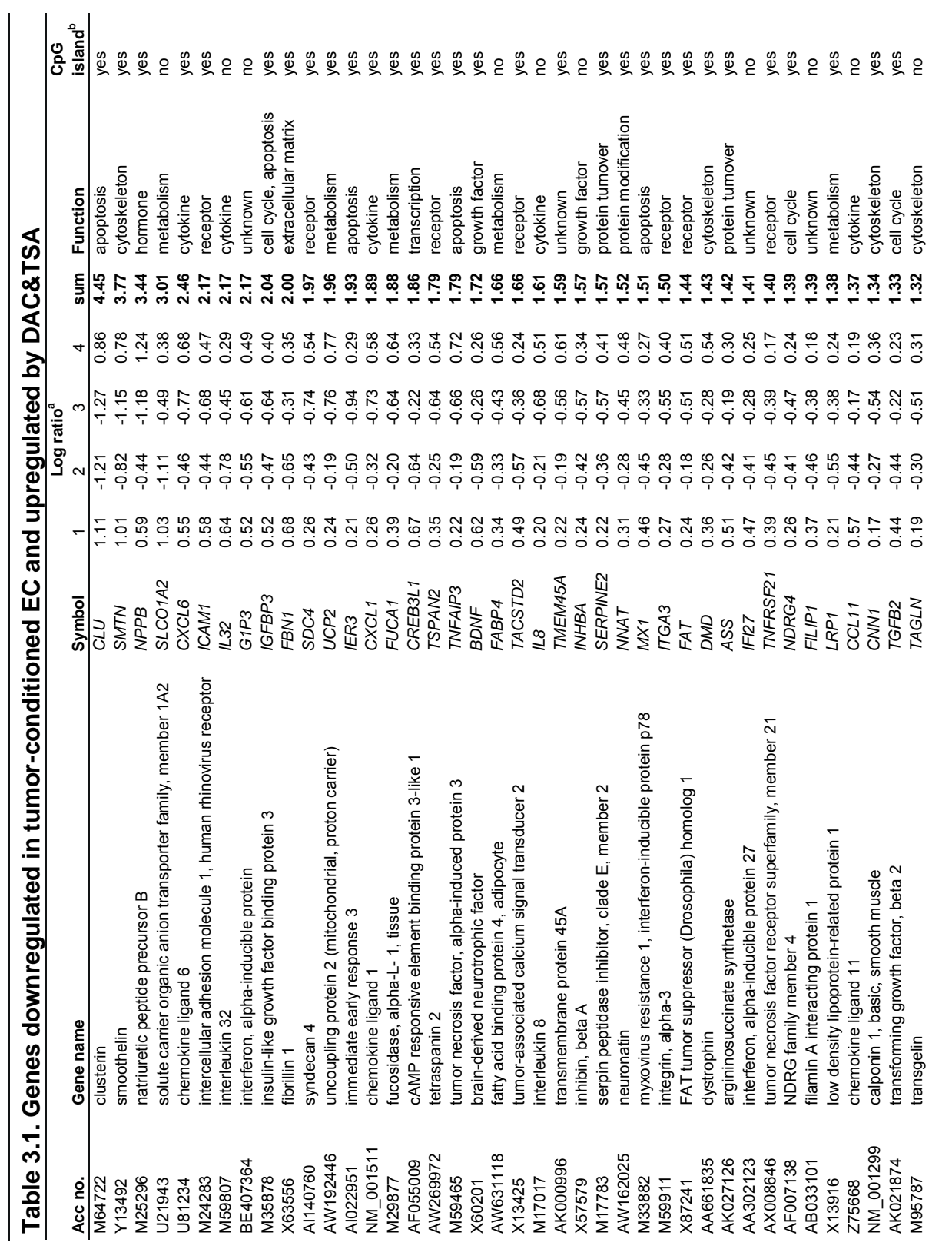




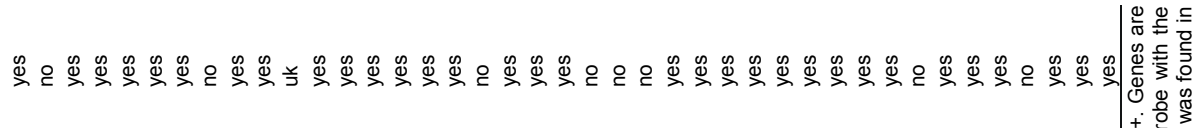

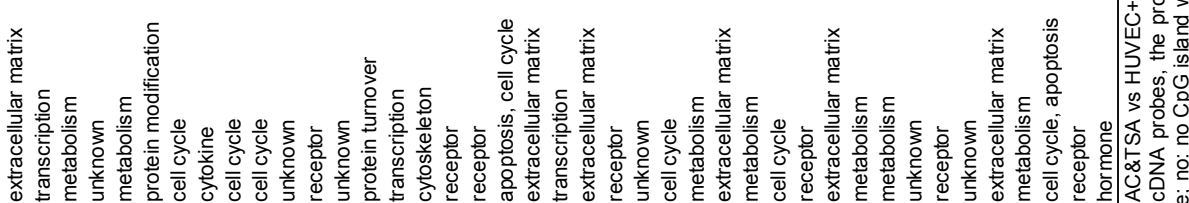

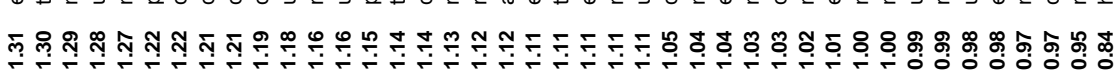

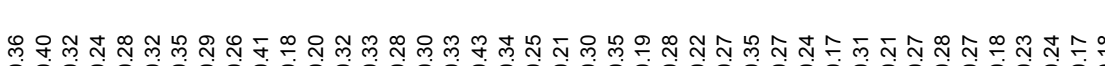

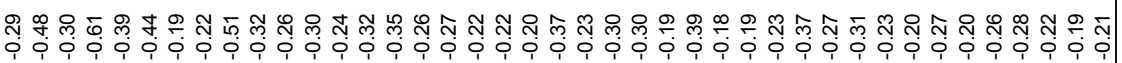

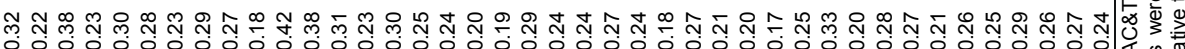

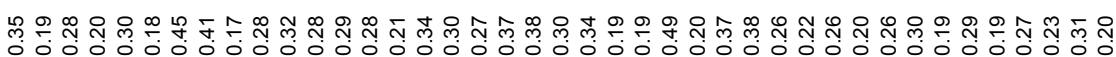

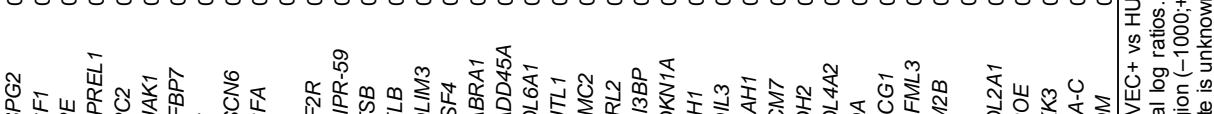

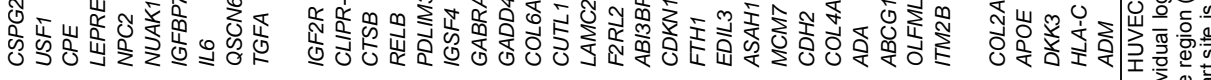

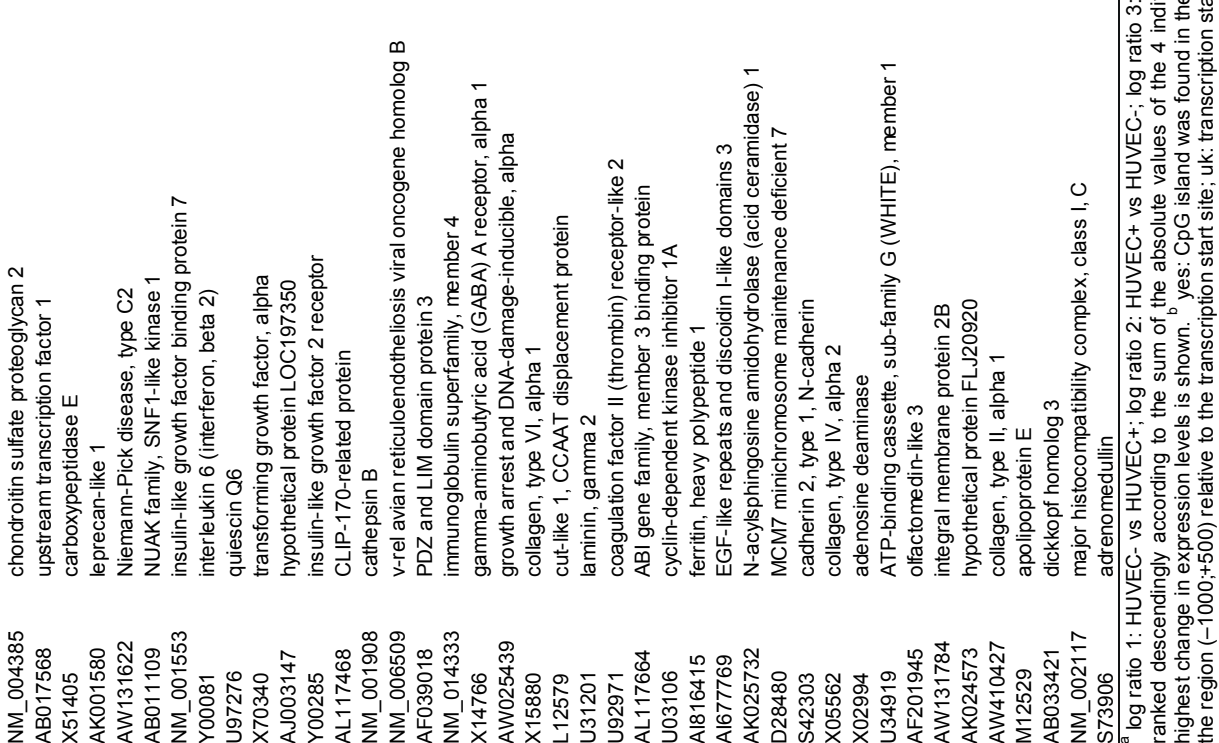




\section{Results}

Identification of genes reactivated by 5-aza-2'-deoxycytidine and trichostatin $A$ in tumor-conditioned endothelial cells

Tumor endothelial cells (EC) were mimicked using tumor-conditioned human umbilical vein endothelial cells (HUVEC, a commercial pool of a mixture of 32 donors), and quiescent EC were prepared by culturing HUVEC under low serum conditions. ${ }^{21}$ For inhibition of DNA methyltransferase (DNMT) and histone deacetylase (HDAC) activity, cells were exposed to low dose (200 nM) of the DNMT inhibitor 5-aza-2'deoxycytidine (DAC) for 48 hours, followed by treatment with $300 \mathrm{nM}$ of the HDAC inhibitor trichostatin A (TSA) for a further 24 hours, a method previously used to reactivate epigenetically silenced genes in tumor cells ${ }^{14}$ and EC. ${ }^{21}$ To identify genes silenced in tumor EC by epigenetic mechanisms, we performed two microarray comparisons. Combining these microarrays enabled us to select transcripts that were downregulated in tumor-conditioned versus quiescent EC as well as re-expressed by pharmacologic treatment (Fig. 3.1). Both comparisons were replicated with cyanine (Cy) 3 and Cy5 dyes switched, obtaining 4 separate log ratios for each cDNA probe. An expression difference of 1.5 -fold was used as a threshold for all 4 hybridisations, thereby increasing statistical reliability. Microarray analysis revealed 86 transcripts, corresponding to 81 unique genes, that showed 1.5-fold and greater downregulation in tumor-conditioned versus quiescent $\mathrm{EC}$, as well as reactivation by DAC and TSA treatment (Table 3.1). Remarkably, $77 \%$ of these genes harboured a $5^{\prime} \mathrm{CpG}$ island (GC content $>60 \%$, ratio of observed $\mathrm{CpG} /$ expected $\mathrm{CpG}>0.6$ and minimum length $200 \mathrm{bp})^{29}$ around the transcription start site or near upstream region, which is significantly more than expected from the genome-wide average of $60 \%{ }^{30}$ applied to the $\sim 15000$ genes from our microarray $(p<0.0001)$. Interestingly, 21 of 81 genes $(26 \%)$ have been reported to be epigenetically silenced in the malignant cells of different tumor types (listed in Supporting Table 3.5).

Changes in gene expression detected by microarray analysis were verified by quantitative real-time RT-PCR in four independent HUVEC cultures. Out of the 81

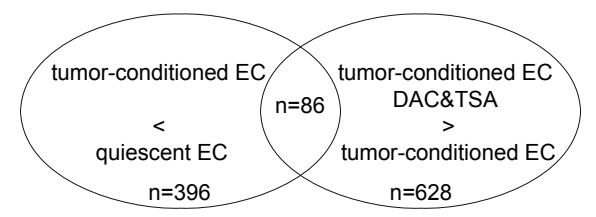

Figure 3.1 Identification of genes reactivated by 5-aza-2'-deoxycytidine and trichostatin $A$ in tumor-conditioned endothelial cells.

Two microarray comparisons were performed: A comparison of tumor-conditioned versus quiescent endothelial cells (EC), and a comparison of tumor-conditioned EC treated with or without 5-aza-2'deoxycytidine (DAC) and trichostatin A (TSA). Using fold change 1.5 as a threshold, 396 transcripts were identified as downregulated in tumor-conditioned versus quiescent $\mathrm{EC}$, and 628 transcripts were activated by DAC and TSA. Combining these microarrays revealed 86 transcripts downregulated in tumor-conditioned versus quiescent HUVEC as well as re-expressed by pharmacologic treatment, corresponding to 81 unique genes. 


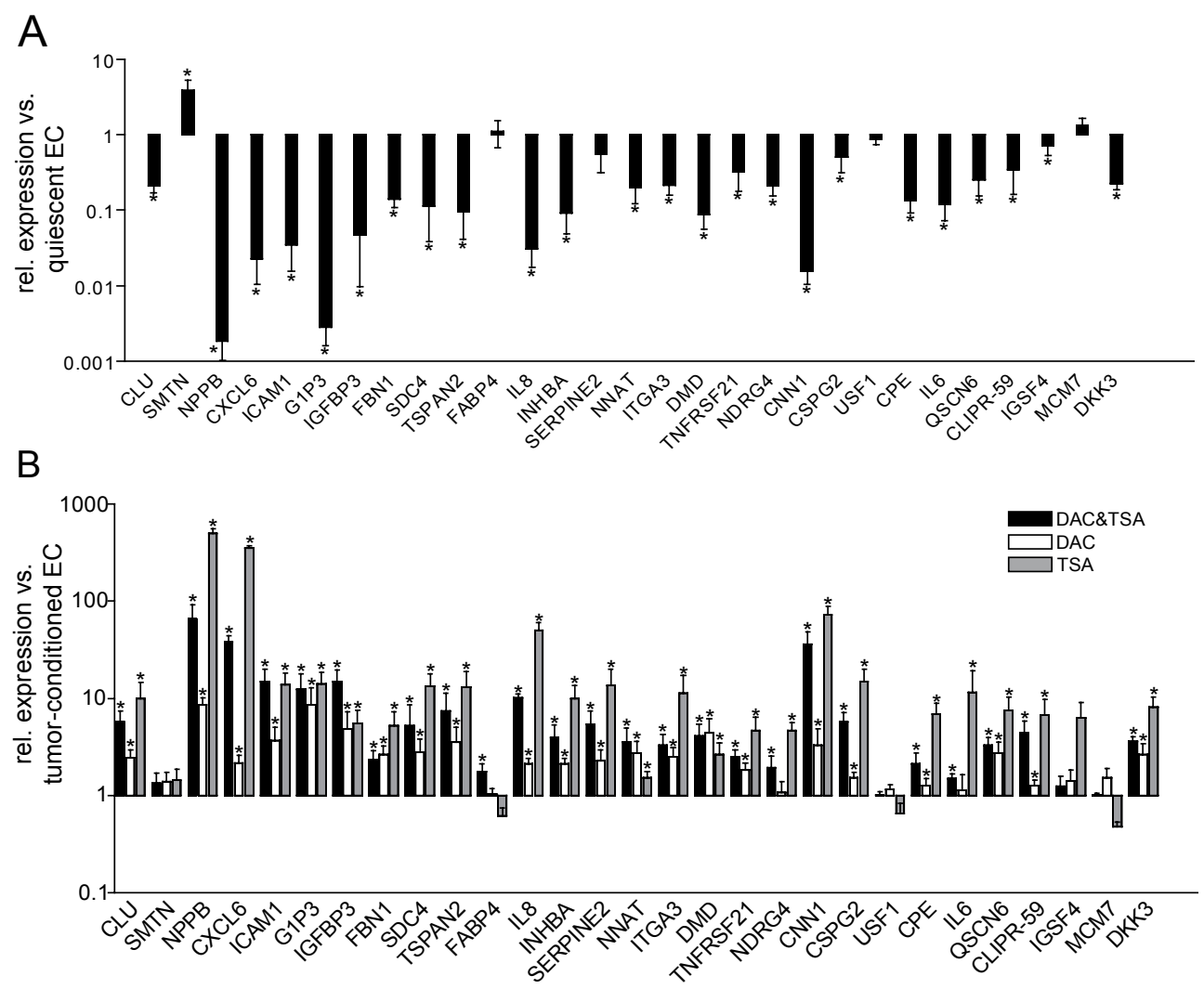

Figure 3.2 Transcriptional validation of candidate genes by quantitative real-time RT-PCR.

(A) Relative mRNA expression of selected genes in tumor-conditioned versus quiescent HUVEC measured by quantitative real-time RT-PCR. Results are plotted as mean values ( \pm SEM) of 4 independent experiments ( ${ }^{*} p<0.05$ vs. quiescent HUVEC). (B) Relative mRNA expression of selected genes in tumor-conditioned HUVEC treated with a combination of DAC (200 nM, 48 hrs) and TSA (300 $\mathrm{nM}$, last $24 \mathrm{hrs})$, similar as the microarray conditions, or with DAC (200 nM, $72 \mathrm{hrs})$ or TSA (300 nM, 72 hrs) alone, versus untreated tumor-conditioned HUVEC. Results are plotted as mean values ( \pm SEM) of 4 independent experiments ( ${ }^{*} p<0.05$ vs untreated tumor-conditioned HUVEC).

genes identified, the $9 \mathrm{CpG}$ island-containing genes with highest differential expression were investigated and, in addition, 20 randomly chosen genes. For 24 of these genes, significant downregulation in tumor-conditioned versus quiescent EC was confirmed using mean relative expression values of the four HUVEC cultures (1.5- to 800 -fold suppression, $\mathrm{p}<0.05$, Fig. $3.2 \mathrm{~A}$ ). Validating re-activation of the selected genes in tumor-conditioned EC by treatment with a combination of DAC and TSA, as well as by both compounds separately revealed that for 25 of the $29(86 \%)$ genes, significant upregulation in tumor-conditioned EC by treatment with the drug combination was confirmed, ranging from 1.5 -fold (IL6) to 66-fold (NPPB) relative induction (Fig. 3.2B). Among these 25 genes, 24 were also significantly reactivated by TSA alone, and 22 by DAC alone. Four of the five genes (SMTN, FABP4, USF1, $M C M 7$ ) that were not (significantly) downregulated in tumor-conditioned EC were also 
not significantly induced by DAC and TSA in the four HUVEC cultures (although FABP4 was induced by the combination, it was not induced by DAC or TSA alone), indicating that the identification of these genes results from microarray background. Interestingly, most of the genes showed much stronger relative induction after treatment with TSA (ranging from 1.5-fold to 498-fold induction) as compared with DAC (ranging from 1.3-fold to 8.5 -fold). Comparison of relative upregulation by the combination treatment with either compound alone showed neither an additive nor synergistic effect for most genes. Moreover, relative induction by treatment with TSA alone was for most genes greater than by the combination treatment (Fig. 3.2B). Together, quantitative real-time RT-PCR confirmed the results of both microarray comparisons.

Silencing of the identified genes in tumor-conditioned EC is associated with promoter histone modifications but not DNA methylation

The restored expression of the selected genes by inhibition of DNMTs and HDACs suggests that epigenetic modifications mediated by these enzymes might be responsible for silencing of these genes in tumor EC. Therefore, we examined promoter DNA methylation and histone modifications in the transcription start site area and near upstream region of the $\mathrm{CpG}$ islands of clusterin (CLU), intercellular adhesion molecule 1 (ICAM1), insulin-like growth factor binding protein 3 (IGFBP3), fibrillin 1 (FBN1), tetraspanin 2 (TSPAN2), tumor necrosis factor receptor superfamily, member 21 (TNFRSF21) and quiescin Q6 (QSCN6). These genes were selected based on (i) the presence of a promoter $\mathrm{CpG}$ island, (ii) relative upregulation by DAC and TSA and (iii) evidence from literature of silencing by promoter methylation, thereby choosing the most likely candidates for DNA methylation. ICAM1, IGFBP3, FBN1, TSPAN2 and QSCN6 were described to be silenced by promoter DNA hypermethylation (ICAM1, IGFBP3, FBN1, TSPAN2) and histone deacetylation (QSCN6) in tumor cells (Supporting Table 3.5). In addition, CLU is reported to be hypermethylated in transformed rat fibroblasts. ${ }^{31}$ We also included a gene not described to be hypermethylated (TNFRSF21). DNA methylation of the promoter CpG islands of the selected genes was evaluated by genomic bisulfite sequencing. Interestingly, (almost) no methylated CpG sites were present in the promoters of CLU, FBN1, TSPAN2, TNFRSF21 and QSCN6 in tumor-conditioned or quiescent EC (Fig. 3.3A). Promoter $\mathrm{CpG}$ islands of ICAM1 and IGFBP3 contained some methylated CpGs, but did not show major differences in methylation patterns between quiescent- and tumorconditioned EC. As a positive sequencing control for $\mathrm{CpG}$ methylation in EC we performed bisulfite sequencing of the iNOS promoter, ${ }^{32}$ which revealed dense methylation in both tumor-conditioned and quiescent EC (data not shown). These results demonstrate that despite their reactivation by DAC, silencing of the selected genes in tumor-conditioned EC occurs without changes in promoter DNA methylation in the regions examined. It is interesting that silencing of CLU, ICAM1, IGFBP3, FBN1, and TSPAN2 in tumor cells occurs by promoter DNA methylation, while the same genes are silenced in tumor-conditioned EC without methylation changes. Moreover, the examined promoter regions of these genes were similar as the regions described to be methylated in tumor cells (except for FBN1, of which the exact location of promoter methylation in tumor cells is not described). 
A

CLU

FBN1

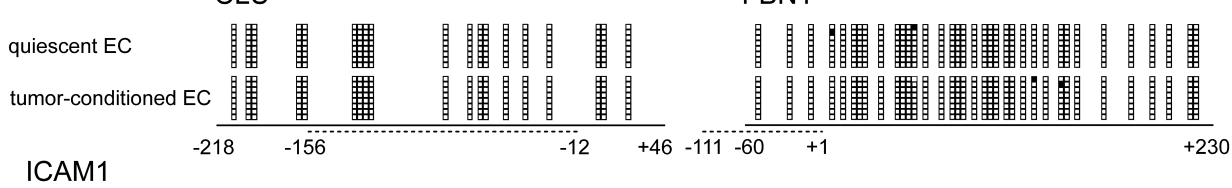

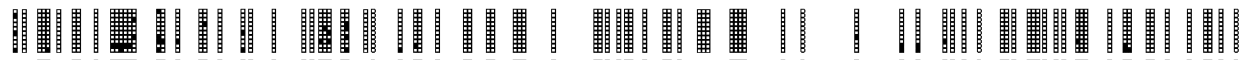

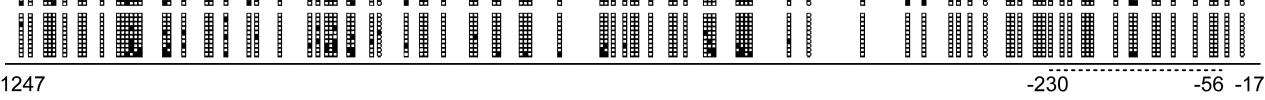

IGFBP3

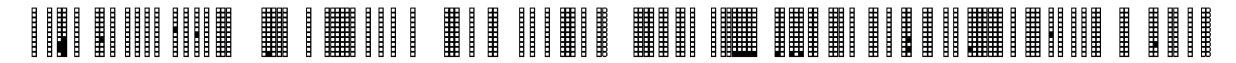

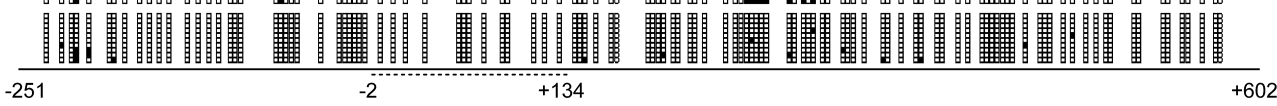
TSPAN2

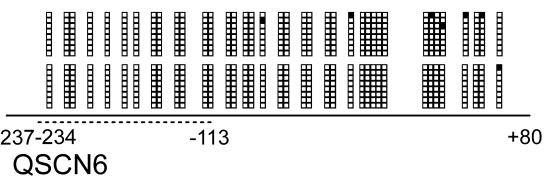

TNFRSF21

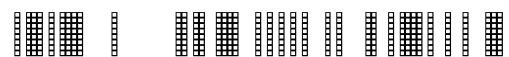

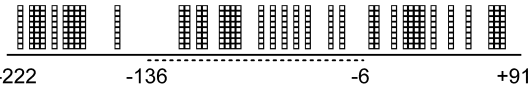

$\mathrm{B}$
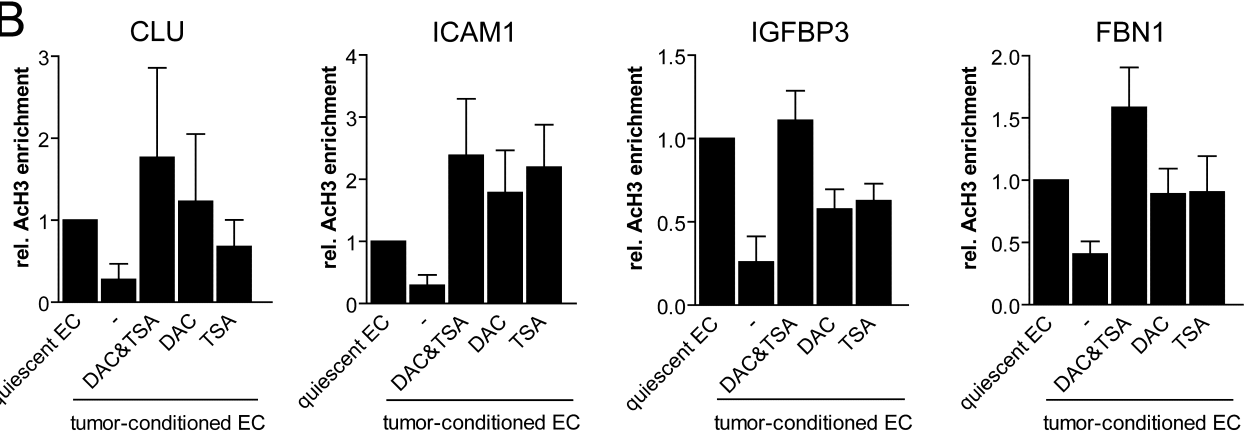

TSPAN2

TNFRSF21

QSCN6
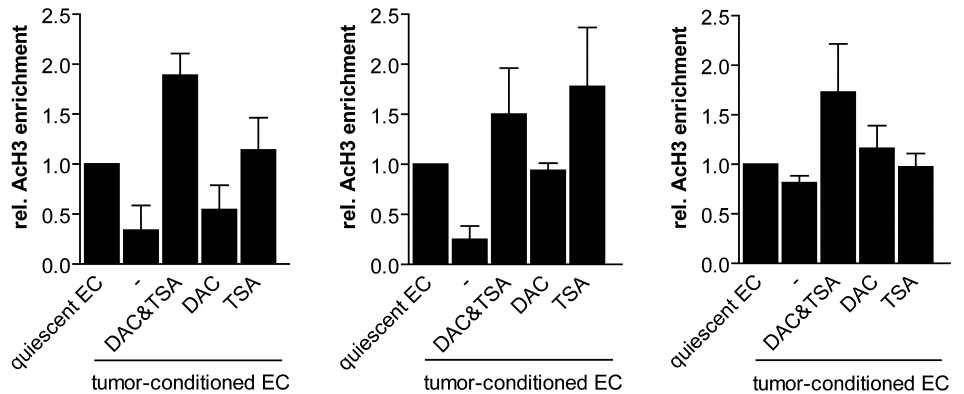

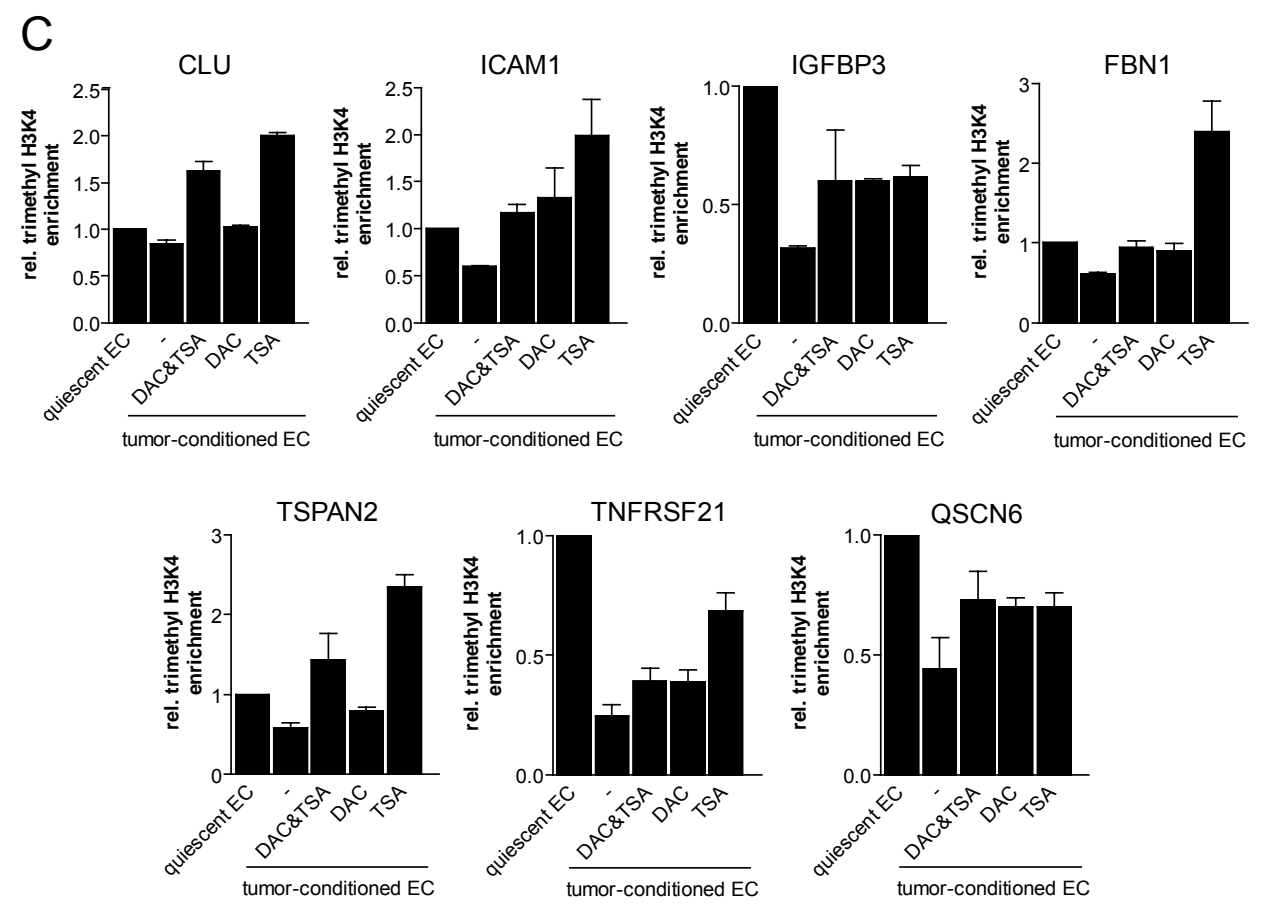

Figure 3.3 Analysis of promoter DNA methylation, histone H3 acetylation and H3 lysine 4 methylation of candidate genes.

(A) Genomic bisulfite sequencing of $5^{\prime} \mathrm{CpG}$ islands of CLU, FBN1, ICAM1, IGFBP3, TSPAN2, TNFRSF2 and QSCN6 in quiescent and tumor-conditioned HUVEC. For each gene, at least 8 individual clones from both quiescent and tumor-conditioned EC were sequenced. The methylation status of each CpG dinucleotide in a clone is represented as a square that is filled if the position is methylated and open if it is not. Numbers indicate positions relative to the transcription start site. The dotted lines denote the regions examined by chromatin immunoprecipitation. (B,C) Chromatin immunoprecipitation (ChIP) assay using anti-acetyl-histone H3 (Lys 9 and Lys 14) (B) and antitrimethyl-histone H3 (Lys 4) (C) antibody in quiescent HUVEC, tumor-conditioned HUVEC, and tumorconditioned HUVEC treated with a combination of DAC (200 nM, $48 \mathrm{hrs})$ and TSA (300 nM, last 24 hrs), similar as the microarray conditions, or with DAC (200 nM, $72 \mathrm{hrs}$ ) or TSA ( $300 \mathrm{nM}, 72 \mathrm{hrs}$ ) alone. The locations of the PCR fragments done on DNA recovered from ChIP experiments are indicated by the dotted lines in (A). PCR was performed on non-immunoprecipitated (input) DNA, immunoprecipitated DNA and a no-antibody (no $\mathrm{Ab}$ ) control DNA. Enrichment was calculated by taking the ratio between the net intensity of the candidate gene PCR product and the net intensity of the GAPDH PCR product for immunoprecipitated DNA and dividing this by the same ratio calculated for the input DNA. Relative acetylated $\mathrm{H} 3(\mathrm{AcH} 3)$ and methylated $\mathrm{H} 3$ Lys 4 (trimethyl H3K4) enrichment is shown (quiescent HUVEC set to 1). Values for enrichment are presented as mean values ( \pm SEM) from two independent ChIP experiments.

Promoter histone $\mathrm{H} 3$ acetylation of the 7 selected genes was examined by chromatin immunoprecipitation (ChIP) in the region surrounding the transcription start site. Promoter acetyl-histone $\mathrm{H} 3$ levels were decreased in tumor-conditioned as compared to quiescent EC in all 7 genes, although subtle for QSCN6 (Fig. 3.3B). Treatment of tumor-conditioned EC with the combination of DAC (200 nM, $48 \mathrm{hrs})$ and TSA (300 nM, last $24 \mathrm{hrs)} \mathrm{caused} \mathrm{a} \mathrm{marked} \mathrm{increase} \mathrm{in} \mathrm{promoter} \mathrm{histone} \mathrm{acetylation}$ 
Identification of epigenetically silenced genes in tumor endothelial cells

of the genes, correlating with their restored expression. Promoter histone acetylation was also induced by treatment with DAC (200 nM, 72 hrs) or TSA (300 nM, 72 hrs) alone, although for QSCN6 again subtle (Fig. 3.3B). We also examined lysine 4 methylation of histone $\mathrm{H} 3$, another histone modification associated with gene expression. As for histone acetylation, $\mathrm{H} 3$ lysine 4 methylation in the gene promoters was decreased in tumor-conditioned versus quiescent EC, and increased by DAC and/or TSA, correlating with changes in gene expression (Fig. 3.3C). Thus, silencing of the selected genes in tumor-conditioned $\mathrm{EC}$ is associated with promoter histone $\mathrm{H} 3$ deacetylation and loss of $\mathrm{H} 3$ lysine 4 methylation, but not with DNA hypermethylation, and re-expression by DAC and TSA occurs in conjunction with restored histone acetylation and $\mathrm{H} 3$ lysine 4 methylation levels.

\section{Clusterin, fibrillin 1 and quiescin Q6 negatively regulate EC growth and sprouting}

To explore the mechanism by which reactivation of the identified genes by DAC and TSA inhibits angiogenesis, functional validation of the identified genes was performed. Of the 7 genes selected, a role in angiogenesis is already reported for IGFBP3 and ICAM1. IGFBP3 has been described to inhibit VEGF-mediated EC growth $^{33}$ and angiogenesis, ${ }^{34}$ and ICAM1 is an important EC adhesion molecule known to be downregulated in tumor EC by angiogenic factors. ${ }^{35}$ Therefore, we further focused on the genes for which a (clear) role in angiogenesis has not been reported yet. From these 5 genes, we selected clusterin, for which both pro- ${ }^{36}$ and anti- ${ }^{37}$ angiogenic activities have been described, as well as two genes that have not been related to angiogenesis (fibrillin 1 and quiescin Q6). Effects of downregulation of these genes on EC proliferation, migration and sprouting were studied. To that end, human microvascular endothelial cells (HMEC) were transiently transfected with CLU, FBN1, QSCN6 or mock GFP-labeled siRNA constructs, and purified by FACS sorting. After 72 hours, siRNA treatment significantly reduced CLU, FBN1 and QSCN6 mRNA expression when compared to mock-transfected cells (Fig. 3.4A). Proliferation of EC was significantly induced upon downregulation of CLU, FBN1 or QSCN6 $(34 \%, 53 \%$ and $67 \%$ induction by CLU, FBN1 and QSCN6 siRNA, respectively), indicating that these genes inhibit EC growth (Fig. 3.4B). Treatment with CLU siRNA showed a small but significant stimulatory effect on the migration rate of EC $(p<0.05)$, which is in agreement with a previous study, ${ }^{37}$ whereas repression of FBN1 or QSCN6 did not affect EC migration (Fig. 3.4C). Finally, three-dimensional sprouting of EC spheroids in a collagen gel was significantly increased by downregulation of $C L U, F B N 1$ or QSCN6 as compared to mock transfected cells ( $p<0.05$, Fig. $3.4 \mathrm{D})$, indicating that these genes are negative regulators in the process of EC tube formation. Together, these results suggest an inhibitory function for clusterin, fibrillin 1 and quiescin Q6 in EC growth and sprouting, indicating that the angiostatic activities of DNMT- and HDAC inhibitors might be explained by reactivation of angiogenesis-suppressing genes in tumor EC. 
A

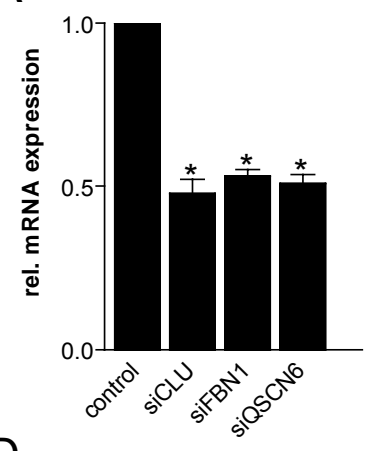

D

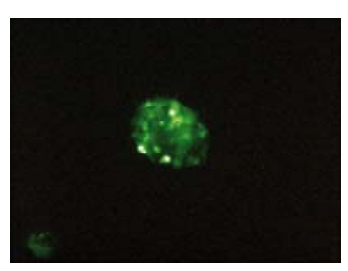

$\mathrm{B}$
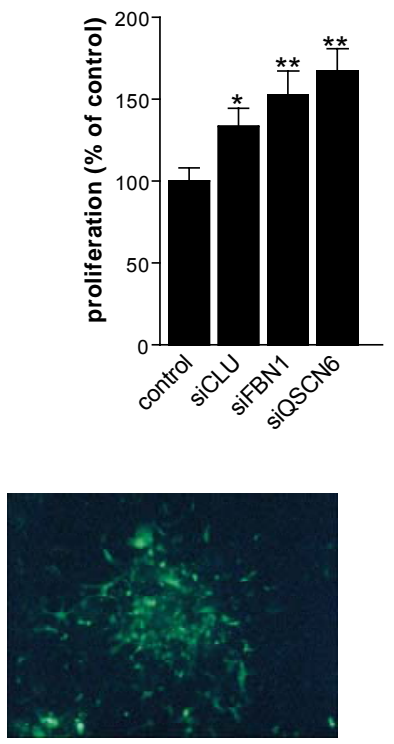

C
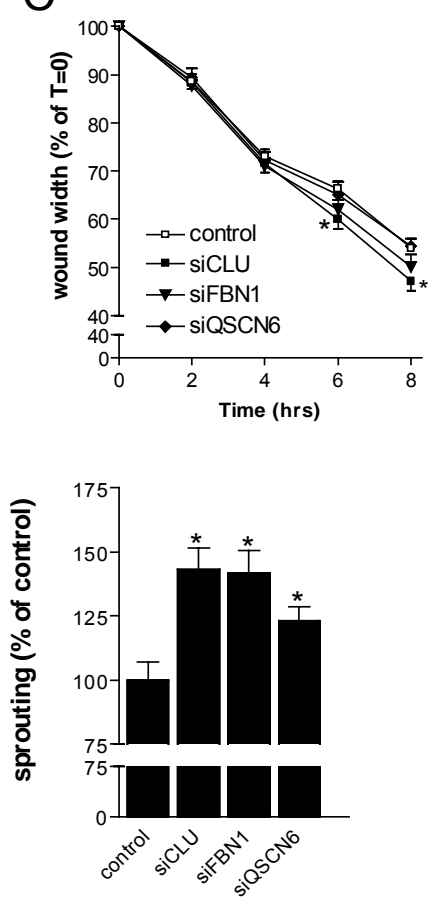

Figure 3.4 Effects of clusterin (CLU), fibrillin 1 (FBN1) and quiescin Q6 (QSCN6) siRNA on EC proliferation, migration and sprouting.

(A) Relative mRNA expression of CLU, FBN1 and QSCN6, determined by quantitative real-time RTPCR, 72 hrs after transfection of human microvascular EC (HMEC) with CLU, FBN1, QSCN6 or mock (control) siRNA constructs. Results are plotted as mean values ( \pm SEM) of 3 independent experiments ( ${ }^{*} p<0.05$ vs control). (B) Relative proliferation of HMEC transfected with CLU, FBN1, QSCN6 or mock (control) siRNA constructs. Results are plotted as mean values $( \pm$ SEM) of 3 independent experiments ( ${ }^{*} p<0.05,{ }^{* *} p<0.01$ vs control). (C) Relative wound width of HMEC monolayers transfected with $C L U$, FBN1, QSCN6 or mock (control) siRNA constructs. Results are plotted as mean values ( \pm SEM) of 3 independent experiments $\left({ }^{*} p<0.05\right.$ vs control). (D) Spheroid of HMECs before (left photograph) and after (right photograph) sprouting into a collagen matrix induced by bFGF and VEGF. Tube formation was quantified by taking the relative increase in diameters (measured in two directions) of the spheroids transfected with CLU, FBN1, QSCN6 or mock (control) siRNA constructs. Results are plotted as mean values $\left( \pm\right.$ SEM) of 3 independent experiments $\left({ }^{*} p<0.05\right.$ vs control).

\section{Discussion}

DNA methyltransferase (DNMT)- and histone deacetylase (HDAC) inhibitors induce growth arrest and apoptosis of tumor cells, which is considered to be due to reactivation of epigenetically silenced tumor suppressor genes. ${ }^{11,38,39}$ Recently, we ${ }^{21}$ and others ${ }^{22,23}$ found that DNMT- and HDAC inhibitors are also potent angiostatic agents, inhibiting endothelial cell (EC) growth and angiogenesis in vitro and in vivo. However, very little is known on the mechanisms behind the direct angiostatic effects of these compounds. In addition, in contrast to the extensive knowledge on epigenetic aberrations in tumor cells, there is almost nothing known about the role of epigenetics 
Identification of epigenetically silenced genes in tumor endothelial cells

in regulation of gene expression in EC during (tumor) angiogenesis. Some studies associated the angiostatic effects of HDAC inhibitors with down-regulation of angiogenesis-related genes in EC. ${ }^{23,40-42}$ However, these studies did not investigate the direct effects of these compounds on EC gene expression, i.e. increased promoter histone acetylation and thus transcriptional activation of EC genes. Furthermore, effects of HDAC inhibitors were not related with epigenetic promoter modifications of EC genes in these studies.

To identify the mechanism behind the direct inhibition of EC growth and angiogenesis by DNMT- and HDAC inhibitors, we performed a comprehensive screen for genes reactivated by these compounds in tumor-conditioned EC. We combined gene expression microarrays with pharmacologic inhibition of DNMT- and HDAC activity to identify genes that are epigenetically repressed in tumor EC, as has been previously performed in tumor cells. ${ }^{14,15,18,20}$ This strategy provided a preliminary mechanism for the direct angiostatic effects of DNMT- and HDAC inhibitors and revealed more insight into the epigenetic regulation of tumor angiogenesis. In addition, novel angiogenesis-regulating genes were identified, increasing our knowledge into the transcriptional responses of EC when exposed to angiogenic growth factors.

Interestingly, microarray analysis revealed a significant overrepresentation of promoter CpG island-containing genes and identified many genes described to be hypermethylated in tumor cells, suggesting that many of the identified genes can be methylated. However, genomic bisulfite sequencing data suggested that silencing of these genes in tumor-conditioned EC occurs without promoter DNA methylation. Five of the genes analyzed by bisulfite sequencing, i.e. ICAM1, IGFBP3, FBN1, TSPAN2 and QSCN6, are described to be silenced in tumor cells by promoter hypermethylation (ICAM1, IGFBP3, FBN1, TSPAN2) at CpGs within the area we analysed, and histone deacetylation (QSCN6). ${ }^{43-46}$ In addition, clusterin (CLU) expression in HRAStransformed rat fibroblasts is regulated by promoter DNA hypermethylation. ${ }^{31}$ Our bisulfite sequencing results might be explained by the presence of very low methylation levels in EC, in which case the number of clones sequenced may not be sufficient to detect this. However, methylation in only few clones would not be able to explain the major loss of expression observed for these genes in tumor-conditioned EC. In addition, promoter methylation of some genes was analyzed by methylationspecific PCR (MSP), which is a more sensitive but less comprehensive technique to study DNA methylation. Yet, this approach also did not identify methylation of the examined genes. Another possibility is that DNA methylation might occur in enhancers or other transcription regulatory sequences located outside the examined region. For example, hypermethylation of CLU was reported within the promoter, but also within a $\mathrm{CpG}$ island $14.5 \mathrm{~kb}$ upstream of the gene. ${ }^{31}$ Furthermore, methylation of upstream (transcription) factors might be indirectly responsible for gene silencing. In addition, the sensitivity of the microarray is an important issue, which might not be high enough to identify methylated genes but instead might be identifying genes with altered histone modifications only.

In contrast to promoter DNA methylation, promoter histone $\mathrm{H} 3$ acetylation and $\mathrm{H} 3$ lysine 4 methylation patterns of the genes examined correlated with changes in gene expression. These data demonstrated that silencing of genes in tumor EC during angiogenesis occurs in association with promoter histone modifications and not DNA 
methylation. Furthermore, DNMT- and HDAC inhibitors reactivated these genes by reversal of promoter histone modifications. Several studies suggest that CpG methylation is not a primary cause of inactivation of transcription, but maintains longterm silencing of genes that have already been switched off by other mechanisms. ${ }^{47-50}$ In contrast, histone deacetylation and loss of $\mathrm{H} 3$ lysine 4 methylation are more dynamic epigenetic modifications which are suggested to be more initial events in gene silencing. It is tempting to speculate that downregulation of (growth) inhibiting genes in tumor-conditioned EC by promoter histone modifications is a reversible phenomenon, while many of these genes can be maintained in a permanently silent state in tumor cells by promoter DNA hypermethylation after initial silencing by histone modifications. In relation to this, it is possible that culturing HUVEC for 6 days with angiogenic growth factors is not sufficient to induce irreversible gene silencing by promoter DNA methylation. Therefore, we examined promoter methylation of one gene (ICAM1) in the HMEC cell line, as well as in microdissected tumor EC, but no increase in the amount of methylated CpGs was observed (data not shown).

Despite absence of promoter DNA hypermethylation, the DNMT inhibitor DAC reactivated genes in tumor-conditioned EC in correlation with increased promoter histone acetylation and $\mathrm{H} 3$ lysine 4 methylation. Reactivation of unmethylated genes by DAC in association with increased histone acetylation and/or $\mathrm{H} 3$ lysine 4 methylation has also been described in tumor cells. ${ }^{51-54}$ This might be attributed to the fact that apart from their methylation ability, DNMTs have additional roles in gene silencing. These enzymes exhibit methylation-independent transcription repressor functions by acting as transcriptional repressors themselves, or by serving as binding scaffolds for histone methyltransferase ${ }^{55,56}$ and HDACs. ${ }^{54,57,58}$ By trapping DNMTs, DAC inhibits both the methylation-dependent as well as the methylation-independent activities of these enzymes. The latter results in reactivation of genes, through removal of DNMT- associated histone modifications.

When comparing relative induction of gene expression by treatment with DAC or TSA separately with the combined treatment, no additive or synergistic effect was observed. Furthermore, most genes showed greater relative induction by TSA than by DAC. Only for the imprinted genes NNAT and DMD, relative induction by DAC was greater than by TSA, which may be due to methylation of these genes at the DNA level. These data suggest that silencing of our candidate genes is predominantly an HDAC-dependent mechanism. In contrast, microarray analysis of the colorectal cancer cell line RKO treated with DAC and TSA identified a group of genes which was unaffected by TSA, upregulated by DAC, and stronger induced by the combination treatment, and a second group which was upregulated by TSA with variable response to DAC. ${ }^{14}$ This was explained by the presence of promoter hypermethylation in the colorectal cancer cell line in the first group of genes and its absence in the second group. In comparison, most of the genes in this study meet the criteria of upregulation by TSA with a variable response to DAC in tumor-conditioned EC, which is reflected by the absence of promoter DNA hypermethylation. A difference between this study and the RKO microarray, however, is that in the latter an initial CDNA subtraction step between mock- treated and DAC- and TSA-treated RKO cells was performed to increase the screening sensitivity. 
Identification of epigenetically silenced genes in tumor endothelial cells

This study identified novel genes functionally involved in angiogenesis. Functional validation revealed that downregulation of clusterin, fibrillin 1 and quiescin Q6 stimulates growth and sprouting of EC, whereas repression of clusterin also increases EC migration. Our findings suggest that clusterin, fibrillin 1 and quiescin Q6 negatively regulate angiogenesis. QSCN6 is proposed to be involved in negative regulation of cell and tissue growth though the exact function is not yet known. ${ }^{59}$ Clusterin is a widely expressed glycoprotein that has been reported to have both pro- and antiapoptotic functions ${ }^{60,61}$ as well as pro- and anti-angiogenic effects, ${ }^{36,37}$ which can be explained by functional differences in the various isoforms of the protein and that the function might be context dependent. ${ }^{62}$ Fibrillin 1 , a calcium binding glycoprotein, is a main structural component of microfibrils situated in the extracellular matrix of connective tissue.$^{63}$ Deposition of fibrillin by EC is required for vessel maturation and EC functioning, ${ }^{64,65}$ and thus can be seen as a characteristic of differentiated EC.

The doses of DAC and TSA used in this study do not induce apoptosis of EC, as we described previously. ${ }^{21}$ Therefore it is not likely that the toxicity of these compounds is a major cause of gene induction in our microarray. Furthermore, the identification of a significantly high percentage of genes containing promoter CpG islands, and of many genes which have been described to be epigenetically silenced in tumor cells, suggests that we selected for genes prone to silencing by DNMTand/or HDAC- dependent epigenetic modifications.

In conclusion, this is the first study describing a comprehensive screen for genes reactivated by DNMT- and HDAC inhibitors in tumor-conditioned EC. We identify novel angiogenesis-regulating genes that are downregulated in activated EC by promoter histone modifications, and reactivated by DAC and TSA through reversal of epigenetic promoter modifications. Our findings provide a preliminary mechanism for the direct angiostatic effects of DNMT- and HDAC inhibitors. Furthermore, this study partly unravels the epigenetic regulation of EC gene expression during (tumor) angiogenesis. The identification of novel EC genes with angiogenesis suppressing activities gives more insight into the biology of (tumor) angiogenesis. Our findings increase our understanding in and help in the future design of epigenetic anti-cancer therapy.

\section{Acknowledgements}

We thank Edith van der Linden and Loes van Eijk for assistance with cell culture, and Mat Rousch for FACS sorting. 


\section{References}

1. Folkman J. Fundamental concepts of the angiogenic process. Curr Mol Med. 2003;3:643651.

2. $\quad$ Carmeliet P. Angiogenesis in life, disease and medicine. Nature. 2005;438:932-936

3. St Croix B, Rago C, Velculescu V, et al. Genes expressed in human tumor endothelium. Science. 2000;289:1197-1202.

4. Bicknell R, Harris AL. Novel angiogenic signaling pathways and vascular targets. Annu Rev Pharmacol Toxicol. 2004;44:219-238.

5. van Beijnum J, Dings RP, van der Linden E, et al. Gene expression of tumor angiogenesis dissected; specific targeting of colon cancer angiogenic vasculature. Blood. 2006

6. Strahl BD, Allis CD. The language of covalent histone modifications. Nature. 2000;403:4145.

7. Bird A. DNA methylation patterns and epigenetic memory. Genes Dev. 2002;16:6-21

8. Jenuwein T, Allis CD. Translating the histone code. Science. 2001;293:1074-1080.

9. Jaenisch $\mathrm{R}$, Bird A. Epigenetic regulation of gene expression: how the genome integrates intrinsic and environmental signals. Nat Genet. 2003;33 Suppl:245-254

10. Baylin SB, Ohm JE. Epigenetic gene silencing in cancer - a mechanism for early oncogenic pathway addiction? Nat Rev Cancer. 2006;6:107-116.

11. Herman JG, Baylin SB. Gene silencing in cancer in association with promoter hypermethylation. N Engl J Med. 2003;349:2042-2054.

12. Cameron EE, Bachman KE, Myohanen S, Herman JG, Baylin SB. Synergy of demethylation and histone deacetylase inhibition in the re-expression of genes silenced in cancer. Nat Genet. 1999;21:103-107.

13. Yoo CB, Jones PA. Epigenetic therapy of cancer: past, present and future. Nat Rev Drug Discov. 2006;5:37-50.

14. Suzuki H, Gabrielson E, Chen W, et al. A genomic screen for genes upregulated by demethylation and histone deacetylase inhibition in human colorectal cancer. Nat Genet. 2002;31:141-149.

15. Yamashita K, Upadhyay S, Osada M, et al. Pharmacologic unmasking of epigenetically silenced tumor suppressor genes in esophageal squamous cell carcinoma. Cancer Cell. 2002;2:485-495.

16. Karpf AR, Peterson PW, Rawlins JT, et al. Inhibition of DNA methyltransferase stimulates the expression of signal transducer and activator of transcription 1, 2, and 3 genes in colon tumor cells. Proc Natl Acad Sci U S A. 1999;96:14007-14012.

17. Liang G, Gonzales FA, Jones PA, Orntoft TF, Thykjaer T. Analysis of gene induction in human fibroblasts and bladder cancer cells exposed to the methylation inhibitor 5-aza-2'deoxycytidine. Cancer Res. 2002;62:961-966.

18. Sato N, Fukushima N, Maitra A, et al. Discovery of novel targets for aberrant methylation in pancreatic carcinoma using high-throughput microarrays. Cancer Res. 2003;63:3735-3742.

19. Pompeia C, Hodge DR, Plass C, et al. Microarray analysis of epigenetic silencing of gene expression in the KAS-6/1 multiple myeloma cell line. Cancer Res. 2004;64:3465-3473.

20. Lodygin D, Epanchintsev A, Menssen A, Diebold J, Hermeking H. Functional epigenomics identifies genes frequently silenced in prostate cancer. Cancer Res. 2005;65:4218-4227.

21. Hellebrekers DM, Jair KW, Vire E, et al. Angiostatic activity of DNA methyltransferase inhibitors. Mol Cancer Ther. 2006;5:467-475.

22. Kim MS, Kwon HJ, Lee YM, et al. Histone deacetylases induce angiogenesis by negative regulation of tumor suppressor genes. Nat Med. 2001;7:437-443.

23. Deroanne CF, Bonjean K, Servotte $S$, et al. Histone deacetylases inhibitors as antiangiogenic agents altering vascular endothelial growth factor signaling. Oncogene. 2002;21:427-436. 
24. van der Schaft DW, Toebes EA, Haseman JR, Mayo KH, Griffioen AW. Bactericidal/permeability-increasing protein (BPI) inhibits angiogenesis via induction of apoptosis in vascular endothelial cells. Blood. 2000;96:176-181.

25. Thijssen VL, Brandwijk RJ, Dings RP, Griffioen AW. Angiogenesis gene expression profiling in xenograft models to study cellular interactions. Exp Cell Res. 2004;299:286-293.

26. Herman JG, Graff JR, Myohanen S, Nelkin BD, Baylin SB. Methylation-specific PCR: a novel PCR assay for methylation status of $\mathrm{CpG}$ islands. Proc Natl Acad Sci $U S A$. 1996;93:9821-9826.

27. Metivier R, Penot G, Hubner MR, et al. Estrogen receptor-alpha directs ordered, cyclical, and combinatorial recruitment of cofactors on a natural target promoter. Cell. 2003;115:751763.

28. van der Schaft DW, Dings RP, de Lussanet QG, et al. The designer anti-angiogenic peptide anginex targets tumor endothelial cells and inhibits tumor growth in animal models. FASEB J. 2002;16:1991-1993.

29. Gardiner-Garden M, Frommer M. CpG islands in vertebrate genomes. J Mol Biol. 1987;196:261-282.

30. Cross SH, Charlton JA, Nan X, Bird AP. Purification of CpG islands using a methylated DNA binding column. Nat Genet. 1994;6:236-244

31. Lund $\mathrm{P}$, Weisshaupt K, Mikeska T, et al. Oncogenic HRAS suppresses clusterin expression through promoter hypermethylation. Oncogene. 2006.

32. Chan GC, Fish JE, Mawji IA, Leung DD, Rachlis AC, Marsden PA. Epigenetic basis for the transcriptional hyporesponsiveness of the human inducible nitric oxide synthase gene in vascular endothelial cells. J Immunol. 2005;175:3846-3861.

33. Franklin SL, Ferry RJ, Jr., Cohen P. Rapid insulin-like growth factor (IGF)-independent effects of IGF binding protein-3 on endothelial cell survival. J Clin Endocrinol Metab. 2003;88:900-907.

34. Iwatsuki K, Tanaka K, Kaneko T, et al. Runx1 promotes angiogenesis by downregulation of insulin-like growth factor-binding protein-3. Oncogene. 2004

35. Griffioen AW, Damen CA, Martinotti S, Blijham GH, Groenewegen G. Endothelial intercellular adhesion molecule-1 expression is suppressed in human malignancies: the role of angiogenic factors. Cancer Res. 1996;56:1111-1117.

36. Jackson JK, Gleave ME, Gleave J, Burt HM. The inhibition of angiogenesis by antisense oligonucleotides to clusterin. Angiogenesis. 2005;8:229-238.

37. Sivamurthy N, Stone DH, LoGerfo FW, Quist WC. Apolipoprotein J inhibits the migration and adhesion of endothelial cells. Surgery. 2001;130:204-209.

38. Bender CM, Pao MM, Jones PA. Inhibition of DNA methylation by 5-aza-2'-deoxycytidine suppresses the growth of human tumor cell lines. Cancer Res. 1998;58:95-101.

39. Marks PA, Richon VM, Kelly WK, Chiao JH, Miller T. Histone deacetylase inhibitors: development as cancer therapy. Novartis Found Symp. 2004;259:269-281; discussion 281 268.

40. Qian DZ, Wang X, Kachhap SK, et al. The histone deacetylase inhibitor NVP-LAQ824 inhibits angiogenesis and has a greater antitumor effect in combination with the vascular endothelial growth factor receptor tyrosine kinase inhibitor PTK787/ZK222584. Cancer Res. 2004;64:6626-6634.

41. Qian DZ, Kato Y, Shabbeer S, et al. Targeting tumor angiogenesis with histone deacetylase inhibitors: the hydroxamic acid derivative LBH589. Clin Cancer Res. 2006;12:634-642.

42. Rossig L, Li H, Fisslthaler B, et al. Inhibitors of histone deacetylation downregulate the expression of endothelial nitric oxide synthase and compromise endothelial cell function in vasorelaxation and angiogenesis. Circ Res. 2002;91:837-844.

43. Friedrich MG, Chandrasoma S, Siegmund KD, et al. Prognostic relevance of methylation markers in patients with non-muscle invasive bladder carcinoma. Eur J Cancer. 2005;41:2769-2778. 
44. Chang YS, Wang L, Liu D, et al. Correlation between insulin-like growth factor-binding protein-3 promoter methylation and prognosis of patients with stage I non-small cell lung cancer. Clin Cancer Res. 2002;8:3669-3675.

45. Miyamoto K, Fukutomi T, Akashi-Tanaka S, et al. Identification of 20 genes aberrantly methylated in human breast cancers. Int J Cancer. 2005;116:407-414.

46. Chiba T, Yokosuka O, Fukai K, et al. Cell growth inhibition and gene expression induced by the histone deacetylase inhibitor, trichostatin A, on human hepatoma cells. Oncology. 2004;66:481-491.

47. Tamaru $\mathrm{H}$, Selker EU. A histone $\mathrm{H} 3$ methyltransferase controls DNA methylation in Neurospora crassa. Nature. 2001;414:277-283.

48. Bachman KE, Park BH, Rhee I, et al. Histone modifications and silencing prior to DNA methylation of a tumor suppressor gene. Cancer Cell. 2003;3:89-95.

49. Bird A. Molecular biology. Methylation talk between histones and DNA. Science. 2001;294:2113-2115.

50. Mutskov V, Felsenfeld G. Silencing of transgene transcription precedes methylation of promoter DNA and histone H3 lysine 9. Embo J. 2004;23:138-149.

51. Nguyen CT, Weisenberger DJ, Velicescu M, et al. Histone H3-lysine 9 methylation is associated with aberrant gene silencing in cancer cells and is rapidly reversed by 5 -aza-2'deoxycytidine. Cancer Res. 2002;62:6456-6461.

52. Schmelz K, Sattler N, Wagner M, Lubbert M, Dorken B, Tamm I. Induction of gene expression by 5 -Aza-2'-deoxycytidine in acute myeloid leukemia (AML) and myelodysplastic syndrome (MDS) but not epithelial cells by DNA-methylation-dependent and -independent mechanisms. Leukemia. 2005;19:103-111.

53. Takebayashi S, Nakao M, Fujita N, et al. 5-Aza-2'-deoxycytidine induces histone hyperacetylation of mouse centromeric heterochromatin by a mechanism independent of DNA demethylation. Biochem Biophys Res Commun. 2001;288:921-926.

54. Fuks F, Burgers WA, Brehm A, Hughes-Davies L, Kouzarides T. DNA methyltransferase Dnmt1 associates with histone deacetylase activity. Nat Genet. 2000;24:88-91.

55. Lehnertz B, Ueda Y, Derijck AA, et al. Suv39h-mediated histone H3 lysine 9 methylation directs DNA methylation to major satellite repeats at pericentric heterochromatin. Curr Biol. 2003;13:1192-1200.

56. Fuks F, Hurd PJ, Deplus R, Kouzarides T. The DNA methyltransferases associate with HP1 and the SUV39H1 histone methyltransferase. Nucleic Acids Res. 2003;31:2305-2312.

57. Robertson KD, Ait-Si-Ali S, Yokochi T, Wade PA, Jones PL, Wolffe AP. DNMT1 forms a complex with Rb, E2F1 and HDAC1 and represses transcription from E2F-responsive promoters. Nat Genet. 2000;25:338-342.

58. Rountree MR, Bachman KE, Baylin SB. DNMT1 binds HDAC2 and a new co-repressor, DMAP1, to form a complex at replication foci. Nat Genet. 2000;25:269-277.

59. Coppock DL, Cina-Poppe D, Gilleran S. The quiescin Q6 gene (QSCN6) is a fusion of two ancient gene families: thioredoxin and ERV1. Genomics. 1998;54:460-468.

60. Chen T, Turner J, McCarthy S, Scaltriti M, Bettuzzi S, Yeatman TJ. Clusterin-mediated apoptosis is regulated by adenomatous polyposis coli and is p21 dependent but p53 independent. Cancer Res. 2004;64:7412-7419.

61. Zhang H, Kim JK, Edwards CA, Xu Z, Taichman R, Wang CY. Clusterin inhibits apoptosis by interacting with activated Bax. Nat Cell Biol. 2005;7:909-915.

62. Leskov KS, Klokov DY, Li J, Kinsella TJ, Boothman DA. Synthesis and functional analyses of nuclear clusterin, a cell death protein. J Biol Chem. 2003;278:11590-11600.

63. Handford PA. Fibrillin-1, a calcium binding protein of extracellular matrix. Biochim Biophys Acta. 2000;1498:84-90.

64. Carta L, Pereira L, Arteaga-Solis E, et al. Fibrillins 1 and 2 perform partially overlapping functions during aortic development. J Biol Chem. 2006;281:8016-8023.

65. Wilson DG, Bellamy MF, Ramsey MW, et al. Endothelial function in Marfan syndrome: selective impairment of flow-mediated vasodilation. Circulation. 1999;99:909-915. 


\section{Supporting Methods}

\section{Chromatin immunoprecipitation (ChIP) Assay}

Chromatin immunoprecipitation (ChIP) assays were performed essentially as described $^{1}$ using anti-acetyl-Histone H3 (Lys 9 and Lys 14), or anti-trimethyl-Histone H3 (Lys 4) antibody (both from Upstate Biotechnology, Lake Placid, New York). One primer set for GAPDH was used to amplify a 128-bp fragment of the genomic sequence to serve as an internal control. ${ }^{2}$ All PCR reactions were optimized with input DNA to ensure that PCR products were in the linear range of amplification. Primer sequences are listed in Supporting Table 3.3. PCR products were size-separated by agarose gel electrophoresis and bands were quantified using Molecular Analyst 2.1 software. Enrichment was calculated by taking the ratio between the net intensity of the candidate gene PCR product and the net intensity of the GAPDH PCR product for the bound sample and dividing this by the same ratio calculated for the input samples. $^{2}$

1. Metivier R, Penot G, Hubner MR, et al., Estrogen receptor-alpha directs ordered, cyclical, and combinatorial recruitment of cofactors on a natural target promoter. Cell, 2003;115:751763.

2. Fahrner JA, Eguchi S, Herman JG, Baylin SB, Dependence of histone modifications and gene expression on DNA hypermethylation in cancer. Cancer Res, 2002;62:7213-7218. 


\section{Supporting Tables}

\begin{tabular}{|c|c|c|}
\hline \multicolumn{3}{|c|}{ Supporting Table 3.1. Quantitative real-time RT-PCR primers } \\
\hline Gene & Forward (5'-> 3') & Reverse (5'->3') \\
\hline$\overline{\mathrm{CLU}}$ & CAGCAGGCCATGGACATC & ATCTCCCGGCACACAGTC \\
\hline SMTN & GCACACAGGCTGGAACAG & GATGTGCTCCCAGGTGG \\
\hline NPPB & CATCTGGCTTTCCTGGG & ATGGTTGCGCTGCTCC \\
\hline CXCL6 & ACGCTGAGAGTAAACCCCAAAA & TTCTTCAGGGAGGCTACCACTT \\
\hline ICAM1 & GGCCGGCCAGCTTATACAC & TAGACACTTGAGCTCGGGCA \\
\hline G1P3 & TCGCTGATGAGCTGGTCTG & TGACGACGCTGCTGCC \\
\hline IGFBP3 & CTGTGGCCATGACTGAGGAAAG & TCCCTGAGCCTGACTTTGCC \\
\hline SDC4 & GCTGTCTGGCTCTGGAGATC & CTTGGCTCCCAGACCCTG \\
\hline FBN1 & CCTGTGCTGGTGGTGAGTG & ACACTCATCAATGTCTCGGC \\
\hline TSPAN2 & CTGCTGAAGTAACCACTGGAG & TTAAGGTAATCATTGTAAGCCTC \\
\hline FABP4 & ATCAACCACCATAAAGAGAAAACG & TGCTCTCTCATAAACTCTCGTG \\
\hline IL8 & TTGCCAAGGCGTGCTAAAGAAC & TGTGTTGGCGCAGTGTGGTC \\
\hline INHBA & GGCAGTGACCTGTCAGTGG & GTGCTTCTGCTGCTGGAA \\
\hline SERPINE2 & GTCGAGGCCTCATGACAAC & CGAGCTGCTTCTTGGTCC \\
\hline NNAT & TGGAACCATGGCGGC & GAACACCTGCAGCAGCAC \\
\hline ITGA3 & TGAGGTCCAGTTCCAGAAGG & CGGACGTCTCTGCTGTACTG \\
\hline DMD & GCTCTGGAGTGAGTCTGTCAT & AAGAACACAACACGAAATAATG \\
\hline TNFRSF21 & CATACGGTGTGTCCTGTGGG & ACACTAGAAGGCACATCTGAGAAG \\
\hline NDRG4 & CCTGAGGAGAAGCCGCTG & ATGTCATGTTCCTTCCAGTCTGT \\
\hline CNN1 & CCATACACAGGTGCAGTCCAC & CGCCСTTCTCTTAGCTTCC \\
\hline CSPG2 & САTСTCACCTATACGTGCAAG & TCATAACGAGGTTTCATCTTTC \\
\hline USF1 & TGATGATGCAGTTGACACGG & AGTAACAACAGCAGCTGTACTCC \\
\hline CPE & CCTGGATAGGATAGTGTACGTG & CTCAGGAGCAAGCTTTGTG \\
\hline IL6 & GCCACTCACСТСTTCAGAACGA & GCCTCTTTGCTGCTTTCACAC \\
\hline QSCN6 & TGCAGAGACTCTCTGGGCTC & TCCAGGTCAGCCATGTAGATC \\
\hline CLIPR-59 & TCAGCCCTGCACATCGC & TCCGCCGGCACCTGT \\
\hline IGSF4 & TGATGATCGATATCCAGAGAGAC & CTTTGAACCACCTGATAGTCG \\
\hline MCM7 & GTTGGTAACTGTGCGTGGAATC & ATCGGCTGGTAGGTCTCTGC \\
\hline DKK3 & GGAGCTAGAGCCTGATGGAG & CACGAAGGTCGGCTTGC \\
\hline Cyclophilin A & CTCGAATAAGTTTGACTTGTGTTT & CTAGGCATGGGAGGGAACA \\
\hline
\end{tabular}


Identification of epigenetically silenced genes in tumor endothelial cells

\begin{tabular}{lll}
\hline \multicolumn{2}{l}{ Supporting Table 3.2 . Bisulfite sequencing primers } \\
\hline Gene & Forward (5'-> 3') & Reverse (5'->3') \\
\hline CLU & GTTTTGGATTGGGATAGATAG & CTAACTACAAACCTACATAACTCAC \\
ICAM1 & & \\
$(-1247 ;-873)$ & GTTTTTGGATGGTTAGTGATT & AAAACTAAAACAACAACCCCC \\
$(-893 ;-489)$ & GGGGGTTGTTGTTTAGTTT & CCTCCACTAAAAATACCCCT \\
$(-583 ;-300)$ & GAGGTGTTTGGTTTTGTTTTGG & TTTTAAATACTACCAACTTCCCC \\
$(-322 ;-17)$ & GGGGAAGTTGGTAGTATTTAAA & CTAACCACCTAAAAACCAAAA \\
IGFBP3 & & \\
$(-251 ;-29)$ & GGGTATATTTTGGTTTTTGTAGA & AAAAACCRAAATAACCCAAAACAC \\
$(-53 ;+189)$ & GTGTTTTGGGTATTTYGGTT & AAACAACACCAACAAAATCAAC \\
$(+167 ;+602)$ & GTTGATTTTGTTGGTTTGTTT & CAACAACCCCCAAACCCTTC \\
FBN1 & TTTGTGTTGTAGTTGGTAGGGG & TTCCCAACCTCCAAATTAAC \\
TSPAN2 & GTTTATTGGAGGGAAGGAAG & CAAACAACAAATACTTAATACACC \\
TNFRSF21 & AAGTTAGATTAGGAGTGAGATGTT & CTTCCAACCACTACCAACC \\
QSCN6 & GGGGTTTGAGGYGGGATT & CTATTACACCTCCTCATCCTC \\
\hline
\end{tabular}

\begin{tabular}{lll}
\hline \multicolumn{3}{l}{ Supporting Table 3.3. ChIP primers } \\
\hline Gene & Forward (5'-> 3') & \\
\hline CLU & AGTTCAGGCTCTTCCCTACTG & Reverse (5'->3') \\
ICAM1 & TGGAGGCCGGGAGCCGGGAGG \\
IGFBP3 & CCAGATGCGAGCACTGGCG & AAACCTCGCGCCTTCCCC \\
FBN1 & AGGCTTCAGCATCCCGAT & CATGACGCCTGCAACCG \\
TSPAN2 & CACTGGAGGGAAGGAAGGTG & CGTGGACCCCAACCAGG \\
TNFRSF21 & CCTCAGCGAACGCCAAG & GGTCGGCGAGGGACTG \\
QSCN6 & CCCTGCAACAAGCTCAGC & CAAGGAGGAGCCACGTGG \\
GAPDH & CAGAGACTGGCTCTTAAAAAGTGC & GTCCACCACCCTGTTGCTGTA \\
\hline
\end{tabular}

\begin{tabular}{|c|c|}
\hline Suppo & g Table 3.4. siRNA sequences \\
\hline Gene & F: Forward (5'-> 3'), R: Reverse (5'->3') \\
\hline CLU & $\begin{array}{l}\mathrm{F} \text { GATCCCGGAAGTAAGTACGTCAATAAGTTGATAT } \\
\text { CCGCTTATTGACGTACTTACTTCCTTTTTTCCAAA }\end{array}$ \\
\hline & R AGCTTTTGGAAAAAAGGAAGTAAGTACGTCAATA \\
\hline & R AGCGGATATCAACTTATTGACGTACTTACTTCCGG \\
\hline & G GATCCCGTGGATTGGAGATGGCATTAATTCAAGA \\
\hline $\mathrm{FBN1}$ & F GATTAATGCCATCTCCAATCCACTTTTTTGGAAA \\
\hline & AGCTTTTCCAAAAAAGTGGATTGGAGATGGCATT \\
\hline & R AATCTCTTGAATTAATGCCATCTCCAATCCACGG \\
\hline & GATCCCGTTGATGGATTCTTTGCGAGAATTCAAG \\
\hline QSCNG & F AGATTCTCGCAAAGAATCCATCAATTTTTTGGAAA \\
\hline & R AGCTTTTCCAAAAAATTGATGGATTCTTTGCGAGA \\
\hline & R ATCTCTTGAATTCTCGCAAAGAATCCATCAACGG \\
\hline
\end{tabular}




\begin{tabular}{|c|c|c|}
\hline \multicolumn{3}{|c|}{$\begin{array}{l}\text { Supporting Table } 3.5 \text {. Genes described to be epigenetically silenced in tumor } \\
\text { cells }\end{array}$} \\
\hline Gene name & Symbol & Ref \\
\hline \multirow{5}{*}{$\begin{array}{l}\text { Intercellular adhesion molecule } 1 \\
\text { insulin-like growth factor binding protein } 3\end{array}$} & ICAM1 & Friedrich et al. $^{\top}$ \\
\hline & IGFBP3 & Chang et al. ${ }^{2}$, \\
\hline & & Hanafusa et al. ${ }^{3}$ \\
\hline & & Chang et al. ${ }^{4}$ \\
\hline & & Fraga et al. ${ }^{5}$ \\
\hline \multirow[t]{2}{*}{ fibrillin 1} & FBN1 & Wang et al. ${ }^{*} 6$ \\
\hline & & Wang et al. ${ }^{* 7}$ \\
\hline syndecan 4 & SDC4 & Toyota et al. ${ }^{8}$ \\
\hline tetraspanin 2 & TSPAN2 & Miyamoto et al. ${ }^{9}$ \\
\hline brain-derived neurotrophic factor & BDNF & Yamashita et al. $^{10}$ \\
\hline neuronatin & NNAT & Kuerbitz et al. ${ }^{11}$ \\
\hline FAT tumor suppressor (Drosophila) homolog 1 & FAT & Paz et al. ${ }^{12}$ \\
\hline calponin 1 , basic, smooth muscle & CNN1 & Yamamura et al. ${ }^{13}$ \\
\hline chondroitin sulfate proteoglycan 2 & CSPG2 & Toyota et al. ${ }^{14}$ \\
\hline insulin-like growth factor binding protein 7 & IGFBP7 & Yamashita et al. ${ }^{10}$ \\
\hline interleukin 6 & IL6 & Armenante et al. ${ }^{15}$ \\
\hline quiescin Q6 & QSCN6 & Chiba et al. ${ }^{16}$ \\
\hline insulin-like growth factor 2 receptor & IGF2R & Huang et al. ${ }^{17}$ \\
\hline \multirow[t]{9}{*}{ immunoglobulin superfamily, member 4} & IGSF4 & Kuramochi et al. ${ }^{18}$ \\
\hline & & Jansen et al. ${ }^{19}$ \\
\hline & & Ito et al. ${ }^{20}$ \\
\hline & & Hui et al. ${ }^{21}$ \\
\hline & & Steenbergen et al. ${ }^{22}$ \\
\hline & & Li et al. ${ }^{23}$ \\
\hline & & Zhang et al. ${ }^{24}$ \\
\hline & & Heller et al. ${ }^{25}$ \\
\hline & & Fukami et al. ${ }^{26}$ \\
\hline \multirow[t]{3}{*}{ growth arrest and DNA-damage-inducible, alpha } & GADD45A & Wang et al. ${ }^{27}$ \\
\hline & & Zerbini et al. $^{28}$ \\
\hline & & Wang et al. ${ }^{6}$ \\
\hline laminin, gamma 2 & LAMC2 & Sathyanarayana et al. ${ }^{29-32}$ \\
\hline \multirow{6}{*}{ cyclin-dependent kinase inhibitor $1 \mathrm{~A}$} & CDKN1A & Allan et al..$^{33}$ \\
\hline & & Chen et al. ${ }^{34}$ \\
\hline & & Roman-Gomez et al. ${ }^{35}$ \\
\hline & & Zhu et al. ${ }^{36}$ \\
\hline & & Yang et al. ${ }^{37}$ \\
\hline & & Bott et al. ${ }^{38}$ \\
\hline \multirow[t]{2}{*}{ cadherin 2, type $1, \mathrm{~N}$-cadherin } & $\mathrm{CDH} 2$ & Hagihara et al. ${ }^{39}$ \\
\hline & & Yamashita et al. $^{10}$ \\
\hline dickkopf homolog 3 & DKK3 & Lodygin et al. $^{40}$ \\
\hline major histocompatibility complex, class I, C & HLA-C & Nie et al. ${ }^{41}$ \\
\hline
\end{tabular}

* Differential methylation of FBN1 between prostate epithelial and cancer cell lines was found by combining methylation-sensitive restriction with a DNA microarray of promoter sequences, but methylation was not validated by genomic bisulfite sequencing or methylation-specific PCR.

1. Friedrich MG, Chandrasoma S, Siegmund KD, et al. Prognostic relevance of methylation markers in patients with non-muscle invasive bladder carcinoma. Eur J Cancer. 2005;41:2769-2778. 

protein-3 promoter methylation and prognosis of patients with stage I non-small cell lung cancer. Clin Cancer Res. 2002;8:3669-3675.

3. Hanafusa T, Yumoto Y, Nouso K, et al. Reduced expression of insulin-like growth factor binding protein-3 and its promoter hypermethylation in human hepatocellular carcinoma. Cancer Lett. 2002;176:149-158.

4. Chang YS, Wang L, Suh YA, et al. Mechanisms underlying lack of insulin-like growth factorbinding protein-3 expression in non-small-cell lung cancer. Oncogene. 2004;23:6569-6580.

5. Fraga MF, Herranz M, Espada J, et al. A mouse skin multistage carcinogenesis model reflects the aberrant DNA methylation patterns of human tumors. Cancer Res. 2004;64:5527-5534.

6. Wang $\mathrm{Y}, \mathrm{Yu} \mathrm{Q}$, Cho $\mathrm{AH}$, et al. Survey of differentially methylated promoters in prostate cancer cell lines. Neoplasia. 2005;7:748-760.

7. Wang Y, Hayakawa J, Long F, et al. "Promoter array" studies identify cohorts of genes directly regulated by methylation, copy number change, or transcription factor binding in human cancer cells. Ann N Y Acad Sci. 2005;1058:162-185.

8. Toyota M, Kopecky KJ, Toyota MO, Jair KW, Willman CL, Issa JP. Methylation profiling in acute myeloid leukemia. Blood. 2001;97:2823-2829.

9. Miyamoto K, Fukutomi T, Akashi-Tanaka S, et al. Identification of 20 genes aberrantly methylated in human breast cancers. Int J Cancer. 2005;116:407-414.

10. Yamashita S, Tsujino Y, Moriguchi K, Tatematsu M, Ushijima T. Chemical genomic screening for methylation-silenced genes in gastric cancer cell lines using 5-aza-2'deoxycytidine treatment and oligonucleotide microarray. Cancer Sci. 2006;97:64-71.

11. Kuerbitz SJ, Pahys J, Wilson A, Compitello N, Gray TA. Hypermethylation of the imprinted NNAT locus occurs frequently in pediatric acute leukemia. Carcinogenesis. 2002;23:559564.

12. Paz MF, Wei S, Cigudosa JC, et al. Genetic unmasking of epigenetically silenced tumor suppressor genes in colon cancer cells deficient in DNA methyltransferases. Hum Mol Genet. 2003;12:2209-2219.

13. Yamamura H, Yoshikawa H, Takahashi K. Aberrant methylation and silencing of the calponin gene in human sarcoma cells. Anticancer Res. 2003;23:107-114.

14. Toyota M, Ho C, Ahuja N, et al. Identification of differentially methylated sequences in colorectal cancer by methylated CpG island amplification. Cancer Res. 1999;59:2307-2312.

15. Armenante F, Merola M, Furia A, Palmieri M. Repression of the IL- 6 gene is associated with hypermethylation. Biochem Biophys Res Commun. 1999;258:644-647.

16. Chiba T, Yokosuka O, Fukai K, et al. Cell growth inhibition and gene expression induced by the histone deacetylase inhibitor, trichostatin $A$, on human hepatoma cells. Oncology. 2004;66:481-491.

17. Huang Z, Wen Y, Shandilya R, Marks JR, Berchuck A, Murphy SK. High throughput detection of M6P/IGF2R intronic hypermethylation and $\mathrm{LOH}$ in ovarian cancer. Nucleic Acids Res. 2006;34:555-563.

18. Kuramochi M, Fukuhara H, Nobukuni T, et al. TSLC1 is a tumor-suppressor gene in human non-small-cell lung cancer. Nat Genet. 2001;27:427-430.

19. Jansen M, Fukushima N, Rosty C, et al. Aberrant methylation of the 5' CpG island of TSLC1 is common in pancreatic ductal adenocarcinoma and is first manifest in high-grade PanINs. Cancer Biol Ther. 2002;1:293-296.

20. Ito T, Shimada Y, Hashimoto $\mathrm{Y}$, et al. Involvement of TSLC1 in progression of esophageal squamous cell carcinoma. Cancer Res. 2003;63:6320-6326.

21. Hui AB, Lo KW, Kwong J, et al. Epigenetic inactivation of TSLC1 gene in nasopharyngeal carcinoma. Mol Carcinog. 2003;38:170-178.

22. Steenbergen RD, Kramer D, Braakhuis BJ, et al. TSLC1 gene silencing in cervical cancer cell lines and cervical neoplasia. J Natl Cancer Inst. 2004;96:294-305.

23. $\mathrm{Li} \mathrm{J}$, Zhang Z, Bidder M, et al. IGSF4 promoter methylation and expression silencing in human cervical cancer. Gynecol Oncol. 2005;96:150-158. 
24. Zhang J, Martins CR, Fansler ZB, et al. DNA methylation in anal intraepithelial lesions and anal squamous cell carcinoma. Clin Cancer Res. 2005;11:6544-6549.

25. Heller G, Fong KM, Girard L, et al. Expression and methylation pattern of TSLC1 cascade genes in lung carcinomas. Oncogene. 2006;25:959-968.

26. Fukami T, Fukuhara $\mathrm{H}$, Kuramochi $\mathrm{M}$, et al. Promoter methylation of the TSLC1 gene in advanced lung tumors and various cancer cell lines. Int J Cancer. 2003;107:53-59.

27. Wang W, Huper G, Guo Y, Murphy SK, Olson JA, Jr., Marks JR. Analysis of methylationsensitive transcriptome identifies GADD45a as a frequently methylated gene in breast cancer. Oncogene. 2005;24:2705-2714.

28. Zerbini LF, Libermann TA. GADD45 deregulation in cancer: frequently methylated tumor suppressors and potential therapeutic targets. Clin Cancer Res. 2005;11:6409-6413.

29. Sathyanarayana UG, Toyooka S, Padar A, et al. Epigenetic inactivation of laminin-5encoding genes in lung cancers. Clin Cancer Res. 2003;9:2665-2672.

30. Sathyanarayana UG, Padar A, Huang CX, et al. Aberrant promoter methylation and silencing of laminin-5-encoding genes in breast carcinoma. Clin Cancer Res. 2003;9:63896394.

31. Sathyanarayana UG, Padar A, Suzuki M, et al. Aberrant promoter methylation of laminin-5encoding genes in prostate cancers and its relationship to clinicopathological features. Clin Cancer Res. 2003;9:6395-6400.

32. Sathyanarayana UG, Maruyama R, Padar A, et al. Molecular detection of noninvasive and invasive bladder tumor tissues and exfoliated cells by aberrant promoter methylation of laminin-5 encoding genes. Cancer Res. 2004;64:1425-1430.

33. Allan LA, Duhig T, Read M, Fried M. The p21(WAF1/CIP1) promoter is methylated in Rat-1 cells: stable restoration of p53-dependent p21(WAF1/CIP1) expression after transfection of a genomic clone containing the p21(WAF1/CIP1) gene. Mol Cell Biol. 2000;20:1291-1298.

34. Chen B, He L, Savell VH, Jenkins JJ, Parham DM. Inhibition of the interferon-gamma/signal transducers and activators of transcription (STAT) pathway by hypermethylation at a STATbinding site in the p21WAF1 promoter region. Cancer Res. 2000;60:3290-3298.

35. Roman-Gomez J, Castillejo JA, Jimenez A, et al. 5' CpG island hypermethylation is associated with transcriptional silencing of the p21(CIP1/WAF1/SDI1) gene and confers poor prognosis in acute lymphoblastic leukemia. Blood. 2002;99:2291-2296.

36. Zhu WG, Srinivasan K, Dai Z, et al. Methylation of adjacent CpG sites affects Sp1/Sp3 binding and activity in the p21(Cip1) promoter. Mol Cell Biol. 2003;23:4056-4065.

37. Yang W, Bancroft L, Augenlicht LH. Methylation in the p21WAF1/cip1 promoter of Apc+/-, p21+/- mice and lack of response to sulindac. Oncogene. 2005;24:2104-2109.

38. Bott SR, Arya M, Kirby RS, Williamson M. p21WAF1/CIP1 gene is inactivated in metastatic prostatic cancer cell lines by promoter methylation. Prostate Cancer Prostatic Dis. 2005;8:321-326.

39. Hagihara A, Miyamoto K, Furuta J, et al. Identification of $275^{\prime} \mathrm{CpG}$ islands aberrantly methylated and 13 genes silenced in human pancreatic cancers. Oncogene. 2004;23:87058710.

40. Lodygin D, Epanchintsev A, Menssen A, Diebold J, Hermeking H. Functional epigenomics identifies genes frequently silenced in prostate cancer. Cancer Res. 2005;65:4218-4227.

41. Nie Y, Yang G, Song Y, et al. DNA hypermethylation is a mechanism for loss of expression of the HLA class I genes in human esophageal squamous cell carcinomas. Carcinogenesis. 2001;22:1615-1623. 


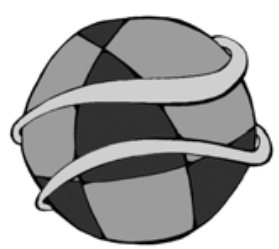

\section{Chapter 4 Epigenetic regulation of tumor endothelial cell anergy; silencing of ICAM-1 by histone modifications}

Debby M.E.I. Hellebrekers, Karolien Castermans, Emmanuelle Viré, Ruud P.M. Dings, Nicole T.H. Hoebers, Kevin H. Mayo, Mirjam G.A. oude Egbrink, Grietje Molema, François Fuks, Manon van Engeland \& Arjan W. Griffioen

Cancer Res. 2006, in press 


\begin{abstract}
Tumors can escape from immunity by repressing leukocyte adhesion molecule expression on tumor endothelial cells (EC), and by rendering EC unresponsive to inflammatory activation. This EC anergy is induced by angiogenic growth factors and results in reduced leukocyte-vessel wall interactions, thereby attenuating infiltration of leukocytes into the tumor. This report describes a novel mechanism of EC anergy regulation. We recently reported that DNA methyltransferase (DNMT)- and histone deacetylase (HDAC) inhibitors have angiostatic activity. Here, we studied whether epigenetic mechanisms regulate this angiogenesis-mediated escape from immunity. We found that DNMT inhibitors 5-aza-2'-deoxycytidine and zebularine, as well as HDAC inhibitor trichostatin A, re-expressed ICAM-1 on tumor-conditioned EC in vitro, resulting in restored leukocyte-EC adhesion. In addition, treatment with DNMT- or HDAC inhibitors in vivo also restored ICAM-1 expression on tumor EC from two different mouse tumor models. Furthermore, leukocyte-vessel wall interactions in mouse tumors were increased by these compounds, as measured by intravital microscopy, resulting in enhanced leukocyte infiltration. We demonstrate that ICAM-1 downregulation in tumor EC is associated with ICAM-1 promoter histone H3 deacetylation and loss of histone $\mathrm{H} 3$ lysine 4 methylation, but not with DNA hypermethylation. In conclusion, our data show that ICAM-1 is epigenetically silenced in tumor EC by promoter histone modifications, which can be overcome by DNMTand HDAC inhibitors, suggesting a new molecular mechanism based on which novel therapeutic approaches for cancer can be pursued.
\end{abstract}

\title{
Introduction
}

Leukocyte rolling on, adhesion to, and diapedesis through the tumor vessel wall are processes of key importance to immune surveillance, as well as to immunotherapy, a well-established anti-cancer approach. ${ }^{1}$ Leukocyte-vessel wall interactions are mediated by endothelial cell $(E C)$ adhesion molecules, such as intercellular adhesion molecule-1 and -2 (ICAM-1 and -2), vascular cell adhesion molecule-1 (VCAM-1), E-selectin, and CD34. ${ }^{2}$ Interference in the expression of EC adhesion molecules is one of the mechanisms tumors have developed to escape the immune response. We and others have shown previously that by producing angiogenic factors, such as vascular EC growth factors (VEGFs) and basic fibroblast growth factors (FGFs), tumors down-regulate vascular adhesion molecule expression. ${ }^{3-6}$ This angiogenesis-mediated EC anergy to inflammatory signals results in diminished leukocyte-vessel wall interactions and, therefore, decreased inflammatory infiltration. ${ }^{7,8}$

Epigenetic mechanisms play a crucial role in regulation of gene expression by affecting chromatin accessibility. Different epigenetic processes are interconnected in gene silencing. ${ }^{9}$ DNA methylation and histone modifications are two important epigenetic mediators of transcriptional repression. ${ }^{10,11}$ Aberrant epigenetic regulation is a frequent event in cancer cells, where DNA hypermethylation and histone 
deacetylation within the promoters of tumor suppressor genes result in undesirable gene silencing ${ }^{12-14}$ Due to the reversibility of epigenetic events, drugs that inhibit DNA methyltransferases (DNMTs) or histone deacetylases (HDACs) can synergistically reactivate epigenetically silenced tumor suppressor genes, thereby suppressing tumor cells in vitro and in vivo. ${ }^{14,15}$ Considerable promise lies in the further development of epigenetic therapies that already have demonstrated anti-tumorigenic effects for several malignancies. ${ }^{16-18}$

In contrast to the increasing knowledge on epigenetic aberrations in tumor cells, there is almost nothing known about the role of DNA methylation and histone modifications in regulation of gene expression in tumor EC. Recently, we and others have shown that DNMT- and HDAC inhibitors are potent angiostatic agents that inhibit EC growth in vitro and in vivo. ${ }^{19,20}$ Since regulation of adhesion molecule expression in tumor EC is pivotal to anti-tumor immunity and ICAM-1 is the key EC adhesion molecule, ${ }^{21}$ we investigated whether epigenetic mechanisms are involved in the regulation of ICAM-1 expression in tumor EC. Here, it is reported for the first time that epigenetic events regulate adhesion molecule expression and leukocyte infiltration in tumors. We found that ICAM-1 expression in tumor EC and leukocyte-EC adhesion are restored by DNMT- and HDAC inhibitors, resulting in enhanced inflammatory infiltration. Our results demonstrate that ICAM-1 is epigenetically silenced in angiogenically-stimulated EC through promoter histone modifications.

\section{Materials and Methods}

Cells, cultures and reagents

Human umbilical vein endothelial cells (HUVEC), mouse b.END5 brain endothelioma cells (ECACC, Salisbury, United Kingdom), mouse B16F10 melanoma cells (kindly provided by dr. J. Fidler, Houston, Texas) and human LS174T colon tumor cells were cultured as previously described. ${ }^{7,19}$ Quiescent EC were prepared by culturing for 3 days in the presence of $2 \%$ serum. Tumor conditions were mimicked by a 6-day exposure to $10 \mathrm{ng} / \mathrm{ml}$ basic Fibroblast Growth Factor (bFGF; Peprotech, London, UK) and $10 \mathrm{ng} / \mathrm{ml}$ Vascular Endothelial Growth Factor (VEGF; Peprotech). During the last 3 days, tumor-conditioned EC were treated with the DNA methyltransferase (DNMT) inhibitors 5-aza-2'-deoxycytidine (DAC; $200 \mathrm{nM})^{14}$ (Sigma, Zwijndrecht, the Netherlands) or zebularine $(100 \mu \mathrm{M})^{22}$ (obtained from NCl, Bethesda, US), or with the histone deacetylase (HDAC) inhibitor trichostatin A (TSA; $300 \mathrm{nM})^{14}$ (Wako, Neuss, Germany), replacing drugs and culture medium every 24 hours, as described previously. ${ }^{14,19}$ Tumor-conditioned EC treated during the last 3 days with a combination of DAC and TSA were first treated with DAC (200 nM) for $48 \mathrm{~h}$, with drug and medium replaced $24 \mathrm{~h}$ after the beginning of the treatment, followed by medium replacement and addition of TSA (300 nM) for a further $24 \mathrm{~h} .{ }^{14,15}$ When applied, TNFa (HUVEC: $4 \mathrm{ng} / \mathrm{ml}$; Peprotech, b.END5: $40 \mathrm{ng} / \mathrm{ml}$; Peprotech) was added $6 \mathrm{~h}$ prior to harvesting. ${ }^{7}$ 


\section{FACS analysis}

The expression of ICAM-1 on HUVEC was determined by mouse anti-human ICAM-1 monoclonal antibody (MEM111, Monosan, Uden, The Netherlands), as described previously. ${ }^{8}$ ICAM- 1 expression on b.END5 cells was determined using rat anti-mouse ICAM-1 monoclonal antibody (CD54; R\&D systems, Abingdon, UK), as described previously. ${ }^{7}$

\section{Quantitative real-time RT-PCR (qRT-PCR)}

Total RNA was isolated from cultured cells or frozen tissue sections using the RNeasy RNA isolation kit (Qiagen, Hilden, Germany) according to the supplier's protocol. cDNA synthesis and quantitative real-time RT-PCR were performed as described previously ${ }^{23}$ using SYBR Green PCR master mix (Applied Biosystems, Nieuwekerk a/d IJssel, The Netherlands). Primer sequences are listed in Supporting Table 4.1.

\section{Adhesion assay}

Human peripheral blood leukocytes were isolated by Ficoll density gradient centrifugation (Amersham, Uppsala, Sweden) and labelled with 5-(and -6)carboxyfluorescein diacetate, succinimidyl ester (CFSE; Molecular probes, Leiden, The Netherlands). Cells were washed twice and subsequently adhered for $1 \mathrm{hr}$ at room temperature to confluent HUVEC cultures. Non-adhering cells were removed by washing with pre-warmed culture medium. Cells were harvested and fixed in $1 \%$ paraformaldehyde (PFA, Merck, Amsterdam, The Netherlands) for 30 minutes at room temperature. Leukocyte-HUVEC adhesion was measured both by fluorescence activated cell sorter (FACS) analysis by detecting the number of CFSE-labelled leukocytes, and by counting under an inverted microscope.

\section{Mouse tumor models and intravital microscopy}

All animal experiments were approved by the local ethical review committee. At day $0,10^{5} \mathrm{~B} 16 \mathrm{~F} 10$ cells or $10^{6} \mathrm{LS} 174 \mathrm{~T}$ cells were inoculated subcutaneously on the right flank of 6 week old C57BL/6 and Swiss nu/nu mice (obtained from Charles River, Maastricht, The Netherlands), respectively. Between day 6 and 9 (B16F10) or between day 10 and 14 (LS174T) the tumors became visible and treatments were initiated. Zebularine $(n=5)$, at doses of $1000 \mathrm{mg} / \mathrm{kg}^{24}$ and TSA $(n=5)$, at doses of 1 $\mathrm{mg} / \mathrm{kg}^{20}$ were administered daily by intraperitoneal injection in a solution of $0.9 \%$ saline for 7 (B16F10) or 10 (LS174T) days. Tumor volumes were measured as described previously. ${ }^{19}$ Intravital microscopic measurements of B16F10 flank tumors were performed after 7 days of treatment. Mice were anesthetized by s.c. administration of a mixture of ketamine $(0.1 \mathrm{mg} / \mathrm{g}$ b.w. Nimatek; Ad Usem Veterinarium, Cuijk, The Netherlands) and xylazine $(0.02 \mathrm{mg} / \mathrm{g}$ b.w. Sedamun; Ad Usem Veterinarium). Intravital microscopy was performed as described before. ${ }^{7}$ Body temperature was kept at $37^{\circ} \mathrm{C}$ by an infrared heating lamp. To enable intravital microscopic observation of leukocytes, 10-20 $\mu \mathrm{l}$ of a Rhodamine 6G solution (Sigma Chemical Co., St. Louis, MO; $1 \mathrm{mg} / \mathrm{ml}$ ) was injected into a tail vein. Images were recorded on DVD for off-line analysis. 
Vessel diameter, centerline blood flow velocity, reduced velocity, local blood flow, leukocyte rolling and leukocyte adhesion were determined as before ${ }^{7,25}$ and are described in Supporting Materials and Methods.

Immunohistochemistry

Frozen sections of tumor tissues were stained using rat anti-mouse CD45 (gift from Dr. A Duijvesteijn, Maastricht), which was detected by biotinylated donkey antirat Ig antibody (Jackson Immuno Research Laboratories, Inc.) and avidin-biotin-HRP complex (Dako). The staining was visualised with DAB and the slides were counterstained with haematoxylin. $\mathrm{CD} 45^{+}$cells were counted in 3 independent areas in each section (using a $0.25 \mathrm{~mm}^{2}$ grid at a 200 times magnification) by two independent observers.

\section{Bisulfite Sequencing}

Genomic DNA was isolated using the Puregene DNA Isolation Kit (Gentra Systems, Biozym, Landgraaf, The Netherlands). Bisulfite modification of genomic DNA was carried out as described previously. ${ }^{19}$ Bisulfite-treated DNA samples were then purified with a Wizard Genomic DNA Purification Kit (Promega, Leiden, The Netherlands), and desulfonated before ethanol precipitation. PCR products were cloned using the TA cloning kit (Invitrogen, Breda, The Netherlands) and single colonies were picked and sequenced. Primer sequences are listed in Supporting Table 4.2.

\section{ChIP assay}

Chromatin immunoprecipitation (ChIP) assays of an ICAM-1 proximal promoter region $(-230$ to -56$)$ were performed essentially as described ${ }^{26}$ using anti-acetylHistone H3 (Lys 9 and Lys 14), or anti-dimethyl-Histone H3 (Lys 4) antibody (both from Upstate Biotechnology, Lake Placid, New York). One primer set for GAPDH was used to amplify a 128-bp fragment of the genomic sequence to serve as an internal control. ${ }^{27}$ All PCR reactions were optimized with input DNA to ensure that PCR products were in the linear range of amplification. Primer sequences are listed in Supporting Table 4.3. PCR products were size-separated by agarose gel electrophoresis and bands were quantified using Molecular Analyst 2.1 software. Enrichment was calculated by taking the ratio between the net intensity of the ICAM-1 PCR product and the net intensity of the GAPDH PCR product for the bound sample and dividing this by the same ratio calculated for the input samples. ${ }^{27}$

\section{Statistical Analysis}

Data obtained from intravital microscopic experiments are presented as medians with interquartile ranges because of their nonsymmetrical distribution. Other data are presented as mean values \pm SEM. Differences between two independent data groups were tested with the Mann-Whitney U test using SPSS 10.0.5 software. Correlation between variables was determined using Spearman's correlation test. Statistical analysis for the tumor volumes was done by means of the two-way ANOVA test. 


\section{Supporting Material}

Supporting Tables $4.1,4.2$ and 4.3 show PCR primers used in this study. The Supporting Materials and Methods section describes determination of vessel diameter, centerline blood flow velocity, reduced velocity, local blood flow, leukocyte rolling and leukocyte adhesion of the intravital microscopy experiments.

\section{Results}

\section{DNMT- and HDAC inhibitors restore ICAM-1 expression in tumor-conditioned EC}

By releasing angiogenic factors, tumors suppress adhesion molecule expression on tumor endothelial cells (EC), thereby reducing leukocyte-vessel wall interactions and inflammatory infiltration., ${ }^{3,4}$ To examine whether epigenetic mechanisms are involved in regulation of adhesion molecule expression on tumor EC, the effects of DNA methyltransferase (DNMT)- and histone deacetylase (HDAC)- inhibitors on EC adhesion molecule expression were studied in vitro. In tumor-conditioned HUVEC, ICAM-1 protein expression was downregulated by $81 \%$ compared to that in quiescent HUVEC ( $p<0.01$, Fig. 4.1A). This is in agreement with previous results. ${ }^{3,4}$ Treatment of tumor-conditioned HUVEC with the DNMT inhibitor 5-aza-2'-deoxycytidine (DAC) significantly restored ICAM-1 protein expression $(p<0.01)$. A similar effect was observed after treatment with zebularine, a recently discovered DNMT inhibitor which requires higher effective concentrations, ${ }^{22,24}$ or with the HDAC inhibitor trichostatin A (TSA) $(p<0.01)$. Since DNMTs and HDACs cooperate in gene silencing, ${ }^{15}$ we further treated tumor-conditioned HUVEC with a combination of DAC and TSA. ${ }^{14}$ Combined treatment also induced ICAM-1 protein expression $(p<0.01)$, although no synergism was observed (Fig. 4.1A). Decreased protein expression of vascular cell adhesion molecule 1 (VCAM-1) and E-selectin in tumor-conditioned HUVEC was also restored by treatment with DNMT- and/or HDAC inhibitors (data not shown). Further studies are focused on ICAM-1, because it has been shown that this is the most important EC adhesion molecule for leukocyte extravasation. ${ }^{21}$

Quantitative real-time RT-PCR analysis of ICAM-1 showed similar results, indicating that ICAM-1 protein induction by DAC, zebularine and TSA results from increased ICAM-1 mRNA levels (Fig. 4.1B). DAC, zebularine, and TSA also significantly restored ICAM-1 protein and mRNA expression in tumor-conditioned HUVEC treated with TNF $\alpha$ (data not shown), i.e. normalizing the upregulation to this inflammatory cytokine. We observed similar effects using b.END5 mouse EC (Fig. 4.1C,D). ICAM-1 upregulation by DNMT- and HDAC inhibitors was not observed in B16F10 mouse melanoma cells and normal cultured human fibroblasts (data not shown), indicating that it is not a general effect of these compounds. 
A

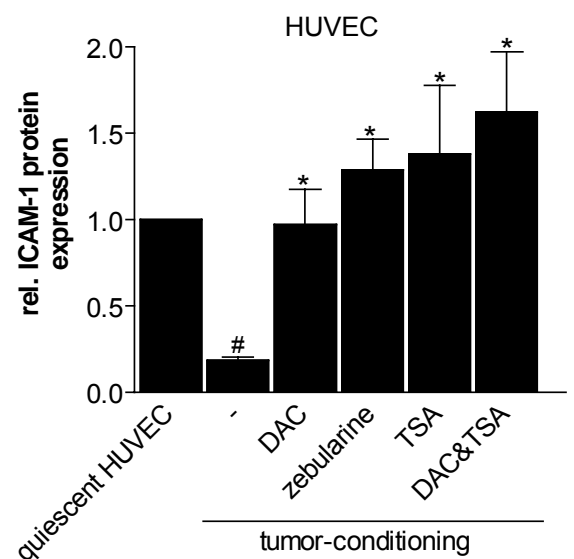

C

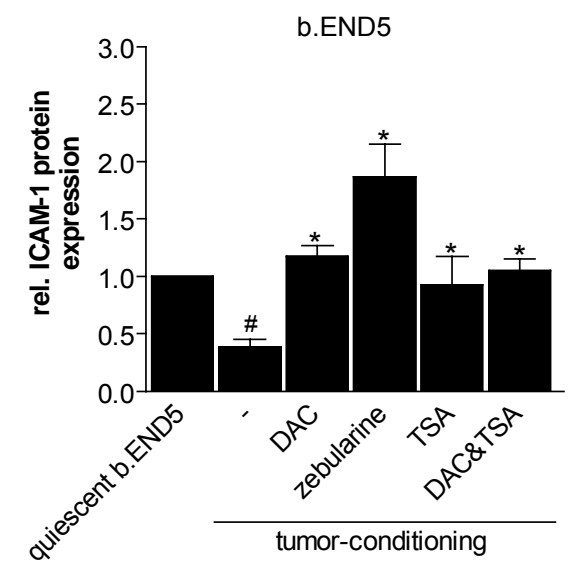

B

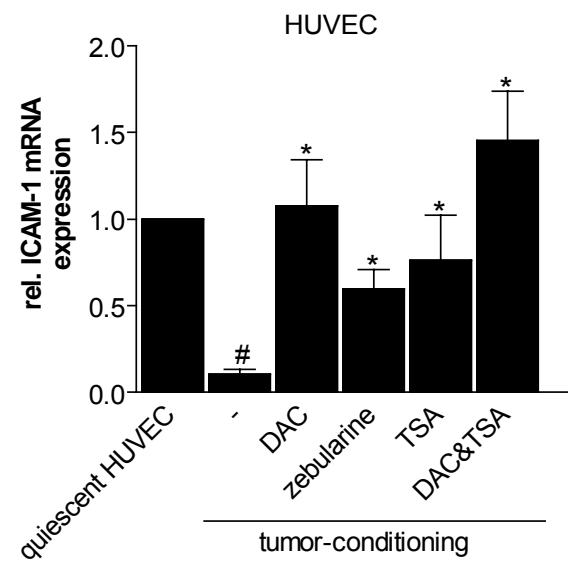

D

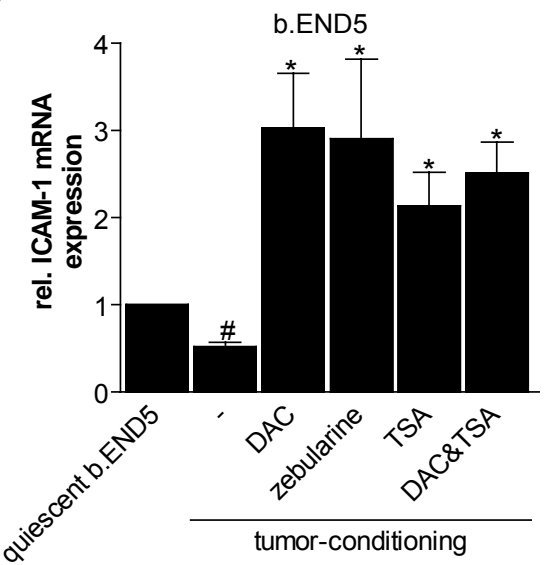

Figure 4.1 DNMT- and HDAC inhibitors restore ICAM-1 expression in tumor-conditioned EC.

(A) ICAM-1 protein expression measured by FACS analysis in quiescent HUVEC, tumor-conditioned HUVEC, and tumor-conditioned HUVEC treated with DAC (200 nM), zebularine (100 $\mu \mathrm{M})$, TSA (300 $\mathrm{nM}$ ), or a combination of DAC and TSA. Results are presented as mean values ( \pm SEM) of relative protein expression (quiescent HUVEC set to 1 ) of at least 3 independent experiments $(\# p<0.01$ vs quiescent HUVEC, ${ }^{*} p<0.01$ vs. tumor-conditioned HUVEC). (B) ICAM-1 mRNA expression measured by quantitative real-time RT-PCR in HUVEC. Results are plotted as mean values ( \pm SEM) of relative mRNA expression of 6 independent experiments (\#p $<0.001$ vs. quiescent HUVEC, ${ }^{*} p<0.05$ vs. tumorconditioned HUVEC). (C) ICAM-1 protein expression in b.END5 mouse EC (\#p<0.05 vs. quiescent b.END5, ${ }^{*} p<0.05$ vs. tumor-conditioned b.END5). (D) ICAM-1 mRNA expression in b.END5 EC $\left(\# p<0.001\right.$ vs. quiescent $b . E N D 5,{ }^{*} p<0.05$ vs. tumor-conditioned b.END5). 
A quiescent EC

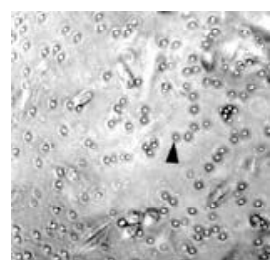

tumor-conditioned EC + zebularine

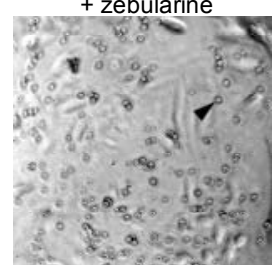

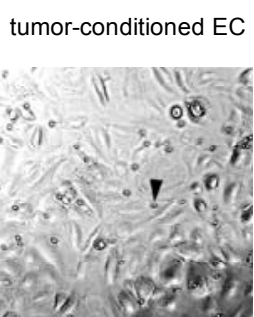

tumor-conditioned EC

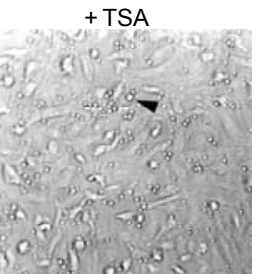

B

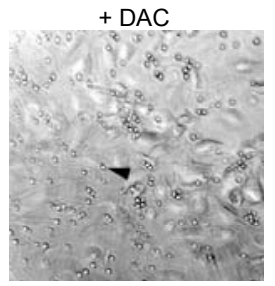

tumor-conditioned EC + DAC\&TSA

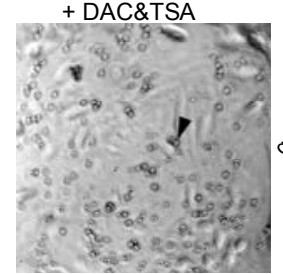

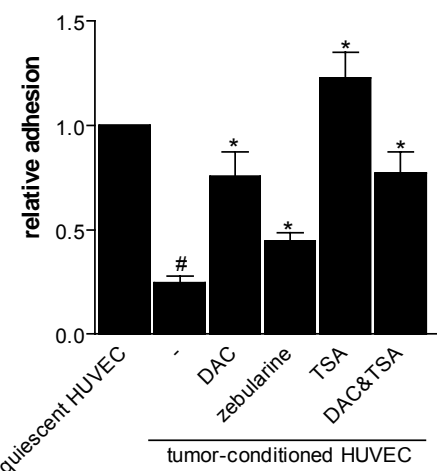

Figure 4.2 DNMT- and HDAC inhibitors restore leukocyte-EC adhesion in vitro.

(A) Adhesion of human peripheral blood mononuclear cells to monolayers of quiescent HUVEC, tumor-conditioned HUVEC, and tumor-conditioned HUVEC treated with DAC (200 nM), zebularine $(100 \mu \mathrm{M})$, TSA $(300 \mathrm{nM})$, or a combination of DAC and TSA. Leukocytes are indicated by the arrow heads. (B) Quantification of adhered CSFE-labelled leukocytes to EC by flow cytometry. Results are presented as mean values ( \pm SEM) of relative adhesion (quiescent HUVEC set to 1 ) of 3 independent experiments (\# $p<0.001$ vs quiescent HUVEC, ${ }^{*} p<0.01$ vs. tumor-conditioned HUVEC, ${ }^{* *} p<0.0001$ vs. tumor-conditioned HUVEC).

To demonstrate the functional impact of restored adhesion molecule expression on tumor-conditioned EC by using DNMT- and HDAC inhibitors, we investigated the adhesion of fluorescein-labelled human peripheral blood leukocytes to EC monolayers. After adding these leukocytes to EC monolayers and removing nonadherent cells, the adherent leukocytes were counted both by using an inverted microscope (Fig. 4.2A) and by flow cytometry (Fig. 4.2B). In tumor-conditioned HUVEC, leukocyte adhesion was decreased by $75 \%$ compared to that using quiescent HUVEC $(p<0.001$, Fig. 4.2A,B). Treatment of tumor-conditioned HUVEC with the DNMT inhibitor DAC or zebularine significantly restored leukocyte adhesion $(p<0.01)$. The same observation was made when EC were treated with TSA, or with a combination of DAC and TSA $(p<0.01)$. The restored leukocyte-EC adhesion by these compounds was mainly due to upregulation of ICAM-1 since a blocking antibody significantly decreased the effects of DNMT- and HDAC inhibitors on adhesion (data not shown).

Zebularine and TSA induce leukocyte-vessel wall interactions in tumor vessels in vivo

In order to infiltrate a tumor, leukocytes must interact first with the tumor vessel wall. We recently demonstrated that leukocyte-vessel wall interactions are reduced in tumors, as compared to those in healthy control vessels. ${ }^{7}$ Here, we examined whether 
Epigenetic regulation of tumor endothelial cell anergy

restored leukocyte-EC adhesion by DNMT- and HDAC inhibitors in vitro is also observed in tumor vessels in vivo. To quantify leukocyte-vessel wall interactions in tumor blood vessels, intravital microscopy was used on immunocompetent B16F10 melanoma-bearing C57BL/6 mice (Fig. 4.3A-C). In B16F10 flank tumors in mice treated with zebularine (the DNMT inhibitor of choice because of its lower toxicity profile and higher stability), ${ }^{24}$ both leukocyte adhesion (Fig. 4.3A) and leukocyte rolling (Fig. 4.3B) were significantly increased compared to those in untreated tumors $(p<0.01$ and $p<0.001$, respectively). The HDAC inhibitor TSA also significantly restored leukocyte adhesion and rolling in tumor vessels (Fig. 4.3A,B).

Vessel diameter and local blood flow did not differ between these groups (Table 4.1), indicating that observed effects from zebularine and TSA cannot be explained simply by changes in local fluid dynamic conditions. Centerline velocity and reduced velocity were significantly increased in TSA treated mice compared with those from the control group $(p<0.05)$. However, no correlation between these parameters and leukocyte adhesion or rolling could be found in these mice. Therefore, observed differences in leukocyte-vessel wall interactions cannot be explained by differences in fluid dynamic parameters.

\begin{tabular}{|c|c|c|c|}
\hline & control & zebularine & TSA \\
\hline $\mathrm{n}_{\mathrm{m}}{ }^{\mathrm{b}}$ & 9 & 5 & 5 \\
\hline $\mathrm{n}_{\mathrm{v}}$ & 30 & 29 & 22 \\
\hline Diameter $(\mu \mathrm{m})$ & $20(20-30)$ & $25(20-35)$ & $25(19-25)$ \\
\hline Centerline velocity $(\mathrm{mm} / \mathrm{s})$ & $0.7(0.5-0.9)$ & $0.6(0.4-0.8)$ & $1.1^{*}(0.9-1.5)$ \\
\hline $\mathrm{U}\left(\mathrm{s}^{-1}\right)$ & $15.6(11.7-35.2)$ & $13(9.4-25)$ & $29 *(23.8-42)$ \\
\hline $\mathrm{Q}(\mathrm{nl} / \mathrm{s})$ & $0.17(0.08-0.30)$ & $0.15(0.07-0.34)$ & $0.27(0.17-0.44)$ \\
\hline
\end{tabular}

${ }^{a}$ Data are presented as median values and interquartile ranges. Statistical significance was assessed in comparison to values in untreated mice $\left({ }^{*} p<0.05\right)$

${ }^{b} \mathrm{~nm}$, number of mice; nv, number of vessels; $U$, reduced velocity; $Q$, flow

To examine whether DNMT- and HDAC inhibitor-induced increased leukocytevessel wall interactions in vivo were associated with enhanced expression of EC adhesion molecules, quantitative real-time RT-PCR was performed on B16F10 tumor tissues. ICAM-1 expression was significantly induced in B16F10 tumors of mice treated with zebularine or TSA compared with that in untreated mice $(p<0.001$, Fig. 4.3D). VCAM-1 was also upregulated in both zebularine- and TSA treated B16F10 tumors. For E-selectin, there was a significant induction upon zebularine treatment $(p<0.001)$, but not with TSA treatment which only suggested a trend in the same direction (Fig. 4.3D). Since expression of VCAM-1 and E-selectin is restricted to the $E C$ of the tumors, increased mRNA levels reflect effects of zebularine and TSA on the expression of these molecules on tumor EC. ICAM-1, however, is expressed by tumor EC, as well as by tumor and/or stromal cells. For this reason, enhancement of ICAM-1 expression observed in zebularine and TSA treated B16F10 tumor-bearing mice might 


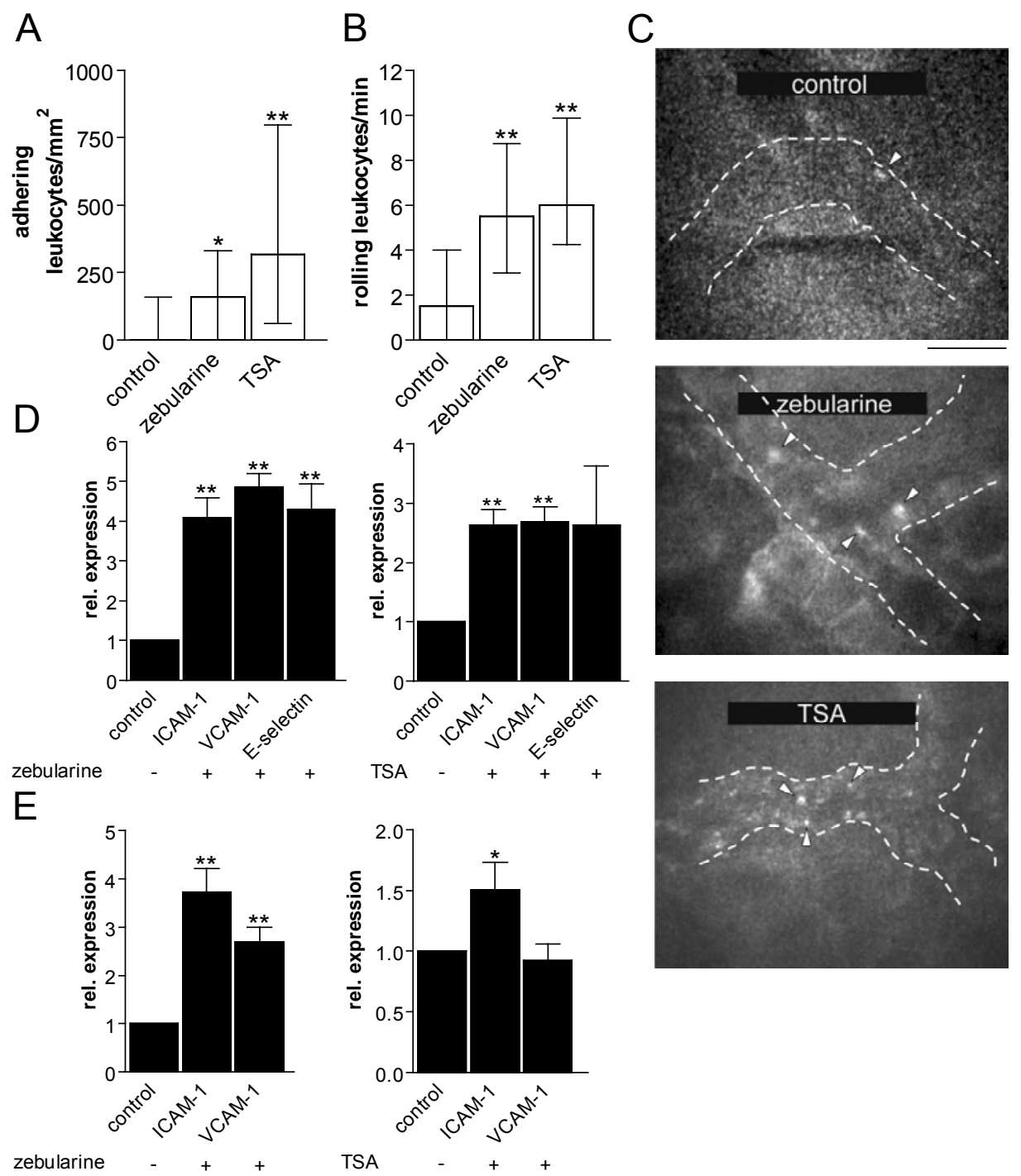

Figure 4.3 Increased leukocyte-vessel wall interactions and ICAM-1 expression in tumor vessels in vivo by zebularine and TSA.

Adhering (A) and rolling (B) leukocytes in flank tumor vessels of C57BI6 mice bearing B16F10 mouse melanoma tumors. Mice were treated with zebularine $(n=5)$ or TSA $(n=5)$. Data are presented as medians with interquartile ranges. Statistical significance was assessed in comparison to values in tumor vessels of untreated mice ( $n=5$; control) $\left({ }^{*} p<0.01,{ }^{* *} p<0.001\right)$. (C) Typical intravital fluorescence microscopy images of an untreated, zebularine treated and TSA treated tumor vessel. Leukocytes are fluorescently labelled with Rhodamine 6G. Vessels are indicated by the dashed lines, examples of leukocytes by the arrow heads. The bar represents $25 \mu \mathrm{m}$. Because the stills have rather low resolution, the video recordings can be observed at 'http://www.fdg.unimaas.nl/AngiogenesisLab/ mirrorsite/movies.htm'. For numbers of mice and vessels see Table 4.1. Expression levels of ICAM-1, VCAM-1 and E-selectin in B16F10 (D) and LS174T (E) tumor tissues of mice treated with zebularine or TSA measured by quantitative real-time RT-PCR. Results are plotted as mean values ( \pm SEM) of relative mRNA expression compared to untreated control mice $\left({ }^{*} p<0.05,{ }^{* *} p<0.001\right.$ vs. control mice). 
have been due in part to expression in tumor cells. However, no effects of these compounds were observed on ICAM-1 expression in B16F10 cells in vitro (data not shown). We also investigated these effects in the human xenograft model of LS174T colon carcinoma in athymic mice. In this model, human tumors have recruited a vasculature of mouse origin. Using species-specific primers, we developed a technique to discriminate between human (tumor) and mouse mRNAs within the xenograft tumor. ${ }^{23}$ Using this technique, we found that with zebularine, expression of both ICAM-1 and VCAM-1 was significantly induced in the vasculature of LS174T tumors (Fig. 4.3E, $p<0.001$ ). Treatment of LS174T tumor bearing mice with TSA significantly increased expression of ICAM-1 $(p<0.05)$, but not VCAM-1. In this mouse model, E-selectin mRNA levels in EC were undetectable.

Leukocyte infiltration is enhanced by zebularine and TSA

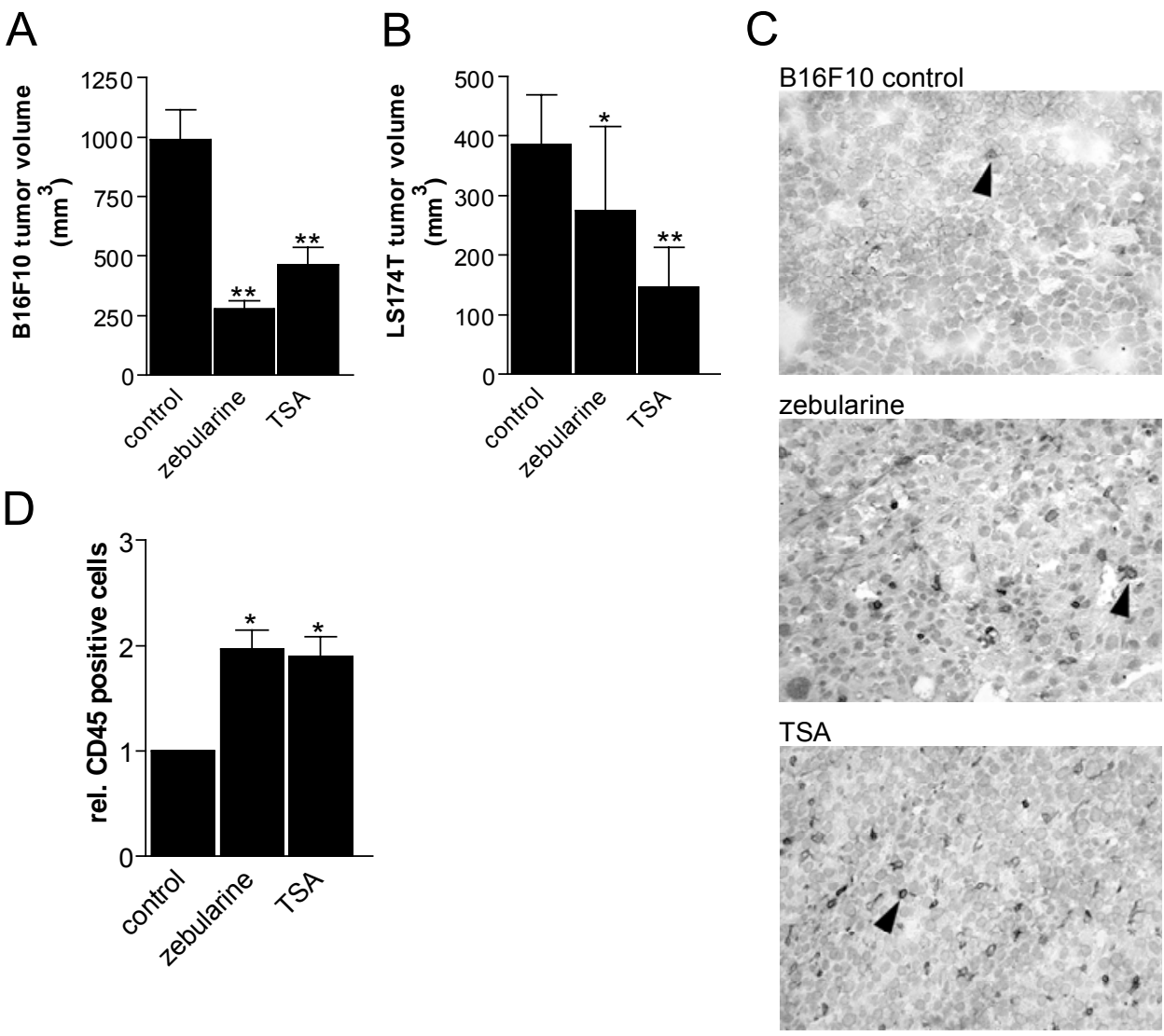

Figure 4.4 Leukocyte infiltration is enhanced by zebularine and TSA.

Tumor size of B16F10 mouse melanoma tumors (A) and human LS174T colon carcinoma (B) after treatment with or without zebularine or TSA for 7 (B16F10) or 10 (LS174T) days. Data are expressed as mean tumor volume \pm SEM $\left({ }^{*} p<0.01,{ }^{* *} p<0.001\right)$. (C) Cryosections of B16F10 tumors from control mice and treated mice stained with CD45 antibody for leukocyte infiltration. (D) Quantification of CD45 positive leukocytes in B16F10 tumors treated with zebularine or TSA. Results are plotted as relative mean values $\left( \pm\right.$ SEM) of CD45 positive leukocytes compared to control mice $\left({ }^{*} p<0.001\right)$. 
Leukocyte-EC adhesion and leukocyte-vessel wall interactions preceed extravasation and infiltration into the tumor. To study the latter effect, we examined whether increased EC adhesion molecule expression and leukocyte-vessel wall interactions induced by using zebularine and TSA treatment, contribute to an enhanced tumor leukocyte infiltration. Treatment of B16F10 or LS174T tumor-bearing mice with zebularine or TSA significantly decreased tumor growth (Fig. 4.4A,B) and microvessel density (data not shown), as we reported previously. ${ }^{19}$ The number of infiltrating leukocytes in both B16F10 and LS174T tumors was determined by staining for the pan-leukocyte marker CD45. In B16F10 tumors, both zebularine and TSA significantly enhanced the number of infiltrating leukocytes by approximately 2 -fold (Fig. 4.4C,D, p<0.001). Comparable results were observed in LS174T tumors $(p<0.001$ for zebularine and $p<0.01$ for TSA, data not shown).

ICAM-1 downregulation in tumor-conditioned EC is associated with promoter histone $\mathrm{H} 3$ deacetylation and loss of $\mathrm{H} 3$ lysine 4 methylation

Since ICAM-1 is the primary EC adhesion molecule ${ }^{21}$ regulation of its expression is pivotal to EC anergy. Re-expression of ICAM-1 by inhibitors of DNA methylation and histone deacetylation suggests that epigenetic mechanisms may be responsible for silencing of this gene in tumor EC. Therefore, epigenetic modifications in the ICAM-1 promoter of quiescent and tumor-conditioned HUVEC were examined. Three $5^{\prime} \mathrm{CpG}$ islands ( $\mathrm{GC}$ content $>60 \%$, ratio of $\mathrm{CpG}$ to $\mathrm{GpC}>0.6$ and minimum length 200 $\mathrm{bp})^{28}$ were identified in the ICAM-1 promoter region (Fig. 4.5A). DNA methylation of ICAM-1 promoter CpG islands was evaluated by genomic bisulfite sequencing. Interestingly, only a few methylated $\mathrm{CpG}$ sites were present in the ICAM-1 promoter of quiescent- and tumor-conditioned HUVEC (Fig. 4.5A). Furthermore, the ICAM-1 promoter showed no major differences in methylation patterns between quiescentand activated EC in the region examined. We also examined DNA methylation of part of the ICAM-1 promoter (-322 to -17) in tumor EC obtained from colorectal tumors by laser microdissection. Similar to tumor-conditioned EC, hardly any methylation was found in the region examined (Fig. 4.5A). These results demonstrate that silencing of ICAM-1 in tumor EC occurs independently of direct dense promoter methylation.

To study whether ICAM-1 downregulation in tumor-conditioned EC is associated with promoter histone deacetylation, we examined acetylation of histone H3 (Lys 9 and 14$)$ in the proximal ICAM-1 promoter region (-230 to -56$)$ by using chromatin immunoprecipitation (ChIP). Interestingly, ICAM-1 promoter histone acetylation was significantly decreased in activated HUVEC compared to quiescent HUVEC, correlating with the decreased gene expression (Fig. 4.5B, p<0.05). Treatment of tumor-conditioned HUVEC with DAC, TSA or a combination of both drugs, greatly increased ICAM-1 promoter histone acetylation, which is associated with gene reactivation induced by these compounds. We also examined another key gene activating histone modification, namely lysine 4 methylation of histone H3. This histone modification also was significantly decreased in tumor-conditioned EC, and was increased by DAC and TSA (Fig. 4.5B, p<0.05). This led us to conclude that ICAM-1 downregulation in tumor-conditioned EC, and resulting EC anergy, is associated with loss of promoter histone $\mathrm{H} 3$ acetylation and of histone $\mathrm{H} 3$ lysine 4 methylation, but not with DNA hypermethylation. 


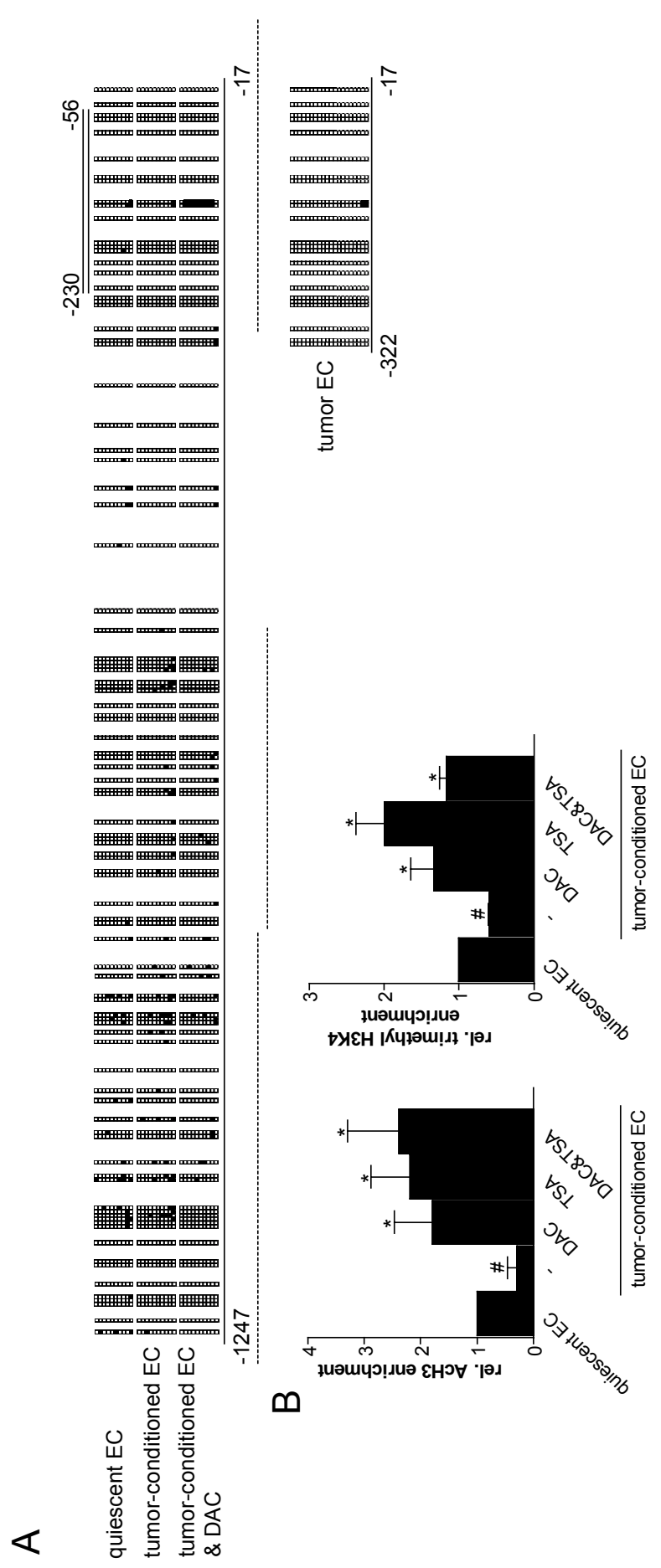

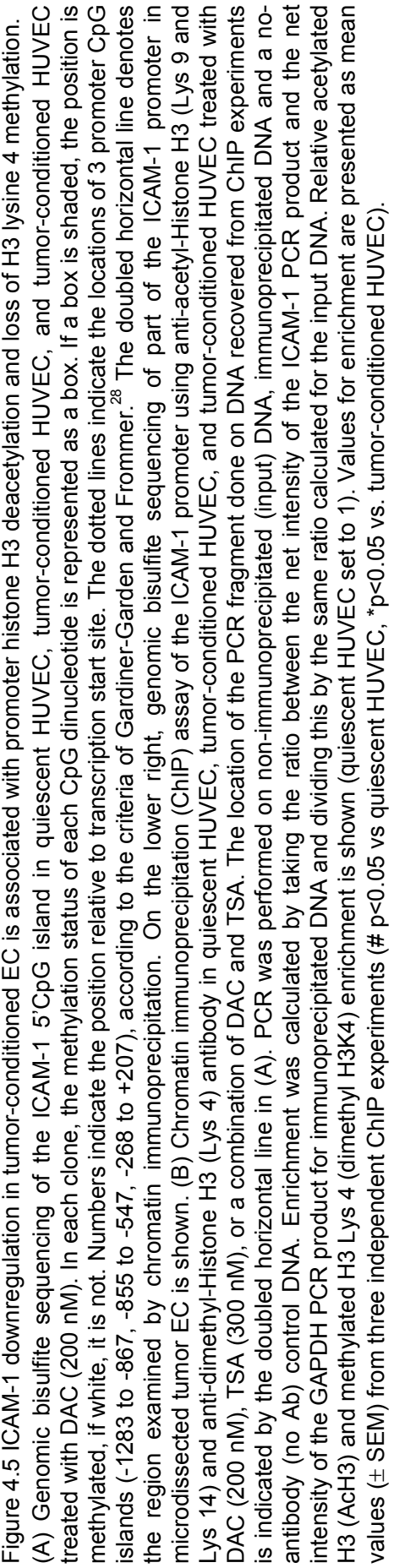




\section{Discussion}

Suppression of endothelial cell (EC) adhesion molecule expression that leads to reduced leukocyte-vessel wall interactions and leukocyte infiltration, is one of the mechanisms tumors have developed to escape from immunity. ${ }^{5,7,8}$ This EC anergy is mediated by angiogenic factors like vascular EC growth factor (VEGF) and basic fibroblast growth factor (bFGF) ${ }^{3,4}$ The mechanism behind angiogenic factor-mediated silencing of tumor EC adhesion molecules was hitherto unknown. Here, we demonstrate that epigenetic mechanisms are involved in the regulation of EC anergy through repression of ICAM- 1 by promoter histone modifications.

In the present study, we found that DNA methyltransferase (DNMT)- and histone deacetylase (HDAC) inhibitors re-express ICAM-1 in tumor EC, both at protein and mRNA level, and restore leukocyte-EC adhesion in vitro and in vivo. While tumor growth and angiogenesis were inhibited by zebularine and TSA, as we published recently, ${ }^{19}$ the amount of infiltrated leukocytes was enhanced markedly in both the syngeneic B16F10 mouse melanoma model and the human LS174T xenograft model. Overall, this provides functional meaning to the observed changes in leukocyte adhesion. This is consistent with what we observed on the molecular level, namely ICAM-1 expression is significantly increased upon DNMT- and HDAC inhibitor treatment of tumors in both these mouse models. Although upregulation of other adhesion molecules, such as CD34, P-selectin and CD44 (that are also involved in leukocyte-vessel wall interactions) can not be excluded, it is unlikely that enhanced leukocyte-vessel wall interactions result from increased expression of adhesion molecules on leukocytes ${ }^{29}$ or changing fluid dynamic parameters (Table 4.1). DNMTand HDAC inhibitors decrease tumor cell growth by reactivation of epigenetically silenced tumor suppressor genes. ${ }^{15}$ Therefore, increased leukocyte infiltration and leukocyte-vessel wall interactions by zebularine and TSA in vivo could result from their inhibitory effects on tumor cells (e.g. interfering in the production of angiogenic factors like bFGF and VEGF). The increased leukocyte-EC adhesion in vitro, however, where no other cells (tumor cells) are present, shows that these compounds directly restore EC ICAM-1 expression and enhance leukocyte-EC adhesion.

Post-translational modifications of histone amino-terminal tails are important epigenetic modifications, which together form the "histone code". ${ }^{11,30-32}$ This "histone code" is "read" by proteins that modulate chromatin structure, thereby regulating gene transcription. ${ }^{33}$ Hyperacetylation of histone $\mathrm{H} 3$ and $\mathrm{H} 4$ lysine residues is generally associated with active chromatin, whereas deacetylation has been correlated with inactive genes. ${ }^{34}$ Another histone modification that has been associated with transcriptionally active chromatin is methylation at lysine 4 of histone $\mathrm{H} 3{ }^{35,36}$ In cancer cells, histone modifications work in concert with DNA methylation to silence tumor suppressor genes. ${ }^{13,27,37}$ In fact, DNA methylation seems to be dominant over histone deacetylation in maintaining transcriptional repression of tumor suppressor genes, because these genes can be activated by DAC but not by TSA alone. ${ }^{15}$ Our data indicate that in tumor EC, histone modifications alone are responsible for ICAM-1 downregulation. ICAM-1 can be reactivated by both DAC and TSA alone, through increasing ICAM-1 promoter histone $\mathrm{H} 3$ acetylation and $\mathrm{H} 3$ lysine 4 methylation. 
Epigenetic regulation of tumor endothelial cell anergy

Increased histone acetylation, $\mathrm{H} 3$ lysine 4 methylation and/or gene expression by DNMT inhibitors independently of effects on DNA methylation have been described before. $^{37-39}$ The potency of the DNMT inhibitors DAC and zebularine to reactivate ICAM-1 independently of promoter DNA methylation indicates that methylationindependent silencing activity of DNMTs might be essential for ICAM-1 downregulation in tumor EC. Methylation-independent transcriptional repressor effects of DNMTs have been linked to the interaction of these enzymes with histone methyltransferases and HDACs. ${ }^{38,40-42}$

In tumor cells, induction of ICAM- 1 by DNMT- ${ }^{43}$ and HDAC inhibitors, ${ }^{44}$ as well as ICAM-1 promoter DNA hypermethylation (in a region within the area we examined by bisulfite sequencing) ${ }^{45}$ have been described. The suggested difference between tumor cells and tumor EC in the involvement of promoter DNA hypermethylation in ICAM-1 silencing is very interesting. Some studies have demonstrated that DNA methylation, which is a more stable epigenetic modification compared to the more dynamic nature of histone modifications, serves to maintain instead of initiate gene silencing ${ }^{46,47}$ It is attractive to speculate that transcription of ICAM-1 is irreversibly "locked" into a permanently silent state in tumor cells by promoter DNA hypermethylation, and that ICAM-1 downregulation in tumor-conditioned EC is a more reversible phenomenon that only involves histone modifications. It could be argued that culturing HUVEC for 6 days with angiogenic growth factors is not sufficient to induce irreversible gene silencing by promoter DNA methylation. Therefore, we also examined ICAM-1 promoter DNA methylation in tumor EC obtained from colorectal tumors by using laser capture microdissection. However, no meaningful promoter methylation was observed in these cells.

Several studies have reported on transcriptional regulators of basal- and cytokineinduced expression of ICAM- $1 .{ }^{48}$ Inflammatory cytokines such as TNF $\alpha$ induce ICAM1 transcription predominantly through activation of the transcription factor NF-kB. ${ }^{49}$ However, preliminary results of electrophoretic mobility shift assay (EMSA) showed that NF-kB activity was not decreased in tumor-conditioned versus quiescent EC, and was not increased by treatment with DAC and/or TSA (data not shown). These data suggest that regulation of ICAM-1 expression in tumor-conditioned EC by DNMT and HDAC inhibitors does not involve NF-kB activation. Nevertheless, involvement of other transcriptional mechanisms in regulating ICAM-1 expression during EC anergy, besides the epigenetic regulation of tumor EC ICAM-1 expression described in this study, cannot be ruled out. In addition, different (epi)genetic mechanisms can cooperate in ICAM-1 transcriptional activation- and repression during tumor angiogenesis.

The potential therapeutic implications of this work are substantial. Untill now, augmentation of anti-tumor immunity by DNMT- and HDAC inhibitors was recognized but attributed mainly to induction of molecules on tumor cells, like cancer testis antigens, HLA class I antigens, and costimulatory/accessory molecules. ${ }^{50,51}$ Here, we show a new mechanism by which DNMT- and HDAC inhibitors might be used in anticancer therapy, for reversal of EC anergy. Together with our recent findings ${ }^{19}$ and findings of others, ${ }^{20,52}$ demonstrating that these compounds are powerful inhibitors of EC growth and tumor angiogenesis in vitro and in vivo, our current data demonstrate that DNMT- and HDAC inhibitors have direct effects on tumor EC. Therefore, the 
therapeutic targets of these compounds can be extended beyond merely tumor cells. Aside from the inhibitory effects of epigenetic therapy on tumor cell growth through reexpression of previously silenced tumor suppressor genes, the potential use of DNMT- and HDAC inhibitors as angiostatic and immunotherapeutic agents makes them promising anticancer drugs.

In conclusion, we have demonstrated a role of epigenetics in regulation of EC anergy. We show that ICAM-1 is epigenetically repressed in tumor EC by promoter histone modifications, and that DNMT- and HDAC inhibitors reinduce expression of this gene by reversal of histone modifications in the ICAM-1 promoter, thereby restoring leukocyte-vessel wall interactions and leukocyte infiltration. This work has laid the foundation for a novel anti-cancer approach, whereby DNMT- and HDAC inhibitors may be used to modulate leukocyte infiltration into tumors.

\section{Acknowledgments}

We are grateful to dr. A. Bloem for providing the F10.2 monoclonal ICAM-1 blocking antibody. 


\section{References}

1. Ribas A, Butterfield LH, Glaspy JA, Economou JS. Current developments in cancer vaccines and cellular immunotherapy. J Clin Oncol. 2003;21:2415-2432.

2. Springer TA. Traffic signals for lymphocyte recirculation and leukocyte emigration: the multistep paradigm. Cell. 1994;76:301-314.

3. Griffioen AW, Damen CA, Martinotti S, Blijham GH, Groenewegen G. Endothelial intercellular adhesion molecule-1 expression is suppressed in human malignancies: the role of angiogenic factors. Cancer Res. 1996;56:1111-1117.

4. Griffioen AW, Damen CA, Blijham GH, Groenewegen G. Tumor angiogenesis is accompanied by a decreased inflammatory response of tumor-associated endothelium. Blood. 1996;88:667-673.

5. Melder RJ, Koenig GC, Witwer BP, Safabakhsh N, Munn LL, Jain RK. During angiogenesis, vascular endothelial growth factor and basic fibroblast growth factor regulate natural killer cell adhesion to tumor endothelium. Nat Med. 1996;2:992-997.

6. Hellwig SM, Damen CA, van Adrichem NP, Blijham GH, Groenewegen G, Griffioen AW. Endothelial CD34 is suppressed in human malignancies: role of angiogenic factors. Cancer Lett. 1997;120:203-211.

7. Dirkx AE, Oude Egbrink MG, Kuijpers MJ, et al. Tumor angiogenesis modulates leukocytevessel wall interactions in vivo by reducing endothelial adhesion molecule expression. Cancer Res. 2003;63:2322-2329.

8. Dirkx AE, oude Egbrink MG, Castermans K, et al. Anti-angiogenesis therapy can overcome endothelial cell anergy and promote leukocyte-endothelium interactions and infiltration in tumors. FASEB J. 2006;20:621-630.

9. Vire E, Brenner C, Deplus R, et al. The Polycomb group protein EZH2 directly controls DNA methylation. Nature. 2006;439:871-874.

10. Jaenisch R, Bird A. Epigenetic regulation of gene expression: how the genome integrates intrinsic and environmental signals. Nat Genet. 2003;33 Suppl:245-254.

11. Jenuwein T, Allis CD. Translating the histone code. Science. 2001;293:1074-1080.

12. Herman JG, Baylin SB. Gene silencing in cancer in association with promoter hypermethylation. N Engl J Med. 2003;349:2042-2054.

13. Jones PA, Laird PW. Cancer epigenetics comes of age. Nat Genet. 1999;21:163-167.

14. Suzuki H, Gabrielson E, Chen W, et al. A genomic screen for genes upregulated by demethylation and histone deacetylase inhibition in human colorectal cancer. Nat Genet. 2002;31:141-149.

15. Cameron EE, Bachman KE, Myohanen S, Herman JG, Baylin SB. Synergy of demethylation and histone deacetylase inhibition in the re-expression of genes silenced in cancer. Nat Genet. 1999;21:103-107.

16. Silverman LR, Mufti GJ. Methylation inhibitor therapy in the treatment of myelodysplastic syndrome. Nat Clin Pract Oncol. 2005;2 Suppl 1:S12-23.

17. Minucci S, Pelicci PG. Histone deacetylase inhibitors and the promise of epigenetic (and more) treatments for cancer. Nat Rev Cancer. 2006;6:38-51.

18. Gore SD. Combination therapy with DNA methyltransferase inhibitors in hematologic malignancies. Nat Clin Pract Oncol. 2005;2 Suppl 1:S30-35.

19. Hellebrekers DM, Jair KW, Vire E, et al. Angiostatic activity of DNA methyltransferase inhibitors. Mol Cancer Ther. 2006;5:467-475.

20. Kim MS, Kwon HJ, Lee YM, et al. Histone deacetylases induce angiogenesis by negative regulation of tumor suppressor genes. Nat Med. 2001;7:437-443.

21. Reiss $Y$, Hoch $G$, Deutsch $U$, Engelhardt B. T cell interaction with ICAM-1-deficient endothelium in vitro: essential role for ICAM-1 and ICAM-2 in transendothelial migration of T cells. Eur J Immunol. 1998;28:3086-3099. 
22. Cheng JC, Yoo CB, Weisenberger DJ, et al. Preferential response of cancer cells to zebularine. Cancer Cell. 2004;6:151-158.

23. Thijssen VL, Brandwijk RJ, Dings RP, Griffioen AW. Angiogenesis gene expression profiling in xenograft models to study cellular interactions. Exp Cell Res. 2004;299:286-293.

24. Cheng JC, Matsen CB, Gonzales FA, et al. Inhibition of DNA methylation and reactivation of silenced genes by zebularine. J Natl Cancer Inst. 2003;95:399-409.

25. Baker $\mathrm{M}$, Wayland $\mathrm{H}$. On-line volume flow rate and velocity profile measurement for blood in microvessels. Microvasc Res. 1974;7:131-143.

26. Metivier R, Penot G, Hubner MR, et al. Estrogen receptor-alpha directs ordered, cyclical, and combinatorial recruitment of cofactors on a natural target promoter. Cell. 2003;115:751763.

27. Fahrner JA, Eguchi S, Herman JG, Baylin SB. Dependence of histone modifications and gene expression on DNA hypermethylation in cancer. Cancer Res. 2002;62:7213-7218.

28. Gardiner-Garden M, Frommer M. CpG islands in vertebrate genomes. J Mol Biol. 1987;196:261-282.

29. Skov S, Rieneck K, Bovin LF, et al. Histone deacetylase inhibitors: a new class of immunosuppressors targeting a novel signal pathway essential for CD154 expression. Blood. 2003;101:1430-1438.

30. Strahl BD, Allis CD. The language of covalent histone modifications. Nature. 2000;403:4145.

31. Kouzarides T. Histone methylation in transcriptional control. Curr Opin Genet Dev 2002;12:198-209.

32. Turner BM. Reading signals on the nucleosome with a new nomenclature for modified histones. Nat Struct Mol Biol. 2005;12:110-112.

33. Margueron $\mathrm{R}$, Trojer $\mathrm{P}$, Reinberg $\mathrm{D}$. The key to development: interpreting the histone code? Curr Opin Genet Dev. 2005;15:163-176.

34. Struhl K. Histone acetylation and transcriptional regulatory mechanisms. Genes Dev. 1998;12:599-606

35. Litt MD, Simpson M, Gaszner M, Allis CD, Felsenfeld G. Correlation between histone lysine methylation and developmental changes at the chicken beta-globin locus. Science. 2001;293:2453-2455

36. Noma K, Allis CD, Grewal SI. Transitions in distinct histone $\mathrm{H} 3$ methylation patterns at the heterochromatin domain boundaries. Science. 2001;293:1150-1155.

37. Nguyen CT, Weisenberger DJ, Velicescu M, et al. Histone H3-lysine 9 methylation is associated with aberrant gene silencing in cancer cells and is rapidly reversed by 5-aza-2'deoxycytidine. Cancer Res. 2002;62:6456-6461.

38. Fuks F, Burgers WA, Brehm A, Hughes-Davies L, Kouzarides T. DNA methyltransferase Dnmt1 associates with histone deacetylase activity. Nat Genet. 2000;24:88-91.

39. Schmelz K, Sattler N, Wagner M, Lubbert M, Dorken B, Tamm I. Induction of gene expression by 5-Aza-2'-deoxycytidine in acute myeloid leukemia (AML) and myelodysplastic syndrome (MDS) but not epithelial cells by DNA-methylation-dependent and -independent mechanisms. Leukemia. 2005;19:103-111.

40. Robertson KD, Ait-Si-Ali S, Yokochi T, Wade PA, Jones PL, Wolffe AP. DNMT1 forms a complex with $\mathrm{Rb}, \mathrm{E} 2 \mathrm{~F} 1$ and $\mathrm{HDAC} 1$ and represses transcription from E2F-responsive promoters. Nat Genet. 2000;25:338-342.

41. Rountree MR, Bachman KE, Baylin SB. DNMT1 binds HDAC2 and a new co-repressor, DMAP1, to form a complex at replication foci. Nat Genet. 2000;25:269-277.

42. Fuks F, Hurd PJ, Deplus R, Kouzarides T. The DNA methyltransferases associate with HP1 and the SUV39H1 histone methyltransferase. Nucleic Acids Res. 2003;31:2305-2312.

43. Arnold JM, Cummings M, Purdie D, Chenevix-Trench G. Reduced expression of intercellular adhesion molecule-1 in ovarian adenocarcinomas. Br J Cancer. 2001;85:1351-1358.

44. Maeda T, Towatari M, Kosugi H, Saito H. Up-regulation of costimulatory/adhesion molecules by histone deacetylase inhibitors in acute myeloid leukemia cells. Blood. 2000;96:38473856. 
45. Friedrich MG, Chandrasoma S, Siegmund KD, et al. Prognostic relevance of methylation markers in patients with non-muscle invasive bladder carcinoma. Eur $\mathrm{J}$ Cancer. 2005; 41:2769-2778.

46. Tamaru H, Selker EU. A histone $\mathrm{H} 3$ methyltransferase controls DNA methylation in Neurospora crassa. Nature. 2001;414:277-283.

47. Bachman KE, Park BH, Rhee I, et al. Histone modifications and silencing prior to DNA methylation of a tumor suppressor gene. Cancer Cell. 2003;3:89-95.

48. Hou J, Baichwal V, Cao Z. Regulatory elements and transcription factors controlling basal and cytokine-induced expression of the gene encoding intercellular adhesion molecule 1. Proc Natl Acad Sci U S A. 1994;91:11641-11645.

49. Ledebur HC, Parks TP. Transcriptional regulation of the intercellular adhesion molecule-1 gene by inflammatory cytokines in human endothelial cells. Essential roles of a variant NFkappa B site and p65 homodimers. J Biol Chem. 1995;270:933-943.

50. Maio M, Coral S, Fratta E, Altomonte M, Sigalotti L. Epigenetic targets for immune intervention in human malignancies. Oncogene. 2003;22:6484-6488.

51. De Smet $C$, Lurquin $C$, Lethe $B$, Martelange $V$, Boon T. DNA methylation is the primary silencing mechanism for a set of germ line- and tumor-specific genes with a CpG-rich promoter. Mol Cell Biol. 1999;19:7327-7335.

52. Deroanne CF, Bonjean K, Servotte S, et al. Histone deacetylases inhibitors as antiangiogenic agents altering vascular endothelial growth factor signaling. Oncogene. 2002;21:427-436. 


\title{
Supporting Materials and Methods
}

\author{
Intravital microscopy
}

Vessel diameters were determined using a home-built image-shearing device, as described before. ${ }^{1}$ Centerline blood flow velocity was measured by frame-to-frame analysis, using the fastest passing fluorescent leukocyte as a marker. Average velocity was calculated as centerline velocity/1.6, ${ }^{2}$ and reduced velocity as average velocity/diameter. Local blood flow was calculated as follows: $\pi$ * (diameter/2) ${ }^{2}$ * (average velocity).

The level of leukocyte rolling was determined by counting the number of rolling cells passing a vessel segment per minute. Leukocytes were considered as rolling when their velocity along the vessel wall was at least an order of magnitude lower than that of the free-flowing blood cells. The level of leukocyte adhesion was assessed in a 100- $\mu \mathrm{m}$ vessel segment, and expressed as number of cells per endothelial surface area (assuming the cross-section of the vessels to be circular). Leukocytes were considered adherent when they remained stationary for at least $30 \mathrm{s.}^{1}$

1. Dirkx AE, Oude Egbrink MG, Kuijpers MJ, et al. Tumor angiogenesis modulates leukocytevessel wall interactions in vivo by reducing endothelial adhesion molecule expression. Cancer Res. 2003;63:2322-2329.

2. Baker $\mathrm{M}$, Wayland $\mathrm{H}$. On-line volume flow rate and velocity profile measurement for blood in microvessels. Microvasc Res. 1974;7:131-143.

\section{Supporting Tables}

\begin{tabular}{|c|c|c|c|}
\hline \multicolumn{4}{|c|}{ Supporting Table 4.1. Quantitative real-time RT-PCR primers } \\
\hline Gene & species & Forward $\left(5^{\prime} \rightarrow 3^{\prime}\right)$ & Reverse $\left(5^{\prime} \rightarrow 3^{\prime}\right)$ \\
\hline cyclophilin A & $\begin{array}{l}\text { human } \\
\text { mouse }\end{array}$ & $\begin{array}{l}\text { CTCGAATAAGTTTGACTTGTGTTT } \\
\text { ATTTCTTTTGACTTGCGGGC }\end{array}$ & $\begin{array}{l}\text { CTAGGCATGGGAGGGAACA } \\
\text { AGACTTGAAGGGGAATG }\end{array}$ \\
\hline \multirow[t]{2}{*}{ ICAM-1 } & human & GGCCGGCCAGCTTATACAC & TAGACACTTGAGCTCGGGCA \\
\hline & mouse & GTGGCGGGAAAGTTCCTG & $\begin{array}{l}\text { CGTCTTGCAGGTCATCTTAGG } \\
\text { AG }\end{array}$ \\
\hline \multirow[t]{2}{*}{ VCAM-1 } & human & TCAGATTGGAGACTCAGTCATGT & АСТССТСАССТTСССGСТС \\
\hline & mouse & AGTTGGGGATTCGGTTGTTC & САТTССТTACСАССССАТTG \\
\hline \multirow{2}{*}{ E-selectin } & human & CCCGAAGGGTTTGGTGAG & TAAAGCCCTCATTGCATTGA \\
\hline & mouse & CCAGAATGGCGTCATGGA & TAAAGCCCTCATTGCATTGA \\
\hline \multicolumn{4}{|c|}{ Supporting Table 4.2. ICAM-1 Bisulfite sequencing primers } \\
\hline Position & & Forward $\left(5^{\prime} \rightarrow 3^{\prime}\right)$ & Reverse $\left(5^{\prime} \rightarrow 3^{\prime}\right)$ \\
\hline$(-1247 ;-873)$ & & GTTTTTGGATGGTTAGTGATT & AAAACTAAAACAACAACCCCC \\
\hline$(-893 ;-489)$ & & GGGGGTTGTTGTTTTAGTTT & ССТССАСТАAАAАATAССССТ \\
\hline$(-583 ;-300)$ & & GAGGTGTTTGGTTTTGTTTTGG & TTTTAАAТАСТАССААСТТСССС \\
\hline$(-322 ;-17)$ & & GGGGAAGTTGGTAGTATTTAAA & СТААССАССТАAАAАCСAAAA \\
\hline
\end{tabular}




\begin{tabular}{lll}
\hline Supporting Table 4.3. ICAM-1 ChIP primers & \\
\hline Position & Forward $\left(5^{\prime} \rightarrow 3^{\prime}\right)$ & Reverse $\left(5^{\prime} \rightarrow 3^{\prime}\right)$ \\
\hline$(-230 ;-56)$ & TGGAGGCCGGGAGCAG & AAACCTCGCGCCTTCCC \\
\hline
\end{tabular}





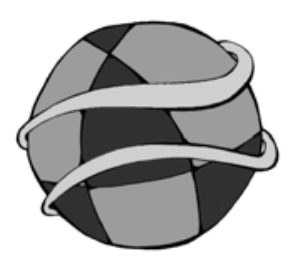

\section{Chapter 5 Dual targeting of epigenetic therapy in cancer}

Debby M.E.I. Hellebrekers, Arjan W. Griffioen, Manon van Engeland

Biochim Biophys Acta. 2006, in press 


\begin{abstract}
Aberrant epigenetic silencing of tumor suppressor genes by promoter DNA hypermethylation and histone deacetylation plays an important role in the pathogenesis of cancer. The potential reversibility of epigenetic abnormalities encouraged the development of pharmacologic inhibitors of DNA methylation and histone deacetylation as anti-cancer therapeutics. (Pre)clinical studies of DNA methyltransferase (DNMT) and histone deacetylase (HDAC) inhibitors have yielded encouraging results, especially against hematologic malignancies. Recently, several studies demonstrated that DNMT- and HDAC inhibitors are also potent angiostatic agents, inhibiting (tumor) endothelial cells and angiogenesis in vitro and in vivo. By reactivation of epigenetically silenced tumor suppressor genes with angiogenesis inhibiting properties, DNMT- and HDAC inhibitors might indirectly - via their effects on tumor cells - decrease tumor angiogenesis in vivo. However, this does not explain the direct angiostatic effects of these agents, which can be unraveled by gene expression studies and examination of epigenetic promoter modifications in endothelial cells treated with DNMT- and HDAC inhibitors. Clearly, the dual targeting of epigenetic therapy on both tumor cells and tumor vasculature makes them attractive combinatorial anti-tumor therapeutics. Here we review the therapeutic potential of DNMT- and HDAC inhibitors as anti-cancer drugs, as evaluated in clinical trials, and their angiostatic activities, apart from their inhibitory effects on tumor cells.
\end{abstract}

\title{
Introduction
}

Epigenetics is the study of heritable changes in gene expression that are not coded in the DNA sequence itself. Essential to regulation of gene expression is chromatin structure. The fundamental repeating unit of chromatin is the nucleosome, which consists of $147 \mathrm{bp}$ of DNA wrapped around a core of eight histone proteins, termed $\mathrm{H} 2 \mathrm{~A}, \mathrm{H} 2 \mathrm{~B}, \mathrm{H} 3$ and $\mathrm{H} 4$. Early cytological studies distinguished two types of chromatin. Heterochromatin is generally condensed and transcriptionally inactive, whereas euchromatin has an "open" configuration that is favourable for gene transcription. In the past decade, remarkable advances in the techniques to study epigenetics revealed distinct mechanisms which are intricately related in initiating and sustaining epigenetic modifications. Amongst these mechanisms are methylation of DNA and post-translational modifications of histone proteins, which cause changes in chromatin configuration, thereby regulating the accessibility of chromatin to transcription regulatory proteins. In addition, Polycomb group (PcG) proteins play a role as transcriptional repressors by modifying chromatin structure and by regulating the deposition and recognition of multiple post-translational histone modifications. ${ }^{1}$ Small non-coding RNA molecules constitute a relatively novel class of epigenetic gene regulators, which are processed from double-stranded precursors and which induce sequence-specific transcriptional gene silencing by targeting chromatin modifications to genomic regions. ${ }^{2}$ 
The best studied epigenetic mechanisms are DNA methylation and posttranslational histone modifications. DNA methylation is the covalent addition of a methyl group to the DNA, predominantly to the base cytosine 5' to guanine, also called a CpG dinucleotide. ${ }^{3}$ These $\mathrm{CpG}$ dinucleotides are underrepresented in the genome, probably because of progressive depletion of methylated CpG dinucleotides due to spontaneous deamination of methylated cytosines into thymidine. If this thymidine is not recognized and repaired, a cytosine-to-thymidine change remains. In contrast to the general underrepresentation of $\mathrm{CpGs}$ in the overall genome, a subset of CpG dinucleotides are clustered in small stretches of DNA called CpG islands, often located in or near the promoter region of approximately half of all genes. Methylation of $\mathrm{CpG}$ dinucleotides, which occurs non-randomly, is an important epigenetic gene silencing mechanism. ${ }^{3}$ Most methylation in the human genome occurs in the non-coding DNA, preventing the transcription of repeat elements, inserted viral sequences and transposons. In contrast, CpG islands are largely unmethylated in both expressing and non-expressing tissues under normal conditions. Exceptions to this unmethylated state of $\mathrm{CpG}$ islands involve the silenced gene alleles for imprinted genes and genes located on the inactive $X$ chromosome of females. ${ }^{3,4}$ DNA methylation is catalysed by DNA methyltransferases (DNMTs), of which three active enzymes have been identified in mammals, namely DNMT1, DNMT3a and DNMT3b. During developmental processes in the mouse, DNMT1 is responsible for maintaining pre-existing methylation patterns during DNA replication, while DNMT3a and DNMT3b are required for initiation of de novo methylation. ${ }^{5,6}$ DNA methylation can induce gene silencing through several mechanisms. By sterically hindering the binding of activating transcription factors to gene promoters, DNA methylation can directly repress gene transcription. Another mechanism is through recruitment of several methyl-binding domain proteins (MBDs) that recognize methylated DNA, including MeCP2, MBD1-4 and Kaiso. These proteins themselves can repress gene transcription, or bind chromatin-remodelling proteins and transcription-regulatory complexes which cause gene silencing. ${ }^{7}$ Apart from their methylation ability, DNMTs have additional roles in gene silencing, by acting as transcriptional repressors themselves, or by serving as binding scaffolds for transcriptional repressors, histone deacetylases and histone methyltransferases. Thereby, DNMTs can establish gene silencing independent of their catalytic activity. ${ }^{8-10}$

The DNA helix is wrapped around a core of histone proteins. The basic aminoterminal tails of histones protrude out of the nucleosome and are subject to various post-translational modifications, including acetylation, methylation, phosphorylation, ubiquitination, sumoylation, ADP-ribosylation, glycosylation, biotinylation and carbonylation. ${ }^{11,12}$ The totality of histone modifications, or "histone code", is read by proteins involved in chromatin remodelling, transcriptional activation- or repression, and thereby governs chromatin dynamics and gene transcription. ${ }^{13}$ Different (combinations of) histone modifications determine a functional outcome, as reviewed by Kouzarides and Martin. ${ }^{14,15}$ The best characterized histone modification is histone acetylation, which is controlled by histone acetyltransferases (HATs) and histone deacetylases (HDACs). HATs can be divided into several families, based on the presence of highly conserved structural motifs. Among these are the GNAT, MYST and p300/CBP families. ${ }^{16}$ The HDAC family contains three classes based on their 
homology to yeast proteins. Class I HDACs (HDAC1-3 and 8) are related to the yeast RPD3 HDAC. Class II HDACs include HDACs 4, 5, 6, 7, 9 and 10, and have similarities with the HDA1 HDAC in yeast. The third group of HDACs, called sirtuins, contains proteins possesing NAD+- dependent activity with homology to yeast SIR2 ${ }^{16}$ Histone acetylation generally correlates to an open and transcriptionally active chromatin state, whereas histone deacetylation is associated with chromatin condensation and transcriptional repression. ${ }^{17}$ By removal of acetyl groups from histone tails, the ionic interaction between histones and DNA results in chromatin condensation, thereby blocking accessibility of transcription factors to their binding sites. Furthermore, histone acetylation has been correlated with other genome functions, including chromatin assembly, DNA repair and recombination, as well as replication timing of specific genomic regions. ${ }^{18-20}$ In addition to histones, many other cytoplasmic and nuclear proteins can be reversibly acetylated, influencing protein stability, protein-protein interactions, protein localization, and DNA binding. ${ }^{21}$ Among the non-histone protein substrates of HATs and HDACs are transcription factors such as $p 53,{ }^{22}$ GATA- $1,{ }^{23}$ E2F, ${ }^{24}$ nuclear receptors (glucocorticoid, thyroid, and estrogen receptor), ${ }^{25} \mathrm{MyoD},{ }^{26}$ RelA, ${ }^{27} \mathrm{TFIIE}$ and TFIIF. ${ }^{28}$ Other examples of non-histone protein targets of HATs and HDACs are regulators of cell growth and death pathways, including the retinoblastoma protein $(\mathrm{Rb}){ }^{29}$ proteins involved in cell motility (e.g. $\alpha$ tubulin) $)^{30}$ and angiogenesis (e.g. hypoxia-inducible factor- $\left.1 \alpha\right)^{31}$ and others such as Hsp90 ${ }^{32}$ and HMGB1. ${ }^{33}$

DNA methylation and histone deacetylation are interconnected in gene silencing. Methyl-binding domain proteins are components of HDAC complexes or recruit these complexes to methylated DNA, resulting in chromatin remodelling and transcriptional silencing. ${ }^{7}$ Furthermore, a much more direct connection between DNA methylation and histone deacetylation exists by direct interactions between DNMTs and HDACs. ${ }^{8,9}$ Thereby, DNMTs can repress transcription using deacetylase activity, independent of their methylation capacity. DNA methylation and histone deacetylation are pivotal in $X$ chromosome inactivation, genomic imprinting and establishment of tissue specific gene expression. ${ }^{34}$ However, aberrant epigenetic regulation of gene expression also plays a major role in the development of human cancer.

\section{DNA methylation and histone deacetylation as therapeutic targets in cancer}

\section{Epigenetic abnormalities in cancer}

Epigenetic changes play a significant role in tumor formation and progression. Overall, the genome of malignant cells is characterized by global DNA hypomethylation and reductions of specific histone modifications, i.e. loss of monoacetylation at lysine 16 and trimethylation at lysine 20 of histone $\mathrm{H} 4 .^{35-37}$ These global epigenetic alterations are thought to contribute to carcinogenesis through harmful expression of inserted viral sequences, oncogene activation, loss of imprinting and $\mathrm{X}$ chromosome inactivation, and genomic instability through hypomethylation of structural elements, such as centromeres. ${ }^{38}$ On the other hand, promoter 
hypermethylation and deacetylation of $\mathrm{CpG}$ islands results in aberrant transcriptional silencing of tumor suppressor genes. ${ }^{4}$ According to Knudson's two-hit model, ${ }^{39}$ complete loss of function of a tumor suppressor gene requires loss of function of both gene copies. Epigenetic silencing of the wild-type allele of a tumor suppressor gene by aberrant promoter hypermethylation and histone deacetylation can be considered as the second hit in this model, resulting in complete loss of function of the gene. Aberrant tumor suppressor gene DNA methylation in human cancer cells is cooperatively maintained by DNMT1 and DNMT3b. ${ }^{40}$ It has become apparent that many genes, located across all chromosome locations, are epigenetically silenced in cancer cells. In fact, more genes might be inactivated by epigenetic silencing as they are by genetic aberrations. ${ }^{4}$ Epigenetic tumor suppressor gene silencing can predispose to mutations during tumor progression. For example, inactivation of the DNA repair genes $M L H 1$ and $M G M T$ by methylation results in microsatellite instability and increased frequency of mutations, respectively. ${ }^{41,42} \mathrm{~A}$ unique profile of promoter hypermethylation for each human cancer in which some methylated genes are shared and others are tumor-type-specific has been identified. ${ }^{43}$ Examples are genes involved in cell cycle regulation and apoptosis (p14ARF, p15INK4b, p16INK4a, APC, RASSF1A, HIC1), DNA repair genes ( $h M L H 1, G S T P 1, M G M T, B R C A 1)$, and genes related to metastasis and invasion (CDH1, TIMP-3, DAPK, p73, maspin, TSP1, $V H L){ }^{4,43-47}$ Since aberrant methylation is linked to transcriptional gene silencing, novel tumor suppressor genes can be identified using methylated CpG islands as a marker. Therefore, several techniques reviewed by Laird et al. ${ }^{48}$ are developed to study methylation content, levels, patterns and profiles. By using methylation-specific PCR (MSP), methylation profiles can be obtained for virtually all major types of cancer. ${ }^{49,50}$ Tumor methylation and histone modification profiles provide one of the most promising biomarkers for early cancer detection and risk assessment, as well as for prediction of cancer prognosis or response to a particular therapy. ${ }^{35,51}$

The mechanisms underlying the epigenetic disruptions in tumor cells are largely unknown. A possibility is that the genes encoding the enzymes that catalyze the chromatin modifications may themselves be targets of genetic disruption. Studies exploring genetic alterations in these epigenetic genes are currently emerging. The activity of HATs is altered in leukemia by the generation of fusion proteins such as MOZ-CBP and MORF-CBP. ${ }^{36}$ In addition, somatic mutations of the HATs CBP, p300 and $\mathrm{PCAF}$ have been described in primary human tumors. ${ }^{52-54}$ Ropero et al. identified truncating mutations in HDAC2 in human cancer cell lines and primary tumors with microsatellite instability causing a loss of HDAC2 protein expression and enzymatic activity. ${ }^{55}$ This mutation renders the cells more resistant to effects of HDAC inhibitors. Two different single nucleotide polymorphisms (SNPs) in the DNMT3b gene have been associated with lung cancer susceptibility. ${ }^{56,57}$ Furthermore, an association between SNPs in chromatin modifying enzymes and susceptibility to breast cancer has been suggested recently. ${ }^{58}$ Further studies are required to unravel the exact functional effects of genetic variations in epigenetic genes.

DNA methyltransferase- and histone deacetylase inhibitors

The importance of epigenetic alterations in the initiation and progression of human cancer creates novel therapeutic targets. In contrast to genetic alterations, which are 
almost impossible to reverse, epigenetic changes in cancer are potentially reversible. This resulted in the development of pharmacologic inhibitors of DNA methylation and histone deacetylation. By inducing DNA demethylation and histone acetylation, these compounds can reverse epigenetic silencing of tumor suppressor genes, resulting in reactivation of these genes in tumor cells and restoring of crucial cellular pathways.

The most extensively studied DNMT inhibitors are 5-azacytidine (Vidaza) and 5aza-2'-deoxycytidine (Decitabine), which were initially developed as chemotherapeutic agents. These nucleoside analogs are incorporated into DNA in place of the natural base cytosine during DNA replication, and are therefore only active during $S$ phase. Once incorporated into the DNA, a complex is formed with active sites of DNMTs, thereby covalently trapping these enzymes. ${ }^{59}$ This results in the depletion of active enzymes and the demethylation of DNA after several cell divisions. A difference between 5-azacytidine and 5-aza- 2'-deoxycytidine is that the first is partly incorporated into RNA, thereby interfering with protein translation, while 5-aza- 2'deoxycytidine is incorporated only into DNA, causing more efficient inhibition of DNMTs. A major disadvantage of 5-azacytidine and 5-aza- 2'-deoxycytidine is their instability in neutral aqueous solution. This resulted in the development of more stable cytidine analogs, such as 5,6-dihydro-5-azacytidine and 5-fluoro-2'-deoxycytidine. ${ }^{60}$ 5,6-Dihydro-5-azacytidine has received mixed reviews on its efficacy in Phase I and II studies, resulting in a discontinuation of clinical studies on this drug. ${ }^{61}$ 5-Fluoro-2'deoxycytidine is currently undergoing Phase I studies, but generates 5fluorodeoxyuridine and its metabolites, which may be toxic. ${ }^{62}$ Zebularine is a novel DNMT inhibitor which is very stable, enabling oral administration of the drug. In addition, this cytidine analog is minimally toxic both in vitro and in vivo ${ }^{63}$ and has a high selectivity for tumor cells. ${ }^{64}$ Although these properties make zebularine a promising candidate for cancer treatment, the requirement of higher concentrations (up to $1 \mathrm{~g} / \mathrm{kg}$ body weight in the mouse model) in comparison with 5-aza- 2'deoxycytidine has important consequences for the clinical potential. The toxicity of nucleoside analogs, associated with their incorporation into DNA, resulted in the search for non-nucleoside DNMT inhibitors. Procainamide and procaine inhibit DNMTs by perturbing interactions between the protein and its target sites. ${ }^{60}$ The DNA demethylating activity of the antihypertensive compound hydralazine can be explained by the interaction between its nitrogen atoms and the DNMT active site. ${ }^{65}$ Epigallocathechin-3-gallate, a natural product derived from green tea, has shown to inhibit DNMT activity by binding to and blocking the active site of human DNMT1. ${ }^{66}$ RG108 is a novel small molecule that blocks the DNMT active site. Intriguingly, it causes demethylation and reactivation of tumor suppressor genes, but does not affect methylation of centromeric satellite sequences. These characteristics make RG108 particularly useful for new drug development. ${ }^{67}$ As described above, three active DNMTs are identified in mammalian cells. Most DNMT inhibitors are not specific for a particular DNMT, which may result in unfavourable toxicity. Therefore, new compounds with specificity for a particular DNMT are being developed. One of these compounds is MG98, an antisense oligonucleotide that specifically inhibits DNMT1 mRNA. $^{68}$

By inhibiting histone deacetylation, HDAC inhibitors cause accumulation of acetylated histones, thereby inducing an open chromatin conformation, leading to 
increased transcription of previously silenced genes. Both naturally existing and synthetic HDAC inhibitors have been characterized. ${ }^{21,69}$ These compounds are structurally heterogeneous, and can be classified according to their chemical nature and mechanism of inhibition. The short-chain fatty acids phenylbutyrate and valproic acid are relatively old drugs that have been used for non oncological uses and recently shown to have activity as HDAC inhibitors. ${ }^{16}$ These compounds possess an acyl group which contacts the catalytic HDAC zinc ion but cannot make significant contact with the catalytic pocket due to their very short side chains. Therefore, phenylbutyrate and valproic acid act as HDAC inhibitors at relatively high concentrations. The hydroxamic acids are very potent but reversible HDAC inhibitors, that bind more strongly to the HDAC catalytic site. ${ }^{16}$ Among these compounds is trichostatin A (TSA), originally developed as an antifungal agent, which is active at nanomolar concentrations. ${ }^{70}$ Other hydroxamic acids are suberoylanilide hydroxamic acid (SAHA), pyroxamide, oxamflatin, PXD101, NVP-LAQ824 and LBH589. ${ }^{21,71}$ The hydroxamate Scriptaid, a novel synthetic HDAC inhibitor with a relatively low toxicity, was isolated from a screening library by $\mathrm{Su}$ et al. ${ }^{72}$ The cyclic hydroxamic-acid containing peptide (CHAP) compounds are built from TSA and cyclic tetrapeptides and inhibit HDACs at nanomolar concentrations. ${ }^{73} \mathrm{~A}$ third class of HDAC inhibitors are the cyclic tetrapeptides, including depsipeptide (FK-228, FR901228), apicidin and trapoxin. Depsipeptide is a prodrug that is activated by reduction upon cellular uptake and inhibits class I HDACs, although the exact mechanism of inhibition remains unknown. ${ }^{74}$ Apicidin is a reversible HDAC inhibitor at low nanomolar concentrations, bearing an alkylketone residue that is supposed to chelate the catalytic HDAC zinc ion. ${ }^{75}$ Trapoxin is closely related to apicidin, and irreversibly inactivates HDAC by covalent interaction between its epoxide group and the HDAC catalytic site. ${ }^{76}$ The benzamides are a structurally diverse fourth class of HDAC inhibitors. It is believed that the benzamide binds the active zinc in the HDAC catalytic site. The synthetic HDAC inhibitor MS-275 inhibits HDAC at micromolar concentrations. ${ }^{77} \mathrm{Cl}-994(\mathrm{~N}-$ acetyl dinaline) is a relatively weak HDAC inhibitor and the mechanism of its action is still unknown. It inhibits histone deacetylation, but not by inhibiting HDAC activity.

\section{Targeting epigenetic processes in tumor cells}

DNMT- and HDAC inhibitors are powerful inducers of genes silenced by epigenetic promoter modifications in tumor cells. Therefore, they can be used to study the role of DNA methylation and histone deacetylation in tumor biology or in regulation of gene expression in tumor cells. Also, new tumor suppressor genes can be identified by reversal of epigenetic gene silencing using DNMT- and HDAC inhibitors.

Decitabine (5-aza- 2'-deoxycytidine) is the most commonly used DNMT inhibitor in assays with cultured cells. This compound reactivates dormant tumor suppressor genes by demethylation of their hypermethylated promoter, thereby restoring their normal function. This seems to be a widespread effect of 5-aza- 2'-deoxycytidine, because all cancer cell lines studied so far are sensitive to the DNA demethylating effects of this agent. ${ }^{78}$ Reactivation of silenced tumor suppressor genes might be the mechanism by which this compound suppresses growth and induces differentiation of human tumor cell lines. ${ }^{79}$ Furthermore, 5-aza- 2'-deoxycytidine can also induce reexpression of some tumor suppressor genes without promoter hypermethylation, such 
as APAF-1. ${ }^{80,81}$ Demethylation of upstream genes, such as transcription factors, might be responsible for these effects. Another possibility is that 5-aza- 2'-deoxycytidine reactivates genes by reversal of methylation-independent transcriptional repressor functions of DNMTs. Although most studies investigating the induction of gene expression by 5 -aza- 2'-deoxycytidine have focused on the reactivation of known genes, epigenetically silenced tumor suppressor genes can be identified using microarray technology. Using this approach, Karpf et al. ${ }^{82}$ revealed transcriptional induction of IFN-responsive genes in HT29 colon carcinoma cells by 5-aza- 2'deoxycytidine. Similar studies have now also been performed using zebularine. ${ }^{83}$ In other studies, microarrays are used to analyze the effect of 5-aza- 2'-deoxycytidine on gene expression in both tumorigenic and non-tumorigenic cells. ${ }^{84,85}$

HDAC inhibitors have many antitumor effects including induction of cell cycle arrest, differentiation, and/or apoptosis in virtually all cultured transformed cell types and in cells from different tumors. ${ }^{21}$ The driving hypothesis behind this observation is that HDAC inhibitors cause accumulation of acetylated histones in nucleosomes, thereby relaxing the chromatin and inducing genes that have become epigenetically silenced in malignant cells. The effects of HDAC inhibitors on gene expression in transformed cells are selective; only about $2-10 \%$ of all known genes are affected by these agents. ${ }^{86}$ One gene most consistently induced by HDAC inhibition is CDKN1A, which encodes the cell cycle inhibitor p21. ${ }^{87}$ The enhanced CDKN1A transcription is associated with increased histone acetylation of this gene. Other growth inhibitory genes that are induced by HDAC inhibitors in transformed cells are CDKN2A, which encodes $\mathrm{p} 16$, and the genes encoding cyclin $\mathrm{E}$, thioredoxin binding protein 2 (TBP2), GADD45 $\alpha$ and $\beta$, and the tumor suppressor gelsolin. ${ }^{16}$ Furthermore, these drugs can relieve inappropriate transcriptional repression mediated by chimeric oncoproteins, such as PML-RAR $\alpha$, thereby inducing differentiation in cells harbouring these translocations. ${ }^{16}$ Besides modulation of gene transcription by directly affecting gene chromatin structure, dysregulated histone acetylation during $S$ phase and/or mitosis might be a cause of cell death induction by HDAC inhibitors. Hyperacetylation of the centromere induces heterochromatin protein release, resulting in abnormal chromosomal segregation, which leads to aberrant mitosis and apoptosis. ${ }^{88}$ As described above, many non-histone proteins are targets for histone acetylation. Therefore, another proposed mechanism behind the antitumor activity of HDAC inhibitors is the increased acetylation of non-histone proteins involved in cell signal transduction pathways or cell death pathways, thereby modifying cell cycle, differentiation and apoptosis. ${ }^{21}$ For example, by inducing acetylation of Hsp90, the chaperone protein for oncoproteins such as Akt and c-Raf, HDAC inhibitors cause proteasomal degradation of these prosurvival proteins. ${ }^{89}$ Furthermore, by increasing acetylation of p53, HDAC inhibition can increase transcriptional activation of this tumor suppressor protein. ${ }^{22}$

As described above, DNA hypermethylation and histone deacetylation are dynamically linked in gene silencing. The relation between these two mechanisms was investigated by Cameron et al., ${ }^{90}$ who demonstrated a synergy between 5-aza2'-deoxycytidine and TSA in reactivation of epigenetically silenced tumor suppressor genes. Using microarray analysis, Suzuki et al. ${ }^{81}$ and Yamashita et al. ${ }^{91}$ revealed novel tumor suppressor genes by treatment of tumor cells with a combination of 5- 
aza- 2'-deoxycytidine and TSA. Indeed, cotreatment of tumor cells with DNMT- and HDAC inhibitors seems to produce stronger anti-neoplastic effects than by either compound alone. ${ }^{92,93}$

\section{Clinical application of DNA methyltransferase- and histone deacetylase inhibitors}

It is clear from in vitro and preclinical studies that the clinical application of reversing epigenetic aberrations in tumor cells, called epigenetic therapy, ${ }^{94}$ is an exciting strategy for cancer treatment. Many agents have been discovered that inhibit DNA methylation or histone deacetylation, and the value of these compounds will be established by ongoing clinical trials.

5-Azacytidine (Vidaza) and 5-aza- 2'-deoxycytidine (Decitabine) represent the two most prominent DNMT inhibitors that are being used in clinical practice. ${ }^{94,95}$ There has been a shift in the clinical use of these compounds from chemotherapeutic to demethylating agents. In the past, prior to the discovery of the demethylating activity of the compounds, 5-azacytidine and 5-aza- 2'-deoxycytidine were used at high, often quite toxic doses for the treatment of leukemia. The recognition of the epigenetic activities of these compounds resulted in the clinical use of much lower doses of these drugs, especially in the field of hematological malignancies. Low-dose 5-azacytidine has been successfully tested in patients with myelodysplastic syndromes (MDS). ${ }^{96}$ The use of DNMT inhibitors in the treatment of MDS results from the knowledge that epigenetic gene silencing of - in particular - p15INK4b is present in poor-risk MDS subtypes and often predicts transformation to acute myeloid leukemia (AML). In a Phase III trial, significantly higher response rates were reported in the 5-azacytidine group as compared with the group receiving supportive care only. ${ }^{97}$ Furthermore, quality of life was significantly improved in the 5-azacytidine group of the same study

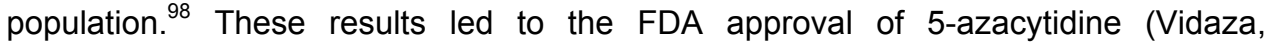
Pharmion, Boulder, CO, USA) for treatment of all MDS subtypes and to the fast-track status of Decitabine (Dacogen, SuperGen Inc., Dublin, CA, USA, and MGI Pharma Inc., Bloomington, MN, USA) for MDS. ${ }^{99}$ In several Phase I/II/III studies, Decitabine (5aza- 2'-deoxycytidine) has also shown promising data in patients with MDS and AML. ${ }^{100-103}$ In addition, this agent has a clinically significant, often long lasting effect on the platelet count in a substantial number of high-risk MDS patients. ${ }^{104}$ Clinical trials with Decitabine were also promising for other leukemias. ${ }^{105,106}$ Several Phase I-II studies for solid tumors have been developed, with prolonged disease stabilization in patients with lung cancer or prostate cancer. ${ }^{107,108}$ Although demethylation of p15INK4b correlated with clinical activity of Decitabine in MDS patients, ${ }^{109}$ the question of whether clinical benefit is mediated through DNMT inhibition, reversal of methylation, and gene reactivation, is not entirely clear. ${ }^{110}$ Therefore, new compounds with specificity for particular DNMTs hold promise for a more targeted approach towards methylation. Of these compounds, MG98 is currently being tested in Phase II clinical trial. ${ }^{110}$

Despite the promising data from clinical trials, there are several pitfalls regarding the clinical application of demethylating agents. Several DNMT inhibitors have been associated with serious side effects. ${ }^{96}$ The inherent toxicity of nucleoside DNMT inhibitors might be caused by the formation of covalent adducts between DNA and trapped DNMTs. ${ }^{111}$ Furthermore, many of the demethylating drugs are not specific for 
a particular DNMT or gene, which can also result in unfavourable effects. Toxicity, a central problem in interpretation of clinical data, might be reversed by optimising treatment schedules, e.g. giving lower doses over longer time periods, thereby exposing more cells during $S$ phase. As described above, development of nonnucleoside inhibitors may be less toxic because they are not incorporated into DNA. Also, compounds that specifically target a particular DNMT, such as MG98, might reduce nonspecific effects. Definition of surrogate endpoints for monitoring changes during treatment of patients will help to interpret clinical responses. Analysis of patterns and/or levels of DNA methylation in patients may be an important endpoint. Therefore, assays for genome-wide and tumor-specific DNA methylation need to be further developed. ${ }^{110}$ Another important aspect that should be taken into account in the clinical use of demethylating agents is induction of global hypomethylation, which might induce tumorigenesis by activation of oncogenes, induction of chromosomal instability and mutagenesis. ${ }^{38,112}$ However, recent data from Yang et al., ${ }^{113}$ describing methylation changes in leukemia patients treated with Decitabine, suggest that aberrantly methylated genes in cancer cells might be particularly susceptible to this drug.

Multiple HDAC inhibitors are currently being tested in patients through intravenous or oral administration. ${ }^{21,71}$ Phenylbutyrate was the first HDAC inhibitor to be tested in patients, and currently Phase I and II trails have been performed. Phenylbutyrate has been evaluated in AML and MDS, ${ }^{114}$ as well as solid tumor malignancies. ${ }^{115,116}$ Another short chain fatty acid HDAC inhibitor, valproic acid, has been used for decades as an antiepileptic drug. Phase I and II clinical trials for evaluation as an antitumor agent have recently been reported, ${ }^{117,118}$ and currently Phase III trials are ongoing. SAHA is one of the HDAC inhibitors most advanced in development. Encouraging results were obtained in Phase I and II clinical trials for patients with both hematologic and solid tumors. ${ }^{119}$ Currently, Phase III studies of SAHA in patients with malignant pleural mesothelioma and diffuse large B-cell lymphoma are ongoing. PXD101, NVP-LAQ824 and LBH589 are currently undergoing Phase I (NVP-LAQ824 and LBH589) and Phase II (PXD101) studies. Phase I trials with depsipeptide have shown encouraging results, especially for patients with cutaneous T-cell lymphoma. Phase II studies are ongoing to study effects in a range of solid and hematological malignancies. ${ }^{120}$ A Phase I study of MS-275 has been performed in patients with advanced solid tumors or lymphoma, and this drug is currently undergoing Phase II trials. ${ }^{121} \mathrm{Cl}-994$ has been introduced in clinical trials for a number of malignancies. ${ }^{122}$ Phase II studies have been conducted in patients with advanced non-small cell lung cancer, metastatic renal cell carcinoma, and advanced pancreatic cancer. ${ }^{123,124}$

It is still unclear whether the clinical effects of HDAC inhibitors are the result of alterations of histone acetylation patterns or changes in growth regulatory pathways by increased acetylation of non-histone proteins. As with DNMT inhibitors, a critical issue is the examination of surrogate markers. Several assays are used to measure histone acetylation, usually in peripheral blood mononuclear cells. ${ }^{125}$ The existence of many different HDACs makes understanding of the specificity of the existing HDAC inhibitors imperative, as well as development of selective inhibitors that target individual enzymes. 
True targeting of epigenetic gene regulation might require a combination of chromatin modifying agents. The synergy between demethylating drugs and HDAC inhibitors in vitro makes combined treatment with DNMT- and HDAC inhibitors a promising epigenetic therapy. Reduction of individual doses should minimize toxic effects and optimize the therapeutic response of such combination. Recently, clinical studies have been reported in which a demethylating agent in combination with an HDAC inhibitor was administered to patients with hematologic and solid tumors, achieving complete and partial remissions. ${ }^{126,127}$

\section{DNA methyltransferase- and histone deacetylase inhibitors as angiostatic agents}

\section{Angiogenesis inhibition as cancer treatment}

A different anti-cancer strategy is based on inhibition of tumor angiogenesis. Tumor growth is dependent on angiogenesis, the sprouting of new capillary vessels from pre-existing blood vessels. ${ }^{128}$ Angiogenesis is required for tumor progression to a size of approximately $2 \mathrm{~mm}^{3}$, but is also instrumental for tumor cells to metastasize to other locations in the body. The induction of tumor angiogenesis is dictated by the levels of pro- and anti- angiogenic molecules. Genetic aberrations of tumor suppressor genes and oncogenes influence the tumor phenotype, of which angiogenesis is a key component. The "angiogenic switch" occurs when tumor cells acquire genetic changes that make them switch to the angiogenic phenotype. As a result, the tumor activates the production of pro-angiogenic factors such as vascular endothelial cell growth factor (VEGF) and basic fibroblast growth factor (bFGF), resulting in a positive balance in favour of angiogenesis. ${ }^{129}$ Binding of pro-angiogenic factors to receptors on the endothelial cells causes endothelial cell activation, the subsequent degradation of the extracellular matrix by production of several proteases and plasminogen activators, followed by sprouting into the extracellular matrix, migration and proliferation of endothelial cells, and finally formation of new capillary tubes. Eventually, neovascular maturation occurs via processes such as the formation of extracellular matrix and recruitment of pericytes. ${ }^{130}$

Angiogenesis is considered to be a promising target of anti-cancer treatment. Because angiogenesis is limited in adults, angiogenesis inhibitors tend to display much less toxicity compared with standard chemotherapy. Another advantage is that endothelial cells are readily accessible to systemically administered angiostatic agents. Furthermore, unlike tumor cells, ECs are considered to be genetically stable, and therefore less likely to develop drug resistance. Over the past decade, extensive research has led to the development of therapeutic strategies to inhibit angiogenesis in cancer. ${ }^{131,132}$ Many angiostatic agents are currently in clinical trials, especially inhibitors of the VEGF pathway. Bevacizumab (Avastin), a humanized variant of a murine anti-VEGF-A monoclonal antibody, is the first antiangiogenic therapeutic approved by the FDA for cancer therapy. ${ }^{133}$ Addition of bevacizumab to chemotherapy resulted in a significant survival advantage to patients with previously untreated metastatic colorectal cancer. ${ }^{134,135}$ Recently, endostatin (Endostar), a $20 \mathrm{kDa}$ internal 
fragent of the carboxyterminus of collagen XVIII, was approved by the State FDA in China for the treatment of non-small-cell lung cancer. ${ }^{136}$ Other angiogenesis inhibitors approved by the FDA include thalidomide and the epidermal growth factor receptor inhibitor Tarceva. ${ }^{136}$

Despite the promising success of anti-VEGF therapy, inhibition of VEGF seems to be insufficient to permanently block tumor angiogenesis. This may be (partially) due to acquired resistance to anti-VEGF agents. Inhibition of VEGF may result in induction of other angiogenic pathways or selection of "hypoxia resistant" tumor cells. ${ }^{137}$ Another mechanism of resistance is provided by recent studies suggesting that, in contrast to what was originally assumed, tumor endothelial cells can in some cases harbor genetic abnormalities. ${ }^{138,139}$ These findings might imply that future anti-angiogenesis strategies will need to be directly targeting endothelial cells. Another option is the use of combinations of angiostatic agents that target different angiogenic factors. Alternatively, monotherapy which targets both endothelial cells and another cell type that indirectly affects angiogenesis demonstrated clinical benefit in certain cancers. Indeed, Avastin only provides an overall survival benefit in colorectal-, breast- and lung cancer patients when combined with conventional chemotherapy, while antiVEGF monotherapy was ineffective in humans. (Pre)clinical studies indicate that combining anti-angiogenesis agents with conventional cytotoxic chemotherapy or radiation therapy results in additive or synergistic anti-tumor effects. ${ }^{140}$ An alternative approach is the use of drugs possessing an intrinsic dual activity against both tumor cells and tumor endothelial cells. Examples of these are the small-molecule receptor tyrosine kinase (RTK) inhibitors, of which the most advanced are SU11248 and Bay 43-9006, and chemotherapeutic agents with a claimed anti-angiogenesis activity, such as taxol.

DNA methyltransferase- and histone deacetylase inhibitors as indirect angiostatic agents

DNMT- and HDAC inhibitors influence the gene expression profile of tumor cells, targeting genes which are regulating angiogenesis. Therefore, indirect angiostatic effects of demethylating agents and HDAC inhibitors might be expected in tumors. Indeed, among the epigenetically silenced tumor suppressor genes in tumor cells are genes with angiogenesis inhibiting properties. By re-expression of these genes in tumor cells, DNMT- and HDAC inhibitors might indirectly - via the tumor cells - exhibit angiostatic effects in vivo.

Miki et al. ${ }^{141}$ demonstrated that the methylation status of p16INK4a in lung tumor cells plays an important role in the regulation of angiogenesis associated with progression of lung cancer, by modulating VEGF expression. They showed that treatment with 5-aza- 2'-deoxycytidine caused demethylation of the p16INK4a gene, with reexpression of the p16INK4a protein and decreased VEGF production. Another epigenetically silenced tumor suppressor gene that inhibits angiogenesis by downregulation of VEGF is $p 73 .{ }^{43}$ Transcriptional silencing of $p 73$ by promoter hypermethylation in correlation with increased VEGF expression was observed in several leukemias and lymphomas. ${ }^{142}$ The tumor suppressor maspin, a member of the serpin family, is an effective inhibitor of angiogenesis. ${ }^{143}$ Maspin gene expression is aberrantly silenced in many human cancers, often in association with epigenetic 
promoter modifications. ${ }^{144}$ Tissue inhibitor of metalloproteinase-2 (TIMP-2) was described to be hypermethylated in lymphoid malignancies and cervical cancer. ${ }^{145}$ TIMP-2 inhibits angiogenesis by decreasing matrix metalloproteinase (MMP) activity, although Seo et al. ${ }^{146}$ revealed that another important component of the antiangiogenic effect of TIMP-2 in vivo is the suppression of endothelial cell proliferation independent of MMP inhibition, by silencing the receptors for VEGF and bFGF. Methylation-associated inactivation of tissue inhibitor of metalloproteinase-3 (TIMP-3) is frequent in many human tumors. ${ }^{147}$ TIMP-3 inhibits angiogenesis by repressing MMPs, but also by blocking binding of VEGF to VEGF receptor 2. ${ }^{148}$ Thrombospondin1 (TSP-1) has been described to be repressed by epigenetic promoter modifications in several adult cancers. The adhesive glycoprotein TSP-1 is a potent inhibitor of angiogenesis. Binding of TSP1 to CD36 has been shown to activate apoptosis by inducing p38 and Jun N-terminal kinase, and subsequently the cell-surface expression of Fas ligand that induces a caspase cascade and apoptotic cell death. ${ }^{149}$ Yang et al. $^{150}$ demonstrated that TSP-1 is silenced by promoter methylation in human neuroblastoma and that treatment with 5-aza- 2'-deoxycytidine restored TSP-1 expression and decreased tumor angiogenesis in vivo. The secreted protease ADAMTS-8 (METH-2) has anti-angiogenic properties, which can specifically suppress endothelial cell proliferation. ${ }^{151}$ Significant downregulation of ADAMTS-8 has been described in different tumor types, with hypermethylation of the promoter region as a mechanism of gene silencing. ${ }^{152}$

DNA methyltransferase- and histone deacetylase inhibitors as direct angiostatic agents

Recently, we ${ }^{153}$ and others ${ }^{154,155}$ showed that HDAC inhibitors are potent angiostatic agents, directly inhibiting endothelial cell growth and angiogenesis in vitro and in vivo. Kim et al. ${ }^{154}$ were the first to demonstrate anti-angiogenic effects by HDAC inhibition. They showed that TSA has potent anti-angiogenic activity in vitro and in vivo, which was more evident in hypoxia-induced angiogenesis. Moreover, they described angiogenic stimulation by HDAC1 overexpression. Direct angiostatic effects of TSA, as well as the HDAC inhibitor SAHA, were also reported by Deroanne et al., ${ }^{155}$ who demonstrated suppression of spontaneous or VEGF-induced angiogenesis by HDAC inhibition in different in vitro, ex vivo and in vivo angiogenesis assays. Antiangiogenesis activity of the hydroxamic acid derivative NVP-LAQ824 was demonstrated by Qian et al. ${ }^{156}$ Moreover, they investigated the antiangiogenic and antitumor effects of the combination of NVP-LAQ824 and the VEGFR2 kinase inhibitor PTK787/ZK222584 and showed that the combination treatment was more effective than single agents. Other HDAC inhibiting drugs for which in vitro and in vivo angiostatic effects have been published are depsipeptide, valproic acid, butyrate, apicidin and LBH589 (Table 5.1). ${ }^{157-163}$ 


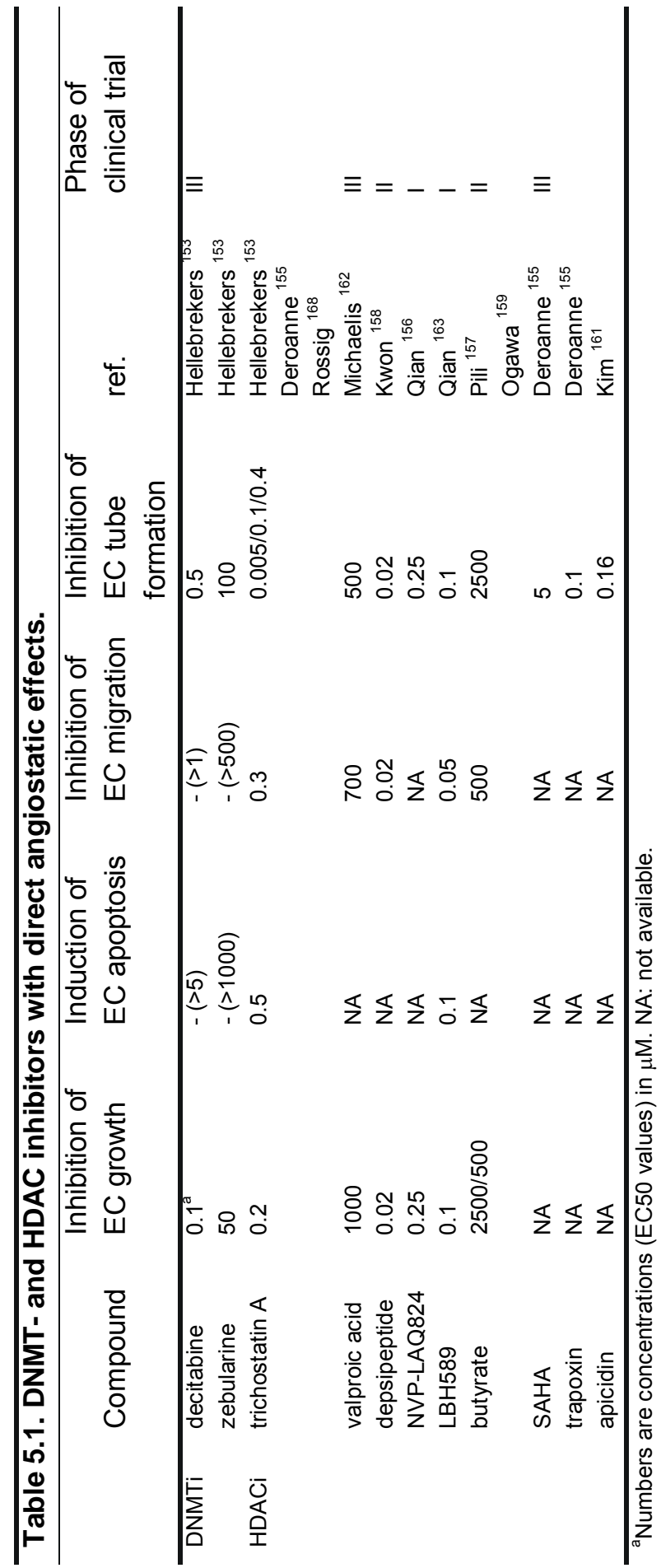


Some groups related the angiostatic activity of HDAC inhibitors to repression of hypoxia-inducible factor-1 $\alpha$ (HIF1 $\alpha$ ) and/or VEGF in tumor cells. ${ }^{154,156,160,164-166}$ HIF1 $\alpha$ is the key determinant of the function of the transcription factor HIF, a major regulator of hypoxia-induced angiogenesis which controls expression of hypoxia-inducible angiogenic factors such as VEGF. HIF1 $\alpha$ activity is controlled by two well known mechanisms. First, VHL targets HIF1 $\alpha$ for ubiquitination and subsequent proteasomal degradation under normoxia. Second, HIF1 $\alpha$ activity is determined by its transactivation potential, provided by the HIF1 $\alpha \mathrm{C}$-terminal transactivation domain through interaction with CREB-binding protein (CBP)/p300. ${ }^{167}$ The anti-angiogenic effects of TSA described by Kim et al. ${ }^{154}$ were explained by suppression of the VHLHIF1 $\alpha$-VEGF pathway in tumor cells. By upregulation of p53 and VHL expression, TSA reduced HIF1 $\alpha$ expression and DNA binding activity and thereby decreased VEGF production by the tumor. Moreover, overexpression of HDAC1 suppressed p53 and VHL levels, but upregulated HIF1 $\alpha$ and VEGF in HepG2 human hepatoblastoma cells. ${ }^{154}$ Angiostatic effects of HDAC inhibition due to repression of HIF1 $\alpha$ levels were also reported by Qian et al., ${ }^{156}$ describing effective reduction of HIF1 $\alpha$ protein levels in tumor cells under normal and hypoxic conditions by NVP-LAQ824, resulting in decreased VEGF expression. Inhibition of hypoxia-induced expression and binding ability of HIF1 $\alpha$, and of hypoxia-induced VEGF upregulation in tumor cells has also been observed for depsipeptide. ${ }^{164}$ Zgouras et al. ${ }^{160}$ attributed the angiostatic effects of butyrate to inhibition of nuclear translocation of HIF1 $\alpha$ in tumor cells and, subsequently, decreased VEGF expression, while observing accumulation of cytoplasmatic HIF1 $\alpha$ protein.

Although repression of HIF1 $\alpha$ and/or VEGF in tumor cells by HDAC inhibitors has been reported by several groups, this is an indirect effect of HDAC inhibition - via the tumor cells - on tumor endothelial cells and angiogenesis. Therefore, it can only explain the inhibition of tumor angiogenesis by HDAC inhibitors in vivo, where new vessel formation is influenced by production of HIF1 $\alpha$ and VEGF by the tumor. However, inhibition of DNA synthesis, migration and tube formation of endothelial cells by HDAC inhibitors in vitro proves that these compounds directly affect endothelial cell biology and angiogenesis. ${ }^{154-163}$ These direct angiostatic effects cannot be explained by effects via tumor cells.

Besides inhibition of HIF1 $\alpha$ and VEGF expression in tumor cells by NVP-LAQ824, Qian et al. ${ }^{156}$ also described a direct inhibitory effect of this HDAC inhibitor on expression of the angiogenesis-related genes angiopoietin-2, Tie-2, and survivin in endothelial cells, as well as increased endothelial cell p21 expression, which might explain the direct angiostatic effects of this compound. Later, this group demonstrated that the HDAC inhibitor LBH589 attenuates VEGF signaling in human endothelial cells. ${ }^{163}$ LBH589 prevented VEGF-induced phosphorylation of AKT and ERK1/2 in EC, without effecting total AKT and ERK1/2 protein stability. Furthermore, angiopoietin-2, survivin and CXCR4 upregulation by VEGF in endothelial cells was inhibited by this drug, as well as endothelial cell HIF1 $\alpha$ expression. The latter finding suggests that HDAC inhibitors can not only reduce expression of HIF1 $\alpha$ in tumor cells, but also in EC. Deroanne et al. ${ }^{155}$ demonstrated inhibition of the VEGF-induced expression of 
VEGFR1, VEGFR2 and neuropilin-1 in endothelial cells by TSA, as well as upregulation of the VEGF competitor semaphorin III. In other studies, angiostatic effects of HDAC inhibitors were associated with down-regulation of COX-2, ${ }^{159}$ eNOS $^{162,168}$ and VEGFR2 ${ }^{158}$ expression in EC. Downregulation of angiogenesisrelated genes in endothelial cells are direct effects of HDAC inhibitors on EC, and can explain their direct angiostatic activity. However, decreased expression of these endothelial cell genes is not due to direct effects of these compounds on epigenetic promoter modifications of these genes, since direct effects of HDAC inhibition would result in increased promoter histone acetylation and thus transcriptional activation. Clearly, further studies are required to unravel the effects of HDAC inhibitors on (tumor) endothelial cell gene expression, and relate these effects with epigenetic promoter modifications of these genes.

The HDAC inhibitor valproic acid was shown to inhibit EC proliferation and angiogenesis by decreasing expression of eNOS, but displays no cytotoxicity in ECs. ${ }^{162}$ Recently, Michaelis et al. demonstrated that valproic acid increases extracellular signal-regulated kinase 1 / 2 (ERK1/2) phosphorylation in EC and, consequently, causes phosphorylation of the anti-apoptotic protein $\mathrm{Bcl}-2$, inhibiting stress-induced apoptosis of EC. ${ }^{169}$ These findings seem to be in contrast with the antiangiogenic activity of valproic acid and other HDAC inhibitors, since ERK $1 / 2$ phosphorylation is regarded to be a proangiogenic event. This apparent contradiction can be explained by the fact that the effects of valproic acid on angiogenesis seem to be mediated by two competing pathways. The decreased eNOS expression in EC by valproic acid, as for other HDAC inhibitors, is dependent on HDAC inhibition. However, the effects of valproic acid on ERK phosphorylation are shown to be HDACindependent. Therefore, inhibition of ERK 1 / 2 phosphorylation by the MEK inhibitor PD98059 abrogates the proangiogenic signaling pathway and synergistically enhances the antiangiogenic activity of VPA. ${ }^{169}$

Targeting of angiogenesis by HDAC inhibitors might not be solely the result of effects on chromatin. In parallel with the inhibitory effects of HDAC inhibitors on tumor cells, angiostatic activities might also be caused by increasing acetylation of nonhistone proteins in tumor cells (indirect angiostatic effects) and/or tumor EC (direct angiostatic effects). Among these targets might be transcription factors and proteins involved in signal transduction, cell cycle, apoptosis, cell motility or angiogenesis. For example, the involvement of HAT/HDAC in regulation of HIF $1 \alpha$ function independent of histone acetylation has been suggested by several studies. Acetylation of HIF1 $\alpha$ by the ARD1 HAT results in increased association with the VHL ubiquitination complex and proteasome-mediated degradation. ${ }^{31}$ In another study, HDAC7 was found to specifically interact with $\mathrm{HIF} 1 \alpha$, resulting in increased nuclear translocation and transcriptional activity of HIF1 $\alpha$ through the formation of a complex between HIF1 $\alpha$, HDAC7, and p300. ${ }^{170}$ Kong et al. show that HDAC inhibitors trigger ubiquitinationindependent proteasomal degradation of $\mathrm{HIF} 1 \alpha$ by a mechanism involving interaction of HIF $1 \alpha$ with the Hsp70/Hsp90 chaperone axis. ${ }^{171}$ Recently, it was reported that HDAC inhibitors, at concentrations that do not affect HIF1 $\alpha$ levels, efficiently repress the transactivation potential of HIF $1 \alpha$ by hyperacetylation of $p 300$, independent of VHL function and HIF1 $\alpha$ degradation. ${ }^{172}$ Therefore, at least part of the angiostatic 
effects of HDAC inhibitors in vivo might be attributed to repression of the HIF1 $\alpha$ transactivation potential independent of histone acetylation. Effects on multiprotein complexes in which HDACs exist might contribute to the angiostatic activities of HDAC inhibition. ${ }^{173-175}$ For example, metastasis-associated protein 1 (MTA1) physically interacts with HDACs forming the nucleosome remodeling histone deacetylation (NuRD) complex. MTA1 is upregulated during hypoxia and enhances the stability and transcriptional activity of HIF1 $\alpha$ by enhancing HIF1 $\alpha$ deacetylation through recruitment of HDAC1 ${ }^{176}$ Inactivation of this MTA1/HDAC1 connection by HDAC inhibitors might be another potential mechanism behind the anti-angiogenic effects of these compounds.

We recently reported that DNMT inhibitors are also potent angiostatic agents in vitro and in vivo. ${ }^{153}$ 5-Aza- 2'-deoxycytidine and zebularine directly inhibited growth and sprouting of growth factor-stimulated EC. Moreover, a 72-hour exposure of endothelial cells to 5-aza- 2'-deoxycytidine resulted in stronger responses compared with treatment for 48 and 24 hours, corresponding with the mechanism of action of this drug, which has to be incorporated into the DNA before it can trap DNMTs. 5-Aza2'-deoxycytidine and zebularine did not affect endothelial cell apoptosis and migration. In comparison, treatment of tumor-conditioned endothelial cells with TSA induced apoptosis and decreased migration of these cells. ${ }^{153}$ Although we showed that both 5aza- 2'-deoxycytidine and TSA re-expressed three growth inhibiting genes silenced in tumor-conditioned endothelial cells (IGFBP3, TSP1, JUNB), further research needs to be performed to relate reactivation of these genes to the angiostatic effects of these epigenetic drugs. Furthermore, the potential role of epigenetic mechanisms in regulating expression of these genes in endothelial cells should be closer examined.

With the data available so far, we propose a model suggesting 3 mechanisms by which the anti-tumor effects of DNMT- and HDAC inhibitors can be explained in vivo (Fig. 5.1). Firstly, reactivation of epigenetically silenced tumor suppressor genes in the tumor cells, such as the cell cycle inhibitors p14ARF, p15INK4b and p16INK4a, the DNA repair genes $h M L H 1$, GSTP1, MGMT, and BRCA1, and the metastasis and invasion- related genes $C D H 1, T I M P 3$, and $D A P K$, reduces tumor cell growth. Secondly, by re-expression of tumor suppressor genes with angiogenesis inhibiting properties in tumor cells, such as p16INK4a, p73, maspin, TIMP-2 and -3, TSP-1 and ADAMTS-8, DNMT- and HDAC inhibitors might indirectly exhibit angiostatic effects in vivo. An additional mechanism behind the anti-tumor activities of DNMT- and HDAC inhibitors is by direct effects on tumor endothelial cells themselves, suppressing endothelial cell growth and (tumor) angiogenesis. ${ }^{153,154}$

The multi-step process of tumor angiogenesis requires intricate regulation at the molecular level. Analyses of tumor endothelial cell gene expression has resulted in the identification of novel genes involved in the generation of new vasculature. ${ }^{177-179}$ Little, however, is known on the role of epigenetics in tumor angiogenesis. In contrast to the extensively described effects of DNMT- and HDAC inhibitors on gene expression in tumor cells - the reexpression of epigenetically silenced tumor suppressor genes there is more to learn about the direct effects of these drugs on endothelial cell gene expression, as well as on the role of epigenetic mechanisms in regulating transcription 


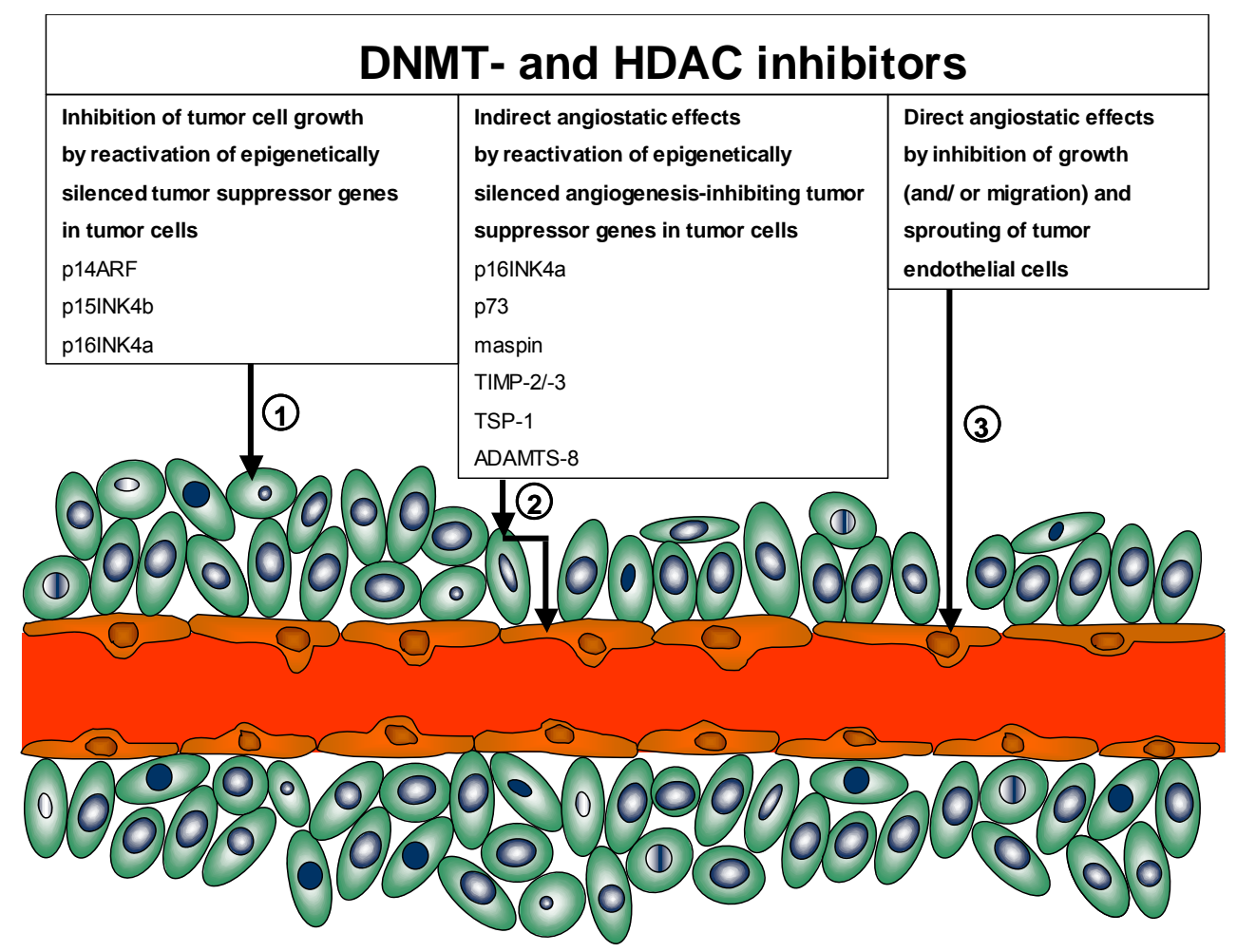

Figure 5.1 Model of anti-tumor effects of DNA methyltransferase and histone deacetylase inhibitors in vivo.

1. DNMT- and HDAC inhibitors decrease tumor cell growth by reactivation of epigenetically silenced tumor suppressor genes in tumor cells. 2. Release of transcriptional repression of angiogenesis inhibiting tumor suppressor genes in tumor cells might result in indirect angiostatic effects of DNMT- and HDAC inhibitors. 3. DNMT- and HDAC inhibitors directly decrease endothelial cell growth and angiogenesis, thereby exhibiting direct angiostatic effects.

of endothelial cell genes during (tumor) angiogenesis. The direct inhibitory effects of demethylating agents and HDAC inhibitors on endothelial cell growth and angiogenesis indicate that epigenetic modifications mediated by DNMTs and HDACs are involved in regulation of endothelial cell gene expression during tumor angiogenesis. Because different epigenetic modifications cooperate in regulation of gene expression, ${ }^{180-182}$ epigenetic modifications mediated by DNMTs and HDACs in tumor ECs are likely to be accompanied by effects on other histone modifications such as histone methylation. Since there is only sparse knowledge on the characterization of histone methyltransferase inhibitors, ${ }^{183}$ possible effects of such compounds on angiogenesis are unknown. Nevertheless, because of the interaction between histone methylation, histone acetylation and DNA methylation, and because of the angiostatic effects of DNMT- and HDAC inhibitors, inhibitors of histone methylation might also affect tumor angiogenesis. It is tempting to speculate that like in tumor cells, silencing of growth suppressing genes in tumor endothelial cells during tumor angiogenesis 
might be caused by epigenetic promoter modifications, i.e. DNA hypermethylation and histone deacetylation. Consequently, reactivation of these genes in tumor endothelial cells by reversal of epigenetic promoter modifications could then explain the inhibition of endothelial cell growth and angiogenesis by DNMT- and HDAC inhibitors. However, it seems unlikely that tumor cells, containing numerous genetic abnormalities, and a normal cell type such as tumor endothelial cells display similar epigenetic aberrations. Indeed, we found that silencing of the growth-inhibiting genes TSP1, JUNB and IGFBP3 in tumor-conditioned endothelial cells and reactivation by treatment with DNMT- and HDAC inhibitors was independent of promoter methylation of these genes. ${ }^{153}$ Gene expression studies examining modifications of endothelial cell transcript profiles by DNMT- and HDAC inhibitors can help identify genes that might be functionally related to the angiostatic effects of these compounds. Furthermore, examination of epigenetic promoter modifications of these genes might unravel the involvement of promoter DNA methylation and histone (de)acetylation in regulating expression of angiogenesis modulating genes in tumor EC, and might give more insight in the effects of DNMT- and HDAC inhibitors on epigenetics in these cells.

\section{Conclusions and future directions}

The reversibility of epigenetic silencing of tumor suppressor genes in tumor cells resulted in the testing of demethylating agents and inhibitors of histone deacetylation as anti-cancer therapeutics. Clinical trials of these agents have yielded promising results, especially against hematologic malignancies. Here, we describe that targets of epigenetic therapy in cancer treatment can be extended beyond tumor cells alone. Direct suppressive effects of DNMT- and HDAC inhibitors on tumor endothelial cells and angiogenesis revealed that these compounds are potent angiostatic agents. The findings that these drugs target both tumor cells, as well as tumor endothelial cells, make them suitable combinatorial cancer therapeutics. By targeting multiple genes and pathways in tumor cells, as well as endothelial cell biology and angiogenesis, epigenetic compounds decrease the development of resistance that is associated with many of the current chemo- and angiostatic- therapies.

Despite the encouraging results of epigenetic therapy in (pre)clinical studies, there are several significant challenges that must be overcome to increase the chances of success in the clinic. Optimisation of treatment schedules, exploration of surrogate markers, and development of specific inhibitors targeting individual enzymes are warranted to achieve maximal clinical results. Many conventional cytotoxic chemotherapeutics possess anti-angiogenic activity, which seems to be optimized by administration of comparatively low doses on a frequent or continuous schedulesometimes referred to as metronomic chemotherapy. ${ }^{184}$ Therefore, the use of DNMTand HDAC inhibitors at a low dose schedule over long time periods might provide better results, reducing host toxicity and decreasing the recovery of EC. Furthermore, combining demethylating agents with HDAC inhibitors might prove beneficial, not only due to their synergistic reexpression of tumor suppressor genes in cancer cells, but also because of the angiostatic effects of both agents. Clearly, the dual targeting of DNMT- and HDAC inhibitors makes them attractive anti-tumor therapeutics and 
encourages the development of improved treatment schedules to reach maximal clinical success.

In contrast to the numerous studies on the effects of DNMT- and HDAC inhibitors on epigenetic aberrations in tumor cells, only few attempts have been made to explain the molecular mechanism behind the direct inhibition of endothelial cell growth and angiogenesis by these compounds. Expression microarray analysis examining effects of demethylating agents and HDAC inhibitors on endothelial cell gene expression will gain better insight into the mechanism behind the angiostatic effects of these drugs. Furthermore, unraveling the role of epigenetic modifications in the regulation of endothelial cell gene expression will improve our understanding of the molecular regulation of endothelial cell biology during tumor angiogenesis. 


\section{References}

1. Bantignies F, Cavalli G. Cellular memory and dynamic regulation of polycomb group proteins. Curr Opin Cell Biol. 2006;18:275-283.

2. Morris KV, Chan SW, Jacobsen SE, Looney DJ. Small interfering RNA-induced transcriptional gene silencing in human cells. Science. 2004;305:1289-1292

3. Bird A. DNA methylation patterns and epigenetic memory. Genes Dev. 2002;16:6-21.

4. Herman JG, Baylin SB. Gene silencing in cancer in association with promoter hypermethylation. N Engl J Med. 2003;349:2042-2054

5. Bestor TH. The DNA methyltransferases of mammals. Hum Mol Genet. 2000;9:2395-2402.

6. Okano M, Bell DW, Haber DA, Li E. DNA methyltransferases Dnmt3a and Dnmt3b are essential for de novo methylation and mammalian development. Cell. 1999;99:247-257.

7. Bird AP, Wolffe AP. Methylation-induced repression--belts, braces, and chromatin. Cell. 1999;99:451-454.

8. Robertson KD, Ait-Si-Ali S, Yokochi T, Wade PA, Jones PL, Wolffe AP. DNMT1 forms a complex with $\mathrm{Rb}, \mathrm{E} 2 \mathrm{~F} 1$ and HDAC1 and represses transcription from E2F-responsive promoters. Nat Genet. 2000;25:338-342.

9. Rountree MR, Bachman KE, Baylin SB. DNMT1 binds HDAC2 and a new co-repressor, DMAP1, to form a complex at replication foci. Nat Genet. 2000;25:269-277.

10. Fuks F, Hurd PJ, Deplus R, Kouzarides T. The DNA methyltransferases associate with HP1 and the SUV39H1 histone methyltransferase. Nucleic Acids Res. 2003;31:2305-2312.

11. Turner BM. Cellular memory and the histone code. Cell. 2002;111:285-291.

12. Strahl BD, Allis CD. The language of covalent histone modifications. Nature. 2000;403:4145.

13. Jenuwein T, Allis CD. Translating the histone code. Science. 2001;293:1074-1080.

14. Kouzarides T. Histone methylation in transcriptional control. Curr Opin Genet Dev. 2002;12:198-209.

15. Martin $\mathrm{C}$, Zhang $\mathrm{Y}$. The diverse functions of histone lysine methylation. Nat Rev Mol Cell Biol. 2005;6:838-849.

16. Marks P, Rifkind RA, Richon VM, Breslow R, Miller T, Kelly WK. Histone deacetylases and cancer: causes and therapies. Nat Rev Cancer. 2001;1:194-202.

17. Struhl K. Histone acetylation and transcriptional regulatory mechanisms. Genes Dev. 1998;12:599-606

18. Polo SE, Almouzni G. Histone metabolic pathways and chromatin assembly factors as proliferation markers. Cancer Lett. 2005;220:1-9.

19. Vidanes GM, Bonilla CY, Toczyski DP. Complicated tails: histone modifications and the DNA damage response. Cell. 2005;121:973-976.

20. Weinreich M, Palacios DeBeer MA, Fox CA. The activities of eukaryotic replication origins in chromatin. Biochim Biophys Acta. 2004;1677:142-157.

21. Minucci S, Pelicci PG. Histone deacetylase inhibitors and the promise of epigenetic (and more) treatments for cancer. Nat Rev Cancer. 2006;6:38-51.

22. Bode AM, Dong Z. Post-translational modification of p53 in tumorigenesis. Nat Rev Cancer. 2004;4:793-805

23. Boyes J, Byfield $\mathrm{P}$, Nakatani $\mathrm{Y}$, Ogryzko V. Regulation of activity of the transcription factor GATA-1 by acetylation. Nature. 1998;396:594-598.

24. Martinez-Balbas MA, Bauer UM, Nielsen SJ, Brehm A, Kouzarides T. Regulation of E2F1 activity by acetylation. Embo J. 2000;19:662-671.

25. Fu M, Wang C, Zhang X, Pestell RG. Acetylation of nuclear receptors in cellular growth and apoptosis. Biochem Pharmacol. 2004;68:1199-1208.

26. Puri PL, Avantaggiati ML, Balsano C, et al. p300 is required for MyoD-dependent cell cycle arrest and muscle-specific gene transcription. Embo J. 1997;16:369-383. 
27. Chen L, Fischle W, Verdin E, Greene WC. Duration of nuclear NF-kappaB action regulated by reversible acetylation. Science. 2001;293:1653-1657.

28. Imhof A, Yang XJ, Ogryzko VV, Nakatani Y, Wolffe AP, Ge H. Acetylation of general transcription factors by histone acetyltransferases. Curr Biol. 1997;7:689-692.

29. Chan HM, Krstic-Demonacos M, Smith L, Demonacos C, La Thangue NB. Acetylation control of the retinoblastoma tumour-suppressor protein. Nat Cell Biol. 2001;3:667-674.

30. Palazzo A, Ackerman B, Gundersen GG. Cell biology: Tubulin acetylation and cell motility. Nature. 2003;421:230.

31. Jeong JW, Bae MK, Ahn MY, et al. Regulation and destabilization of HIF-1alpha by ARD1mediated acetylation. Cell. 2002;111:709-720.

32. Kovacs JJ, Murphy PJ, Gaillard S, et al. HDAC6 regulates Hsp90 acetylation and chaperone-dependent activation of glucocorticoid receptor. Mol Cell. 2005;18:601-607.

33. Bonaldi $\mathrm{T}$, Talamo $\mathrm{F}$, Scaffidi $\mathrm{P}$, et al. Monocytic cells hyperacetylate chromatin protein HMGB1 to redirect it towards secretion. Embo J. 2003;22:5551-5560.

34. Jaenisch R, Bird A. Epigenetic regulation of gene expression: how the genome integrates intrinsic and environmental signals. Nat Genet. 2003;33 Suppl:245-254.

35. Seligson DB, Horvath S, Shi T, et al. Global histone modification patterns predict risk of prostate cancer recurrence. Nature. 2005;435:1262-1266.

36. Fraga MF, Ballestar E, Villar-Garea A, et al. Loss of acetylation at Lys16 and trimethylation at Lys20 of histone H4 is a common hallmark of human cancer. Nat Genet. 2005;37:391400.

37. Feinberg AP, Vogelstein B. Hypomethylation distinguishes genes of some human cancers from their normal counterparts. Nature. 1983;301:89-92.

38. Gaudet F, Hodgson JG, Eden A, et al. Induction of tumors in mice by genomic hypomethylation. Science. 2003;300:489-492.

39. Knudson AG. Chasing the cancer demon. Annu Rev Genet. 2000;34:1-19.

40. Rhee I, Bachman KE, Park BH, et al. DNMT1 and DNMT3b cooperate to silence genes in human cancer cells. Nature. 2002;416:552-556.

41. Herman JG, Umar A, Polyak K, et al. Incidence and functional consequences of hMLH1 promoter hypermethylation in colorectal carcinoma. Proc Natl Acad Sci U S A. 1998;95:6870-6875.

42. Esteller M, Garcia-Foncillas J, Andion E, et al. Inactivation of the DNA-repair gene MGMT and the clinical response of gliomas to alkylating agents. N Engl J Med. 2000;343:13501354.

43. Esteller M, Corn PG, Baylin SB, Herman JG. A gene hypermethylation profile of human cancer. Cancer Res. 2001;61:3225-3229.

44. Dammann R, Li C, Yoon JH, Chin PL, Bates S, Pfeifer GP. Epigenetic inactivation of a RAS association domain family protein from the lung tumour suppressor locus 3p21.3. Nat Genet. 2000;25:315-319.

45. van Engeland M, Roemen GM, Brink M, et al. K-ras mutations and RASSF1A promoter methylation in colorectal cancer. Oncogene. 2002;21:3792-3795.

46. Wales MM, Biel MA, el Deiry W, et al. p53 activates expression of HIC-1, a new candidate tumour suppressor gene on 17p13.3. Nat Med. 1995;1:570-577.

47. Murakami J, Asaumi J, Maki Y, et al. Effects of demethylating agent 5-aza-2(')-deoxycytidine and histone deacetylase inhibitor FR901228 on maspin gene expression in oral cancer cell lines. Oral Oncol. 2004;40:597-603.

48. Laird PW. The power and the promise of DNA methylation markers. Nat Rev Cancer. 2003;3:253-266.

49. Herman JG, Graff JR, Myohanen S, Nelkin BD, Baylin SB. Methylation-specific PCR: a novel PCR assay for methylation status of CpG islands. Proc Natl Acad Sci U S A. 1996;93:9821-9826.

50. Derks S, Lentjes MH, Hellebrekers DM, de Bruine AP, Herman JG, van Engeland M. Methylation-specific PCR unraveled. Cell Oncol. 2004;26:291-299.

51. Sidransky D. Emerging molecular markers of cancer. Nat Rev Cancer. 2002;2:210-219. 
52. Ionov $\mathrm{Y}$, Matsui S, Cowell JK. A role for p300/CREB binding protein genes in promoting cancer progression in colon cancer cell lines with microsatellite instability. Proc Natl Acad Sci U S A. 2004;101:1273-1278.

53. Gayther SA, Batley SJ, Linger L, et al. Mutations truncating the EP300 acetylase in human cancers. Nat Genet. 2000;24:300-303.

54. Ozdag $\mathrm{H}$, Batley SJ, Forsti A, et al. Mutation analysis of CBP and PCAF reveals rare inactivating mutations in cancer cell lines but not in primary tumours. $\mathrm{Br} \mathrm{J}$ Cancer 2002;87:1162-1165.

55. Ropero S, Fraga MF, Ballestar E, et al. A truncating mutation of HDAC2 in human cancers confers resistance to histone deacetylase inhibition. Nat Genet. 2006;38:566-569.

56. Shen H, Wang L, Spitz MR, Hong WK, Mao L, Wei Q. A novel polymorphism in human cytosine DNA-methyltransferase-3B promoter is associated with an increased risk of lung cancer. Cancer Res. 2002;62:4992-4995.

57. Lee SJ, Jeon HS, Jang JS, et al. DNMT3B polymorphisms and risk of primary lung cancer. Carcinogenesis. 2005;26:403-409.

58. Cebrian A, Pharoah PD, Ahmed S, et al. Genetic variants in epigenetic genes and breast cancer risk. Carcinogenesis. 2006.

59. Jones PA, Taylor SM. Cellular differentiation, cytidine analogs and DNA methylation. Cell. 1980;20:85-93.

60. Villar-Garea A, Esteller M. DNA demethylating agents and chromatin-remodelling drugs: which, how and why? Curr Drug Metab. 2003;4:11-31.

61. Curt GA, Kelley JA, Fine RL, et al. A phase I and pharmacokinetic study of dihydro-5azacytidine (NSC 264880). Cancer Res. 1985;45:3359-3363.

62. Boothman DA, Briggle TV, Greer S. Exploitation of elevated pyrimidine deaminating enzymes for selective chemotherapy. Pharmacol Ther. 1989;42:65-88.

63. Cheng JC, Matsen CB, Gonzales FA, et al. Inhibition of DNA methylation and reactivation of silenced genes by zebularine. J Natl Cancer Inst. 2003;95:399-409.

64. Cheng JC, Yoo CB, Weisenberger DJ, et al. Preferential response of cancer cells to zebularine. Cancer Cell. 2004;6:151-158.

65. Segura-Pacheco B, Trejo-Becerril C, Perez-Cardenas E, et al. Reactivation of tumor suppressor genes by the cardiovascular drugs hydralazine and procainamide and their potential use in cancer therapy. Clin Cancer Res. 2003;9:1596-1603.

66. Fang MZ, Wang $\mathrm{Y}, \mathrm{Ai} \mathrm{N}$, et al. Tea polyphenol (-)-epigallocatechin-3-gallate inhibits DNA methyltransferase and reactivates methylation-silenced genes in cancer cell lines. Cancer Res. 2003:63:7563-7570.

67. Brueckner B, Boy RG, Siedlecki $P$, et al. Epigenetic reactivation of tumor suppressor genes by a novel small-molecule inhibitor of human DNA methyltransferases. Cancer Res. 2005;65:6305-6311.

68. Yan L, Nass SJ, Smith D, Nelson WG, Herman JG, Davidson NE. Specific inhibition of DNMT1 by antisense oligonucleotides induces re-expression of estrogen receptor-alpha (ER) in ER-negative human breast cancer cell lines. Cancer Biol Ther. 2003;2:552-556.

69. Johnstone RW. Histone-deacetylase inhibitors: novel drugs for the treatment of cancer. Nat Rev Drug Discov. 2002;1:287-299.

70. Yoshida M, Kijima M, Akita M, Beppu T. Potent and specific inhibition of mammalian histone deacetylase both in vivo and in vitro by trichostatin A. J Biol Chem. 1990;265:17174-17179.

71. Monneret C. Histone deacetylase inhibitors. Eur J Med Chem. 2005;40:1-13.

72. Su GH, Sohn TA, Ryu B, Kern SE. A novel histone deacetylase inhibitor identified by highthroughput transcriptional screening of a compound library. Cancer Res. 2000;60:31373142.

73. Furumai R, Komatsu Y, Nishino N, Khochbin S, Yoshida M, Horinouchi S. Potent histone deacetylase inhibitors built from trichostatin $A$ and cyclic tetrapeptide antibiotics including trapoxin. Proc Natl Acad Sci U S A. 2001;98:87-92.

74. Furumai R, Matsuyama A, Kobashi N, et al. FK228 (depsipeptide) as a natural prodrug that inhibits class I histone deacetylases. Cancer Res. 2002;62:4916-4921. 
75. Murray PJ, Kranz M, Ladlow M, et al. The synthesis of cyclic tetrapeptoid analogues of the antiprotozoal natural product apicidin. Bioorg Med Chem Lett. 2001;11:773-776.

76. Kijima M, Yoshida M, Sugita K, Horinouchi S, Beppu T. Trapoxin, an antitumor cyclic tetrapeptide, is an irreversible inhibitor of mammalian histone deacetylase. J Biol Chem. 1993;268:22429-22435.

77. Saito A, Yamashita T, Mariko Y, et al. A synthetic inhibitor of histone deacetylase, MS-27275 , with marked in vivo antitumor activity against human tumors. Proc Natl Acad Sci U S A. 1999;96:4592-4597.

78. Paz MF, Fraga MF, Avila S, et al. A systematic profile of DNA methylation in human cancer cell lines. Cancer Res. 2003;63:1114-1121.

79. Bender CM, Pao MM, Jones PA. Inhibition of DNA methylation by 5-aza-2'-deoxycytidine suppresses the growth of human tumor cell lines. Cancer Res. 1998;58:95-101.

80. Soengas MS, Capodieci P, Polsky D, et al. Inactivation of the apoptosis effector Apaf-1 in malignant melanoma. Nature. 2001;409:207-211.

81. Suzuki H, Gabrielson E, Chen W, et al. A genomic screen for genes upregulated by demethylation and histone deacetylase inhibition in human colorectal cancer. Nat Genet. 2002;31:141-149.

82. Karpf AR, Peterson PW, Rawlins JT, et al. Inhibition of DNA methyltransferase stimulates the expression of signal transducer and activator of transcription 1, 2, and 3 genes in colon tumor cells. Proc Natl Acad Sci U S A. 1999;96:14007-14012.

83. Pompeia C, Hodge DR, Plass C, et al. Microarray analysis of epigenetic silencing of gene expression in the KAS-6/1 multiple myeloma cell line. Cancer Res. 2004;64:3465-3473.

84. Liang G, Gonzales FA, Jones PA, Orntoft TF, Thykjaer T. Analysis of gene induction in human fibroblasts and bladder cancer cells exposed to the methylation inhibitor 5-aza-2'deoxycytidine. Cancer Res. 2002;62:961-966.

85. Karpf AR, Lasek AW, Ririe TO, Hanks AN, Grossman D, Jones DA. Limited gene activation in tumor and normal epithelial cells treated with the DNA methyltransferase inhibitor 5-aza2'-deoxycytidine. Mol Pharmacol. 2004;65:18-27.

86. Van Lint C, Emiliani S, Verdin E. The expression of a small fraction of cellular genes is changed in response to histone hyperacetylation. Gene Expr. 1996;5:245-253.

87. Richon VM, Sandhoff TW, Rifkind RA, Marks PA. Histone deacetylase inhibitor selectively induces p21WAF1 expression and gene-associated histone acetylation. Proc Natl Acad Sci U S A. 2000;97:10014-10019.

88. Taddei A, Maison C, Roche D, Almouzni G. Reversible disruption of pericentric heterochromatin and centromere function by inhibiting deacetylases. Nat Cell Biol. 2001;3:114-120.

89. Atadja P, Hsu M, Kwon P, Trogani N, Bhalla K, Remiszewski S. Molecular and cellular basis for the anti-proliferative effects of the HDAC inhibitor LAQ824. Novartis Found Symp. 2004;259:249-266; discussion 266-248, 285-248.

90. Cameron EE, Bachman KE, Myohanen S, Herman JG, Baylin SB. Synergy of demethylation and histone deacetylase inhibition in the re-expression of genes silenced in cancer. Nat Genet. 1999;21:103-107.

91. Yamashita K, Upadhyay S, Osada M, et al. Pharmacologic unmasking of epigenetically silenced tumor suppressor genes in esophageal squamous cell carcinoma. Cancer Cell. 2002;2:485-495.

92. Yang H, Hoshino K, Sanchez-Gonzalez B, Kantarjian H, Garcia-Manero G. Antileukemia activity of the combination of 5-aza-2'-deoxycytidine with valproic acid. Leuk Res. 2005;29:739-748.

93. Belinsky SA, Klinge DM, Stidley CA, et al. Inhibition of DNA methylation and histone deacetylation prevents murine lung cancer. Cancer Res. 2003;63:7089-7093.

94. Egger G, Liang G, Aparicio A, Jones PA. Epigenetics in human disease and prospects for epigenetic therapy. Nature. 2004;429:457-463.

95. Fenaux P. Inhibitors of DNA methylation: beyond myelodysplastic syndromes. Nat Clin Pract Oncol. 2005;2 Suppl 1:S36-44. 
96. Silverman LR, Holland JF, Weinberg RS, et al. Effects of treatment with 5-azacytidine on the in vivo and in vitro hematopoiesis in patients with myelodysplastic syndromes. Leukemia. 1993;7 Suppl 1:21-29.

97. Silverman LR, Demakos EP, Peterson BL, et al. Randomized controlled trial of azacitidine in patients with the myelodysplastic syndrome: a study of the cancer and leukemia group B. J Clin Oncol. 2002;20:2429-2440.

98. Kornblith AB, Herndon JE, 2nd, Silverman LR, et al. Impact of azacytidine on the quality of life of patients with myelodysplastic syndrome treated in a randomized phase III trial: a Cancer and Leukemia Group B study. J Clin Oncol. 2002;20:2441-2452.

99. Kaminskas E, Farrell A, Abraham S, et al. Approval summary: azacitidine for treatment of myelodysplastic syndrome subtypes. Clin Cancer Res. 2005;11:3604-3608.

100. Wijermans P, Lubbert M, Verhoef $G$, et al. Low-dose 5-aza-2'-deoxycytidine, a DNA hypomethylating agent, for the treatment of high-risk myelodysplastic syndrome: a multicenter phase II study in elderly patients. J Clin Oncol. 2000;18:956-962.

101. Lubbert $M$, Wijermans $P$, Kunzmann $R$, et al. Cytogenetic responses in high-risk myelodysplastic syndrome following low-dose treatment with the DNA methylation inhibitor 5-aza-2'-deoxycytidine. Br J Haematol. 2001;114:349-357.

102. Silverman LR, Mufti GJ. Methylation inhibitor therapy in the treatment of myelodysplastic syndrome. Nat Clin Pract Oncol. 2005;2 Suppl 1:S12-23.

103. Kantarjian H, Issa JP, Rosenfeld CS, et al. Decitabine improves patient outcomes in myelodysplastic syndromes: results of a phase III randomized study. Cancer. 2006.

104. van den Bosch J, Lubbert M, Verhoef G, Wijermans PW. The effects of 5-aza-2'deoxycytidine (Decitabine) on the platelet count in patients with intermediate and high-risk myelodysplastic syndromes. Leuk Res. 2004;28:785-790.

105. Issa JP, Gharibyan V, Cortes J, et al. Phase II study of low-dose decitabine in patients with chronic myelogenous leukemia resistant to imatinib mesylate. J Clin Oncol. 2005;23:39483956.

106. Kantarjian HM, O'Brien S, Cortes $\mathrm{J}$, et al. Results of decitabine (5-aza-2'deoxycytidine) therapy in 130 patients with chronic myelogenous leukemia. Cancer. 2003;98:522-528.

107. Momparler RL, Bouffard DY, Momparler LF, Dionne J, Belanger K, Ayoub J. Pilot phase I-II study on 5-aza-2'-deoxycytidine (Decitabine) in patients with metastatic lung cancer. Anticancer Drugs. 1997;8:358-368.

108. Thibault A, Figg WD, Bergan RC, et al. A phase II study of 5-aza-2'deoxycytidine (decitabine) in hormone independent metastatic (D2) prostate cancer. Tumori. 1998;84:8789.

109. Daskalakis M, Nguyen TT, Nguyen C, et al. Demethylation of a hypermethylated P15/INK4B gene in patients with myelodysplastic syndrome by 5-Aza-2'-deoxycytidine (decitabine) treatment. Blood. 2002;100:2957-2964.

110. Lyko F, Brown R. DNA methyltransferase inhibitors and the development of epigenetic cancer therapies. J Natl Cancer Inst. 2005;97:1498-1506.

111. Juttermann R, Li E, Jaenisch R. Toxicity of 5-aza-2'-deoxycytidine to mammalian cells is mediated primarily by covalent trapping of DNA methyltransferase rather than DNA demethylation. Proc Natl Acad Sci U S A. 1994;91:11797-11801.

112. Feinberg AP. Cancer epigenetics is no Mickey Mouse. Cancer Cell. 2005;8:267-268.

113. Yang AS, Doshi KD, Choi SW, et al. DNA Methylation Changes after 5-Aza-2'-Deoxycytidine Therapy in Patients with Leukemia. Cancer Res. 2006;66:5495-5503.

114. Gore SD, Weng LJ, Figg WD, et al. Impact of prolonged infusions of the putative differentiating agent sodium phenylbutyrate on myelodysplastic syndromes and acute myeloid leukemia. Clin Cancer Res. 2002;8:963-970.

115. Carducci MA, Gilbert J, Bowling MK, et al. A Phase I clinical and pharmacological evaluation of sodium phenylbutyrate on an 120-h infusion schedule. Clin Cancer Res. 2001;7:30473055. 
116. Gilbert J, Baker SD, Bowling MK, et al. A phase I dose escalation and bioavailability study of oral sodium phenylbutyrate in patients with refractory solid tumor malignancies. Clin Cancer Res. 2001;7:2292-2300.

117. Chavez-Blanco A, Segura-Pacheco B, Perez-Cardenas E, et al. Histone acetylation and histone deacetylase activity of magnesium valproate in tumor and peripheral blood of patients with cervical cancer. A phase I study. Mol Cancer. 2005;4:22.

118. Pilatrino C, Cilloni D, Messa $E$, et al. Increase in platelet count in older, poor-risk patients with acute myeloid leukemia or myelodysplastic syndrome treated with valproic acid and alltrans retinoic acid. Cancer. 2005;104:101-109.

119. Kelly WK, Marks PA. Drug insight: Histone deacetylase inhibitors--development of the new targeted anticancer agent suberoylanilide hydroxamic acid. Nat Clin Pract Oncol. 2005;2:150-157.

120. Piekarz R, Bates S. A review of depsipeptide and other histone deacetylase inhibitors in clinical trials. Curr Pharm Des. 2004;10:2289-2298.

121. Ryan QC, Headlee D, Acharya M, et al. Phase I and pharmacokinetic study of MS-275, a histone deacetylase inhibitor, in patients with advanced and refractory solid tumors or lymphoma. J Clin Oncol. 2005;23:3912-3922.

122. Nemunaitis JJ, Orr D, Eager R, et al. Phase I study of oral Cl-994 in combination with gemcitabine in treatment of patients with advanced cancer. Cancer J. 2003;9:58-66.

123. Richards D, Waterhouse D, Wagener Dea. Proc Annu Meet Am Chem Soc Clin Oncol. 2002;21.

124. Kraker AJ, Mizzen CA, Hartl BG, Miin J, Allis CD, Merriman RL. Modulation of histone acetylation by [4-(acetylamino)-N-(2-amino-phenyl) benzamide] in HCT-8 colon carcinoma. Mol Cancer Ther. 2003;2:401-408.

125. Ronzoni S, Faretta M, Ballarini M, Pelicci P, Minucci S. New method to detect histone acetylation levels by flow cytometry. Cytometry A. 2005;66:52-61.

126. Rudek MA, Zhao M, He P, et al. Pharmacokinetics of 5-azacitidine administered with phenylbutyrate in patients with refractory solid tumors or hematologic malignancies. J Clin Oncol. 2005;23:3906-3911.

127. Gore SD. Changes in promoter methylation and gene expression in patients with MDS and MDS-AML treated wit 5-azacitidine and sodium phenylbutyrate [abstract]. Blood. 2004;104:469.

128. Folkman J. Fundamental concepts of the angiogenic process. Curr Mol Med. 2003;3:643651.

129. Hanahan D, Folkman J. Patterns and emerging mechanisms of the angiogenic switch during tumorigenesis. Cell. 1996;86:353-364.

130. Carmeliet P. Mechanisms of angiogenesis and arteriogenesis. Nat Med. 2000;6:389-395.

131. Griffioen AW, Molema G. Angiogenesis: potentials for pharmacologic intervention in the treatment of cancer, cardiovascular diseases, and chronic inflammation. Pharmacol Rev. 2000;52:237-268.

132. Ferrara N, Kerbel RS. Angiogenesis as a therapeutic target. Nature. 2005;438:967-974.

133. Ferrara N, Hillan KJ, Gerber HP, Novotny W. Discovery and development of bevacizumab, an anti-VEGF antibody for treating cancer. Nat Rev Drug Discov. 2004;3:391-400.

134. Hurwitz H, Fehrenbacher L, Novotny W, et al. Bevacizumab plus irinotecan, fluorouracil, and leucovorin for metastatic colorectal cancer. N Engl J Med. 2004;350:2335-2342.

135. Jain RK, Duda DG, Clark JW, Loeffler JS. Lessons from phase III clinical trials on anti-VEGF therapy for cancer. Nat Clin Pract Oncol. 2006;3:24-40.

136. Folkman J. Antiangiogenesis in cancer therapy-endostatin and its mechanisms of action. Exp Cell Res. 2006;312:594-607.

137. Kerbel R, Folkman J. Clinical translation of angiogenesis inhibitors. Nat Rev Cancer. 2002;2:727-739.

138. Hida K, Hida Y, Amin DN, et al. Tumor-associated endothelial cells with cytogenetic abnormalities. Cancer Res. 2004;64:8249-8255. 
139. Streubel B, Chott A, Huber D, et al. Lymphoma-specific genetic aberrations in microvascular endothelial cells in B-cell lymphomas. N Engl J Med. 2004;351:250-259.

140. Gasparini G, Longo R, Fanelli M, Teicher BA. Combination of antiangiogenic therapy with other anticancer therapies: results, challenges, and open questions. J Clin Oncol. 2005;23:1295-1311.

141. Miki K, Shimizu E, Yano S, Tani K, Sone S. Demethylation by 5-aza-2'-deoxycytidine (5azadC) of p16INK4A gene results in downregulation of vascular endothelial growth factor expression in human lung cancer cell lines. Oncol Res. 2000;12:335-342.

142. Salimath B, Marme D, Finkenzeller G. Expression of the vascular endothelial growth factor gene is inhibited by p73. Oncogene. 2000;19:3470-3476.

143. Zhang $\mathrm{M}$, Volpert $\mathrm{O}$, Shi $\mathrm{YH}$, Bouck N. Maspin is an angiogenesis inhibitor. Nat Med. 2000;6:196-199.

144. Domann FE, Rice JC, Hendrix MJ, Futscher BW. Epigenetic silencing of maspin gene expression in human breast cancers. Int J Cancer. 2000;85:805-810.

145. Galm O, Suzuki H, Akiyama $\mathrm{Y}$, et al. Inactivation of the tissue inhibitor of metalloproteinases-2 gene by promoter hypermethylation in lymphoid malignancies. Oncogene. 2005;24:4799-4805.

146. Seo DW, Li H, Guedez L, et al. TIMP-2 mediated inhibition of angiogenesis: an MMPindependent mechanism. Cell. 2003;114:171-180.

147. Bachman KE, Herman JG, Corn PG, et al. Methylation-associated silencing of the tissue inhibitor of metalloproteinase-3 gene suggest a suppressor role in kidney, brain, and other human cancers. Cancer Res. 1999;59:798-802.

148. Qi JH, Ebrahem Q, Moore N, et al. A novel function for tissue inhibitor of metalloproteinases3 (TIMP3): inhibition of angiogenesis by blockage of VEGF binding to VEGF receptor-2. Nat Med. 2003;9:407-415.

149. Armstrong LC, Bornstein P. Thrombospondins 1 and 2 function as inhibitors of angiogenesis. Matrix Biol. 2003;22:63-71.

150. Yang QW, Liu S, Tian Y, et al. Methylation-associated silencing of the thrombospondin-1 gene in human neuroblastoma. Cancer Res. 2003;63:6299-6310.

151. Vazquez F, Hastings G, Ortega MA, et al. METH-1, a human ortholog of ADAMTS-1, and METH-2 are members of a new family of proteins with angio-inhibitory activity. J Biol Chem. 1999;274:23349-23357.

152. Dunn JR, Panutsopulos D, Shaw MW, et al. METH-2 silencing and promoter hypermethylation in NSCLC. Br J Cancer. 2004;91:1149-1154.

153. Hellebrekers DM, Jair KW, Vire E, et al. Angiostatic activity of DNA methyltransferase inhibitors. Mol Cancer Ther. 2006;5:467-475.

154. Kim MS, Kwon HJ, Lee YM, et al. Histone deacetylases induce angiogenesis by negative regulation of tumor suppressor genes. Nat Med. 2001;7:437-443.

155. Deroanne CF, Bonjean K, Servotte S, et al. Histone deacetylases inhibitors as antiangiogenic agents altering vascular endothelial growth factor signaling. Oncogene. 2002;21:427-436.

156. Qian DZ, Wang X, Kachhap SK, et al. The histone deacetylase inhibitor NVP-LAQ824 inhibits angiogenesis and has a greater antitumor effect in combination with the vascular endothelial growth factor receptor tyrosine kinase inhibitor PTK787/ZK222584. Cancer Res. 2004;64:6626-6634.

157. Pili R, Kruszewski MP, Hager BW, Lantz J, Carducci MA. Combination of phenylbutyrate and 13-cis retinoic acid inhibits prostate tumor growth and angiogenesis. Cancer Res. 2001;61:1477-1485.

158. Kwon HJ, Kim MS, Kim MJ, Nakajima H, Kim KW. Histone deacetylase inhibitor FK228 inhibits tumor angiogenesis. Int J Cancer. 2002;97:290-296.

159. Ogawa H, Rafiee P, Fisher PJ, Johnson NA, Otterson MF, Binion DG. Sodium butyrate inhibits angiogenesis of human intestinal microvascular endothelial cells through COX-2 inhibition. FEBS Lett. 2003;554:88-94. 
160. Zgouras D, Wachtershauser A, Frings D, Stein J. Butyrate impairs intestinal tumor cellinduced angiogenesis by inhibiting HIF-1alpha nuclear translocation. Biochem Biophys Res Commun. 2003;300:832-838.

161. Kim SH, Ahn S, Han JW, et al. Apicidin is a histone deacetylase inhibitor with anti-invasive and anti-angiogenic potentials. Biochem Biophys Res Commun. 2004;315:964-970.

162. Michaelis M, Michaelis UR, Fleming I, et al. Valproic acid inhibits angiogenesis in vitro and in vivo. Mol Pharmacol. 2004;65:520-527.

163. Qian DZ, Kato Y, Shabbeer S, et al. Targeting tumor angiogenesis with histone deacetylase inhibitors: the hydroxamic acid derivative LBH589. Clin Cancer Res. 2006;12:634-642.

164. Mie Lee Y, Kim SH, Kim HS, et al. Inhibition of hypoxia-induced angiogenesis by FK228, a specific histone deacetylase inhibitor, via suppression of HIF-1alpha activity. Biochem Biophys Res Commun. 2003;300:241-246.

165. Sasakawa $\mathrm{Y}$, Naoe $\mathrm{Y}$, Noto $\mathrm{T}$, et al. Antitumor efficacy of FK228, a novel histone deacetylase inhibitor, depends on the effect on expression of angiogenesis factors. Biochem Pharmacol. 2003;66:897-906.

166. Zgouras D, Becker U, Loitsch S, Stein J. Modulation of angiogenesis-related protein synthesis by valproic acid. Biochem Biophys Res Commun. 2004;316:693-697.

167. Semenza GL. Hydroxylation of HIF-1: oxygen sensing at the molecular level. Physiology (Bethesda). 2004;19:176-182.

168. Rossig L, Li H, Fisslthaler B, et al. Inhibitors of histone deacetylation downregulate the expression of endothelial nitric oxide synthase and compromise endothelial cell function in vasorelaxation and angiogenesis. Circ Res. 2002;91:837-844.

169. Michaelis M, Suhan T, Michaelis UR, et al. Valproic acid induces extracellular signalregulated kinase 1/2 activation and inhibits apoptosis in endothelial cells. Cell Death Differ. 2006;13:446-453.

170. Kato H, Tamamizu-Kato S, Shibasaki F. Histone deacetylase 7 associates with hypoxiainducible factor 1alpha and increases transcriptional activity. J Biol Chem. 2004;279:4196641974.

171. Kong X, Lin Z, Liang D, Fath D, Sang N, Caro J. Histone deacetylase inhibitors induce VHL and ubiquitin-independent proteasomal degradation of hypoxia-inducible factor 1alpha. Mol Cell Biol. 2006;26:2019-2028.

172. Fath DM, Kong X, Liang D, et al. Histone Deacetylase Inhibitors Repress the Transactivation Potential of Hypoxia-inducible Factors Independently of Direct Acetylation of HIF-\{alpha\}. J Biol Chem. 2006;281:13612-13619.

173. Cai RL, Yan-Neale Y, Cueto MA, Xu H, Cohen D. HDAC1, a histone deacetylase, forms a complex with Hus1 and Rad9, two G2/M checkpoint Rad proteins. J Biol Chem. 2000;275:27909-27916.

174. Yu J, Angelin-Duclos C, Greenwood J, Liao J, Calame K. Transcriptional repression by blimp-1 (PRDI-BF1) involves recruitment of histone deacetylase. Mol Cell Biol. 2000;20:2592-2603.

175. Smirnov DA, Hou S, Ricciardi RP. Association of histone deacetylase with COUP-TF in tumorigenic Ad12-transformed cells and its potential role in shut-off of MHC class I transcription. Virology. 2000;268:319-328.

176. Yoo YG, Kong G, Lee MO. Metastasis-associated protein 1 enhances stability of hypoxiainducible factor-1alpha protein by recruiting histone deacetylase 1. Embo J. 2006;25:12311241.

177. St Croix B, Rago C, Velculescu V, et al. Genes expressed in human tumor endothelium. Science. 2000;289:1197-1202.

178. Bicknell R, Harris AL. Novel angiogenic signaling pathways and vascular targets. Annu Rev Pharmacol Toxicol. 2004;44:219-238.

179. van Beijnum JR, Griffioen AW. In silico analysis of angiogenesis associated gene expression identifies angiogenic stage related profiles. Biochim Biophys Acta. 2005; 1755:121-134. 
180. Fahrner JA, Eguchi S, Herman JG, Baylin SB. Dependence of histone modifications and gene expression on DNA hypermethylation in cancer. Cancer Res. 2002;62:7213-7218.

181. Nguyen CT, Weisenberger DJ, Velicescu M, et al. Histone H3-lysine 9 methylation is associated with aberrant gene silencing in cancer cells and is rapidly reversed by 5-aza-2'deoxycytidine. Cancer Res. 2002;62:6456-6461.

182. Kondo Y, Shen L, Issa JP. Critical role of histone methylation in tumor suppressor gene silencing in colorectal cancer. Mol Cell Biol. 2003;23:206-215.

183. Greiner D, Bonaldi T, Eskeland R, Roemer E, Imhof A. Identification of a specific inhibitor of the histone methyltransferase SU(VAR)3-9. Nat Chem Biol. 2005;1:143-145.

184. Kerbel RS, Kamen BA. The anti-angiogenic basis of metronomic chemotherapy. Nat Rev Cancer. 2004;4:423-436. 



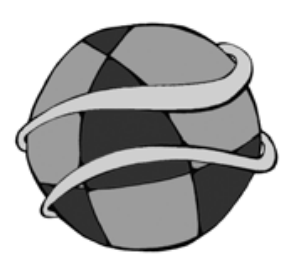

Chapter 6 General discussion and conclusions 


\section{General discussion and conclusions}

The aim of this thesis was to investigate the role of epigenetic regulation of gene expression in EC biology during tumor angiogenesis. To that end, effects of DNA methyltransferase (DNMT)- and histone deacetylase (HDAC) inhibitors were examined on EC biology and (tumor) angiogenesis. In the two different mouse tumor models we used in Chapter 2, decreased tumor growth by treatment with 5-aza-2'deoxycytidine (DAC), zebularine or TSA was accompanied by suppressed tumor angiogenesis. These angiostatic activities of DNMT- and HDAC inhibitors in vivo might be (partly) a consequence of repressive effects on tumor cells, including reactivation of epigenetically silenced tumor suppressor genes with angiogenesis-inhibiting properties, and decreased VEGF production by the tumor. Besides possible indirect repression of angiogenesis in vivo, we examined whether DNMT inhibitors have direct effects on EC biology and tumor angiogenesis. Therefore, we mimicked tumor EC in vitro by activation of human umbilical vein endothelial cells (HUVEC) with the angiogenic growth factors bFGF and VEGF, and culture supernatants of LS174T and CaCo-2 human colon carcinoma cell lines. Van Beijnum et al. described that the gene expression signature of growth factor-stimulated ECs in vitro is indicative of active proliferation and turnover, but that extrapolation to the transcript profile of tumor EC in vivo is limited. ${ }^{1}$ Careful evaluation of this comparison is necessary, and might imply that tumor-conditioned EC in vitro are not ideal models for tumor EC, especially in studies aimed to identify specific tumor endothelial markers for vascular targeting purposes. Our study, however, was not designed primarily to reveal novel tumor EC specific genes, but mainly to study the role of epigenetics in regulation of the process of tumor angiogenesis. Since only a small percentage of EC in a human tumor are angiogenically active, proliferating tumor-conditioned EC in vitro might be more suitable to analyze the involvement of epigenetics in ECs during (tumor) angiogenesis. Furthermore, the difficulty of obtaining a pure population of EC from tumor tissue versus the use of $100 \%$ pure tumor-conditioned EC in culture is another reason for favoring the use of the latter model. Especially for analysis of epigenetic promoter modifications, the use of pure EC populations is essential, to prevent contamination with tumor cell DNA containing altered DNA methylation and histone modification patterns. ${ }^{2-4}$ Using tumor-conditioned EC, we demonstrated direct angiostatic effects of the DNMT inhibitors DAC and zebularine in vitro.

DNMT- and HDAC inhibitors both repressed sprouting of tumor-conditioned EC and microvessel formation in the chick chorioallantoic membrane (CAM), but differed in their effects on EC migration and apoptosis. Decreased EC tube formation by DAC and zebularine appeared to be mainly due to inhibition of EC growth, whereas TSA repressed both proliferation and migration of tumor-conditioned EC and, in addition, induced EC apoptosis at concentrations above $400 \mathrm{nM}$. These observations indicate a (partly) different molecular mechanism behind the angiostatic effects of DNMT- and HDAC inhibitors. This is not unexpected because the processes targeted by these agents, DNA methylation versus histone deacetylation, are interacting but separate epigenetic modifications. Further gene expression analysis might reveal whether the 
different effects of DNMT- and HDAC inhibitors on EC biology are paralleled by differences in functional classes of genes reactivated by these compounds in (tumor) EC.

Decreased tumor cell growth by DNMT inhibitors is considered at least in part to be the result of reactivation of tumor suppressor genes by demethylation of their promoter $\mathrm{CpG}$ islands. In analogy, we speculated that promoter demethylation of angiogenesis-suppressing genes might be involved in the direct angiostatic effects of DNMT inhibitors. Therefore, we screened several well-known angiostatic proteins for the presence of $\mathrm{CpG}$ islands in the region from -1000 to +500 relative to the transcription start site. ${ }^{5,6}$ Remarkably, only a minority of these genes, including thrombospondin-1 (TSP1), contains a promoter CpG island, while almost half of the genes in our genome have a CpG-rich promoter region. ${ }^{7}$ Interferon- $\alpha$ and $-\beta$ (IFN- $\alpha$ and $-\beta$ ), platelet factor-4 (PF-4), interferon- $\gamma$-inducible protein-10, plasminogen activator inhibitor (PAI), bactericidal/permeability-increasing protein (BPI) and pigment epithelium-derived factor (PEDF) are examples of endogenous angiogenesis inhibitors without a promoter $\mathrm{CpG}$ island. Thus, in contrast to tumor suppressor genes, many of the classical angiogenesis-suppressing genes lack a promoter $\mathrm{CpG}$ island.

Possible explanations that have been provided for the angiostatic activity of HDAC inhibitors are decreased production of HIF1 $\alpha$ or VEGF by tumor cells, or reduced expression of EC genes including those encoding VEGF receptors, angiopoietin-2 (ang-2), CXCR4, survivin, Tie-2 and eNOS. ${ }^{8-16}$ However, repression of VEGF production by tumor cells can only explain indirect angiostatic effects of HDAC inhibitors, via inhibition of tumor cells. Although downregulation of angiogenesisrelated genes in EC can explain angiogenesis inhibition in vitro, this is unlikely to be due to direct effects of HDAC inhibitors on the promoters of these genes, since direct effects of these compounds would be increased promoter histone acetylation and transcriptional activation.

To investigate the mechanism behind the direct inhibition of EC growth and angiogenesis by DNMT- and HDAC inhibitors, we performed microarray analysis to identify genes downregulated in tumor-conditioned EC and reactivated by DAC and TSA (Chapter 3). This strategy has been used previously to identify novel epigenetically silenced tumor suppressor genes in cancer cell lines. ${ }^{17,18}$ Among the genes we identified from the microarray were (i) interferon-responsive genes (G1P3, $M X 1$, IFI27), which have been previously reported to be activated by DAC treatment, ${ }^{19,20}$ and (ii) imprinted genes (DMD, NNAT, IGF2R). Furthermore, (iii) two of the identified genes, GADD45A and CDKN1A, are among the small group of genes (about $2-10 \%$ of all genes) reported to be most commonly induced by HDAC inhibitors in tumor cells. ${ }^{21}$ Interestingly, (iv) $77 \%$ of the genes identified from the microarray contained a promoter CpG island, and (v) $26 \%$ has been described to be epigenetically silenced in different tumor types, suggesting that we selected for genes prone to silencing by promoter DNA methylation and histone modifications. Examination of epigenetic promoter modifications of these genes, however, revealed that it was not DNA methylation, but histone $\mathrm{H} 3$ deacetylation and loss of $\mathrm{H} 3$ lysine 4 methylation that were associated with gene inactivation in tumor-conditioned EC. Although our study indicates that DNA methylation is not the mechanism by which 
genes are suppressed in tumor-conditioned EC, a possibility is that the sensitivity of our microarray might not be good enough to identify the truelly methylated genes. Techniques to specifically search for methylated promoters in the genome of ECs could further unravel the involvement of promoter DNA methylation in silencing genes in tumor(-conditioned) versus quiescent EC. For example, chromatin immunoprecipitation using a 5-methyl-cytosine antibody followed by hybridization of precipitated DNA to a CpG island or promoter microarray can be used to generate methylation profiles for a large set of $\mathrm{CpG}$ islands. ${ }^{22}$

Our study reveals differences in the involvement of promoter DNA methylation and histone modifications in downregulation of inhibitory genes in tumor EC versus silencing of tumor suppressor genes in tumor cells (Table 6.1). In tumor cells, tumor suppressor genes are epigenetically silenced by promoter DNA hypermethylation accompanied by histone deacetylation, histone H3 lysine 9 hypermethylation and histone $\mathrm{H} 3$ lysine 4 hypomethylation. ${ }^{23-25}$ In comparison, we found that downregulation of inhibitory genes in tumor-conditioned $\mathrm{EC}$ involves histone $\mathrm{H} 3$ deacetylation and loss of $\mathrm{H} 3$ lysine 4 methylation but not DNA hypermethylation. This correlates with the dominant effect of TSA over DAC in relative induction of these genes in tumorconditioned EC. In comparison, many epigenetically silenced tumor suppressor genes in tumor cells cannot be upregulated by TSA alone, but require DAC for reactivation. ${ }^{26}$ The difference in epigenetic gene silencing in tumor EC versus tumor cells might be in line with the model that histone modifications are primary events in gene silencing, while DNA methylation is a consequence of, and dependent on, inactivating histone marks, and serves to stably maintain permanent silencing of genes rather than initiating it. ${ }^{27-31}$ It is attractive to speculate that silencing of inhibitory genes in tumor EC during angiogenesis is a temporary phenomenon, that is reversed when the EC are no longer angiogenically active. Therefore, epigenetic processes involved in gene silencing in these cells might only consist of reversible histone modifications. In contrast, tumor cells might add an extra layer of permanent silencing on the tumor suppressor genes by promoter DNA hypermethylation. Another possibility, however, is that the sequence of events during epigenetic gene silencing is different in tumor cells, containing genetic alterations of histone acetyltransferases, histone methyltransferases and chromatin remodeling factors, versus non-neoplastic tumor EC. According to this scenario, DNA methylation might be the initial step in tumor suppressor gene silencing in tumor cells, recruiting histone modifying enzymes via methyl-binding domain proteins, while histone modifications initiate silencing of inhibitory genes in tumor EC. Nevertheless, it is important to emphasize that our data are consistent with a role of histone deacetylation and loss of histone H3 lysine 4 methylation in switching off transcription of genes in tumor-conditioned EC, but do not prove that these modifications initiate gene silencing. For example, decreased availability of essential transcription factors might result in switching of the gene promoters to an inactive chromatin state. Yet, reactivation of our candidate gene by DAC and TSA through reversal of promoter histone modifications show that increased histone acetylation and histone $\mathrm{H} 3$ lysine 4 methylation are sufficient for gene reexpression. Various techniques are emerging that can be applied to further exploit our 


\begin{tabular}{|c|c|c|c|c|}
\hline $\begin{array}{l}\text { Epigenetic } \\
\text { modifications }\end{array}$ & Tumor cell & Ref. & Tumor endothelial cell & Ref. \\
\hline $\begin{array}{l}\text { global epigenetic } \\
\text { alterations }\end{array}$ & $\begin{array}{l}\text { genetic defects (e.g. } \\
\text { mutations, deletions) } \\
\text { global DNA } \\
\text { hypomethylation } \\
\text { increased DNMT levels } \\
\text { and activity } \\
\text { loss of AcK16 H4 and } \\
\text { triMeK20 H4 } \\
\text { disrupted HDAC levels } \\
\text { genetic alterations of } \\
\text { histone acetyltransferases, } \\
\text { histone } \\
\text { methyltransferases and } \\
\text { chromatin remodelling } \\
\text { factors }\end{array}$ & 57 & $\begin{array}{l}\text { genetically stable } \\
\text { global DNA } \\
\text { hypermethylation } \\
\text { increased DNMT levels and } \\
\text { activity } \\
\text { loss of histone acetylation } \\
\text { increased HDAC levels and } \\
\text { activity }\end{array}$ & $\begin{array}{l}55 \\
55 \\
8\end{array}$ \\
\hline $\begin{array}{l}\text { (tumor) } \\
\text { suppressor gene } \\
\text { silencing }\end{array}$ & $\begin{array}{l}\text { DNA methylation of } \\
\text { promoter } \mathrm{CpG} \text { islands } \\
\text { loss of promoter } \mathrm{AcH} 3 \text { and } \\
\text { MeK4 } \mathrm{H} 3 \text {, gain of MeK9 } \\
\mathrm{H} 3 \\
\text { permanent silencing }\end{array}$ & $23-25$ & $\begin{array}{l}\text { DNA methylation- } \\
\text { independent silencing } \\
\text { loss of promoter AcH3 and } \\
\text { MeK4 H3 } \\
\text { reversible silencing? }\end{array}$ & \\
\hline \multirow[t]{2}{*}{ effects DAC/TSA } & $\begin{array}{l}\text { reactivation of } \\
\text { epigenetically silenced } \\
\text { tumor suppressor genes; } \\
\text { synergistic effect; } \\
\text { DAC is dominant }\end{array}$ & & $\begin{array}{l}\text { reactivation of epigenetically } \\
\text { silenced angiogenesis- } \\
\text { suppressing genes; } \\
\text { no synergistic effects; } \\
\text { TSA is dominant }\end{array}$ & \\
\hline & $\begin{array}{l}\text { inhibition of tumor cell } \\
\text { growth and tumorigenesis }\end{array}$ & 58 & $\begin{array}{l}\text { inhibition of tumor EC growth } \\
\text { and angiogenesis }\end{array}$ & 55 \\
\hline
\end{tabular}

insight into the role of different epigenetic modifications in regulation of EC gene expression during (tumor) angiogenesis. ${ }^{32}$ For example, large-scale examination of (additional) promoter histone modifications in tumor-conditioned and quiescent EC could be performed by ChIP on chip, a microarray platform upon which immunoprecipitated DNA is hybridised against known probes, a strategy used for high-throughput mapping of chromatin marks. ${ }^{33}$

Despite the absence of promoter DNA hypermethylation, our candidate genes are reactivated by the DNMT inhibitor DAC in tumor-conditioned EC. Also in tumor cells, this phenomenon has been reported for some genes such as Apaf- $1 .{ }^{34}$ This might be explained by the fact that DNMTs are dual function proteins. Apart from silencing genes by catalysing promoter DNA methylation, DNMTs can inhibit transcription through recruitment of HDACs, histone methyltransferases and chromatin remodeling proteins, independent of their methylating activities. ${ }^{35-39}$ These methylationindependent gene silencing activities can be partially relieved by TSA. We 
hypothesize that methylation-independent transcription-repressing effects of DNMTs might be involved in silencing of inhibitory genes in tumor-conditioned EC. By trapping DNMTs, DAC inhibits the methylation-independent effects of these enzymes, resulting in release of DNMTs and associated histone modifying enzymes from the promoters of the candidate genes, relieving transcriptional repression by reversal of promoter histone modifications. Clearly, it is very interesting that many of the genes identified, like IGFBP3, are reactivated by DNMT inhibition in both tumor cells ${ }^{40,41}$ as well as tumor EC, while this appears to be through different mechanisms. We hypothesize that our microarray analysis identified genes prone to epigenetic silencing by DNMTs in both tumor cells as well as in tumor EC. In the former cells, DNMTs induce transcriptional inactivation by catalysing promoter DNA methylation, while in the latter, methylation-independent effects of these enzymes mediate epigenetic gene silencing. Further studies are required to provide evidence for a role of DNMTs in silencing of our candidate genes. To that end, chromatin immunoprecipitation (ChIP) of endogenous DNMTs using DNMT1/3a/3b antibodies, or ChIP of EC transfected with wild-type versus catalytically mutant DNMT constructs, followed by PCR analysis of the candidate gene promoters, might be suitable approaches.

Recently, methylation-independent transcriptional repressor effects of DNMTs were described for T-cadherin (T-Cad) during neuronal differentiation. ${ }^{42} \mathrm{~T}$-Cad, a negative regulator of neurite outgrowth, is one of the genes downregulated during nerve growth factor (NGF)-induced neuronal differentiation. In tumor cells, T-Cad is often targeted for promoter DNA methylation. ${ }^{43,44}$ Bai et al. demonstrated that DNMT3b is required for NGF-mediated neurite outgrowth. ${ }^{45}$ Recently, they revealed that T-Cad is downregulated by DNMT3b during neuronal differentiation of PC12 cells. Specific association of DNMT3b with the T-Cad promoter was demonstrated by ChIP, and the inhibitory effect of DNMT3b on this promoter was shown to be independent of its enzymatic activity and of DNA methylation, and could be relieved by TSA. ${ }^{42}$ This remarkable parallel between the mechanism behind silencing of growth-inhibiting genes in EC during angiogenesis and of a neurite growth-inhibiting gene in neuronal cells during neurogenesis further stresses upon the striking similarities between growing axons in the nervous system and EC sprouting in angiogenesis.

In addition to the difference in the involvement of promoter DNA hypermethylation in silencing of suppressive genes in tumor cells versus tumor EC, these cell types also demonstrate opposing changes in global 5-methylcytosine content. While tumor cells undergo global DNA hypomethylation, ${ }^{4}$ tumor-conditioned EC show increased total genomic 5-methylcytosine levels compared with quiescent EC. Despite several attempts to unravel the apparent paradox of tumor suppressor gene hypermethylation and global genomic hypomethylation in tumor cells, ${ }^{46}$ it is unclear whether these methylation changes are causally related. One hypothesis might be that, due to the increased promoter DNA methylation of tumor suppressor genes in tumor cells, less DNMTs are available for methylation in other areas of the genome. Consequently, the apparent absence of promoter DNA hypermethylation of inhibitory genes in tumor EC might explain why global methylation levels of the tumor EC genome are not decreased. Rather, the small increase of global DNA methylation levels in tumorconditioned versus quiescent EC might be simply a consequence of the enhanced DNMT expression and activity, due to increased proliferation of tumor-conditioned EC. 
Besides unraveling part of the epigenetic regulation of tumor angiogenesis, our microarray analysis identifies novel angiogenesis-regulating genes. Functional validation indicated that clusterin, fibrillin 1 and quiescin Q6 inhibit EC growth and sprouting. Although our findings suggest that the microarray analysis identified angiogenesis-suppressing genes, we did not identify the classical anti-angiogenic factors such as TSP1, PF-4, BPI and PEDF. Rather, several of the genes identified have a known or suspected tumor suppressor function such as IGFBP3, FAT, IGFBP7, IGSF4, GADD45A, CDKN1A and DKK3. Thus, it seems we did not select for genes with specific repressive properties against EC, but for general (growth) inhibitory genes, which now turn out to be involved in angiogenesis regulation. We propose that reactivation of these genes in tumor-conditioned EC, by reversal of promoter histone modifications, provides a mechanism behind the direct angiostatic activities of DNMT- and HDAC inhibitors.

In Chapter 4, we reveal an epigenetic mechanism behind the process of EC anergy, an angiogenesis-mediated escape from immunity. ${ }^{47-51}$ We demonstrated that DNMT- and HDAC inhibitors can restore ICAM-1 expression on tumor(-conditioned) $\mathrm{EC}$ in vitro and in vivo, resulting in enhanced leukocyte-EC adhesion in vitro and increased leukocyte-vessel wall interactions and inflammatory infiltration in mouse tumors. In analogy with the other genes identified in the microarray, downregulation of ICAM-1 in tumor-conditioned EC was associated with histone $\mathrm{H} 3$ deacetylation and loss of $\mathrm{H} 3$ lysine 4 methylation, which was reversed by DNMT- and HDAC inhibitors. Flati et al. present another cell biological regulation of EC anergy (Flati et al., unpublished data). They show that bFGF inhibits the tumor necrosis factor- $\alpha$ (TNF- $\alpha$ )induced activation of NFkB in ECs by blocking phosphorylation and degradation of $\mathrm{lkB} \alpha$, and suggest that this is mediated by sustained activation of p38-MAPK through bFGF. Nevertheless, our data on epigenetic regulation of EC anergy are not incompatible with the findings of Flati et al., since promoter histone modifications induce a repressive chromatin conformation, thereby inhibiting binding of transcription factors such as NFkB. Recently, our group reported that the angiogenesis inhibitors anginex, endostatin, and angiostatin significantly stimulate leukocyte-vessel wall interactions by circumvention of EC anergy, by the up-regulation of endothelial adhesion molecules in vitro and in tumor vessels. ${ }^{52,53}$ Yet, the epigenetic mechanism by which DNMT- and HDAC inhibitors reactivate ICAM-1 expression, and the mechanism behind the reactivation of this molecule by classical angiogenesis inhibitors do not necessarily have to be the same. In addition, suppression of EC ICAM-1 expression by angiogenic growth factors and restoration of this phenomenon by classical angiostatic agents do not necessarily have to proceed via the same pathway. Therefore, examining effects of classical angiogenesis inhibitors on epigenetic modifications in the ICAM-1 promoter might further unravel the association between angiogenesis, EC anergy, and epigenetics.

Besides revealing part of the role of epigenetic mechanism in tumor angiogenesis, the data presented in this thesis have important therapeutic implications (Chapter 5 ). We demonstrate that the targets of epigenetic therapy can be extended beyond tumor cells alone. DNMT- and HDAC inhibitors target three important processes in cancer; growth of tumor cells, tumor angiogenesis and tumor EC anergy. Reactivation of 
epigenetically silenced tumor suppressor genes in tumor cells affects virtually all pathways suggested by Hanahan and Weinberg ${ }^{54}$ to be involved with the cancer process. In addition, tumor cells show decreased expression of genes encoding angiogenic factors, i.e. VEGF, after treatment with HDAC inhibitors. ${ }^{8,11,14-16}$ Besides these indirect pathways through which angiogenesis can be suppressed by DNMTand HDAC inhibitors, we demonstrate direct angiostatic activities of these compounds. In addition, reversal of the angiogenesis-induced EC anergy to inflammatory stimulation by these agents would improve the anti-tumor immune response. The findings described in this thesis, i.e. that DNMT- and HDAC inhibitors suppress tumor vasculature and angiogenesis-associated escape from the immune response, in addition to the previously reported inhibition of tumor cell growth, are very exciting and make these compounds attractive combinatorial anti-cancer therapeutics. 


\section{References}

1. van Beijnum JR, Griffioen AW. In silico analysis of angiogenesis associated gene expression identifies angiogenic stage related profiles. Biochim Biophys Acta. 2005;1755:121-134

2. Herman JG, Baylin SB. Gene silencing in cancer in association with promoter hypermethylation. N Engl J Med. 2003;349:2042-2054.

3. Fraga MF, Ballestar E, Villar-Garea A, et al. Loss of acetylation at Lys16 and trimethylation at Lys20 of histone $\mathrm{H} 4$ is a common hallmark of human cancer. Nat Genet. 2005;37:391400.

4. Feinberg AP, Vogelstein B. Hypomethylation distinguishes genes of some human cancers from their normal counterparts. Nature. 1983;301:89-92.

5. Gardiner-Garden M, Frommer M. CpG islands in vertebrate genomes. J Mol Biol 1987;196:261-282.

6. Takai D, Jones PA. Comprehensive analysis of $\mathrm{CpG}$ islands in human chromosomes 21 and 22. Proc Natl Acad Sci U S A. 2002;99:3740-3745.

7. Cross SH, Charlton JA, Nan X, Bird AP. Purification of CpG islands using a methylated DNA binding column. Nat Genet. 1994;6:236-244.

8. Kim MS, Kwon HJ, Lee YM, et al. Histone deacetylases induce angiogenesis by negative regulation of tumor suppressor genes. Nat Med. 2001;7:437-443.

9. Deroanne CF, Bonjean K, Servotte S, et al. Histone deacetylases inhibitors as antiangiogenic agents altering vascular endothelial growth factor signaling. Oncogene. 2002;21:427-436

10. Qian DZ, Kato Y, Shabbeer S, et al. Targeting tumor angiogenesis with histone deacetylase inhibitors: the hydroxamic acid derivative LBH589. Clin Cancer Res. 2006;12:634-642.

11. Qian DZ, Wang X, Kachhap SK, et al. The histone deacetylase inhibitor NVP-LAQ824 inhibits angiogenesis and has a greater antitumor effect in combination with the vascula endothelial growth factor receptor tyrosine kinase inhibitor PTK787/ZK222584. Cancer Res. 2004;64:6626-6634

12. Michaelis M, Michaelis UR, Fleming I, et al. Valproic acid inhibits angiogenesis in vitro and in vivo. Mol Pharmacol. 2004;65:520-527.

13. Kwon HJ, Kim MS, Kim MJ, Nakajima H, Kim KW. Histone deacetylase inhibitor FK228 inhibits tumor angiogenesis. Int J Cancer. 2002;97:290-296.

14. Mie Lee Y, Kim SH, Kim HS, et al. Inhibition of hypoxia-induced angiogenesis by FK228, a specific histone deacetylase inhibitor, via suppression of HIF-1alpha activity. Biochem Biophys Res Commun. 2003;300:241-246.

15. Sasakawa Y, Naoe Y, Noto T, et al. Antitumor efficacy of FK228, a novel histone deacetylase inhibitor, depends on the effect on expression of angiogenesis factors. Biochem Pharmacol. 2003;66:897-906.

16. Zgouras D, Becker U, Loitsch S, Stein J. Modulation of angiogenesis-related protein synthesis by valproic acid. Biochem Biophys Res Commun. 2004;316:693-697.

17. Suzuki H, Gabrielson E, Chen W, et al. A genomic screen for genes upregulated by demethylation and histone deacetylase inhibition in human colorectal cancer. Nat Genet. 2002;31:141-149

18. Yamashita K, Upadhyay S, Osada M, et al. Pharmacologic unmasking of epigenetically silenced tumor suppressor genes in esophageal squamous cell carcinoma. Cancer Cell. 2002;2:485-495

19. Karpf AR, Peterson PW, Rawlins JT, et al. Inhibition of DNA methyltransferase stimulates the expression of signal transducer and activator of transcription 1, 2, and 3 genes in colon tumor cells. Proc Natl Acad Sci U S A. 1999;96:14007-14012. 
20. Liang G, Gonzales FA, Jones PA, Orntoft TF, Thykjaer T. Analysis of gene induction in human fibroblasts and bladder cancer cells exposed to the methylation inhibitor 5-aza-2'deoxycytidine. Cancer Res. 2002;62:961-966.

21. Johnstone RW, Licht JD. Histone deacetylase inhibitors in cancer therapy: is transcription the primary target? Cancer Cell. 2003;4:13-18.

22. Weber M, Davies JJ, Wittig D, et al. Chromosome-wide and promoter-specific analyses identify sites of differential DNA methylation in normal and transformed human cells. Nat Genet. 2005;37:853-862.

23. Fahrner JA, Eguchi S, Herman JG, Baylin SB. Dependence of histone modifications and gene expression on DNA hypermethylation in cancer. Cancer Res. 2002;62:7213-7218.

24. Nguyen CT, Weisenberger DJ, Velicescu M, et al. Histone H3-lysine 9 methylation is associated with aberrant gene silencing in cancer cells and is rapidly reversed by 5-aza-2'deoxycytidine. Cancer Res. 2002;62:6456-6461.

25. Kondo Y, Shen L, Issa JP. Critical role of histone methylation in tumor suppressor gene silencing in colorectal cancer. Mol Cell Biol. 2003;23:206-215.

26. Cameron EE, Bachman KE, Myohanen S, Herman JG, Baylin SB. Synergy of demethylation and histone deacetylase inhibition in the re-expression of genes silenced in cancer. Nat Genet. 1999;21:103-107.

27. Tamaru H, Selker EU. A histone $\mathrm{H} 3$ methyltransferase controls DNA methylation in Neurospora crassa. Nature. 2001;414:277-283.

28. Tamaru $\mathrm{H}$, Zhang $\mathrm{X}$, McMillen $\mathrm{D}$, et al. Trimethylated lysine 9 of histone $\mathrm{H} 3$ is a mark for DNA methylation in Neurospora crassa. Nat Genet. 2003;34:75-79.

29. Mutskov V, Felsenfeld $G$. Silencing of transgene transcription precedes methylation of promoter DNA and histone H3 lysine 9. Embo J. 2004;23:138-149.

30. Lehnertz B, Ueda Y, Derijck AA, et al. Suv39h-mediated histone H3 lysine 9 methylation directs DNA methylation to major satellite repeats at pericentric heterochromatin. Curr Biol. 2003;13:1192-1200.

31. Jackson JP, Lindroth AM, Cao X, Jacobsen SE. Control of CpNpG DNA methylation by the KRYPTONITE histone H3 methyltransferase. Nature. 2002;416:556-560.

32. Callinan PA, Feinberg AP. The emerging science of epigenomics. Hum Mol Genet. 2006;15 Spec No 1:R95-101.

33. Ren B, Robert F, Wyrick JJ, et al. Genome-wide location and function of DNA binding proteins. Science. 2000;290:2306-2309.

34. Soengas MS, Capodieci P, Polsky D, et al. Inactivation of the apoptosis effector Apaf-1 in malignant melanoma. Nature. 2001;409:207-211.

35. Fuks F, Hurd PJ, Deplus R, Kouzarides T. The DNA methyltransferases associate with HP1 and the SUV39H1 histone methyltransferase. Nucleic Acids Res. 2003;31:2305-2312.

36. Rountree MR, Bachman KE, Baylin SB. DNMT1 binds HDAC2 and a new co-repressor, DMAP1, to form a complex at replication foci. Nat Genet. 2000;25:269-277.

37. Fuks F, Burgers WA, Brehm A, Hughes-Davies L, Kouzarides T. DNA methyltransferase Dnmt1 associates with histone deacetylase activity. Nat Genet. 2000;24:88-91.

38. Fuks F, Burgers WA, Godin N, Kasai M, Kouzarides T. Dnmt3a binds deacetylases and is recruited by a sequence-specific repressor to silence transcription. Embo J. 2001;20:25362544.

39. Robertson KD, Ait-Si-Ali S, Yokochi T, Wade PA, Jones PL, Wolffe AP. DNMT1 forms a complex with Rb, E2F1 and HDAC1 and represses transcription from E2F-responsive promoters. Nat Genet. 2000;25:338-342.

40. Hanafusa T, Yumoto $\mathrm{Y}$, Nouso K, et al. Reduced expression of insulin-like growth factor binding protein-3 and its promoter hypermethylation in human hepatocellular carcinoma. Cancer Lett. 2002;176:149-158.

41. Chang $Y S$, Wang $L$, Suh $Y A$, et al. Mechanisms underlying lack of insulin-like growth factorbinding protein-3 expression in non-small-cell lung cancer. Oncogene. 2004;23:6569-6580. 
42. Bai S, Ghoshal K, Jacob ST. Identification of T-cadherin as a novel target of DNA methyltransferase $3 \mathrm{~B}$ and its role in the suppression of nerve growth factor-mediated neurite outgrowth in PC12 cells. J Biol Chem. 2006;281:13604-13611.

43. Takeuchi T, Liang SB, Ohtsuki Y. Downregulation of expression of a novel cadherin molecule, T-cadherin, in basal cell carcinoma of the skin. Mol Carcinog. 2002;35:173-179.

44. Hibi K, Kodera $\mathrm{Y}$, Ito K, Akiyama S, Nakao A. Methylation pattern of $\mathrm{CDH} 13$ gene in digestive tract cancers. Br J Cancer. 2004;91:1139-1142.

45. Bai S, Ghoshal K, Datta J, Majumder S, Yoon SO, Jacob ST. DNA methyltransferase 3b regulates nerve growth factor-induced differentiation of PC12 cells by recruiting histone deacetylase 2. Mol Cell Biol. 2005;25:751-766.

46. Ehrlich M, Woods $\mathrm{CB}, \mathrm{Yu} \mathrm{MC}$, et al. Quantitative analysis of associations between DNA hypermethylation, hypomethylation, and DNMT RNA levels in ovarian tumors. Oncogene. 2006;25:2636-2645

47. Griffioen AW, Damen CA, Blijham GH, Groenewegen G. Tumor angiogenesis is accompanied by a decreased inflammatory response of tumor-associated endothelium. Blood. 1996;88:667-673.

48. Griffioen AW, Damen CA, Martinotti S, Blijham GH, Groenewegen G. Endothelial intercellular adhesion molecule-1 expression is suppressed in human malignancies: the role of angiogenic factors. Cancer Res. 1996;56:1111-1117.

49. Griffioen AW, Relou IA, Gallardo Torres HI, et al. The angiogenic factor bFGF impairs leukocyte adhesion and rolling under flow conditions. Angiogenesis. 1998;2:235-243.

50. Melder RJ, Koenig GC, Witwer BP, Safabakhsh N, Munn LL, Jain RK. During angiogenesis, vascular endothelial growth factor and basic fibroblast growth factor regulate natural killer cell adhesion to tumor endothelium. Nat Med. 1996;2:992-997.

51. Dirkx AE, Oude Egbrink MG, Kuijpers MJ, et al. Tumor angiogenesis modulates leukocytevessel wall interactions in vivo by reducing endothelial adhesion molecule expression. Cancer Res. 2003;63:2322-2329.

52. Griffioen AW, Damen CA, Mayo KH, et al. Angiogenesis inhibitors overcome tumor induced endothelial cell anergy. Int J Cancer. 1999;80:315-319.

53. Dirkx AE, oude Egbrink MG, Castermans K, et al. Anti-angiogenesis therapy can overcome endothelial cell anergy and promote leukocyte-endothelium interactions and infiltration in tumors. FASEB J. 2006;20:621-630.

54. Hanahan D, Weinberg RA. The hallmarks of cancer. Cell. 2000;100:57-70

55. Hellebrekers DM, Jair KW, Vire E, et al. Angiostatic activity of DNA methyltransferase inhibitors. Mol Cancer Ther. 2006;5:467-475.

56. Robertson KD, Uzvolgyi E, Liang G, et al. The human DNA methyltransferases (DNMTs) 1 , $3 \mathrm{a}$ and $3 \mathrm{~b}$ : coordinate mRNA expression in normal tissues and overexpression in tumors. Nucleic Acids Res. 1999;27:2291-2298.

57. Esteller M. Epigenetics provides a new generation of oncogenes and tumour-suppressor genes. Br J Cancer. 2006;94:179-183.

58. Egger G, Liang G, Aparicio A, Jones PA. Epigenetics in human disease and prospects for epigenetic therapy. Nature. 2004;429:457-463. 



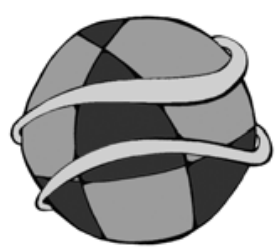

Summary 
Tumor angiogenesis is required for tumor growth and the development of metastasis, therefore inhibition of tumor vascularization is an attractive anti-cancer approach. Early in tumorigenesis, the angiogenic switch induces expression of proangiogenic factors and down-regulates anti-angiogenic proteins. By binding of angiogenic factors to receptors on the endothelium, endothelial cells become activated, resulting in degradation of the surrounding extracellular matrix and endothelial cell migration, proliferation and tube formation. This multi-step cascade is accompanied by alterations in endothelial cell gene expression. Several studies searched for differentially expressed genes between tumor- and normal endothelial cells, most of which were designed to identify genes preferentially expressed on tumor endothelium. Genes specifically expressed on tumor endothelial cells might be used for specific therapeutic targeting of tumor vasculature to minimize unwanted side effects. In addition, analysis of endothelial cell gene expression profiles enhances our knowledge of biology during tumor angiogenesis.

Tight regulation of gene expression in endothelial cells during tumor angiogenesis is pivotal. Epigenetic processes are essential for gene expression regulation by influencing chromatin structure. Two major epigenetic modifications are DNA methylation and histone modifications. In tumor cells, major epigenetic aberrations have been described which play a role in the initiation and progression of tumorigenesis. The best studied epigenetic alteration in these cells is inappropriate transcriptional repression of tumor suppressor genes by promoter DNA hypermethylation and histone deacetylation. The reversibility of epigenetic events encouraged the development of DNA methyltransferase (DNMT)- and histone deacetylase (HDAC)- inhibitors as anti-cancer therapeutics. In contrast with the extensive knowledge on epigenetic alterations in tumor cells, comparatively little is known on epigenetic modifications in tumor endothelial cells. In this thesis, we investigated the role of epigenetics in tumor angiogenesis.

In Chapter 2 we examined the effects of DNMT inhibitors on endothelial cell biology and tumor angiogenesis. In addition to decreased tumor angiogenesis in different mouse tumor models by the DNMT inhibitors 5-aza-2'-deoxycytidine (DAC) and zebularine, we demonstrate that these compounds have direct angiostatic activity. We show decreased growth of tumor-conditioned endothelial cells by DAC and zebularine, without affecting apoptosis and migration of endothelial cells. Furthermore, these drugs markedly inhibit tube formation of endothelial cells in vitro, and angiogenesis in vivo in the chorioallantoic membrane.

Our findings that DNMT inhibitors directly repress growth and angiogenesis of endothelial cells, similar as previously described for HDAC inhibitors, indicates that epigenetic modifications mediated by DNMTs and HDACs are involved in regulation of gene expression in endothelial cells during tumor angiogenesis. To gain more insight into (i) the role of epigenetic modifications in regulating tumor endothelial cell gene expression, and (ii) the mechanism behind the angiostatic effects of DNMT- and HDAC inhibitors, we performed a comprehensive screen to identify genes downregulated in tumor-conditioned versus quiescent endothelial cells, and reactivated by DAC and trichostatin A (TSA) (Chapter 3 ). This analysis revealed that $77 \%$ of the genes identified harboured a promoter $\mathrm{CpG}$ island, which is more than expected based on chance, and many genes were described to be hypermethylated in 
tumor cells. We demonstrate that silencing of these genes in tumor-conditioned endothelial cells is associated with promoter histone $\mathrm{H} 3$ deacetylation and loss of $\mathrm{H} 3$ lysine 4 methylation, but not with promoter DNA methylation. Reactivation of these genes by DAC and TSA correlates with reversal of these promoter histone modifications. Functional validation of three candidate genes (clusterin, fibrillin1, and quiescin Q6) reveals that these genes are negative regulators of endothelial cell growth and angiogenesis. These findings suggest that the angiostatic activities of DNMT- and HDAC inhibitors can be explained by reactivation of angiogenesis suppressing genes in tumor endothelial cells by increasing promoter histone $\mathrm{H} 3$ acetylation and $\mathrm{H} 3$ lysine 4 methylation.

In Chapter 4 we examine the role of epigenetics in tumor endothelial cell anergy. By production of angiogenic factors, tumors escape from immune surveillance by downregulation of leukocyte adhesion molecules in tumor endothelial cells and, consequently, reduction of leukocyte-vessel wall interactions. We show that DNMTand HDAC inhibitors have the capacity to reactivate expression of intercellular adhesion molecule 1 (ICAM-1) in tumor(-conditioned) endothelial cells in vitro and in vivo. This is accompanied by restored leukocyte adhesion to tumor-conditioned endothelial cells in vitro, and enhanced leukocyte-vessel wall interactions and leukocyte infiltration in mouse tumors. We show that downregulation of ICAM-1 in tumor endothelium and the resulting endothelial cell anergy occurs in association with reduced promoter histone $\mathrm{H} 3$ acetylation and of $\mathrm{H} 3$ lysine 4 methylation, which can be overcome by DNMT- and HDAC inhibitors.

In Chapter 5 we describe the dual targeting of DNMT- and HDAC inhibitors on both tumor cells and tumor angiogenesis. We provide an overview of currently used DNMT- and HDAC inhibitors and describe their effects on tumor cells as well as the results of (pre)clinical studies of these drugs as anti-cancer therapeutics. Furthermore, several studies are reviewed on the angiostatic effects of different HDAC inhibitors. Finally, we propose a model suggesting three mechanisms by which DNMT- and HDAC inhibitors exert their anti-tumor effects. Firstly, these drugs inhibit growth of tumor cells by reactivation of epigenetically silenced tumor suppressor genes in these cells. Secondly, upregulation of tumor suppressor genes with angiogenesis inhibiting properties cause indirect angiostatic effects in vivo. In addition, direct repression of tumor endothelial cell growth and angiogenesis results in direct targeting of tumor vascularization by DNMT- and HDAC inhibitors.

In conclusion, we have demonstrated that DNMT inhibitors are potent angiostatic agents, and reactivate epigenetically silenced angiogenesis suppressing genes in tumor endothelial cells through reversal of promoter histone modifications. By reexpressing ICAM-1 on tumor endothelium, DNMT- and HDAC inhibitors restore leukocyte-vessel wall interactions and reverse endothelial cell anergy. Our findings give more insight into the role of epigenetics in regulation of endothelial cell gene expression during tumor angiogenesis, and (partly) unravel the mechanism behind the angiostatic effects of DNMT- and HDAC inhibitors. Furthermore, new angiogenesisregulating genes exhibiting suppressive effects on growth and sprouting of endothelial cells were identified. In addition to increasing our knowledge on tumor endothelial cell biology, this work also has important therapeutic implications, demonstrating that the inhibitory effects of DNMT- and HDAC inhibitors can be extended beyond tumor cells 
alone. By direct targeting of (i) tumor cells, (ii) tumor angiogenesis, and (iii) tumor endothelial cell anergy, these drugs are promising combinatorial anti-cancer therapeutics 


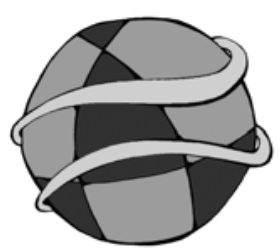

\section{Samenvatting}


Tumorangiogenese is noodzakelijk voor tumorgroei en voor de vorming van metastasen. Dit maakt remming van tumorvascularisatie een aantrekkelijke behandelingsstrategie voor kanker. Angiogenese wordt geïnduceerd in een vroeg stadium van de tumorvorming, dit als gevolg van een toename in de expressie van pro-angiogene factoren en een afname van anti-angiogene eiwitten. Door de binding van pro-angiogene factoren aan hun receptoren op het endotheel worden de endotheelcellen geactiveerd, resulterend in afbraak van de omringende extracellulaire matrix en endotheelcel migratie, proliferatie en buisvorming. Deze cascade gaat gepaard met veranderingen in de genexpressie van de endotheelcellen. Verschillende studies zijn gericht op identificatie van genen die differentieel tot expressie komen in tumorendotheelcellen versus normale endotheelcellen, waarvan de meeste als doel hebben om genen te identificeren die preferentieel tot expressie komen in tumorendotheel. Genen die specifiek tot expressie komen in tumorendotheelcellen kunnen worden gebruikt voor specifieke targeting van de tumorvasculatuur om ongewenste neveneffecten te minimaliseren. Bovendien vergroot bestudering van de genexpressie in endotheelcellen onze kennis van de endotheelcelbiologie tijdens tumorangiogenese.

Correcte regulatie van de genexpressie in endotheelcellen tijdens tumorangiogenese is cruciaal. Epigenetische processen zijn essentieel voor de regulatie van genexpressie door het beïnvloeden van de chromatinestructuur. Twee belangrijke epigenetische modificaties zijn DNA methylering en histon modificaties. In tumorcellen zijn diverse epigenetische afwijkingen beschreven die een rol spelen in de initiatie en de progressie van tumorigenese. De best bestudeerde epigenetische verandering in deze cellen is ongewenste remming van de transcriptie van tumor suppressor genen door promoter DNA hypermethylering en histon deacetylering. De reversibiliteit van epigenetische veranderingen heeft geleid tot de ontwikkeling van DNA methyltransferase (DNMT)- en histon deacetylase (HDAC) inhibitoren als antikanker therapeutica. In tegenstelling tot de uitgebreide kennis van epigenetische veranderingen in tumorcellen is er in verhouding weinig bekend over epigenetische modificaties in tumorendotheelcellen. In dit proefschrift wordt de rol van epigenetica in tumorangiogenese bestudeerd.

In Hoofdstuk 2 hebben we de effecten van DNMT inhibitoren op endotheelcelbiologie en tumorangiogenese bestudeerd. Naast de remming van tumorangiogenese door de DNMT inhibitoren 5-aza-2'-deoxycytidine (DAC) en zebularine in verschillende muis-tumor modellen tonen wij aan dat deze stoffen direkte angiostatische activiteit hebben. Wij laten zien dat DAC en zebularine de groei van tumor-geconditioneerde endotheelcellen verminderen, maar geen effect hebben op migratie en apoptose van endotheelcellen. Verder remmen deze stoffen buisvorming van endotheelcellen in vitro en angiogenese in vivo, gemeten in het chorioallantoic membraan.

Onze vinding dat DNMT inhibitoren de groei en angiogenese van endotheelcellen direct represseren, zoals voorheen ook beschreven is voor HDAC inhibitoren, suggereert dat epigenetische modificaties door DNMTs en HDACs betrokken zijn bij de regulatie van genexpressie in endotheelcellen tijdens tumorangiogenese. In Hoofdstuk 3 hebben we met behulp van microarray analyse genen geïdentificeerd die een verlaagde expressie hebben in tumor-geconditioneerde endotheelcellen ten 
opzichte van rustende endotheelcellen, en gereactiveerd worden door DAC en trichostatine A (TSA), om meer inzicht te krijgen in (i) de rol van epigenetische modificaties in de regulatie van gen expressie in tumorendotheelcellen en (ii) het mechanisme van de angiostatische effecten van DNMT- en HDAC inhibitoren. Analyse van de microarrays toonde aan dat $77 \%$ van de geïdentificeerde genen een $\mathrm{CpG}$ eiland in de promoter heeft, wat meer is dan op basis van het toeval verwacht zou worden, en veel van de genen beschreven zijn als gehypermethyleerd in tumorcellen. Wij laten zien dat de verlaagde expressie van deze genen in tumorgeconditioneerde endotheelcellen geassocieerd is met promoter histon $\mathrm{H} 3$ deacetylering en verlaging van $\mathrm{H} 3$ lysine 4 methylering, maar niet gekenmerkt wordt door promoter DNA methylering. Reactivatie van deze genen door DAC en TSA correleert met omkering van deze promoter histon modificaties. Functionele validatie van drie kandidaat genen (clusterine, fibrilline 1 en quiescin Q6) bewijst dat deze genen negatieve regulatoren zijn van endotheelcelgroei en angiogenese. Deze resultaten suggereren dat de angiostatische activiteiten van DNMT- en HDAC inhibitoren verklaard kunnen worden door reactivatie van angiogenese-remmende genen in tumorendotheelcellen ten gevolge van toename van promoter histon $\mathrm{H} 3$ acetylering en $\mathrm{H} 3$ lysine 4 methylering.

In Hoofdstuk 4 bestuderen we de rol van epigenetica in tumorendotheelcel anergie. Door de productie van angiogene factoren kunnen tumoren ontsnappen aan een immuunreactie door verlaging van de expressie van leukocyt adhesiemoleculen op endotheelcellen en, als gevolg daarvan, reductie van leukocyt-vaatwand interacties. Wij bewijzen dat DNMT- en HDAC inhibitoren in staat zijn om de expressie van intercellular adhesion molecule-1 (ICAM-1) op tumor(-geconditioneerde) endotheelcellen in vitro en in vivo te reactiveren. Dit gaat gepaard met herstelling van de leukocyt adhesie aan tumor-geconditioneerde endotheelcellen in vitro en verhoging van de leukocyt-vaatwand interacties en leukocyt infiltratie in muizen tumoren. Wij bewijzen dat verlaagde expressie van ICAM-1 in tumorendotheel en de resulterende endotheelcel anergie geassocieerd is met verlaagde promoter histon $\mathrm{H} 3$ acetylering en $\mathrm{H} 3$ lysine 4 methylering, en dat DNMT- en HDAC inhibitoren dit kunnen opheffen.

In Hoofdstuk 5 beschrijven we de dubbele targeting van zowel tumorcellen als tumorangiogenese door DNMT- en HDAC inhibitoren. Tevens geven we een overzicht van de meeste huidige DNMT- en HDAC inhibitoren en beschrijven de effecten van deze stoffen op tumorcellen, alsmede de resultaten van (pre)klinische studies van deze stoffen als anti-kanker therapeutica. Verder bespreken we verscheidene publicaties over de angiostatische effecten van HDAC remmers. Tenslotte stellen we een model voor waarin wordt gesuggereerd dat de anti-tumor effecten van DNMT- en HDAC inhibitoren op drie manieren verklaard kunnen worden. Ten eerste remmen deze stoffen de groei van tumorcellen door re-expressie van tumor suppressor genen die geïnactiveerd zijn door epigenetische modificaties. Ten tweede veroorzaakt reactivatie van tumor suppressor genen met angiogenese remmende eigenschappen indirecte angiostatische effecten in vivo. Daarnaast leidt directe repressie van de groei van tumorendotheelcellen en angiogenese tot directe targeting van tumorvascularisatie door DNMT- en HDAC remmers.

Concluderend hebben wij bewezen dat DNMT inhibitoren anti-angiogene stoffen zijn, die angiogenese-remmende genen, welke epigenetisch geïnactiveerd zijn in 
tumorendotheelcellen, re-expresseren door verandering van promoter histon modificaties. Door re-expressie van ICAM-1 op tumorendotheel kunnen DNMT- en HDAC inhibitoren leukocyt-vaatwand interacties herstellen en wordt endotheelcel anergie opgeheven. Onze resultaten verschaffen meer inzicht in de rol van epigenetica in de regulatie van genexpressie in endotheelcellen tijdens tumorangiogenese, en ontrafelen (deels) het mechanisme van de angiostatische effecten van DNMT- en HDAC inhibitoren. Verder hebben we nieuwe angiogeneseregulerende genen geïdentificeerd die remmende effecten hebben op de groei en buisvorming van endotheelcellen. Naast het vergroten van onze kennis over tumorendotheelcelbiologie heeft dit werk belangrijke therapeutische implicaties, namelijk dat de remmende effecten van DNMT- en HDAC inhibitoren niet beperkt zijn tot tumorcellen alleen. Directe targeting van (i) tumorcellen, (ii) tumorangiogenese, en (iii) tumorendotheelcel anergie maakt deze stoffen veelbelovende anti-kanker combinatie-therapeutica 


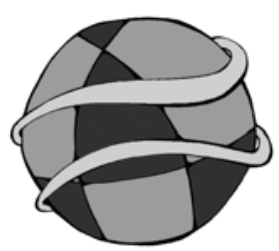

Dankwoord 
De afgelopen 4 jaar heb ik met heel veel plezier onderzoek gedaan. Er zijn veel mensen die hebben bijgedragen aan de prettige tijd die ik heb gehad.

Allereerst mijn begeleiders:

Manon, het is super dat jouw deur altijd open staat! Ontzettend bedankt voor je wetenschappelijke begeleiding en interesse. Ook jouw oppeppende en leerzame woorden wanneer mijn artikel weer eens werd afgewezen (of onze genen niet gemethyleerd waren...) heb ik erg gewaardeerd. Ik verheug me enorm op ons verdere epigenetica onderzoek!

(Gloednieuwe) Professor Arjan, ons congres-bezoek aan München, voor mij de eerste kennismaking met de "grote" wetenschappers uit de angiogenese (en met Opera), is een prettige herinnering! Met name van je uitstekende kritische correcties van mijn manuscripten heb ik veel geleerd, bedankt!

Verder wil ik ook prof. Daemen bedanken, die mijn promotor was voordat Arjan hoogleraar werd, en die mij heeft gewezen op dit interessante AIO project.

Veerle, Femke, Karolien en Ricardo, mijn collega AIOs van het angiogenese-lab: jullie waren fijne collega's en hebben mede gezorgd voor de prettige tijd en natuurlijk de gezelligheid!

Veerle, epi-angio partner, lab-buurvrouw (wat is het toch héérlijk om samen rommel te maken...) en kamergenootje: Bedankt voor de prettige samenwerking aan onze microarray, en natuurlijk voor alle gezelligheid en toffe gesprekken! Fijn dat je mijn paranimf wilt zijn! Femke, je was een erg gezellig hoek-lab-genootje, al onze plezierige gesprekken over van-alles-en-nog-wat zal ik niet gauw vergeten (evenals je heerlijke massages...wanneer mag ik weer?)! Veel succes met je verdere promotieonderzoek! Karolien - klein :) maar dapper - ander gezellig hoek-lab-genootje: Onze intravitaal-microscopie experimenten begonnen nogal ambetant, maar hebben toch mooie data opgeleverd (en grappige gesprekken op DVD....), bedankt hiervoor! succes verder met je muisjes! Ricardo: Als enige mannelijke AIO moest jij de rust bewaren tussen alle meiden, daar ben je goed in geslaagd (evenals in paaldansen). Jouw behulpzaamheid is vaak goed van pas gekomen: veel succes met je boekje (en sorry dat ik geen 3 pagina's aan je gewijd heb....)! Natuurlijk was het ook prettig om af en toe met de cardio-AIOs te kletsen op de gang: ook jullie veel succes met je onderzoek!

Ook de analisten wil ik zeker niet overslaan: Jullie zijn onmisbaar op het lab!

Van alle analisten wil ik Kim en Nicole natuurlijk het meest bedanken: ik heb met jullie beiden een periode prima mogen samenwerken. Kim, na onze fijne samenwerking ben ik blij dat we nu collega's blijven in het Angels-lab (ik beloof plechtig de chaos op mijn bench beperkt te houden (-))! Nicole, na onze prettige samenwerking in de tweede periode van mijn project kwam jouw verblijf op de pathologie helaas ten einde. Gelukkig is je nieuwe werkplek vlakbij, dus we zien elkaar nog regelmatig! Loes, jij had altijd oprechte interesse in hoe het ging met mijn proeven, artikels en zaken buiten het werk. Bedankt daarvoor, en natuurlijk ook voor al je kennis en tips bij het doen van experimenten! Sietske, (ex-) hoek-lab-genootje: we hebben leuke gesprekken gehad in het hoek-lab! Ondanks dat je nu voor een 
ander vak hebt gekozen, blijf je toch bij ons in de buurt; veel succes met je nieuwe baan! Edith, jouw inzet op het lab is enorm! Je geeft altijd goede adviezen, maar ook vele - tevens algemene - werkzaamheden worden door jou geruisloos uitgevoerd. Petra, ofschoon je nog niet zo lang op ons lab werkt, verricht jij je experimenten met veel enthousiasme: Veel succes en plezier verder!

En dan de post-docs: Victor (Galectin-Man), op jouw hulp kon ik altijd rekenen! Heel erg bedankt voor alle tips op het gebied van moleculaire biologie en je assistentie bij computerproblemen; bovendien ben je altijd in voor een goede wetenschappelijke discussie! Ennuh... leeftijd is echt niet zo belangrijk... Daisy, dankjewel voor je enorme behulpzaamheid (niet alleen bij de muizenexperimenten) en zeker ook voor de gezellige gesprekken over wetenschap en over veel andere dingen! Bovendien vind ik het erg knap hoe je ons hebt overtuigd van het bestaan van VM... Judy (woesj): eerst toffe collega AIO en sinds kort collega post-doc op dezelfde afdeling. Ik wens je veel succes met de identificatie van nieuwe TAGs en met voorbijrennen :) (wel voorzichtig met je knie aub)! Sébastien, I appreciate your help with the EMSA in the lab in Liège. Because of your efficient planning we could do a lot in little time. Thank you!

Uiteraard wil ik ook Charlie \& zijn Angels niet vergeten. Charlie (Adriaan); bedankt voor je kritische vragen bij de patho-onco (en voor onze limousine-rit...); ik heb veel zin in onze toekomstige samenwerking! (B)engeltjes Sandra, Kim, Iris, Kathleen, Peter, Nathalie, Angela en Fiona, dankjewel dat jullie altijd zo behulpzaam en gezellig zijn! De Angel AIOs Sarah, Marjolein, Ingrid (tevens gezellig kamer-genootje) en Arjen toonden altijd veel interesse, en ook de gezelligheid was erg fijn: veel succes nog met jullie promotie-onderzoek! Vanaf nu word ik omgedoopt tot echte Angel, joepieeeeeeeeeeeee!!!

I would like to thank Emma Viré for our ChIP-collaboration and for our conversations about science and life. Ook de prettige en leerzame samenwerking met Wim van Criekinge heb ik altijd erg gewaardeerd. Coen, je was een gezellig kamergenootje en collega AIO; heel veel succes met je chirurgie-opleiding! De treinmeisjes Claudia, Sandra, Angelique, Eveline en Marjo (tevens toffe collega), en natuurlijk onze hunk Brad (alias Guido, via wie ik in eerste instantie de pathologie afdeling heb leren kennen): jullie maken de trein-ritjes in de ochtend erg plezierig!

Fijne dingen buiten het werk zijn onmisbaar ter afwisseling van het onderzoek... Marije, Marjon, Inge, Monique, Mechteld (\& partners): bedankt voor jullie begrip, interesse en voor alle gezellige dingen die we doen! Ik weet zeker dat we nog lang goede vriendinnen zullen blijven! Monique, Lars, Ralph en Sabine dank-jullie-wel voor alle gezelligheid met z'n 6-en, de 13 glazen (die kunnen jullie nu terug pakken...), en vooral voor alle potjes Catan die ik heb mogen winnen (); (wanneer gaat het weer sneeuwen?)! Studie-vriendinnen Debbie en Ellen; ofschoon we elkaar door de afstand nog maar weinig zien, is het erg gezellig als we bij elkaar zijn! lk beloof dat we snel weer eens zullen afspreken. Nu op naar jullie promotie, ik weet zeker dat jullie het uitstekend zullen volbrengen! 
Last-but-not-least wil ik het thuisfront bedanken: jullie vormen de wortels van dit proefschrift. Pap, Mam, Laura (Mollie) en Martijn, bedankt voor alle kansen die jullie me altijd gegeven hebben, en voor jullie steun en interesse. En tenslotte: Lieve Marc, bedankt dat je er altijd bent....en nu samen naar Costa Rica!!!!

Bedankt allemaal!!!!!!!!! 


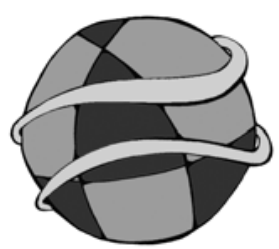

\section{Curriculum Vitae}


Debby Hellebrekers was born on August $26^{\text {th }} 1980$, in Sittard, The Netherlands. She graduated from the Bisschoppelijk College in Echt (VWO) in 1998. In the same year, she started the study Medical Biology at the University of Utrecht. In December 2002 she obtained her MSc degree (Cum Laude). From October 2002 to October 2006 she worked as a PhD student at the Angiogenesis Laboratory at the Department of Pathology at the faculty of Medicine of the University of Maastricht. Under supervision of dr. Manon van Engeland and prof. dr. Arjan Griffioen she investigated the role of epigenetics in tumor angiogenesis. As of October 2006, she will start working as a post-doc in the Cancer Biology Laboratory of the same department under supervision of dr. Manon van Engeland.

\section{List of publications}

Hellebrekers DMEl, Melotte V, Viré E, Fuks F, Herman JG, van Criekinge W, Griffioen AW, van Engeland M. Identification of epigenetically silenced genes in tumor endothelial cells. Submitted

Hellebrekers DMEI, Viré E, Castermans K, Dings RPM, Hoebers NTH, Mayo KH, oude Egbrink MGA, Molema G, Fuks F, van Engeland M, Griffioen AW. Epigenetic regulation of tumor endothelial cell anergy; silencing of ICAM-1 by histone modifications. Cancer Res. 2006, in press

Hellebrekers DMEI, Griffioen AW, van Engeland M. Dual targeting of epigenetic therapy in cancer. Biochim Biophys Acta. 2006, in press

Dings RPM, Chen X, Hellebrekers DMEl, van Eijk LI, Zhang Y, Hoye TR, Griffioen $\mathrm{AW}$, Mayo $\mathrm{KH}$. Design of non-peptidic topomimetics of anti-angiogenic proteins with anti-tumor activities. J Natl Cancer Inst. 2006 Jul 5;98(13):932-6.

Hellebrekers DMEI, Jair KW, Viré E, Eguchi S, Hoebers NTH, Fraga MF, Esteller M, Fuks F, Baylin SB, van Engeland M, Griffioen AW. Angiostatic activity of DNA methyltransferase inhibitors. Mol Cancer Ther. 2006 Feb;5(2):467-75.

Derks S, Lentjes MHFM, Hellebrekers DMEl, de Bruïne AP, Herman JG, van Engeland $\mathrm{M}$.

Methylation-specific PCR unraveled. Cell Oncol. 2004;26(5-6):291-9. 